\title{
Valuation and interest rate risk of mortgages in the Netherlands
}

Citation for published version (APA):

van Bussel, P. J. M. (1998). Valuation and interest rate risk of mortgages in the Netherlands. [Doctoral Thesis, Maastricht University]. Universiteit Maastricht. https://doi.org/10.26481/dis.19980528pb

Document status and date:

Published: 01/01/1998

DOI:

10.26481/dis.19980528pb

Document Version:

Publisher's PDF, also known as Version of record

\section{Please check the document version of this publication:}

- A submitted manuscript is the version of the article upon submission and before peer-review. There can be important differences between the submitted version and the official published version of record.

People interested in the research are advised to contact the author for the final version of the publication, or visit the DOI to the publisher's website.

- The final author version and the galley proof are versions of the publication after peer review.

- The final published version features the final layout of the paper including the volume, issue and page numbers.

Link to publication

\footnotetext{
General rights rights.

- You may freely distribute the URL identifying the publication in the public portal. please follow below link for the End User Agreement:

www.umlib.nl/taverne-license

Take down policy

If you believe that this document breaches copyright please contact us at:

repository@maastrichtuniversity.nl

providing details and we will investigate your claim.
}

Copyright and moral rights for the publications made accessible in the public portal are retained by the authors and/or other copyright owners and it is a condition of accessing publications that users recognise and abide by the legal requirements associated with these

- Users may download and print one copy of any publication from the public portal for the purpose of private study or research.

- You may not further distribute the material or use it for any profit-making activity or commercial gain

If the publication is distributed under the terms of Article $25 \mathrm{fa}$ of the Dutch Copyright Act, indicated by the "Taverne" license above, 


\section{Valuation and interest rate risk of mortgages in the Netherlands}

\section{PROEFSCHRIFT}

ter verkrijging van de grad van doctor an do Universiteit Matshicht. op gezag van de Rechor Magnificus, Prof. Ar. A.C. Nicuwenhuijzen Rinstenan, volgens het besluit van het College van Deanen, in he openban te verdedigu op donderdag 28 mei 1998 om 16.00 un

doot

Patrus Johannes Micharal van Bussel 


\section{Promotor:}

Prot. dr. P.C. Schotman

\section{Beoordelingscommissie:}

Prof. dr. A.G.Z. Kemna (voorzititer)

Prof. dr. P.M.A. Eichboltz (Universiteit van Ansterdam)

Prof. dr. A.C.F. Vorst (Erasmus Universiteit Rotterdam)

Prof. dr. C.C.P. Wolfl (Universiteit Maastricht)

Financiële steun :

Assurantieconcem Stad Rotterdam anno 1720 N.V. 


\section{Preface}

Writing a dissertation is a one-man sport that nevertheless requires the team-effort of many. Throughout my four year stay at the Finance Department of Maastricht University, I was surrounded by a team of people who all deserve a word of thanks for their warm encouragement and excellent input.

Jan-Willem Goslings was the first to spark my interest for financial research and to convince me that I was up to the challenge ahead. Many thanks go to him for getting me warmed up and started out on the right path. It was also thanks to him that Assurantieconcern Stad Rotterdam anno 1720 N.V. became interested in my research and I am very grateful for all of their financial support.

My largest debt by far is to Peter Schotman, whose excellent econometric skills, economic intuition and scholarly eye have provided me with the best constructive criticism possible. Many of the chapters of this dissertation have been shaped by his comments and advice. But I am most thankful to Peter for creating an atmosphere where I could be myself at all times, mistakes were allowed, Tibetan travel stories could be compared and the Smashing Pumpkins played in the background. Such things keep one whistling in the hallway.

Ronald Mahieu was another key supporter of this atmosphere. Despite the time pressures of finishing his own dissertation, Ronald found time to answer my numerous questions and play the role of assistant coach - not only academically, but also literally when I was training for the Rotterdam Marathon. I am pleased that Ronald and I were able to work on a research project together, the results of which you will find in Chapter 8 . The data for that particular project were kindly provided by the Dutch Association of Real Estate Agents (NVM), with the generous help of Patrick Kerkhoffs, both of whom I an wery grateful to.

Towards the end of my first year at the Finance Department, Dennis Bams joined our ranks and instantly became a good friend. Unlike myself, Dennis is a true econometrician and I appreciated his expertise on many occasions. But even more than this, I enjoyed our wide-ranging discussions at the student pub around the corner, frequently over a plate of satay.

I extend these thanks for a wonderful four years to my other colleagues at Maastricht University. Through all of you, indoor soccer and computer games acquired a new meaning! Christel Geus and Jaap Nijsen get a special thank-you for all of their hard work in assisting 
me with the less glanorons sicle of research. The nembers of my academic committee Piet Eichloltz, Angelien Femna Ton Vorst and Christian Wolf-provided comments and adve which we respecially valuable during the last phase of research and writing.

Equally important to the support of ny fellow academics has been the understanding and patience of thoes who are part of my nom-iniversity world. My family and friends have given mo essential indirect support by keping me happy, sane and well-fed.

Finally. I would like to thank Margaret Gold for her supporit, encouragement, and comments on whous drafs of this dissertation. Most of all. I thank her for putting up wh me while I was preoceupied with this project. I would like lo assure her that I have no plats att this stage for future dissertations!

Arjantu van Bussel

Mand 1998 


\section{Contents}

Preface

1 Introduction 1 1.

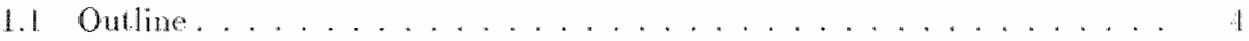

2 The mortgage market in the Netherlands 7

2.1 Introduction ........................

2.2 Recent developments within the Dutch mortgige market . . . . . . . . \$

2.3 The suppliers of mortgage financing . . . . . . . . . . . . 14

2.4 Types of mortgage loans . . . . . . . . . . . . . . . . . 14

2.4 .1 Fully amortizing morlgages ................ 17

2.4 .2 Saving-to-repay mortgages . . . . . . . . . . . . Is

2.4 .3 Non repayment nortgages . . . . . . . . . . . . . . . . 19

2.4.4 Alternative mortgages . . . . . . . . . . . . . I!

2.5 Complementary perspertives. ............... 20

2.5 Modificalions and pentalies . . . . . . . . . . . . . . 20

2.6 National nootgrage guamtee . . . . . . . . . . . . . . . 22

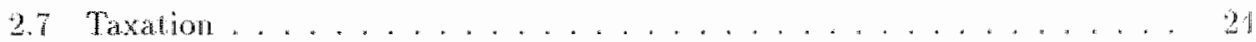

2.8 Securitization . . . . . . . . . . . . . . . . . . . . . . . . . . . . .

2.9 Summary and conctusion . . . . . . . . . . . . . . 27

3 An overview of mortgage pricing $\quad 29$

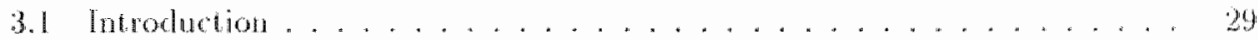

3.2 Tnterest tate processes . . . . . . . . . . . . . . . . . . . . . . . .

3.3 Multi-factor interest rate models . . . . . . . . . . . . . . . 31

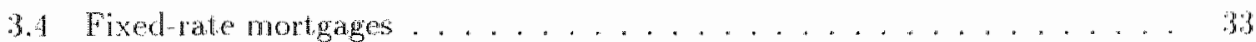

3.4 .1 Introducing defantt for fixed rate mortgages . . . . . . . \$3

3.5 Adjustable rate nortgages . . . . . . . . . . . . . . 36

3.5 .1 Introducing the default factor into adjustable rate mortgage valuation 37 
3.6 Prepayment behavior . . . . . . . . . . . . . . . 38

3.6.1 Endogenous prepayment models extended to include exogenous calls 39

3.6 .2 Strictly empirical prepayment models . . . . . . . . . 40

3.7 Coniclusion . . . . . . . . . . . . . . . . . . . . 44

4 Principles of mortgage valuation $\quad 47$

4.1 Introduction . . . . . . . . . . . . . . 47

4.2 Numerical solution techniques . . . . . . . . . . . . . 47

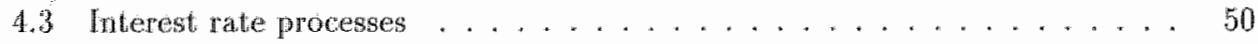

4.4 Fixed-rate mortgages . . . . . . . . . . . . . . . 52

4.5 Adjustable-rate mortgages . . . . . . . . . . . . . . 54

4.6 Mortgages with limited prepayment options $\ldots \ldots \ldots \ldots \ldots 58$

4.7 Conclusion . . . . . . . . . . . . . . . . . . . 62

5 Mortgage pricing under alternative prepayment behavior 65

5.1 Introduction . . . . . . . . . . . . . . . . 65

5.2 Mortgage valuation . . . . . . . . . . . . . . 67

5.2.1 Term structure of interest rates . . . . . . . . . . 67

5.2 .2 Short-term interest rates . . . . . . . . . . . 68

5.2 .3 Mortgage rates . . . . . . . . . . . . . . . 69

5.2 .4 Prepayment behavior . . . . . . . . . . . . . 70

5.3 Valuation procedure $\ldots \ldots \ldots \ldots \ldots \ldots \ldots \ldots \ldots$

5.3 .1 Optimal prepayments . . . . . . . . . . 74

5.3 .2 Moneyness boundary . . . . . . . . . . . . . . 76

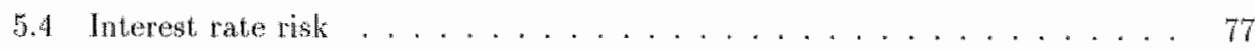

5.5 Description of the data $\ldots \ldots \ldots \ldots \ldots \ldots \ldots \ldots \ldots$

5.6 Spot rate dynamics . . . . . . . . . . . . . . . . 80

5.6 .1 The CIR model . . . . . . . . . . . . . . . 80

5.6 .2 A nonlinear model . . . . . . . . . . . 82

5.6 .3 A nonparametric density estimation . . . . . . . . 85

5.7 Mortgage rate dynamics . . . . . . . . . . . . . . . . 88

5.8 Optimal prepayment results . . . . . . . . . . . . . . . 89

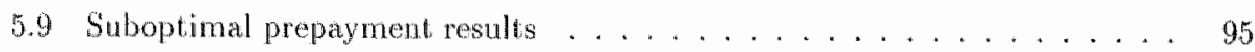

5.9 .1 Exogenous interest rate relations . . . . . . . . . . . . . . . . .

5.9 .2 Endogenous interest rate relations . . . . . . . . . . . . . . 98

5.10 Conclusion . . . . . . . . . . . . . . . . . . . 102

Appendix 5.A: Duration and "life expectations" of a mortgage contract. . . . 104

Appendix 5.B: The Markov transition matrix for the CIR model . . . . . 107 
6 A VAR analysis of interest rates in the Netherlands

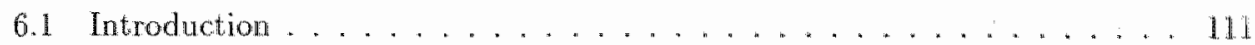

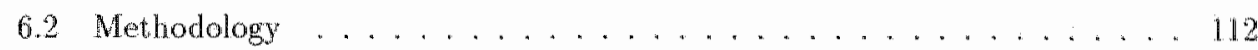

6.3 Description of the data . . . . . . . . . . . . . . . 115

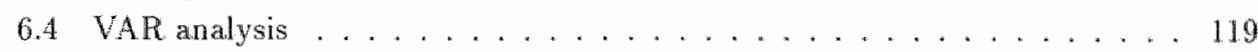

6.4 .1 Determining the order ................. 119

6.4 .2 Granger causality ..................... 119

6.4 .3 Impulse response functions . . . . . . . . . . . . . . . 1.21

6.4 .4 Variance decompositions ................... 127

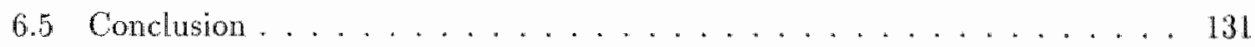

7 Multi-factor interest rate models and the valuation of Dutch mortgagesi33

7.1 Introduction . . . . . . . . . . . . . . . . . $\ldots 33$

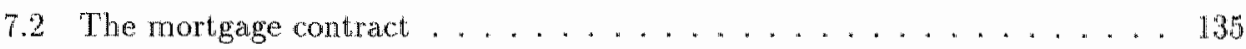

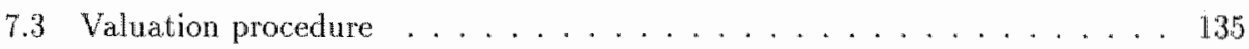

7.3 .1 Interest ratues simulation . . . . . . . . . . . . . 135

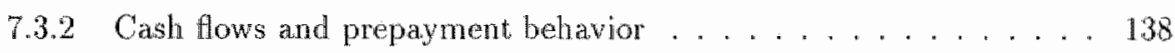

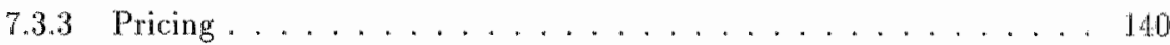

7.4 Interest rate risk . . . . . . . . . . . . . . . . . . 142

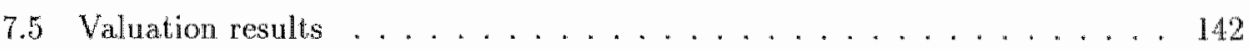

7.6 Sample period sensitivity . . . . . . . . . . . . . 150

7.7 One-factor models versus multi-factor models . . . . . . . . . 153

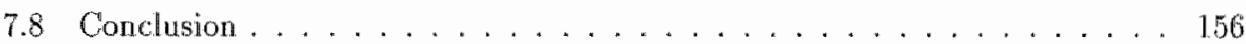

8 A repeat sales index for residential property in the Netherlands 159

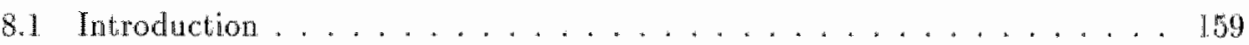

8.2 Index methodologies . . . . . . . . . . . . . . . . 160

8.3 Weighted repeat salles methodology . . . . . . . . . . . 163

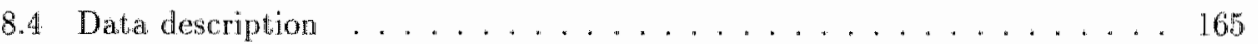

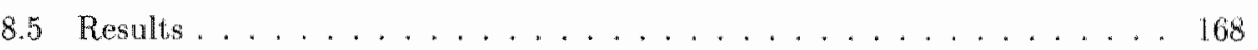

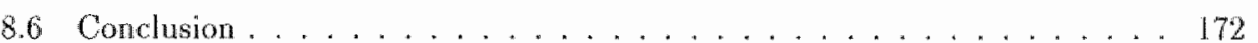

9 Empirical mortgage prepayment behavior in the Netherlands $\quad 175$

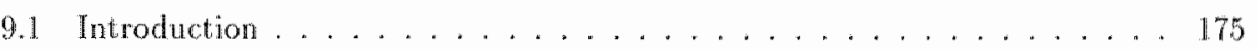

9.2 Description of the data . . . . . . . . . . . . . 176

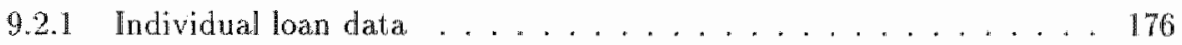

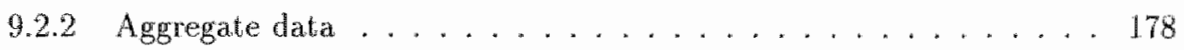

9.3 Observed and interest rate driven prepayment behavior . . . . . . . . 178

9.4 Modelling Dutch prepayment data. . . . . . . . . . . . . . 181

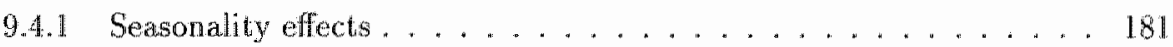




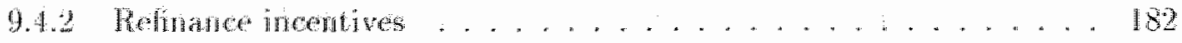

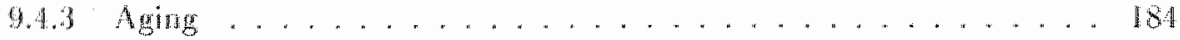

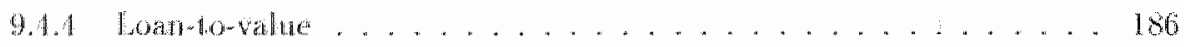

9.4 .5 Honsing prices. . . . . . . . . . . . . . . . . . . . . . . . . . . . . .

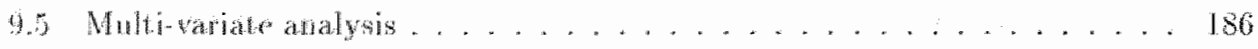

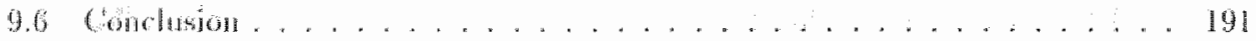

10 Summary and conduding remarks $\quad 193$

Nederlandse samenvatting / Dutch summary $\quad 199$

$\begin{array}{lr}\text { Bibliography } & 205\end{array}$

Curriculum Vitae $\quad 215$ 


\section{Chapter 1}

\section{Introduction}

A mortgage loan is a long-tern loan secured by registered goods, such as reall estaten, ships or aircrat. A montgage contract authorizes the lender (the morgaged) ho sell the mortgaged property and foreclose the loan il the borrower (the mortgugor) laits to make the agreed upon payments. That is, if the mortgagor defauts, the mongagee las the right to sell the property in order to ensure that the debt is repaid. If the ensuing revenues are insufficient to cover the remaining mortgage debt, the mortgagee may join other creditors in laying claim to the debtor's estate.

Recent low mortgage rates bave led to enomous growth in the number of loans issued to finance residential property purchases in the Netherlands. In 1996 , the number of mortgages taken out by homeowners rose by 42 pencent to 550 thousand (CBS, 1997). The amount, outstanding on residential montgages increased in 1996 by 10 percent to $37 y$ billion guilders, such that the vahe of outstanding residential mortgages per capita in the Netheriands, with its 15.6 million inhabiants, is approximately 24,400 gulders. ${ }^{3}$

The increase in the total annount of mortgage debt is smaller than the guilder value of the newly issued residential mortgages because more than one thind of the new contucts replaced existing ones. Whih replacement and prepayment playing such an imporant. role. it is evident that much of the concen about nortgage valuation focuses on then propensity of mortgagors to prepay their loans prior to maturity. This propayment option affects both the value and interest rate risk of the montgage contract. Alongside the sharp increase in prepayment activity, the importance of an accurate morigage valluation model is accentuated by the size and substantial growth of the market, the frequent introduction of new loan ypes, the substantial over-the-counter market and the growing interest in the public secondary morlgage martet.

To value a mortigage contract properly it is essential to understand how nortigigors prepay in today's economic enviromment and how prepayment will fluctuate ats economic

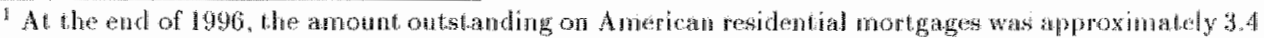

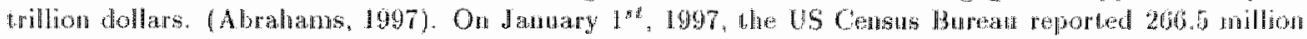

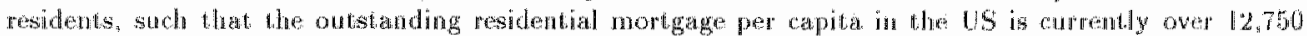

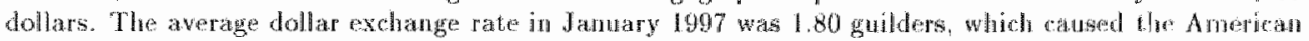

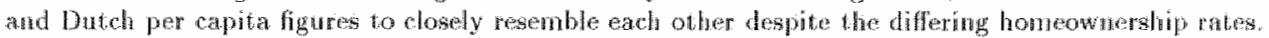


conditions change. The prevaling approach on Wall Street is to isolate the determinants of past prepayments and to extrapolate into the future. Most of this empirical research is based on large nortgage pools constructed for securitization purposes. ${ }^{2}$ This aggregation smooths out the individual loan characteristics that are behind the pool arerages. In smoothing, much information is lost. One of the few exceptions is the research by Abrahams (1997), who focuses on individual incentives to prepay. For his sindy, Abrahams drew on historical prepayment data from more than 206 thousand individual loans. Such an extensive data set is not avallable for the Netherlands. For the empirical study described in Chapter 9, lor example, we have prepayment details regarding a mere 333 Dutch mortgage contracts over a five and a half year period at our disposal.

The empirical relations found to hold in the US car not be directly translated to the Dutch mortgage market, as the differences are too large. The most noticeable is the contrast between the well-developed secondary mortgage market in the US and the modest. size of this market in the Netherlands. The differences between the contract specifications in both countries are equally important. In the Netherlands, only 10 to 20 percent of the initial loan can be called in a calender year whout penalty. Additional prepayments are settled at costs equal to the present value of the differences between future payments of the existing mortgage and a new contract. Annual prepayment restrictions are not common in the US, where the loar can be fully called without penalty.

Due to the anmual prepayment limitations, curtailments (partial prepayments) have a much larger impact in the Netherlands than in the US. At the beginning of the life of an American mortgage pool, curtailments generally account for less than 1 percent of total prepayment (Patruno, 1994). The prepayment data studied in Chapter 9 shows that this is around 55 to 60 percent in the Netherlands.

Adjustable-rate mortgages whose contract rates are reset after a 5 to 10 year period are widespread in the Netherlands. After the fixed-rate period, the contract rate is freely reset to the prevaling mortgage rate. In the US, adjustable-rate mortgages contain cap and floor restrictions to linid the degree by which the contract rate can fluctuate. Those resilvictions partially offset the uncertainty for the borrower but increase the prepayment risk faced by the lender, e.g. whenever the embedded floor-restriction is binding, there is an incentive to replace the existing contract with new loan.

Saving-to-repay mortgages are very popular in the Netherlands but virtually unknown in the US. These credit types do not require periodical repayments of the principal amount. Instead the borrower pays instrance and savings premiums on a regular basis. Upon mortgage maturity, the loan is repaid with the money saved in the savings account. Such an account commonly takes the form of a life insurance contract. Since no repayments take place during the tem of these contracts, the outstanding balances remain untouched. Consequently, the interest costs to the mortgagors do not decline over the years. However,

\footnotetext{
2 For axmple, (Kang and Zenios (1992) used obserwations of several hundred thousand Mortgage-Backed Sectrities over an eight-year pentiod to estimate their empirical prepayment madel. Golab and Pohlman (1994) included over 28 million historical prepatment rates to calibrate the wharton prepayment model.
} 
interest paid on a mortgage is tax deductible in the Netherlands, and the return on the life insurance of a saving-to-repay mortgage is commonly not taxed. The combination of both tax facilities makes the prepayment of mortgages with life instrance unatractive.

Dutch mortgage contracts are often preceded by a quotation offer which embodies a minimum interest rate guarantee. During the months this offer is valid, the client can consider the loan conditions and is guaranteed that the lowest contract rate over that period will be honored. This minimum interest rate guarantee reduces the prepayment likelihood during the life of the mortgage.

The above analysis shows the larger prepayment risk laced by American mortgagees than that by Dutch lenders. However, the mortgage market in the Netherlands is rajidly becoming more dynamic and competitive. The increased competition has been prompting lenders to relax many of the prepayment restrictions and the risk of early receipt of principal is hereby becoming larger. As previously mentioned, this risk cannot be analyzed by looking at the refinancing experiences of the US or the Netherlands. Even if Dutch prepayment data was available, these observations would refer to past contract specifications. Any econometric model which fits this data would be outdated as soon as the prepaymert restrictions are adjusted. As Lucas (1987) pointed out, it is dangerous to make inferences about the future based on past behavior for which the assumptions have now changed.

Hence, in order to analyze current. Dutch mortgage contracts and assess the value and risk consequences of relaxing prepayment restrictions we must turm to a theoretical valuation model. An accurate mortgage pricing model consists of several components, of which the process to describe the interest rate dynamics is the most, fundamental. "The other necessary components are those which relate this process to the term structure of interest rates and mortgage rates, and those which address prepayment betavior.

The description of default behavior is of secondary importance in a theoretical model to value Dutch mortgages. Most studies which include the default possibility ignore the effect defaulting has on the credit rating of the individual. In the Netherlands a nationwide credit registry is kept which records current individual loans as well as those redeened and defulted within the last five years. Before a new mortgage is issued, the lender will consult this registry. Hence, the credit history of a potential mortgagor will infuence the conditions against which he can borrow. Individuals who once delaulted face stricter conditions and acquiring a new mortgage becomes more difficult for them. Despite the fact that theoretical mortgage valuation studies do not include such extra costs they still conclude that default risk is of secondary importance to the lender. Including these extra costs will undoubtedly further reduce the relative importance of the default option. Consequenty, delanli is omitted in the mortgage valuation models developed in the Chapters 5 and 7 . Rather, we concentrate on the interest rate dynamics and the models which reldate these dynamics to the term structure of interest rates and mortgage ralies.

The choice of a particular interest rate model affects both the discount rates and opportunity costs for borrowers who consider refnancing. Tf the oppontunity costs are lower than the coupon rate of the current mortgage, the homeowner has an incentive to replace 
the contract with a new one. The expected ansh flow pattem therefore also depends on the intrest rate model. Accordingly, the mortgage valuation results are sensive to the interest rate model anderlying the pricing algoribm. This thesis focuses on the impact athernative interest nate models have on the value and risk characteristics of a mortgage contract.

\subsection{Outline}

This thesis starts with an elaboration on the size and expansion of the Dutch mortgage market. Following this short overvew, Chapter 2 briefly traces the most mportant characteristics of this maket. The mortgage lenders and their market shares are discussed, as are the most popular loan types. The prepayment restrictions incorporated in Dutch mortgage contracts are introduced and the recently adjusted national mortgage guarantec program is summanized. Furthermore, Chapter 2 considers the taxation features of the diflerent loan types and the recent developments on the secondary market for montgages.

The literature summarized in Chapter 3 reviews the various factors relevant for mortgage pricing. The first part of this chapter locuses on theoretical pricing models, while the second part surveys the body of literature on empirical prepayment behavior. The overwiew reveals that no closed form solutions exist to value fixed-income securities as complex as mortgages. For that we must resont to numerical methods as summarized in Chapter 4 , where the strengths and weaknesses of the interest mate tree approach are considered in particular. With the help of simpilitied examples, this chapter introduces the principles of mortgage valuation on which the pricing algorithms developed in successive chapters are based.

The callable mortgage contracts studied in Chapter 4 are prepaid when the valte of the mortgage, if left uncalled. exceds the outstanding debt plus any transaction costs assonded with refmancing the loan. This prepayment behavior is entrelly determined by the dymanic process of the discomb rate. There is no role for the nortgage rate at which the borrower can obtain a new loan. In Chapter 5 we compare this prepayment rule with one that depends explicitly on the mortgage rate at which the homeowner can refinance his loan on the markel.

A second central topic of Chapter 5 is the impact altemative interest rate processes have on mortgage pricing. For this purpose, three empirical one-lactor models for the short-tem interest rate are specified. The dynamics of these single factor processes are described by discrete time, finitestate Marlow chains. For mortgage pricing algorithms based on single factor interest rate models, the contract rate is a deterministic function of the shorbtem interest rate. For this fumctional relation, both exogenous and endogenons specifications are considered. The axogenous relations are based on historical observations in the Netherlands and the US. In the endogenous specification, the mortgage rate is determined such that the walle of the contract equals the face value of the loan. 
Allhough the short-term interest rate is the key valuble in chapter 5 other variables are frequenty included as well. Commonly, these additional wariables are related to long term interest rates and mortgatge rates.

Chapter 6 analyzes the empirical relation between the one-mont interest rate, the long-tem interest rate and the mortgage rate in the Netherlands. To study the dymamic Interactions between these variables. Vector AutoRegressive technigues are used. Wr concentrate on the question whether the dynamics of the mortgage rate can be described by a one-factor interest nate model. The results indicate that a single factor does not correcty describe the inferest rate term structure. Hence, to model the mortgage rate dynamics accurately more lactors should be induded.

In keeping with this, a mult-lactor mortgage pricing model is developed in Chapter 7 . The parameters resulting from the analyses in Chapter 6 are ubilized to simulate shorterm and long-term interest rates as well as mortgage rates. The resulting pseudo-historits of interest rates are used as the input of the valuation procedure.

One of the advantages of a valuation model based on a simulation procedure is illat it can handle complicated contract specifications. In comparison with the contract analyon in Chapter 5. wo typical Dutch features are included in tho contract studiad in (thapter 7 . The first one refteds the annual prepayment restriction. Secondly, we indude the mininum interest rate guarantes frequenty embodied in the quotation offer which precedos the contract. In onder to compare the multifactor approach with the single factor mothods applied in Chapter 5 . Chapter 7 also considers the standard contract withoul thesc additional features.

In Chapter 8 we make a side step and concentrate on the housing market. The developments in this property marked are closely bound to the developments in the mortgago market. The vast majority of mortgage loans are secured by residential propenty, such that an indepth andysis of the residential property market is appropriate here. In Chapter 8. we construct a repeat salos index to identify the general tendrucy of the Duth honsing maked betwen May 1973 and Decomber 1995. The index is based on data provided by Whe Dutch Association of Real Estate Agents (NVM).

The monthly return on this index is one of the independent variables in the regression analyses described in Chapter 9 . Tn this chapter we study the prepayment behavion in the Netherlands in the late eighties and early nineties. For this we have hishorical prepayment

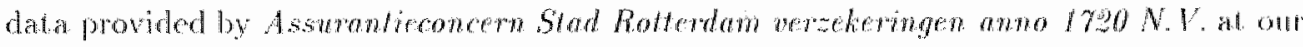
disposal. The observed prepayment behavion is compared with the prepayment activity as it would proced from the prepayment rule applied in Chapteps 5 and 7 . The second past of Chapter 9 redates the obserwed prepayment rates to varions valibles suggested hy econonic theory as summarized in Chapter 3. These variables include housing prices, scasonality. aging. loan-fo-value ratios. previous prepaymens and prevaling mortgage fates.

Finally, Chapter 10 provides a summary and suggests directions for further resenth. 


\section{Chapter 2}

\section{The mortgage market in the Netherlands}

\subsection{Introduction}

In recent years, mortgage rates have dropped to their lowest level in 25 years. At the end of 1996, rates were below $6 \%$. These bistorically low rates have led to a substantial growtly in the mortgage market in the Netherlands. Simultaneously, mortgage refuancing activities have intensified, interest in the public secondary mortgage market has increased and the variety of loan types has expanded. The purpose of this chapter is to introduce the basic aspects of the highly dynamic Dutch mortgage market.

To analyze the Dutch mortgage market the annual reports and quarterly reviews of the Dutch Ceatral Banh (DNB) are extensively relled upon, as are the publications of the Central Bureaw of Stalistics and the mortgage guides of the homeowners association Verenging Eigen Huis.

The Central Bureau of Statistics (CBS) publishes figures of newly issued, open regis. trations and redeemed mortgages. The mortgage statistics of the CBS are batsed on dalla. recorded in mortgage deeds as kept by the land registry. The titles of the retevant CBS publications have changed over the years. From 1965 until 1975, the mortgage data were reported in Hypotheek en hypotheekbanken. Between 1976 and 1992, the figures were presented in Statistiek der hypotheken. And nowadays the mortgage figures are published in Financiele mandstatistiek.

Each year in March, the homeowners association Vereniging Eigen Huis publishes a Dutch-language mortgage guide (hypothekengids). The guide book discusses the various loan types, insurance and prepayment possibilities, tax treatment and government subsidies. Sections $2.4,2.5$ and 2.7 below borrow considerably from the $1994 / 1995$ and $1997 / 1998$ editions of this guide book. 


\subsection{Recent developments within the Dutch mortgage market}

One of the keg platorms of Duth public policy is to ensure that sufficient adequate and affordable lotuing is provided. In onder to acheve this. the anthorites introduced two significant imowations in the late fifties. A tax deduction was created for the interest paid on mortgage loans, and a muncipal guarantee program was established. The fomer stimulated homeownersip at all levels of society and the latter eased the way for lowincome eaners to own their own homes.

These iniliatives had posidve eftect on the Dutch mortgage market which experienced considerables growth over the last decades. In 1950, 544,000 mortgages were outstanding. By 1965 this number was almost doubled, by 1980 it was quadrupled to 2.25 million contracts, and at the end of 1996, 4.34 million mortgages were outstanding, an 11.16 percent rise compared whth the previous year. The rise in guilder value is equally remarkable. This is illustrated in Figure $2 . \mathbb{1}$, where the amount of outstanding residential mortigages is compared with the Duth Gross National Protuct and the market eapitalization of the 130 largest companies quoted on the Amsterdam Stock Exchange. The amoun of outstanding residential mortgages is the sum of the amounts ontstanding at general, cooperative and savings banks plus the outstanding amounts of pension funds, insumance companies, nutual funds and social funds. These data are collected by the Dutch central bank on a quarterly basis. ${ }^{1}$

The Gross National Product time series in Figure 2.1 are anmally reported by the IMF. The stock market captalization time series are constructed by Datasiream and are available on a monthly basis starting from January 1973. The same staring date was used as the basis point lor the time series of the real amount of ontstanding residential mortgages. Fon this, the nominal numbers were adjusted by using the seasonally adjusted IMT consumer price index.

At the end of 1996, a total of 379 billion guilders was outstanding on residential mortgages, an inerose of 9.9 percont relative to the year bofore. The growth in the mortgage marke becones cuen mone visible when the annual expansion is studied. For residential now gages this is illustated by the lhick line in Figure 2.2. Here only mortigages ontstanding at financial institutions under supervision of the Duth centrat bank are inchuded. This Way it is possible to compare the estimated growth with the arnual net call on the captal market concening loans on houses and combinations honse/industrial premises (the thin line). The net calls are based on residential mortgage data published in Table 7 of ilue amat reports of the Duteh Coutral Bank.

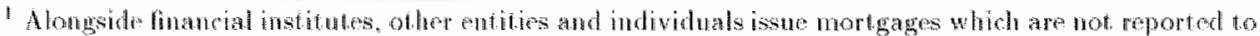

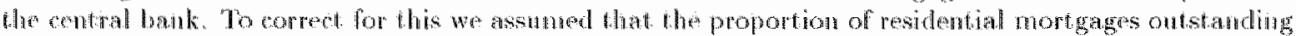

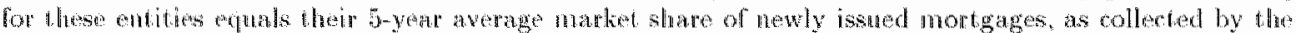

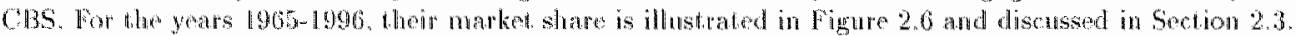

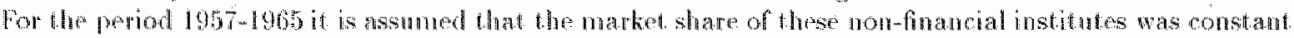

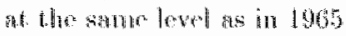




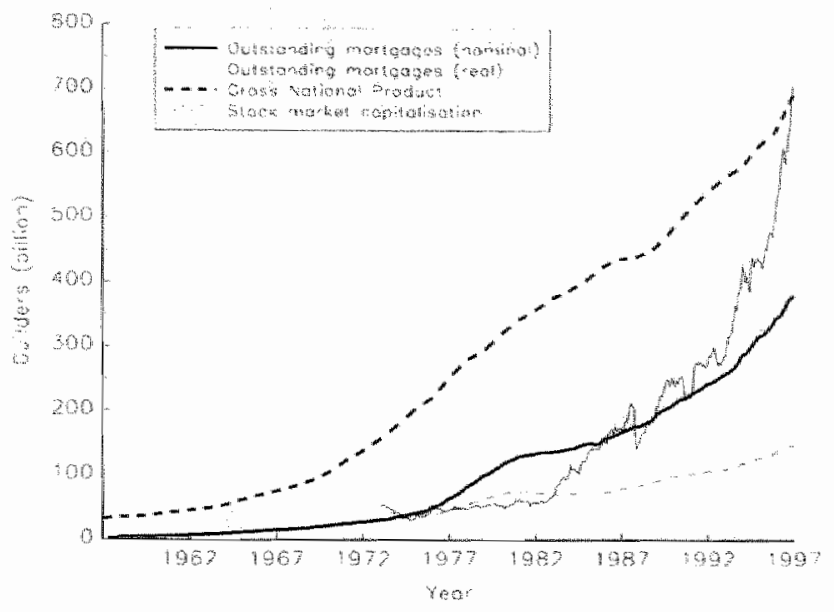

FIGURE 2.1: RESUDENTIAL MORTGAGES, STOCK MARKET CAPITALISATION AND GNP

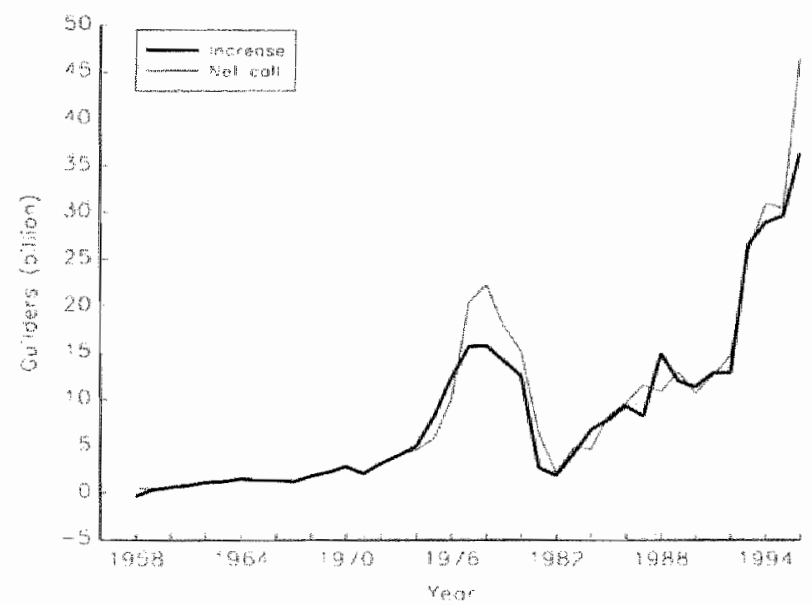

FIGURE 2.2: ANNUAL GROWTH OF THE DUTCH MORTGAGE MARKET 
The time series of newly registered mortgages, plotted in Figure 2.3 , also illustrate the recent expansion of the mortgage market in the Netherlands. Here the newly registered mortgages are categonzed by nature of the mortgaged property. In this figure, the category "houses \& comb." contains both houses and combinations of residential and commercial spes.2
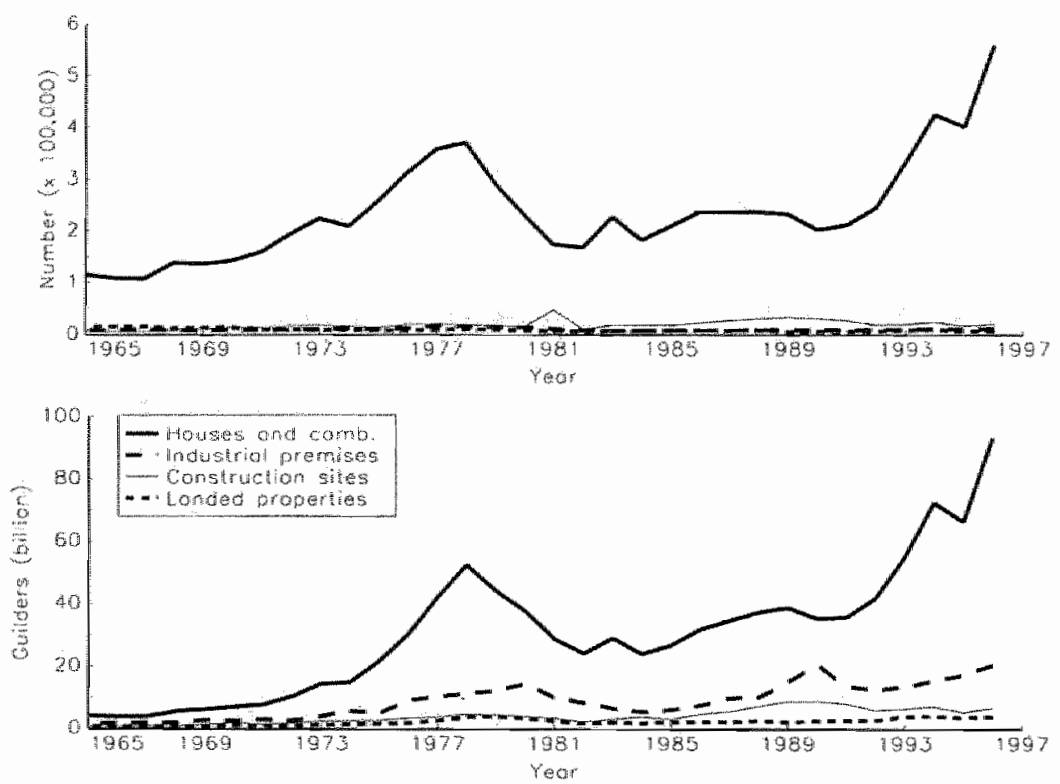

FIGURE 2.3: NEWIY REGISTERED MORTGAGES CATEGORIED BY UNDERLYNG PROP. ERTY

The upper diagram of Figure 2.3 shows the number of newly registered mortgages between 1965 and 1996. The overwhelming majority of mortgages on houses is clear. This also bolds true for 1996. In that year a total of 600 thousand mortgages were issued, 92.87 percent concened mortgenges on houses and residential/commercial combinations, 1.83 percent referred to commercial industrial premises, and the construction sites and landed properties accounted for 3.25 and 1.07 percent, respectively. Not enough information is available to allocate the remaining 1 percent over the various categories. Looking at the principal anounts rather than the number of newly issucd mortgages, the relative size of the house category decreases but remains by far the most important category. For the period 1965-1996, this is illustrated in the lower diagram of Figure 2.3.

\footnotetext{
${ }^{3}$ However, the other ategories might also embody some homes, e. farmhouses and the porter's gate houses. Besides farnhouses, the category landed properties contains farmland, agricultural latad, and rural properties snch as barns.
} 
Figures $2.1,2.2$ and 2.3 display a sharp rise in the size of the residential mortgage market in the mid seventies, a period which is known for the low-sometimes even negative-spread between the mortgage rate and inflation and the rapidly increasing housing prices. The relation between the residential mortgage market and housing prices becomes visible when the figures are compared with the price index for residential property in the Netherlands as constructed in Chapter 8 . In the late seventies and early eighties the housing price bubble exploded. In real terms, housing prices dropped by more than 40 percent over a period of four years. In the same four-year-period the number of newly issued mortgages, as well as the total amount of granted mortgages, decreased by a similar amount. In 1982 this sharp decline in housing prices halted and the residential mortgage production stabilized at a level of around 200 thousand a year. In 1992 the number of newly issued nortgages started to increase again. In 1994, 424,700 residential mortgages were issued, and by 1996 this was already more than 550,000 . This latter number represents a total anount of 93.132 billion guilders, such that the average principal was around 167 thousand guilders.

Housing prices in the early nineties also increased significantly, whle at the same time the mortgage rate decreased from more than 9 percent to less than 6 percent by 1996 . Consequently, a significant proportion of the newly issued mortgages reflects second mortgages and the replacement of existing mortgages with new morigage loans. In 1993, 37,100 second mortgages were granted and 67,800 contracts were replaced with new mortgages. ${ }^{3}$ These numbers measured 51,600 and 117,100 for 1994 , and 49,500 and 90,600 for 1995 , respectively. The low mortgage rate in 1996 had a significant infuence on the numbers for that year. In 1996, 70 thousand mortgages were issued with a principal of less than 50 thousand guilders. Commonly, such small mortgages refer to second mortgages. In the same year a total of 190 thousand mortgages were replaced by a new loan with a lower contract rate. Due to these replacements, the total amount of outstanding residential mortgages increased much less than the figures of newly issued mortgage contracts would suggest. In 1996 the amount of newly issued residential mortgages was 42 percent higher than in 1995 , while the total amount of outstanding mortgages was only 9.9 percent highon.

The time series of the amount of ontstanding vesidential mortgages shown in Figure 2.4 concerns mortgages on houses and residential/commercial combinations. The lotal redemption is found by subtracting the annual increase in this economic variable from the newly issued contracts. This total redemption is plotted in the upper diagram of Figure 2.4 and is distinct from the total cancellations in the sense that the redemption includes total and partial repayments, while cancellations only refer to mortgages which crase to exist and as a consequence are removed from the public mortgage register.

The amount redeemed each year is in itself already interesting. Even more interesting is to look at it as a proportion of outstanding mortgages. This is illustrated in the lower diagram of Figure 2,4. The result is striking.

First of all, the redemption percentage is remarkably high. The maturity of most

\footnotetext{
See Van De Beek and Vissers (1995), De Kraijk and Visgers (1960) and presg relenge mumber PQ97-39 of the CBS on Febuary 6t, 1997.
} 

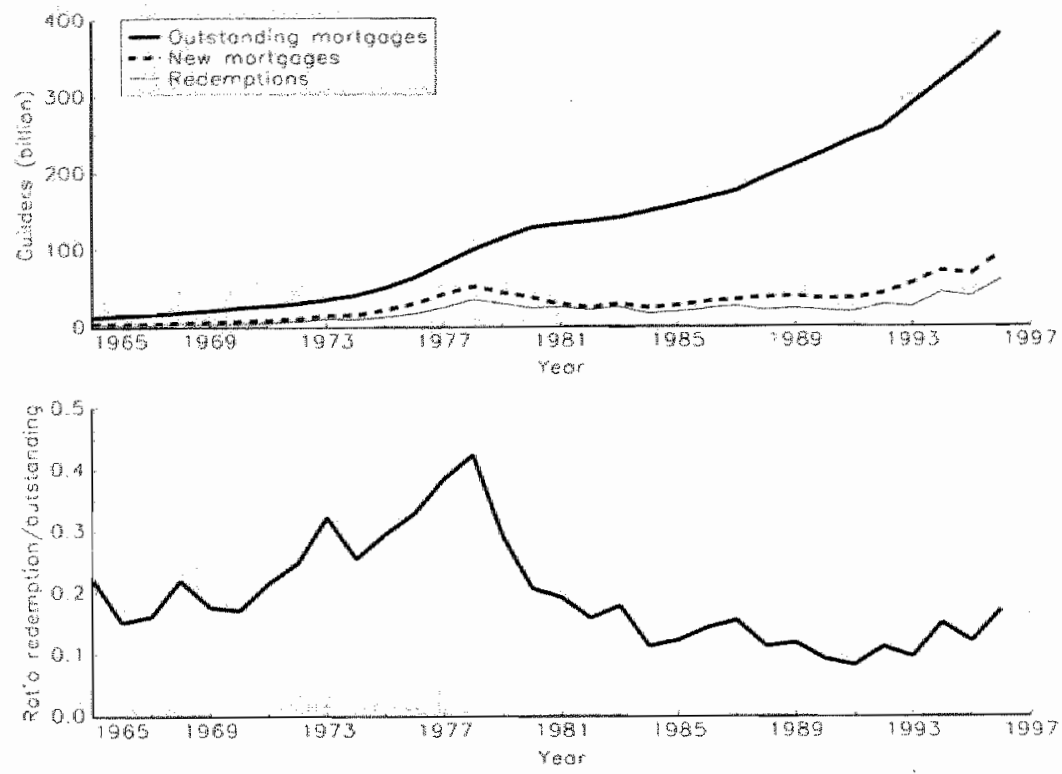

FIGURE 2.4: REDEMPTIONS, OUTSTANDING AND NEWLY ISSUED MORTGAGES

mortgages is 30 years, one would therefore expect that on average $3.33 \%$ of the outstanding mortgages would be redeemed each year. The lower diagram of Figure 2.4 shows that the realized percentage is much higher. In the seventies wo redemption peaks can be recognized. These peaks, as well as the local minimums, can be explained with the help of the fluctuating mortgage rate. In Figure 2.5 the mortgage rate is plotted together with the sewsonally adjusted inftation rate and the short and long-tern interest rate. Up until 1970 the mortgage rate is only avaliable on an annual basis, after which monthly average rates are at hand. These rates refer to annuity-mortgages. For inflation, the IMF consumer price index is used, here monthly data becomes available as of January 1972 . From January 1970 to April 1980, the return on one month loans to local governments is used as the short-term interest rate. From April 1980 on, the one-month Holland Interbank rate is used for this. Similar to the return on loans to local governments, this interbank rate refers to end-ofmonth observations. The long-term interest rate, as illustrated in the lower diagram of Figure 2.5, concerns government bonds with a remaining time to maturity of 5 to 8 years. ${ }^{4}$

The total redemption on residential mortgages as a percentage of the open registrations peak in 1973, just prior to a period of increasing mortgage rates. In 1974, when the mortgage rate tose 200 basis points within 7 months the relative redemption decreased.

\footnotetext{
*In Chapter 6 a more detaled description of these time series is given as well as an in-depth analysis of the interelations betwen the mortgage rate and the short-term and long-term interest rates.
} 

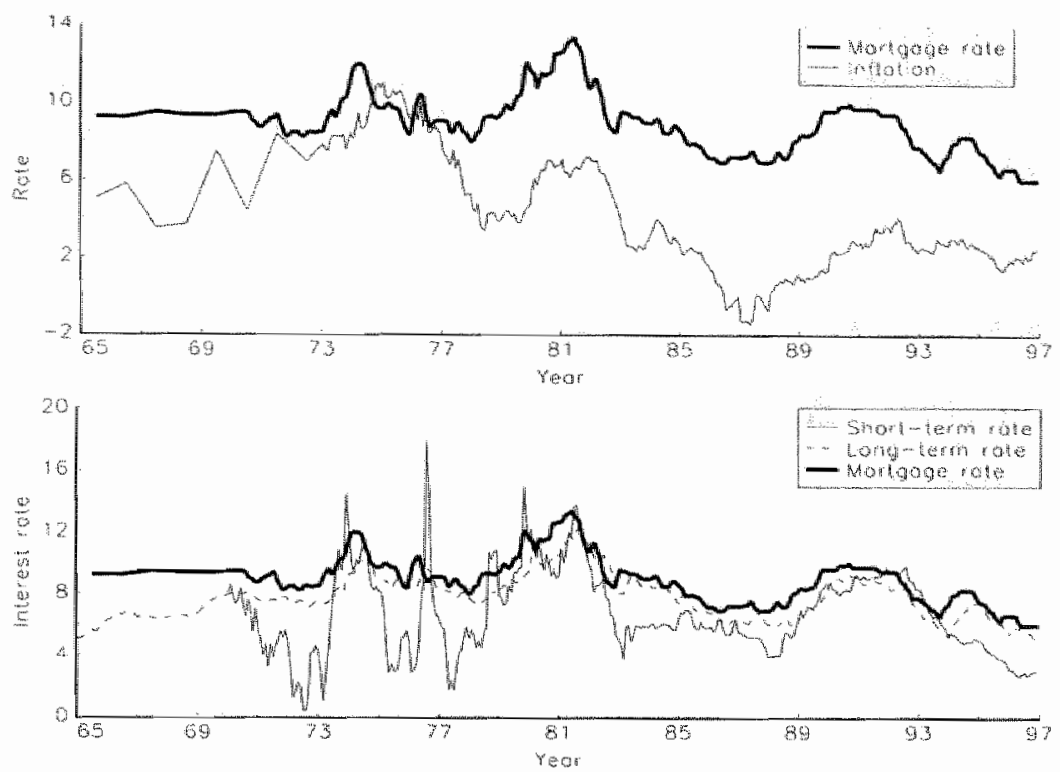

FIGURE 2.5: INFLATION AND INTEREST RATES

This suggests a negative correlation between the mortgage rate and the relative redemption. The observations of 1975 confirm this. In the last few months of 1974 and most of 1975 the mortgage rate decreased while the relative redemption increased. The correlation between the redemption rate and the mortgage rate is less clear in 1976. The redemption rate increased in respect to 1975 , while the mortgage rate fluctuated like a yo-yo,

In the last quarter of 1976 the mortgage rate stanted to decline. In 1977 and for the most of 1978 this trend continued. In May and June 1978, the lowest mortgage rate in the seventies was reached, 8.02 percent. "This coincided whth the largest redemption rate of that decade. Alter that the mortgage rate started to increase. In November 1981 the highest mortgage rate in the considered period between 1965 and 1996 was reached, 13.45 percent. During this period of rising mortgage rates the redemption rate decreased. Once the mortgage rate began to decrease again, the redemption rate went up. Since 1983 the redemption rate has been relatively stable and low.

High redenption levels indicate a high activity of replacing one mortgage contract with another and can therefore be expected to occur at times when mortgage rates are low for example in the mid-nineties. And as the upper diagram of Figure 2.4 illustrates, the re demption level increased during that period. Due to the low interest rates many new mortgages were issued in that same period. As a consequence the ratio rexlemption/outstanding mortgages, as plotted in the lower diagram of Figure 2.4 , does not substantially increase. 


\subsection{The suppliers of mortgage financing}

On the supply side of the mortgage market various parties can be distinguished. The largest group of mortgage originators are the general and cooperative banks, which issue mortgages as part of their total financial services package. Mortgage banks, on the other hand, specialize in granting long-term loans secured by registered goods such as real estate, ships and arcraft. Those activities used to be financed by issuing mortgage bonds. Nowadays, most mortgage banks form a part of a large financial institute. This integration is often reflected in the attraction of funds. For example, over-the-counter loans from the mother institute have replaced the issuance of mortgage bonds to finance the lending activities.

Although cooperative, generall and mortgage banks make up the largest proportion of entities participating in mortgage lending, other parties are active on this market as well. Savings banks and pension funds also account for a substantial market share. These financial institutes enter the mortgage market mainly for investment purposes. The main motivation for insurance companies to be active on this market is in order to stimulate the sale of conmected life insurance contracts and to invest premiums in a safe and profitable way. The impact of building funds on the mortgage market is rather small and directly related to the houses built. Among the other entities with legal status which grant mortgages are mutual funds and employers. Finally, as illustrated in Figure 2.6, participation in the granting of mortgages is not limited to entities with legal status, however, the market share of entities without legal status (such as individuals) has become very smail over the years.

Figure 2.6 shows the market shares of the major suppliers of mortgage financing in the Netherlands from 1965 to 1996. The figure is solely based on newly issued mortgages excluding open registrations. The large market share of the banks is especially distinguished.

\subsection{Types of mortgage loans}

The types of mortgage loans are divided into two broad categories: fixed mortgages and equable mortgages. "The most important characteristic of a fixed mortgage is that the borrower is obligated to make a predetermined series of payments, which might be adjusted when the contract rate alters. "Equitable mortgages, on the other hand, take the shape of a current account or checking account. From this account, the mortgagor can withdraw and redeem as he wishes, as long as an agreed-upon limit is not exceeded. This limit depends, among other lactors, on the income of the mortgagor and the value of the property. The property is then usually appraised every five years, and the loan may generally not exceed $75 \%$ of that appraisal value. No redemption is required during the maturity of an equitable

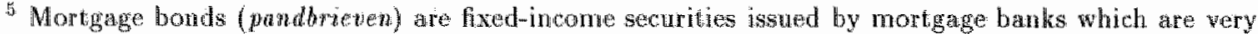
similar to standard bonds. See Rempt (1993) for an overview of the history of mortgage banks alld motignge bonds in the Notherlands.

6 fixed morgages may not be confused whin fixed rate mortgages whose contract rate remains constant during the tarm of the loan
} 


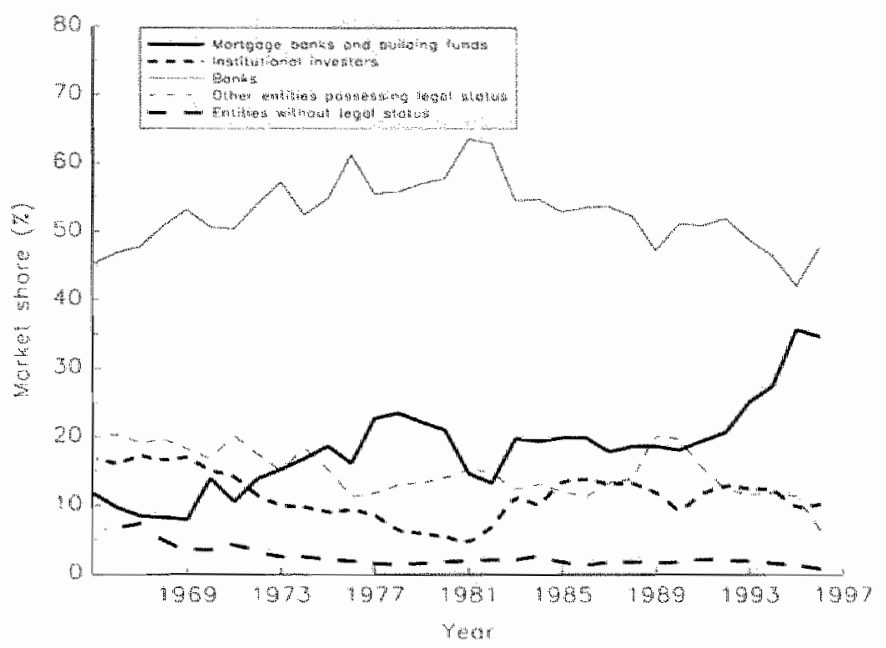

FiguRE 2.6: SUPPLIERS OF MORTGAGE FINANCING

mortgage, and interest is only paid on the amount actually withdrawn. This interest rate is variable and frequently reset.

In 1972 a new type of equitable nortgage, called a bank mortgoge, was introduced. This vehicle also offers the borrower the opportunily to withdraw as desired, however, it differs from a standard equitable mortgage in the redemption of the loan. A redemption schedule is drawn up each time the borrower withdraws money from a bank mortgage. The most important characteristic of a bank mortgage is that the mortgaged property does not only secure the mor gage loan but also the other liabilities owed by the borrower to the bank. In Figure 2.7 bank mortgages are embocied in equitable mortgages. This figure illustrates the explosive growth of the Dutch mortgage market, distinguishing betwen fixed and equitable mortgages. The numbers are based on newly issued mortgages on real estate.

Mortgage loans can also be categorized according to their repayment schedules, distinguishing amongst three loan types. "The first, type, the fully amortizing loan, is designed such that the anount of the outstanding mortgage balance is zero after the last scheduled periodical payment has been made. The second type, saving-tomrepay mortgages, are coupled with a saving construction wherelby the saved money will be used to repay the entire loan on the day the mortgage matures. The thind category, nom-repayment mortgages, is similar to saving-to-repay mortgages in that they do not require any repayments during the life of the mortgage. However, there is no savings account that corresponds with the loan. Redemption takes place in a lump sum financed by taking out a new loar, selling

\footnotetext{
7 This categorization is based on the mortgage guide published by the homeowners ansociation Vereniging Figen Huis.
} 


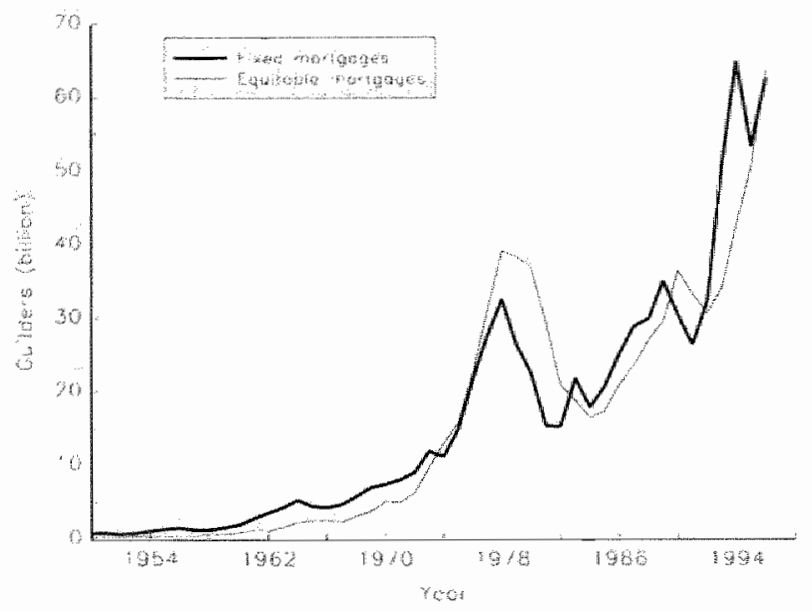

FIGURE 2.7: FIXEd AND EquTable mortaAges

the house and so on.

In Figure 2.8 the fixed mortgages are subdivided amongst smaller mortgage categories. As of January $1^{\text {st }}, 1994,40$ percent of the outstanding residential mottgage contracts were annuity mortgages, 15 percent were traditional mortgages with life insurance, 25 percent were savings mortgages, and the market share of linear redemption mortgages was 15 percent. The average remaining time to maturity of savings mortgages was 23.3 years, 18.9 years for annuty contracts, 17.6 years for traditional mortgages with life insurance and 16.2 years for linear redemption mortgages (CBS, 1996a).

Similar to figure 2.7 , Figure 2.8 is based on nowly issued montgages. However, while Figure 2.7 refers to real estate loans in general, independent of property and mortgagors, Figure 2 . 8 focuses on mortgages concerning lowns on houses chargeable to individuals. The difference is remankable. In 1992, a total of 30.65 billion guilders in equitable nortgages was granted on reat estate of which only 9.06 billion guilders was to finance a house chargeable to individuals. This means that 70.43 percent of equitable nortgage financing was issued to bodies with legal stalus. This portion is smaller for fixed mortgages at 58.86 percent, with 11.14 percent being granted to individuals.

Figure 2.8 shows a steady growth in the popularity of mortgages combined with life insurance contracts. In 1992, the market share of this type of mortgage increased rapidly, probably due to a tax revision.

Even though many bank savings instruments were similar to contracts offered by life

* This alistinction is only available for the years $1983-1992$. Due to retrenchment policies, the CBS stopped collecting this information on such a disaggregate level. Currenty, the CBS is preparing to resunte the collection of detailed mortgage information on an anmal basis. 

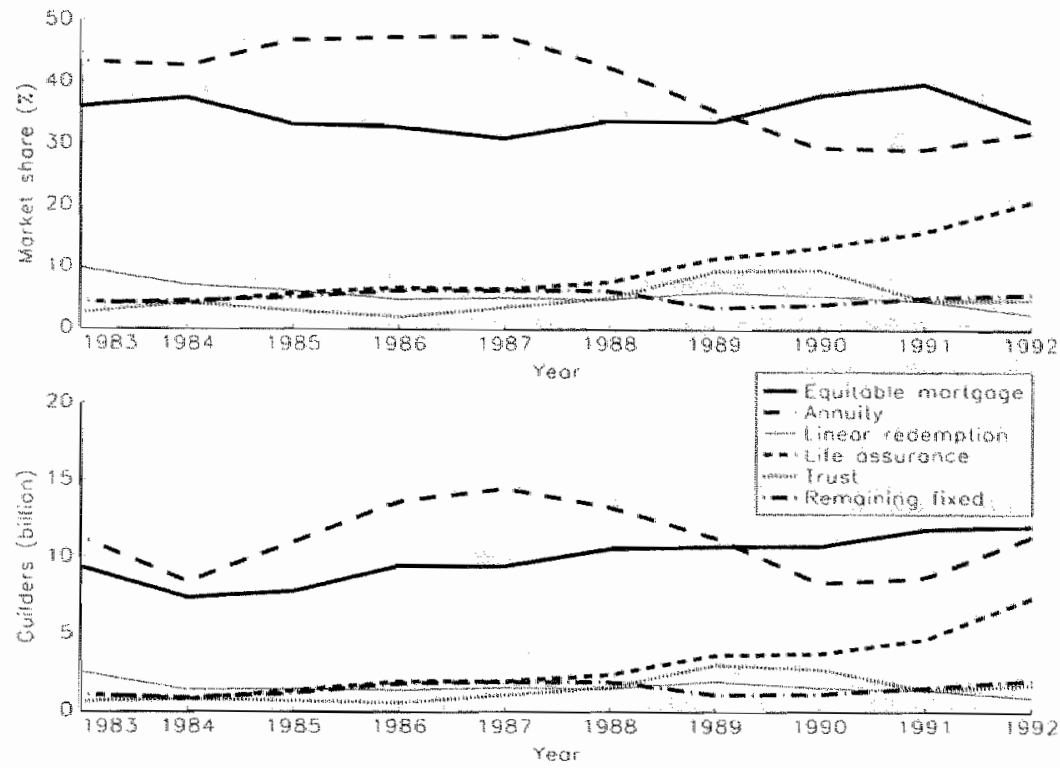

FIGURE 2.8: THE MARKET SHARE OF MORTGAGE TYPES

insurance companies, the income tax levied on payments was very different up until January $1^{\text {st }}$, 1992. The tax revision "Brede Herwardering" (Broad Rewaluation) took effect on that: date, the main purpose of which was to treat similar financial instruments in the same manner. As a consequence, the conditions for life insurance payments to be exempted from income lax narrowed down. Only payments upon death of the insured or apon mortgage loan repayment remained tax exempt. Under the new tax regine, life insurance contract payments resulting from other events are liable.

\subsubsection{Fully amortizing mortgages}

The basic idea brehind fully amortizing mortgages is that the borrower periodically pays interest and repays a portion of the outstanding principal. At the maturity date of the contract, the outstanding balance is zero and the loan is fully repaid. The two most. well-known examples of this category are the so-called hinear redemption mortgage and annuity mongage. The basic idea behind a mortgage with linear redemption is that the borrower repays a fixed amount per period, so that the debt gradually decreases. Due to the decreasing outstanding ballance the interest payments decrease proportionally. Hence. the gross mortgage costs (interest plus repayments) decrease from period to period along a straight line. With an annuity mortgage, the periodical gross mortgage payments are 
constant over time. The interest payments decrease as principal repayments increase.

Besides linear redemption mortgages and annuity mortgages, there is a thrd loan type in this category of lully amortizing mortgages, called fixed-wage mortgage. This mortgage type is only issued by building funds to finance newly buil homes. It is unique to the fixed-wage loan that it must be completely repaid before the borrower turns 66 . However, the main characteristic of a fixed wage loan is that the annually reset mortgage costs depend both on the interest rate and on the general wage index. A wage ratio is set for each mortgagor to fix the percentage of income used towards mortgage payment. This ratio is based on the general wage index rather than the individual income. As a result the mortgage costs rise when national aggregate wages rise, and vice versa. The relative number of fixed-wage mortgages is negligible in the Netherlands.

\subsubsection{Saving-to-repay mortgages}

Mortgages in this second category all share the characteristic of opening a savings account at the time the mortgage is issued. Under such mortgages no principal is repaid during the term of the contract. Instead the borrower makes payments on a regular basis to the lender which comprise interest on the mortgage loan, an insurance premium and a savings element. Upon mortgage maturity, the loan is repaid with the money saved in the savings account. Commonly, such an account takes the form of a life insurance contract, although other constructions are possible, e.g. participating in a mutual fund or starting an annuity insurance.

In the Netherlands, the interest paid on a mortgage is tax deductible. This makes mortgages with life insurance very attractive for high tax-bracket income levels in particular. Since no repayment takes place during the term of the contract, the outstanding mortgage balance remains unimpaired. As a consequence, the interest cost to the mortgagor does not decline over the years. These high interest costs are tax deductible for the entire term of the contract, while the returns on the life insurance are not taxed as long as some fiscal conditions are met. These conditions are discussed in Section 2.7 .

Traditionally, the lump sun payment at the end of the maturity of a mortgage with life insurance depends on the return of an agreed-upon investment benchmark. In practise, returns on stocks, bonds or mutual funds are among the most common benchmarks used. Alongside these measurements, the profitability of the insurance company is frequently used as the benchmakk. However, independent of the utilized benchmark, a traditional mortgage with life insurance does not guarantee that at the end of the term the sum of the accmed retums and constant premium payments will be large enough to repay the entire principal amount. Only a minimum retum, commonly 4 percent, is guaranteed on the savings premiums. However, mortgage contracts with life insurance are often established with a payment schedule based on expected returns on the savings premiums of more than 4 percent. In the event of disappointing economic performance these expected returns may not be realized, and the resulting lump sum payment be too small to repay the loan. This 
scenatio would leave the mortgagor with debt at the end of the term. On the other hand, more favorable economic conditions would leave the montgagor with more money after repayment than expected. The same uncertainty holds when the life insurance contract is prematurely closed or when the insured person dies.

This uncertainty is absent in the mortgage whith improved lffe insurance often referted to as the savings mortgage. With a savings mortgage, the borrower is ensured that at the end of the term the saved money is enough to repay the loan. In contrast to a traditional mortgage with life insurance, the premiums paid on a savings mortgage are variable and the payment at the end of the term is known with certainty. Due to this fixed lump sum payment, the premium payment will decrease with rising interest rates, and vice versa. And because the interest costs of a savings mortgage are equal to the interest compensalion received on the corresponding lile insurance contract, it has a counter-intuitive effect, such that whenever the mortgage rate is low, the periodical savings premum has to be high to reach the same lump sum payment at the end of the term. The periodical mortgage burden thus can increase with decreasing mortgage rates. As a consequence, there is a positive correlation between the popularity of this mortgage type and the nortgage rate, i.e. demand for this product is low when the rate is low.

\subsubsection{Non-repayment mortgages}

Non-repayment mortgages are free of redemption during the maturity of the contract. Since only interest has to be paid, the mortgage burden per period is low. At the end of the term, however, the entire principal has to be repaid in full. This lump sum can be financed by taking out a new loan or by selling the house.

The restrictions on the relation between the size of the loan and the value of the underlying property are very rigid for non-repayment mortgages. In general, the lender requires that the mortgage credit does not exced $75 \%$ of the forced-sate value of the house.

The most well-known non-repayment, mortgage is the equitable mortgage. As discussed in Section 2.4, with an equitable mortgage the borrower does not receive the entire loan at once. This is in sharp contrast with standard non-repayment mortgages.

Another wariant of non-repayment montgages, is the morlgage-for-life with life insurance. No redemption need be paid on this mortgage during the life of the borrower. To ensure that the mortgage will be repaid, the mortgagee requires a life assurance to repay the loan when the borrower dies. The borrower need only to pay interest and a life insurance premiam for as long as be or she lives.

\subsubsection{Alternative mortgages}

The mortgage types discussed in the above subsections are amongst the most popular in the Netherlands. Of course there are many more mortigage types, but most of these loans resemble the standard contract types discussed here. Alternative mortgages generally 
consist of a standard contract plus one or more extra options. These various options are athractive to mortgagors who are able to foresee or expect certain events to occur. For example, a social housing project homeowner may recewe a subsidy from the government which has to be prefinanced, making a compound mortgage an attractive option. Similarly, if the mortgagor expects to be able to quickly repay a portion of the mortgage, or if a larger credit limit is foreseen to be needed, a compound mortgage might be the best solution. Most individal wishes can be combined with a standard mortgage contract to create a hybrid-contract, but the mortgage costs often increase substantially as a consequence.

\subsubsection{Complementary perspectives}

This section takes a step back from the focus on the analysis of interest rate risk and the valuation of mortgages from the lender's perspective. Instead, we switch over to the borrowers point of vew in order to illustrate the different loan types available on the Dutch mortgage market. There is a variety of choice amongst the different loan types, each with its own tax-characteristics, rights and obligations, but the resulting cash flow patterns are very similar. The differences between the various mortgage types are therefore much less pronounced for the lender than for the borrower. Whether a lender grants a fully amortizing annuity mortgage or a savings mortgage will not substantially influence the periodical cash flows received. In the first case it consists of repayments plus interest while in the second case it is composed of savings premiums and interest. In essence, the resulting cash flow pattern is the same. The same holds true for the outstanding balance. The remaining debt of a fully amortizing annuity-mortgage decreases with time. For a savings mortgage, the debt does not change during the maturity of the contract. However, savings premiums are collected during the life of such a mortgage contract and since the interest rembursement on these premiums equals the mortgage rate, the outstanding balance of a savings mortgage is equal to the remaining debt of comparable annuty mortgage at any moment in time.

From the lender's perspective the key difference between both popular mortgage types is the level of prepayment risk. A savings mortgage is often chosen because of its taxcharacteristics. Prepaying such a morlgage can eliminate these tax advantages. The tax leatures of the alternative mortgage contracts are discussed in more detail in Section 2.7. Due to the diflering tax status, the prepayment risk of a savings mortgage is smaller than 1. Hat of an annuity-mortgage.

\subsection{Modifications and penalties}

Since October $1^{\text {st }}, 1996$, practically all mortgage suppliers subscribe to the credit code of practise. This code is arawn up in cooperation with the government, consumers" associations and advisory bodies. The provision of information by mortgage suppliers has to meet the minimum requirements laid down in this credlit code. Furthermore, this credit code prescribes minimum requirements regarding offer and contract conditions. Despite 
this standardization, the variety of rules and conditions embodied in the various mongage contracts is vast. This section gives a short, general overwew of modificalion conditions and penalties, especially focusing on the opportunity to prepay the mortgage or to make an extra premium deposit."

If the prevailing mortgage rate is lower than the contract rate, a wealth-maximing borrower will consider the possibility to prepay the existing mortgage and open a new one. This is generally not a cost-free decision. Besides the administration and transaction costs, a penally is often imposed. These costs are often equal to the present walue of the difference between the future monthly payments of a new contract and the existing mortgage. Both the applied discount rate and the periodical payments of the new contract are hereby based on the prevailing mortgage rate of a contract comparable to the existing one. Sometimes an additional fixed amoun between 250 and 500 guilders is added to this penaly. The credit code prescribes that variable penalty costs may only be charged on the amount exceding the penalty-free prepayment limit. It also requires that at least 10 percent of the initial principal may be prepaid within any full callendar year without penalties, but various lenders offer a larger percentage, such as 15 or 20 percent. Mortgages secured by the national mortgage guarantee, as is described in Section 2.6, have an extra prepayment feature. If a lender requires that the mortgagor anmually repays part of the mortgage, then the mortgagor has the right to prepay an additional amount without penalty. This amount permitted must be at least as large as the obligated annual repayments.

Alongside (partially) prepaying a savings mortgage, the bortower might want to consider the possibility of making an extra savings deposit. This can have three effects. First, the borrower can choose to decrease the future premiums. For this it is important to know when the lender adjusts the savings and risk premiums. Whether this happens immediately after the extra premium is deposited or just once a year makes a large difference. Instead of lower future premiams, it is also possible to leave the premiums untouched and shorten the term of the contract. Finally, an extra deposit can lead lo a higher lump sum payment at the end of the term. Finch alternative has different efects on the taxation of the premiums or the final lump sum payment.

Besides the annul partial penalty-free prepayment opportunity, there are situtions in which complete prepayment is free of costs: the demise of the mortgagor, bankruptcy, reception of a fire-insurance benefit, and the sale of the house. The only other instance that prepayment is free, is when the mortgage rate is reset at the beginning of the next. fixed-rate period. Dutch mortgages usually have a malurity of thirty years with the interest. rate fixed for a period of between one and ten years. At the end of each fixed-rate period the mortgage rate is reset to the prevailing market mortgage rate. ${ }^{10}$ Usually there are no caps or floors restricting the interest rate adjustments at the reset date so that the new

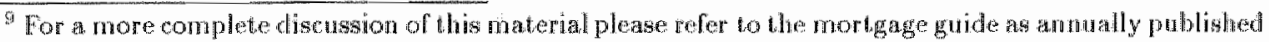
by the homeowners association Vereniging Eigen Hois.

10 Some contrats add the option that the borrower can decide to switch at any point during the last. year (sometimes ever the last two years) before renewal to the prevaling mortgage rate and hoose a new fixed rate preriod.
} 
contact rate is in conformity with the market rate.

When a cliert moves, most contracts offer the option to arrage a new mortgage at the same contract rate as the mortgage on the existing house. However, the principal of the new mortgage may not be bigger than the unpaid balance of the existing contract. Otherwise the rew contract rate will be a weighted average of the old contract rate and the actual mortgage rate. The option to use the old contract rate will of course only be exercised if the mortgage rate at that time is higher than the old contract rate.

\subsection{National mortgage guarantee}

In the Netherlands, local governments have guaranteed mortgages since 1956 . This wunicipal guarantee was replaced by the national mortgage guarantee on January $1^{\text {st }}, 1995$. The mational mortgage guarantee is an assurance towards the mortgage lender. Whenever the mortgagor does not meet his financial obligations and the mortgaged home is sold for a price which is less than the remaining debt, the guarantee foundation will cover the diference. However, the guarantee is a suretyship-contract rather than an insurance in the sense that the individual is still responsible for any resulting loss. This means that the debt does not vaporize after the foundation has paid the difference. Instead of owing the mortgagee, the individual is now in debt to the foundation. As a result of the extra. certainty, the default risk faced by the mortgagee is eliminated. This is reflected by a lower mortgage rate. The discound depends on the loan-ton-value ratio. "The larger this ratio, the larger the discount. On average the corresponding interest rate is 20 basis points lower than without a guarantee. Sometimes the discount is even as high as 50 basis points.

To qualify for the mortgage guarantee program, the cost of the house may not exceed 315,000 guilders. ${ }^{12}$ On at least half of the mortgage periodical redemptions must talie place The other 50 percent of the loan may be non-repayable during the life of the contract. The costs of participating in the program are equal to 0.36 percent of the principal plus 40 guilders administration costs. Ignoring tax, these costs are equal to 760 guilders for a secured mortgage of 200,000 guilders. If we assume that the discount on the mortgage rate is 20 bxis points and that the mortgage term structure is flat with a mortgage rate equal to $6 \%$, as it was in the beginning of 1997 , then the present value of the savings is equal to 4,306 guilders and hence runch larger than the initial costs.

During the 40 years that the municipal guarantee existed, it secured more than 1.5 million montgages with a cumulative principal of 120 billion guilders. ${ }^{13}$ In total, 19,000 forced-sales occurred duririg that period with a total loss of 900 million guilders. The axerage loss on a secured mortgage was 600 guilders.

There is not much actual data regarding defauls available in the Netherlands. The foundation running the rational mortgage program only reports 100 defauls for 1996 . It

\footnotetext{
11 The loanto-value ratio compares the amount of the loan with the value of the underlying property.

12 The conditions described in this section hold as of January $1^{s t}, 1997$.

1.39e Bassant (1994).
} 
is important to note that this foundation only becomes involved when the sale revenne of the house is rot enough to cover the remaining debt. Due to the sharp rise in house prices and the relatively low mortgage rate in 1996 , the number of such problem cases remained low.

Eicholtz (1994, 1995) found that regional economic stability and diwersity can explain regional mortgage default risk. Ficholtz had Dutch morigage default data from 1983 to 1991 at his disposal for this analysis. Figure 2.9 contains an overview of these data. The data solely refers to mortgages secured under the municipal mortgage guarantee program which was ralid at that time.
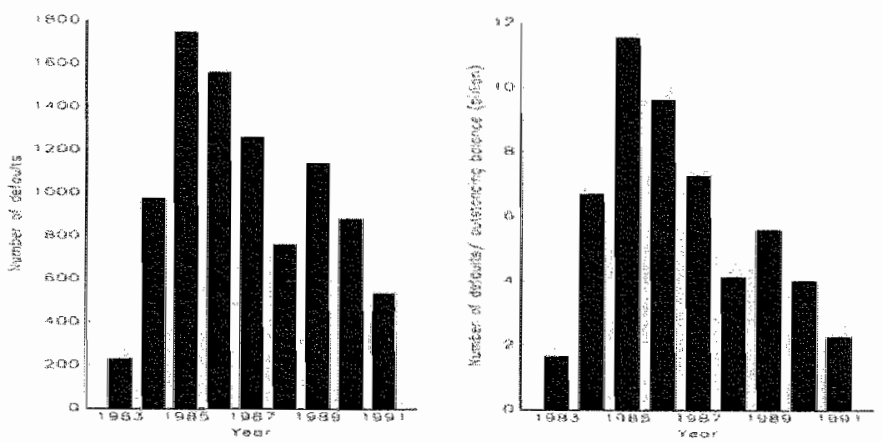

Figure 2.9: GuaranteEd Mortgage defaults in THE NETHERLANDS Source: Eichlioltz (1994, 1995)

Between 1983 and 1991 a total of 9.096 guallanted mortgages defulted. The left diagram of Figure 2.9 illustrates that the number of guaranteed defauls increased rapidly between 1983 and 1985 . In this period, the nominal price of houses hardly rose and the mortgage rate decreased, with the exception of the first half of 1983. As we discussed in Chapter 8,1986 saw a slow but sure increase in house prices which rose more rapidly towards the end of the decade. The mortgage rate did not change much between 1986 and the end of 1988 . For the same reason that the ntumber of defauls in 1996 is low, the degree to which the muncipal guarantee program needed to chip in declined over this period. Ir 1989 the mortgage rate started to increase, as did the number of defaults. Once this sliarp rise in the mortgage rate halted, the number of defautts decreased once again.

Unfortunately, no data are available as to the total number of guaranted mortgages outstanding duning this perjod so that the relative importance of default risk can not directly be derived. As a proxy, we divide the number of defaults in a year by the average amount outstanding during that year. The resulting ratio is ploted in the right diagram of Figure 2.9 and shows the same fuctuations as the left histogram. 


\subsection{Taxation}

The Notherlands is similar to many countries in allowing advisory, appraisal and administration costs to be tax deduchble in the year the house is bought and the mortgage is issued. ${ }^{14}$ Amongst other tax deductible items in the Netherlands are the cost of applying for the national mortgage guaratee, the cost of any required structural surveys, and the cost of the mortgage deed. Depending on the details of the situation, the handling fee, relocation expenses, and interest incurred during construction may also be deducted.

It is important to take note of a number of items which are tax deductible during the term of the mortgage contract:

- the interest paid on the nortgage,

- late payment penalty interest,

- prepayment and repayment costs, including penalty interest,

- the cost of mortgage registry annument alter the loan is completely repaid, and

- the cost of replacing the existing mortgage loan with a new one.

In contrast to non-mortgage loan, mortgage interest costs do not need to be used towards the tax liability on interest income. Saving-to-repay mortgages, with their simultaneous debt and savings characteristics make optimal use of this tax-deduction and exemption opportunity.

Section 2.4 .2 introduced nortgages with life insurance, where the life insurance payment is not taxed as long as certain conditions are met. If the fiscal conditions are not met, the lump sum payment is taxed according to the graduated tax system in the Netherlands. To qualify for a tax-exemption, the life insurance payment may not exced a predetermined amonnt of money. If the individual has paid premiums for 15 years, the largest of which does not exceed 10 times the size of the smallest, then a lump sum amount of 59,000 guilders is exempted from taxation. If, however, 20 years of premium payments were made, and the largest premium did not exced 10 times the size of the smallest one, then the tax-free amoun becomes 258,000 guilders. These restrictions hold for 1997 , but the relevant limits are the ones which are valid when the lump sum payment occtrs. The limits are adjusted for inflation such that a 30 year mortgage with life insurance issued today will have much higher limits in the fulure.

The tax-deductibility of interest paid on mortgages is frequently a topic ofdiscussion between politicians and tax-authorities. ${ }^{15}$ The rathonale behind the assessable rential value

\footnotetext{
14 For an elaborated discussion (in Duteh) on tax matters related to buying, owning and financing a house set the mortgage gaide published anmally by the lhomeowners association Vereniging Eigen Huis.

It Recenty, as described by Neuvel (1996), the Parlianentary Undessectary of Finonce prohibited the somedlud conthumg-construction. Inder such a constuction, as sings mortgage is not repaid when the accruet money on the life insurance cout ract is large enough. Instead the contract is continued either with
} 
(huwrwardeforfait) is often drawn in this discussion. In the Netherlands, homeowners have to include a portion of the deemed rental value of their house in their annual incone statements. Those who live in fully-owned home must increase their taxable income by 1.25 percent of the sale-value of the house. Some anthors advocate a higher percentage (such as De Kam (1996)), while others suggest abolishing both mechanisms simuldaneously.

\subsection{Securitization}

Until recently, mortgage bonds offered investors the only possibility to be involved on the Dutch mortgage market. A mortgage bond is similar to a standard bank and debenture bond in the sense that it is a fxed-income security on which interest will be paid out. Mortgage bonds, issued solely by mortgage banks, are quoted on the Amsterdam Exchange and are therefore easily transferable. The return on Dutch mortgage bonds is independent of the cash flow pattern of the underlying mortgages issued by the bank. The mortgage bank will remain exposed to the risks involved in mortgage financing.

The Hooge Huys mortgage fund has been quoted on the Amsterdam Stock Exchange since October $18^{\text {th }}, 1993$ and offers an alternative to direct investment in Dutch mortgages. This mutual fund invests at least 90 percent of its portfolio in residential mortgages. The remaining 10 percent can be invested in liquid assets and government bonds. More than half of the financed mortgages are guaranteed, while a maximum of 45 percent of the portfolio is invested in mortgages without guarantee. The payments following from the underlying morigages are not directly passed-through to the participants in the fund, but annually drawn up in a profit and loss account. The Hooge Huys mortgage fund is a mutual fund which distributes the entire profit to its shareholders, such that the corporate tax is zero percent. Moreover, the shares enjoy infinite maturity in principal.

This in sharp contrast with the morgage pass-through securities that exist in the US. These securities are created when mortgages are pooled and sold to a logally independent. entity, called a special purpose vehich. This velicle sells participations to the public, referred to as Mortgage-Backed Securities (MBSs). The risks inherent in mortigage investing are passed on to the inwestors through MBSs. The originator for anothen institution which purchased this right) will continue collecting the interest and redemption payments. These payments minus the servicing, guarantee and other fees are passed on to the purchasers of such participations. This procedure is often referred to as securitization, which is not limited to mortgages. In the United States, credit card dobt, taxi permits and automobilelease loan portfolios are also frequently securitized.

Mortgage-Backed Securities in Europe still assume modest proportions and are yet in

or without paying new premiums. In this way the interest on the mortgage renains tax-ded dutatbit at the same time as the extra savings are tax-free. Howewer, the Parliamentary Undersecretary made an appeal to fraus legis to prohibit such constructions. Whenever the net-savings are larger than the net-costs, the continuing-construction is refered to as fraws legis, and the tax-ded uction and exemption opportunities are cancelled. 
their infancy. The frst European MBSs were issued in the United Kingdom in 1985, France ard Span followed in 1991 and 1993 , respectively. MBSs have also been issued recently in Germany, Ireland and Belgium. In Austria and Luxembourg. MBSs are technically allowed but to the best of my knowledge have never been issued. The first MBSs were issued in the Netherlands on July, $24^{\text {th }}, 1996$ by Fortis, a Belgian-Dutch financial conglomerate. ${ }^{17}$ The size of this MBS issuance was 500 million gulders and the initial effective yield to maturity was around 20 basis points above a comparable government bond. The maturity runs from July 1996 to July 2006.

With securitization in mind, Fortis founded the special purpose vehicle F.I. Mortgage Securities B.V.(FIMS). This vehiche purchased a portfolio of residential mortgages from the VSB Bank N.V. and financed itself through the issuance of MBSs. Due to the securitization operation, the balance of the VSB Bank shortened by 500 million guilders which improved the asset-liability match. The ratio of equity-borrowed capital, and thus the solvability, also rose as a consequence of the transaction. For small, whealthy financial institutions this can be an incentive to securitize assets. The major general and cooperative banks of the Netherlands have good solvability and no balance sheet problems. This holds to a lesser degree for insurance companies, who in the last two years have been able to sell more mortgages than they could finance. Hence these companies in particular may be expected to be interested in selling part of their mortgage portlolio on the liquid secondary mortgage martice.

For an MBS market to be successful, a sufficiently large demand is needed. Whether this is the case in the Netherlands is not yet clear. The fact that all Fontis MBSs were sold within 15 minutes suggests that this is the case. Another indication is the fact that the idea behind Mortgage-Backed Securities has already been expanded to other assets. On December 18 1996 , the Batavia Credit Card Corporation, an American financial institution, issued a 600 million guilder loan backed by credit card debt.

The existence of a good government guartintee program was a key factor in getting the MBS market started in the US. In the Netherlands the guarantee program is much more modest. Even though these residential mortgages are relatively standardized, this may be at handicap for the liquid secondary mortgage market. Due to the well-developed guarantee program, the debt risk is smaller for American MBSs than it is for Dutch ones. On the other hand, due to more flexible prepayment conditions, American mortgages have higher prepayment levels and therefore bigher interest rate risks than their Dutch counterparts.

The success of the MBS market in the Netherlands will depend on the acceptance

th The first publichy traded mortgage pass though sexurity the US was issued in 1970 on a 7.5 million dollar pool wh a 7.00 percent coupon. "The secondary mortgage market grew, afler a modest start in the seventies, from It billion dollars in 1980 to 914 billon doliars in 1989 . During the earty nineties this anotnt rose even futher, with nearly 7 trillon dollars outstanding by the end of 1996 , such that almost, onc out of every two exhisting US mortgage loans is securtized. (Lowell (1995) and Abrathans (1997)) Only the US lreasury market is langer in vohme.

17. This discussion is based on circulars pubished prior to the issuance of the MBS by Fortis lnvestnents (1996) and UBS Globah Rescarth (1906). 
of these securities by institutional investors. A large over-the-counter market exists for mortgages among those investors. No exact data exists about the size of this over-thecounter market, but practitioners estimate that the anmal turnover on this market is between 2.5 and 4.5 billion gulders. The future will show whether the investors prefer liquid public secondary mortgage market over the current over-the-counter market.

\subsection{Summary and conclusion}

With the help of low interest rates, the mortgage market in the Netherlands has increased substantially in the recent past. At the end of 1996, a total of 379 billion guilders was ontstanding on residential mortgages, up $9.9 \%$ from 1995 . The number of nortgages refinanced more than doubled from 90.6 thousand in 1995 to 190 thousand in 1996 . This means that about one third of newly issued mortgages in 1996 replaced older existing ones. This emphasizes the impact prepayment has on the mortgage market and the cash flow uncertainty faced by mortgage lenders.

The largest group of mortgage suppliers are the cooperative, general and savings banks, whose market share made up $47.8 \%$ of the Dutch in 1996. Looking at mortgage loan types, we see that fixed and equitable mortgages are equally popular. Within this group of fixed mortgages, the annuity contract is still the most predominant. However, due to their tax characteristics, the popularity of saving-to-repay mortgages bas been increasing rapidly.

Historically, only between 10 and $20 \%$ of the initial Dutch mortgage loan can be called without penalty in a calendar year. Additional prepayments are commonly settled against costs equal to the present value of the difference between the future monthy payments of a new contract and the existing mortigage. This feature together with the taxalion characteristics of saving-to-repay mortgages causes prepayment activity to be smaller in the Netherlands than in countries such as the United States.

In 1985, the first Mortgage-Backed Securities were issued in Europe. Recently, these instruments were introduced on the Dutch market. The first issuance had a value of 500 million guilders and was settled by Fortis on July $24^{\text {th }}, 1996$. 



\section{Chapter 3}

\section{An overview of mortgage pricing}

\subsection{Introduction}

This chapter presents the central concepts of mortgage pricing. Although the main part of the chapter is based on studies describing the US mortgage market, our primary interest is to raise general issues relevant in valuing a mortgage contract.

The majority of mortgage valuation studies tend to focus on a description of the term structure of interest rates as the key element in mortgage pricing. Many of then assume that all interest rates are solely driven by the instantaneous short-term interest rate. This implies that a deterministic relation exists between the short-term interest rate, the discount rates of the periodic cash flows and the mortgage rate. This assumption simplifies the description of the term structure of interest rates and its dynamics.

Although the short-term interest rate is the key variable in most studies, other variables are frequently included as well. These additional variables are commonly related to longterm interest rates, mortgage rates and house prices. Accordingly, this chapter stants in Section 3.2 with a discussion of alternative short-term interest rak processes and continues in Section 3.3 with a review of the eftect additional variables have on mortgage pricing.

Sections 3.4 and 3.5 discuss various mortgage contracts. We begin in Section 3.4 with a default-free fixed-rate mortgage contract where the contract rate remains untouched during the entire maturity of the mortgage. Under the assumption of nondefault, its value depends on the contract rate, time to maturity, other details of the contract and the prevailing discount rates which are deternined by market interest rates. An investor in default-free fixed-rate mortgages faces two risks: the influence of fluctuating discount rates on the value of the contract, and the mortgagor"s possible decision to prepay the contract when mortgage rates fall. As a consequence, the lender will incur a loss if interest, wates increase, while the gain is limited when interest rates drop.

In actual fact, there is no such thing as a default-free mortgage, only mortgages which are insured. The effect which the default option has on the valuation of fixed-rate mortgages is discussed in Section 3.4.1. In Section 3.5 an adjustablemate mortgage contract is considered. For such a mortgage the contract rate is periodically reset. The contract rate 
can usually not freely fluctuate due to restrictions by caps and foors. Consequently, the new contract tate not only depends on the prevaling mortgage rate at the reset date but also on rates prior to that date.

The US prepayment and default data show that many mortgagors fail to exercise the option to prepay when the prevalling nortgage rate is below the contract rate, whereas the option is frequently exercised even if the market rate is above the contract rate. This suboptimal termination behavior is discussed in Section 3.6. In Section 3.6.1 endogenous prepayment models which impose optimal termination behavior are extended with exogenous calls. Section 3.6 .2 reviews empirical prepayment models. Section 3.7 concludes.

\subsection{Interest rate processes}

The effectiveness of a mortgage valuation model relies on the underlying interest rate process together with the theory on the term structure of interest rates. A distinction can be made between exogenous and endogenous term structure models.

Within the class of exogenous term structure models, the dynamics of the short-term interest rate are specified such that the resulting term structure exactly matches the term structure observed at the valuation date. Examples include the Ho and Lee model (1986), the Black, Derman and Toy model (BDT, 1990), and the model developed by Heath, Jarrow and Morton $(1990,1992)$. These models are partial equilibrium models in the sense that the initial term structure and the process generating shifts are determined exogenous to the model. In contrast with this, endogenous term structure models explain the movements in the term structure inside the model. The most frequently used endogenous interest rate models are one-factor models. The dynamics of the long-term interest rates for such single factor models are described by a deterministic function of the instantaneous short-term interest rate, $r$. Changes in this short-term interest rate are commonly described by the following continuous-time diffusion process: ${ }^{1}$

$$
d r=\mu(r, t) d t+\sigma(r, t) d z
$$

where the functions $\mu$ and $\sigma$ are the instantaneous drift rate and the volatility, respectively, and where $d^{*}$ is a Wiener process and $t$ indicates the time period. The general diffusion process in applications is often specialized as a mean-reverting model where the interest. ralle, $r$, is pulled back to its unconditional mean, $\theta$, with a speed-of adjustment factor, $k$ :

$$
d r=k(\theta-r) d t+\sigma r^{\gamma} d z
$$

where $\kappa \geq 0$. Vasicek (1977) applied the Ornstein-Uhlenbeck process by letting $\gamma=$ 0 , accepting the possibility of $r$ becoming negative. Courtadon (1982) assumed $\gamma=1$. However, the most widely-applied specification of the mean-reverting process is the Cox,

\footnotetext{
For an introduction into continuous-time finance see Shimko (1992). For an chaborated discussion see Merbon (1904).
} 
Ingersoll and Ross (CTR) model $(1985 a, b)$, with $\gamma=\frac{1}{2}$. The ChR model is derived from a general equilibrium framework and has several attractive properties. For example, the variance is proportional to the level of the instantaneous risk-free rate. Low interest rates correspond with low volatilities. The disturbance term goes to zero as $r$ goes to mero, and with $x \geq 0$ and $\sigma^{2}>0$ the drift tem remains positive such that negative interest rates are excluded.

The effect altemative interest rate models have on the value of Mortgage-Backed Securicies is studied by Chen and Yang (1995) and by Archer and Ling (1995). Chen and Yang (1995) compare valuation results using four widely-applied interest rate processes: (a) the Ornstein-Uhlenbeck process as proposed by Vasicek (1977), (b) the mean-neverting square root process developed by Cox, Ingersoll and Ross (1985b), (c) the log-nomat process discretized by Rendleman and Barter (1980), and (d) the Ho and Lee process (1986). The latter two processes are exogenous term structure models. Chen and Yang (1995) report that the actual shape of the term structure has a substintial impact on the accuracy of the pricing models. The Ho and Lee model tumed out to provide the best empirical fit, while the log-normal process, without mean-reversion, yiclds the worst results. Furthermore, their results indicate that the volatility only plays a minor role in the pricing process and that possible negative interest rates do not harm the performance of the Ornstein-Uhlenbeck and the Ho and Lee model.

As Chen and Yang (1995), Archer and Ling (1995) reject the simple log normal interest rate process for its poor fit, with the term structure. Archer and Ling (1995) also included the CIR model and the no-arbitrage process of Black, Deman and Toy (BDT, j.990) in their study. The BDT model is also a log-normal interest rate motel but is a more general model than the simple log-normal model in the sense that both the drift and volatility parameter are allowed to vary over time. This is because the current volatility curve is included in the log-normal BDT process which describes the distribution of future interest rates. Archer and Ling's comparative tests do not pin-point either the CIR or the BDT model as being more suitable for pricing mortgages and the prepayment option. The CIR model was found to yield higher option values than the BDT interest rate process. However, the results demonstrate that the effect the variance has on the option value is dominated by the mean-reversion characteristics of the underlying interest rate process.

\subsection{Multi-factor interest rate models}

Breman and Schwartz $(1978,1979)$ raised the question whether the short-term interest. rate is perfectly correlated with the long-term interest rate and the mortgage rate as in the single factor models. Instead they proposed to include a second variable in the valuation function of a default-free discount bond. Alongside the instantaneous rate, the long-term interest rate is embodied in their pricing model. Hereby they assumed that the two interest rates follow a joint Markov process. This assumption allows the derivation of 
a mulfidimensional partial differential equation to value a fixed-income security. A similar result is found in Section 3.4 .1 where house prices are introduced as a second state variable. Another two factor arbitrage model was developed by Schaefer and Schwartz (1984) who use the long-term interest rate logether with the spread between the long and short-term interest rates.

Cox, Ingersoll and Ross (1985a,b) suggest a two-factor equilibrum model where an inflation process is added to the original one-factor interest rate model. Closely related to this approach, Longstaft and Schwartz $(1992,1993)$ developed a two-factor model where the instantaneous variance of changes in the short-term interest rate is added to the short-term interest rate.

The results by Litterman and Scheinkman (1991) suggests that three factors influence the tern structure of interest rates. The thee principal components which explain most of the wariation in returns on all fixed-income securities are the level, steepness and curvature of the yjeld curve. In a study by Buser, Hendershott and Sanders (1990), the level of the short-term interest rate, as well as the slope of the term structure, stood out as a. determinant of bond option values. Alongside these two variables, a general measure of interest rate uncertainty was included as a third fundamental factor. Although including more factors improves the moctelling of interest rate dynamics, Buser, Hendershoti and Sanders (1990) found that bond option models based on one-factor interest rate models produce price estimates similar to option values resulting from multi-factor models provided that comparable term structures and volatility levels are used. Hence, they conclude that with regard to bond option pricing

". . the number and nature of interest rate factors are largely irrelevant and so too is the reason that the term structure takes a particular shope."

This suggests that a onemactor interest rate model based on an exogenous lem structure is adequate to price a mortgage and its prepayment option. This proposition is based on simulations, but due to the absence of analytical results Buser, Hendershott and Sanders temper their conclusion by not claming that it holds for all possible specifications of multiple-factor models.

Canabarro (1995) also found that one-factor interest rate models work relatively well in pricing interest.rate derivatives such as bond options. Most montgage valuation models are based on this result and use a single factor model to describe the underlying interest rate dynamics. In contrast, Brennan and Schwartz (1985), Schwartz and Torons (1989, 1992) and Boudoukh, Richardson, Stanton and Whitelaw (1997) argue that a second state variable is necessary for pricing mortgages and Mortgage-Backed Securities.

Following their earlier papers (1978, 1979) Brenan and Schwartz (1985) include the longterm interest rate as a second variable in their mortgage pricing model. They found that single factor interest rate models understate the value of the prepayment option compared to their two-state variable model. 
Inspired by the tremendous growth on the secondary mortgage market in the US, Schwartz and Torous $(1989,1992)$ examined the waluation of mortgage derivatives. They employed a two-state factor model to describe the interest rate dymamics underlying the valuation procedure. Following Brennan and Schwartz (1985) the level of the short-term interest rate together with the yield on default-free long-term bonds are utilized by Schwarta and Torous $(1989,1992)$. The same two factors were used by McConnell and Singh (1998) to value Collateralized Mortgage Obligations. This is in contrast to Boudoukh ot al. (1997), who assume that all information regarding the lerm structure of interest rates can be summarized by the 10 year yield and the spread between that yicld and the 3-month T-bill rate. Using weekly prices for Government National Mortgage Association (GNMA) Mortgage. Backed Securities between 1987 and 1994, they found that a mortgage valuation model based on a single factor interest rate model is insufficient. Their results favor a valuation procechre based on both the short-term interest rate and the slope of the term structure.

\subsection{Fixed-rate mortgages}

A fixed-rate mortgage is a fixed-income security combined with a call option which gives the borrower the right to repurchase the mortgage at its book value at any time before the contract matures. Because of the callable features, intenest rate fluctuations will not only infuence the discount factor, but the projected cash flows as well. Declining interest rates will increase the probability that the mortgage contract will be prepaid. A rise in the market value of the contract is therefore limited, whereas higher interest rates result in a decreased market walue, as with any fixed-income security.

A mortgage is a derivative asset in the sense that its value depends on interest rates and house prices. The walue of the mortgage is just a package of possible pay-onts affected by the outcomes of these economic variables. Assuming no-defatt, the interest rate is the only relevant economic factor and the outcome of the package cars also be attained by a portfolio of Treasury securities whose cash flows exachly mimic the expected flows of the mortgage. It follows from the law of one price thathe defauli-free mortgage has the same value as the portifolio or arbitrage opportunities would exist. This approacli has been followed by Dunn and McConnell (1981a,b) and Buser and Hendershot (1983), among others.

\subsubsection{Introducing default for fixed-rate mortgages}

Early mongage valuation models concentrate on the option to prepay the nortgage before it matures. Alongside prepaying the remaining principal, a borrower can terminate the mortgage contract ahead of schedule by exercising the option to default. Wealthmaximizing mortgagors will exercise this option whenever the market value of the house plus delault costs fall below the book value of the mortgage. Cunningham and Hendershot. 
(1984), Epperson, Kau, Keenen and Muller (1985) and Titman and Torous (1989) ignore the prepayment option and focus on the default option. In more recent writings, authors have atternpted to value both options simultaneously. Foster and Van Order (1985) were among the frst to recognize the substitution effect between the prepayment and defaul option: by exercising one option the other is left worthess. Chen and Ling (1989), Leung and Simans (1990), Kau, Keenen, Muller and Epperson (1992) and Kan and Kim (1994) followed.

All papers on delaut have a second state variable in common, house price $H$, which is added to the single factor interest rate model. The fuctuations in house prices are hereby modelled as a continuous randon walk:

$$
\frac{d H}{H}=(\alpha-s) d t+\sigma_{h} d z
$$

Here $\alpha$ is the expected total return to owning a house. This return consists both of price appreciation and service flows from using the house, s. This imputed rental value of the house has to be subtracted from the total return to model the expected house appreciation $(a-s)$. The disturbance term in Equation (3.3) is equal to the product of the house price volatility, $\sigma_{h}$, and a Wiener process denoted by $d z$.

The option pricing technique applied by Kau et al. (1992) and Kau and Kim (1994) among others, leads to a two-dimensional partial differential equation which describes the value of the mortgage contract. The default frequency implied by this differential equation does not correspond with the observed default numbers. Foster and Van Order (1985) empirically examined default behavior and found that mortgagors do not exercise the default option as strict as the economic theory prescribes. They attribute this discrepancy between theory and practice wo large transaction costs. The findings of Vandell and Thibodeau (1985) are consistent with this. On the other hand, Kau ot al. (1992), Kau et al. (1994) and Kau and Kim (1994) point out that these studies do not adequately account for the possibility to wat and exercise the defaul option at a later point in time. A rational mortgagor will not default as soon as the house price drops below the promised mortgage payments. By waiting to defanlt, a mortgagor will profit from possible house price increases. This is, however, not free of cost. By postponing, one keeps the obligation to pay periodically the required mortgage payraents.

Exercising the option or delaying defant, both decisions are only driven by house price Hactuations. Fven though the income, employment status and savings of an individual are among the factors that influence the default occurrence, neither Foster and Van Order (1985) nor Kau and Kim (1994) include personal characteristics of the mortgagor in the analysis. Moreover, negative equity may cause default regardless of the housing market or paymont: burden.

Alongside these personal fieatures, the amount of the loan as compared to the market value of the property infuences the defaut probability. This loan-to-value ratio is embodied in the studies of Vandell and Thibodeau (1985) and Kau et al. (1992). Their findings illustrate that high loan-to-value ratios increase the default probability. Furthermore, Kau 
et al. (1992) found that as long as the loan-to-value ratio and the house price wolatility are not large, the

". marginal contribution of default is small and a model without explact defoult meed not seriously misestimate a mortgage 's value."

However, at the same time, they state that

".. for largen price nolatitites the marginal malue of default can be as large as the total walue of prepayment."

They hereby applied volatility parameters in the same range as used by Titman and Torous (1989). The volatility is considered to be low when the annualized standard deviation of property returns is 0.10 or less, and high when 0.20 or more.

Both Leung and Sirmans (1990) and Kan and Kim (1994) conclude that the option to default is of secondary importance to prepayment. In the mutual interaction, prepayment. turned out to have a far greater impact on default than default had on prepayment. When the loan-to-value ratio is low the default risk is small, even when the house price variance is high. The default risk only increases rapidly at high loan-to-value ratios (0.95 and higher).

The delault of a fully-insured mortgage can result in principle in either a profit or a loss for the bank. However, if the market value exceeds the remaining unpaid principal the contract will be prepaid rather than defaulted. In the reverse case, the mortgagee will make a profit in the event the borrower defaults and the par value is paid by the insurer. Hence, a morlgage with full insurance has no default risk.

Many mortgages are partially-insured rather than fully-insured. However, the results of Kau et al. (1992) illustrate that there is hardly any difference in the value of a contract. which is fully-insured and one whose coverage is limited to 20 or 25 percent of the loan. This is not only because it is unlikely that the value of the house will decrease what much, but also, and more importantly, because the mortgagor will have exercised the default option betore such a significant fall in the house price can occur.

In conclusion most theoretical option-based studies assume that the mortgagor will default immediately after the value of the house falls below the mortgage value. Bmpirical studies tend to observe a delay in defaulting and generally attribute that to large transaction costs. Kau et al. (1992), Kau et al. (1994) and Kan and Kim (1994) argue that borrowers who do not want to sacrifice the right to default in the future, will make a rational choice to wait before defaulting.

Only some of the option-based models include mortgage leatures, like the lom-to-value ratio, in the analysis. Due to the difficulty of capturing divorce, death and unemployment in an econometric model, none of the studies include these important personal influences on default. In principle, transaction costs are easier to include in a valuation model despite the difficulty in identifying the true transaction costs of default. It is also very difficult to estimate the costs of the mortgagor who delaults and suffers a loss in this credit rating, 
making it much more difficult to get a new mortgage in the future. Moreover, foreclosure laws, not cmbodied in ary of the atorementioned analyses, play an important role in practice. These laws, as do deficiency judgements, make defaulting much more expensive and decrease the value of the default option. ${ }^{2}$

\subsection{Adjustable-rate mortgages}

In September 1981 the rate on fixed rate montgages in the US reached a peak of $18 \%$ after an increase of 850 basis point during the preceding the years. ${ }^{3}$ Mortgagees obtaining their lunds through deposits of a shont-term nature, as Savings and Loan banks, saw their mortgage portfolio devaluate rapidly while their liabilities increased. To prevent insolvency problems during such periods of highly fuctuating interest rates, financial institutions have to match the duration of the instruments on their balance sheet. This can be done by either lengthening the liabilities or shortening the assets. One instrument that satisfies this latter requirement is the adjustable-rate mortgage which was introduced in the US that same year.

An adjustable-rate mortgage (ARM) is a loan in which the contract rate is reset periodically in accordance with a suitable reference rate. The periodic adjustment of the contract rate shifts part of the interest rate risk from the lender to the borrower. Lenders frequently encourage individuals to choose A.RMs over fixed-rate mortgages by offering a "teaser"-contract rate below the prevailing market rate.

The uncertainty for the borrower is partially offset by cap and floor-features embodied within the ARM contract. These features restrict the degree by which the contract rate can Huctuate between reset dates (periodic cap or floor) or during the entire life of the mortgage (lifetime cap or floor). Often both periodic and lifetime caps and floors are imposed in the ARM contract. In the US, ARM contracts are required to contain a lifetime cap, which is usually an out-of-the-money option bought by the borrower at the time the mortgage is issued. If a lifetime foor is embodied in the contract, the borrower sells an option to the lender at the same time. The walue of the caps and floors depend on the benchmark index used to periodically reset the contract rate. At each adjustment date, the new contract rate is set by adding a margin to the prevailing level of the underlying index, taking the caps and foors restrictions into consideration along the way.

Hendershot: and Shilling (1985) analyzed the margins required to earn the same return on ARM contracts as or fixed-incone securities with a holding period of 7.5 years. These margins were found to depend on the slope of the term structure and the variance. A similar result was found by Buser, Hendershott and Sanders (1985) and by Huang and Xia

\footnotetext{
${ }^{2}$ Deficiency judgements give the lender the right to recover any deficiencies from the borrower's personal assets. In the US, only six states do not allow these judgements. See Fabozi and Modigliam (1992) and Qlaurete and Hrizog (1989). In the Netherlands, mortgagee, just as any creditor, is allowed to ask the bajliff to take possession of the borrower's assets if the latter fails to meot his obligations. However, the mortgagee has no priority when the assets are sold to pay outt all creditors.

* See Conningham and Capone (1990).
} 
(1996) who indicate that mortgagors refnance their ARM contracts by moving into fixedrate mortgages when the term structure flattens or becomes inverse." An ARM contract will only be replaced by another ARM contract if the market rate is decreasing rapidly and the floor restrictions embodied in the old ARM contract prevent the contract rate from adjusting quickly enough.

The prepayment rate on ARM contracts is relatively stable and low compared to fixedrate mortgages due to periodical adjustment of the contract rate to reflect the prevailing. market rate. However, this is not true of the default rate. Cunningham and Capone (1990) illustrate that the shift of the interest rate risk to the borrowers results in higher default rates for ARMs than for fixed-rate mortgages and consequently advorate the inclusion of default probabilities in the valuation of ARMs.

The valuation of ARM contracts is cormplicated by the path-dependency of the contract rate. At an adjustment date, this rate depends not only on the prevaling mortgage rate but also on previous rates. When working backwards through the interest rate tree, these earlier rates are not available when necessary. Kau of al. (1990, 1993) overcame this impasse by introducing an auxiliary state variable.

The backward pricing approach starts at the maturity date of the contract, but, the contract rate and the unpaid principal of the ARM are determined earlier in time. To untangle this problem, Kau et al. (1990, 1993) observe that the value of the promised mortgage payments, the value of the prepayment option and thus the value of the mortgage are homogeneous of degree one in the unpaid balance. Therefore the problem can be solved for an arbitrary unpaid balance and rescalled as required.

\subsubsection{Introducing the default factor into adjustable-rate mort- gage valuation}

Introducing default as a factor complicates the valuation of adjustable-rate mortgages because house prices become then also infuential and have a direct effect on the option to default. Exercising this option leaves the prepayment option worthlegs. Congequently, the house price indirectly affects the prepayment option. Sincen both option values depend on the house price, their values are no longer homogeneous in the unpaid balance. However, each option value is homogeneous in the house price and unpaid balance together. This means that an equal change in the house price and the loan size is directly proportionate to the change in defaut and prepayment option values. Noting this makes it possible to calculate the value of the mortgage together with both embedded options." However, as Kau et al. (1993) stress:

4 Sone AM contracts contain a conversion aption which gives the borrower the right to convert their ARM into a fixed-rate morlgage Non-contertible ARMs do not liave this option bul can be propaid in favour of a fixed-rate mortgage though a normal refinane procedure, which of course is more expensive than exercising a comversion option.

5 To determine the correct value numerical solution techniques are resorted to. The frechnque applied by Kan at al ( 1993$)$ is a two-state explicit finite difference method. 
"It is important to observe that the technigu wsed here to incorporate house price into the waluation technigue is fundamentally different from the basic technique that suffices to walue the promised payments. That basic technique, which extends to include prepayment on a default free mortgage, in no way depends on the precise form of the interest rate process. Howener, the method used here to incorporate house prices works because the log-normal form assumed for the underlyng asset $H$ is a proportionate process, with the property that the rete of appreciation independent of the size of the house"

Empirical studies by Cunningham and Capone (1990) and VanderHoff (1996) confirm that ARMs are less frequently prepaid than fixed-rate mortgages. Exact figures are hard to come by and depend directly on the size of the rate caps and the length of the adjustment period. The defaul rists appears to be larger for ARMs than for fixed-rate mortgages. VanderHoff's results indicate that $60 \%$ of such defaults are sub-optimal from a financial point of view. His results also reveal that ARM holders are less apt to relocate. The teaser rate provides the opportunity to purchase a larger house which more closely matches their future housing clemand and therefore clecreases the probability of moving.

\subsection{Prepayment behavior}

Previous sections analyzed mortgage pricing models and results based on modern contingent clam techniques. Many of the studies described in Section 3.4 and 3.5 assume optimal prepayment and default behavior, in the sense that the mortgagor tries to mimimize the market value of the loan. The resulting prepayment and default behavior is dependent only on the tem structure of interest tates and house prices, thereby ignoring the individual characteristics of the borrower. These contingent claim techniques with endogenously determined lemination are inappropriate for modelling observed prepayment and default numbers. Prepayment data on residential mortgages reveal that the prepayment option is freguently exercised when the prevailing mortgage rate is above the contract rate, while the mortgage is often not prepaid when it would be optimal to do so. Optimal call valuation models can not explain this behavior. The same holds true for the option to default.

Valuation models in which prepayments and defauls are exogenously specified override this empirical shortcoming. Exogenous prepayment valuation models can be divided into two categories. First, there are models which are based on endogenous models. These models take an optimal call and default valuation model as a starting point and add exogenous calls and defaults which are unrelated to the interest rate. On the other hand, there are strictly empirical prepayment models, which do not assume any optimal behavior. Instead, these models relate the observed prepayments to a set of explanatory variables. 


\subsubsection{Endogenous prepayment models extended to include ex- ogenous calls}

In optimal call valuation models, the prepayments are entirely endogenously determined. In such a model, the mortgage will only be called when it is financially optimal to do so. However, the prepayment option is often exercised when is is of - the money. This means that the mortgage is prepaid even though the refinancing rate exceds the contract rate on the existing mortgage. Dunn and McConnell (198la,b) acknowledged this non-optimal behavior and incorporated it into a model in which prepayments are only interest rate driven with non-financial temination features. The model developed by Dunn and McConnell is based on the CIR term structure model. Dumn and McConnell augment this defult-free model with a Poisson-driven process to explain the non-optimal prepayments. The nean of the Poisson process, which describes the probability that a non-financial termination will occur, is estimated from historical data. Dunn and McConnell emphatically assume that the so-called suboptimal prepayments are

"... uncorrelated" with all relevant matket factors and are, therefore, purely nonsystematic."

Even though such exogenous terminations always increase the market value of the mortgage they are not necessarily irrational. Such behavior is often due to personal circumstances, such as job relocation or change in family size.

The Brennan and Schwartz valuation model (1985) adopts Dunn and McConnell's approach to include suboptimal prepayment behavior. Instead of using a one-factor model, as Dumn and McConnell do, Brennan and Schwartz use a two-factor model to value the mortgage and its prepayment option. They abstract from defaut, a possibility that is included in the two-factor nodel developed by Kau, Keenan, Muller and Epperson (1992). Unliko Breman and Schwart, they use house prices as the second state vartable, as opposed to the long-term interest rate. The procedure applied by Kau el al. (1992) to value a mortgage under optimal call behavior alternates between the backward and forward-solving technique. Alongside this optimal termination behavior they also use a Poisson process to include suboptimal termination decisions. None of these models address transaction costs - a shortcoming that does not hold for the models developed by Gillibetio and Ling (1992) and Archer and Ling (1993). As well as considering prepayments which occur when the option is ont-of-the-money, Archer and ling (1993) recognize that matry mortgagors fall to exercise the prepayment option when this would be optimal. Their results indicate that transaction costs account for the observed lags in exercing in-the money prepayment options. Stanton (1995) explicitly modelled heterogeneity in prepayment costs. He finds that the transaction costs implied in the observed termination data are signilicantly highen than the explicit monetary costs associated with refinancing. 


\subsubsection{Strictly empirical prepayment models}

Strictly empirical models base the prepayment behavior only on a set of non-model-based explanatory variables. The prepayment decision is exogenously determined by models estimated from historical data. In such models, four main determinants are specified. The first and most important element that determines prepayment is the refinancing incentive. Homeowners tend to refinance the existing mortgage when the current mortgage rate is far enough under the contract rate. Different mortgagors face different refinance costs, this leterogeneity among households reappears in the prepayment data.

Not everybody will react immediately when faced with a prepayment opportunity. The most aware mortgagors will react and prepay their mortgage the first time a refinance incentive occus. If the same refinance incentive occurs at a later stage, a smaller number of the remaining mortgagors will respond. The phenomenon of prepayment rates declining as mortgage pools age through interest cycles is known as burnout. The burnout effect is an aging effect, the older the pool of mortgages, the lower the prepayment rates.

Seasoning is also an aging factor but one with an opposite effect. When borrowers take out a new mortgage it, is generally unlikely that the interest rate, family or employment circumstances change in the near future. The prepayment rates are therefore low at the beginning of a mortgage contract and increase gradually over time until they reach a stable or "seasoned" level. The American PSA (Public Securities Association) model is based on this idea. The PSA model assumes that the prepayment rates increase linearly during the first thirty months of the contract until they reach a $6 \%$ per year level, at which prepayment. rates will romain constant.

Seasoning should not be confused with seasonality, which measures the correlation between prepayment rates and the month of the year. This cyclical behavior is highly linked with the cyclical behavior in house sales. Homeowners relocation tends to peak in the spring and summer and decline in the autumn and winter months. Tax considerations and contract-specific constraints also play an important role in creating seasonality, particularly in relation to an increase in prepayment activity at the end of the year. Most Dutch mortgage contracts embody a naximum-prepayment-without-penally clause for each year of the mortgage. If that maximum is not reached by the end of the year the option to prepay will loose its value, thus encouraging mortgagors to make full use of this option before it expires.

A macro-conomic variable which is frequently mentioned as an explanatory variable is the house price. This variable is more useful in explaining prepayment behavior ex post than it is at enhancing long-term prepayment forecasts. If house prices were to be included in the prepayment forecast model, the variable itself would also have to be forecast. Hence, most empirical prepayment models concentrate on the four aforementioned factors: refinancing incentives, burmout, seasoning and scasomality.

There are several methods of applying historical prepayment numbers to project future

\footnotetext{
See for examplte Richard and Roll (1989).
} 
mortgage cash flows. The traditional procedure to deal with prepayment uncertainties was to assume that the mortgage will be prepaid after a period which is equal to the average life of a portfolio of comparable mortgages. Instead of estimating the average life from historical data, the convention was to assume termination in 12 years. In practice, this pricing policy was not only applied on newly-issued mortgages, but also iraders on the secondary mortgage market have even based their yields on this benchmark regardless the actual age of the underlying mortigages.

Curley and Gutientag (1977) recognized a life cycle pattern in the observed termination rates. They stressed the importance of using the entire distribution of temination probabilities rather than the average life rule-of-thumb.

Dunn and McConnell (1981 a,b) compared both the average life rule-of thumb and Cur ley and Guttentag's method with their own contingent claims model. In their valuation algorithm, Dunn and McConnell use a Poisson process to model non-interest-rate-driven prepayments while an optimal prepayment strategy is applied to model the finance driven prepayments. As previously mentioned, this is an endogenous prepayment model with exogenous calls as opposed to a strictly empirical prepayment model.

Rather than opposing optimal prepayment behavior. Green and Shoven (1986) posit that each period holds a possibility that the mortgage will be prepaid, depending on the age of the contract and on the exercise value of the call option. They construct a life-table for mortgages similar to actuarial mortality tables based on prepayment data collected regarding 4,000 mortgages in California from 1975 to 1982.

Green and Shoven employ a proportional hazard model to more easily divide the probability of prepayment into two multiplicative factors, the age of the contract, and the exercise value of the call option. This proportional hazard model reacls:

$$
\Gamma\left(a_{1}, 1\right)=\Lambda(a) \cdot \Pi\left(x_{1}, x_{2}, \ldots, x_{N}\right),
$$

where $\Gamma(a, b)$ is the turnover probability of a mortigage with age a at limel. The proportion of the mortgages that would be prepaid even under completely stationary homogeneous conditions is the "base-line hazard", $\Lambda(a)$. This base-line hatard measures the ffect of mortgage age or seasoning on prepay ment behavior. The exogenous factors, $x_{1}, x_{2}, \ldots, x_{\mathbb{N}}$, determine whether the value of the function $\Pi(-)$ is greater or less than one, indicating the increased or decreased prepayment likelihood as compared to the base-line hazard estimate. Equation (3.4) implies that the hazard function is memoryless, i.e. past figures (and also

$\pi$ For an overview of the prepayment behavior of Federall Nationall Mortigage Association (FNMA) Mortgage-Backed Securities see Becketti and Morris (1990). They observed that prepayment rates are related to the relative coupon and the age of the morigage. Hereby, the rative coupon is defined as the difference between the prevailing mortgage rate and the contract rate on the existing moingage. However, as. Becketiti and Morris note, modelling prepayments as a function of these variables is only useful if they account for a substantial part of the variability of the prepay rnents. Surprisingly, the single bext factor for explaining prepayment rates, the relative coupon, has only very litile ability to predict prepaynuents. The age and size of the mortgage pool are more succesful in acconnting for the decision to prepay. However, the main contribution of Becketti and Morris" study is not in predicting prepayment rates, But in illustrating the different relations that might exist between various variables and observed prepayment rates. 
expected future values) do not have any effect on present prepayments. This hazard model is proportional due to the assumption that exogenous factors have an equi-proportional impact at all mortgage ages. That is, if the exogenous factors make prepayment more likely at one age, they make prepayment more likely at any other mortgage age. Hence, factors that infuence prepayments are time-homogeneous.

Similar to Green and Shoven, Schwartz and Torous (1989) do not oppose optimal prepayment behavior. In each state of the economy they assume a conditional probability that the mortgage will be prepaid. How large these probabilities are, is exogenously determined. They also use a proportional hazard model to estinate the relative importance of various variables to explain prepayment behavior. However, unlike Green and Shoven, Schwartz and Torous include several explanatory variables in their model: the effects of seasoning, interest costs savings from refinancing, lagged refinancing rates, and seasonality. For this they collect data for thirty year Single-Family pools over the period January 1978 to November 1987. Since the sampled mortgages are guaranteed by the Govenment. National Mortgage Association (GNMA), defaul can not be determined separately from prepayment.

Given the four explanatory variables and the GNMA prepayment data, Schwartz and Torous (1989) estimate the prepayment function. They find that the probability of prepayment increases significantly when the refinance rate is under the mortgage's contract rate, and that the seasonality parameter does not differ significantly from zero.

Schwartz and Torous integrate the estimated prepayment function into a MortgageBacked Securities valuation model, which is based on a two-factor model as in Brennan and Schwartz (1985). In their valuation model, Schwartz and Torous do not impose an optimal value-minimizing condition. The prepayments are fully based on empirical relations, and the Brennan and Schwartz' two-factor model is solely used to model the processes of the refinance and discount rates.

In their 1992 paper, Schwartz and Torous extend the above andysis by introducing a defalt possibility. Both the prepayment and default option affect the value of the raortgage contract, even if the mortgage is fully-insured. In this case, default by the mortgagor obligates the insurer to pay the outstanding principal. Although the effect is comparable to prepaying, the economic conditions are completely different. Schwartz and Torous focus on the pricing of default insurance, describing default with a hazard function and prepayment with a proportional harard model. Unfortmately, due to lack of default data on individual homes, Schwartz and Torous do not estimate the default function parameters. In the prepayment model, the base line hazard function is assumed to be consistent with the standard PSA prepayment rule-of thumb, while the other parameters are based on the empirical analysis of Green and Shoven (1986). In 1993, Schwartz and Torous applied at Poisson regression to estimate both prepayment and defanlt based on extensive Federal Home Loan Corporation (Freddie Mac) data which was now at their disposal. The results indicate that the prepayment decision depends on the refinance opportunities and that prepayment and default differs greatly amongst regions. The age of the mortigage was 
also found to play a significant role in explaining the observed prepayment and defanlt behavior. Moreover, default is affected by the initial loan to value ratio as well as by the volatility of the housing index returns.

Rather than using Poisson processes and proportional hazard models to estimate the montgagor's financing decision, Richard and Roll (1989) advocate an altemative approach. In their model the four previously mentioned economic factors (refinancing incentive, seasoning, seasonality and bumout) are combined in a multiplicative formula to delermine conditional prepayment rates (CPR):

$$
\text { CPR }=\text { refinancing incentive } \times \text { seasoning } \times \text { seasonality } \times \text { burnout. }
$$

Among the alternative features of this model, one stiands out in particular: Richard and Roll measure the refinancing incentive as the ratio of the contract rate to the refinancing rate as opposed to looking at the difference between them. In order to prepay the loan, the mortgage is retired and the remaining principal is paid off, thus giving up any embedded option. If the prepayment costs are proportional to the outstanding principal, then the value of this option per outstanding dollar depends on the ratio Present Value of an Anmuity Mortgage. Richard and Roll show that if an annuity mortgage is considered, this ratio can be approximated by $\frac{\text { Contractrate }}{\text { Fefinancing rate }}$ and that option theory implies that it is rational to prepay the mortgage if this ratio exceeds some critical value.

Usually mortgagors need time to react to interest rate fluctuations. A variable developed to model refinancing incentives should include this. To most accurately express the refinancing incentive, the Richard and Roll prepayment model therefore uses a weighted average of recent ratio values.

The results show a highly non-linear relationship between the prepayment rate and the refinancing ratio. Whenever the ratio is less than one, the prepayment activity is relatively small, but increases rapidly as it exceeds one.

The seasoning effect is also a function of this ratio. However, this time only the most recent ratio value is considered. The larger the ratio, the faster a mortgage pool appears to season. It takes an average of around five years for a mortgage pool whose ratio equals one to fully season. Once a pool is seasoned, Richard and Roll assume that aging has no further effect on prepayment rates.

The third factor, seasonality, is inchuded because it is generally assumed that prepayment tates are higher in the summer months than in the winter. Richard and Roll, bowever, find that the peak in prepaying occurs in October and November, while the prepayment rates are the lowest during February and March.

Different households face different refinancing costs, therefore the critical value of the ratio that triggers prepayment differs among households. And even for one household the critical ratio value is not constant over time. The heterogeneity among mortgagors and the fact that the critical value is not time-homogeneous is captured by the burnout factor. This bumout factor is path-dependent. 
Richard and Roll found that roughly $95 \%$ of the prepayment differences ower time and across coupons can be attributed to the four explanatory variables. This result indicates that the Richard and Roll model has a good fit to the data avalable. However, Richard and Roll do not discuss the actual functional relationships between whe separate factorg and the ratio $\frac{\text { Compact rate. }}{\text { Fefinming rate }}$. How the factors proceed from the historical data is not mentioned. Kang and Zenios (1992) devote a large part of their paper to overcome this by describing the techniques for filtering the four factors out of the historical observations.

Golub and Pohlman (1994) compare the multiplicative model with other Wall Street models. They find that the multiplicative model, which they call the Wharton prepayment model, yields credible prepayment rate projections and includes all the essential economic variables which are commonly embodied in practitioners' models. Golub and Pohlman

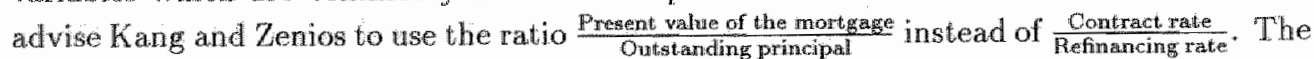
latter ratio does not capture the joint impact of actual mortgage rates and the remaining time to maturity. In a postscript to their paper, Kang and Zenios acknowledged that this adjustment did indeed generate better results.

\subsection{Conclusion}

This chapter gives an werview of the central concepts of mortgage pricing. The first being the importance of the stochastic environment of the mortgage. The fundamental stochastic variable underlying all mortgage studies is the short-term interest rate even though various authors argue that additional state variables are necessary to price mortgages and Mortgage- Backed Securities accurately.

The prevailling approach to price fixed-rate mortgages is to mimic its cash flows. Noarbitrage principles require that these cash flows have the same present value as the mortgage contract. This approach works well when fixed-rate mortgages are analyzed. The procedure becomes more complex when adjustable rate mortgages are considered. The cakt flows proceeding from such contracts depend on the history of the interest rates. Kau, Kenan, Muller and Epperson. (1990, 1993) developed a methodology to overcome this path-dependency problem.

Studies which incorporate the possibility of default conclude that the marginat contribution of this option is small as long as the loan-to-value ratio is low and the house price volatility is not large either.

Finally, this chapter summarizes the body of literature published on empirical mortgage prepayment behavior. Here the assumption of wealth-maximizing borrowers was relaxed. Rather than imposing optimal call and default decisions, observed termination behavior is analyzed in these studies. Early empirical models are based on basic rules-of-thumb, e.g. the average life nodel and the PSA benchmark. However, as mortgage contracts became more complicated over the years and the mortgage market increased in size, prepayment behavior became far too important to rely uncritically on these rules-of-thumb. In the 
more recent studies a distinction can be made between those applyng an endogenous prepayment model which is extended with exogenous calls and those who dexelop a strictly empirical model. Commonly, these empirical prepayment models specify foum man determinants of prepayment activities. The first one captures the refinance incentive and is related to prevaling mortgage rates. Seasonality measures the variety in prepayment rates over months. Seasoning and burnout are both aging factors. Seasoning refers the beginning of a contract, when the prepayment rates are low and gradually increase, while: burnout describes the decreasing prepayment activities as mortgages age through interest rate cycles. 


\section{Chapter 4}

\section{Principles of mortgage valuation}

\subsection{Introduction}

The mortgage market has become a highly dynamic market. The undeniable signs are the substantial growth of the market, the increasing interest for the secondary marliet and the sharp increase in the variety of loan types. The complexity of these newly cleveloped contracts necessitates the use of numerical methods in mortgage pricing. In this chapter the principles of mortgage valuation are explained.

Following a short elaboration in Section 4.2 on numerical procedures, this chapter focuses on the general idea of interest rate tree methods by working out some simplified. examples. Various interest rate derivatives will be priced by using backward recursion, and methods alternating between backward and forward techniques. The fundamental variable wnderlying all these numerical solution techniques is the short-term interest rate. Section 4.3 thus introduces a short-term interest rate model which is borrowed from B].ack, Derman and Toy (1990). Non-amortizing mortgages and mortgage-annuities are valued (both callable and noncallable) in Section 4.4. Similarly, callable and noncallable adjustable-rate mortgages are priced in Section 4.5. The pricing technique introduced by Kau, Keenan, Muller and Epperson (1990, 1993) is explained in more detail here. Section 4.6 studies at typical Dutch mortgage contract which is not fully callable, but limited to a percentage of the initiall loan in each calendar year. Due to the path-dependency of the cash Hows, this loan type cannot be valued by backward induction only. The problems that arise when such a mortgage contract is valued in a more realistic setting are explained in great detail in Section 4.6 and summarized in Section 4.7 .

\subsection{Numerical solution techniques}

A mortgage valuation model consists of several major ingredients: a description of the interest rate dynamics, a model of the term structure of interest rates, the relation between mortgage rates and the term structure, and a model describing the prepayment and defauli behavior. Integrating these elements within one mortgage valuation model reguires 
simplifying assumptions for computational reasons. For this we must compromise and weigh one simplification against another. A more elaborated model for the term structure involves simple prepayment and default behavior rules. On the other hand, sophisticated prepayment rules require a less complicated process to describe the interest rate dy namics.

The majority of montgage valuation models, e.g. Dum and McConnell (1981a,b). utilize anefactor model to describe the interest rate dynamics. In a one-factor model all interest rates are driven by the instantaneous short-term interest rate, $r$. Based on the assumptions that (1) the single state variable ${ }^{*}$ summarizes all relevant information, (2) the capital manket is compettive and perfect, (3) trading takes place continuousty and that the cash flows are paic continuously, and (4) individuals are non-satiated and behave in a rational manner, Dunn and McConnell (1981.a,b) show that the value of a default free fixed-income security, $V$, can be described by the following Partial Differential Equation $(\mathrm{PDE})^{1}$ :

$$
\frac{1}{2} \sigma^{2}(r, t) V_{r r}+[\mu(r, t)-\lambda(r) \sigma(r, t)] V_{r}+V_{t}-r V+C\left(t, r, r_{h}\right)=0
$$

where $\mu(r, t)$ is the drift of the process, $\sigma^{2}(r, t)$ is the variance, and $\lambda(r)$ is the market price of interest rate risk. Subscripts on $V$ denote partial derivatives. The fundamental state variable in Equation (4.1) is the instantaneous risk-free rate $r$. The variable $c\left(t, r, r_{k}\right)$ represents the cash flows at time $t$ which depend on the prevailing short-term interest rate $r$ and the history of the short-term interest rate, $r_{h}$. This path-dependency is a very important factor when pricing a typical Dutch mortgage contract with only restricted penalty-free prepayment possibilities. In the Netherlands, generally only between 10 and 20 percent of the initial loan can be called in a callender year without penalty. Pathdependency also complicates the valuation of adjustable-rate mortgages with caps or floors. In this case, the current contract rate is not only determined by the interest rate on the adjustment date but allso by the rates before that. Kau, Keenan, Muller and Epperson (1990, 1993) introduced an auxiliary state variable to overcome this problem. This is discussed in Section 4.5, where a simplifed adjustable rate mortgage is analyzed.

There are an infinite number of functions that satisfy Equation (4.1). A unique solution requires boundary conditions which capture the characteristics of the mortgage contract: The value of the mortgage at maturity must equal its face value or the remaining principal. The value at maturity for anon-amortizing mortgage equals the initial loan, while for a fully amortizing mortgage this value is equal to zero, $V(r, T)=0$. Secondly, the value of the mortgage contract must go to zero as the interest rate approaches infinity, $V(\infty, t)=0$. These two conditions hold for each fixed-income security. A third constraint has to be introduced for a callable security in order to specify the interest rate at which the mortgage is called. Wealth-maximizing borrowers will choose the call strategy that minimizes the value of the mortgage contract. This strategy is driven by the stochastic process of the risk-free instantaneous interest rate. Ignoring transaction costs, optimal calls will prevent

\footnotetext{
1 This PDE is the basic pricing equation of all securities, see Duffie (1996) for a detailed discussion.
} 
the market walue of the contract from exceeding the remaining unpaid principal of the loan, $V(r, t) \leq U(r, t)$.

Given these boundary conditions, Equation (4,1) can be solved to value a defauld free fixed-rate mortgage. Howewer, in order to accomplist this, numerical solution techniques are mandatory. ${ }^{2}$ Here, three numerical solution techniques are considered. The finite differ. ence method converts Partial Differential Equation (4.1) into a set of difference equations which will be solved iterativelly. Such a set of difference equations is a discrete approximation of a continuous-time diffusion process commonly used to describe the interest rate dymamics.

Simulation methods are a second group of numerical solution techniques applicable to mortgage pricing. Simulation procedures are well-suited to valut deriwative securities whose payoff depend on the history of the underlying variable or when there are several underlying variables. Rather than solving the Partial Differential Equation (4.1) directly, simulation procedures utilize expected value calculations. In such procedures interest rate paths are simulated. Subsequently, cash flow pratierns are allocated to those paths and the mortgage contract is valued for each path. An approximation of the true value of the mortgage contract is found by calculating the average value of the contract over all simulated paths.

In contrast to finite difference methods, simulation procedures are forward solution methods. The problem with forward pricing methods is the dependency of the prepayment decision at a specific point in time on the value of the contract in that situation. Simulation procedures inevitably require the use of an exogenous prepayment decision rule which does not always lead to optimal prepayment behavior. This problem is often bypassed by the third numerical solution technique based on interest rate trees. The general idea behind interest rate trees is illustrated in Figure 4.1.

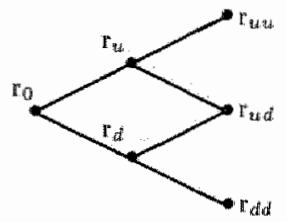

A recombining tree

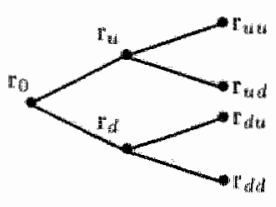

A ron-recombining tree

\section{Figure 4.1: InTEREST Rate TREes}

Figure 4.1 shows two alternative binomial interest rate trees. The interest rate at time $t+\Delta t$ in a binomal tree can retain one of two values depending on the ontcome of a random draw, the probabilities of which are determined solely by the interest rate at time t. Two new branches arise from each of the possible interest rates at time $t+\Delta t$, and it only takes a few periods for the lattice to start looking like a tree (hence the rame). The

\footnotetext{
${ }^{2}$ For an overview of numerical procedures see Duffe (1997) and Hull (1997).
} 
interest rates from which new branches arise are called nodes. In a single factor model, the state of the economy can be summarized by these nodes, or states of the short-term interest rate.

The left diagram of Figure 4.1 shows a recombining interest rate tree. In such a tree, an interest rate path with an increasing rate in the first period and a decreasing rate in the second one has the sane impact as a path where the interest rate first decreases and successively increases. This contrasts with non-recombining interest rate trees where the order of stecessive interest rate fluctuations is of great importance. This latter tree is suited for valuing contracts whose cash flows depend on the actual interest rate path.

Backward pricing methods are based on interest rate trees. Such methods evaluate the mortgage contract with its embedded options by starting at the end of the interest rate tree. At time $T$, when the contract matures, the value of the contract is kmown with certainty. This value is fed into earlier ones. The rude value at time $T-\Delta t$ can be calculated as the expected value at time $T$ discounted at rate $r$, which corresponds with the node under consideration for time $T-\Delta t$. This can be done for all nodes at time $T-\Delta t$. For each of the nodes it is necessary to check whether exercising the option is preferable to holding the contract. By working back through all nodes, the value of the mortgage contract at the moment of origimation is found.

The major difficulty in using backward pricing methods is determining how to include the path-dependence of cash flows. Mortgage cash flows are path-dependent in the sense that prepayment not only depends on the current state, but also on the history of the interest rates. This is cue to the simple fact that today"s cash flow depends on the prepayment experience in the past.

\subsection{Interest rate processes}

Various mortgage loan types are valued in this chapter based on binomial trees. Before turning to numerical examples for illustration, we first need to introduce the interest rate model on which the valuations will be based. This chapter uses the Black, Deman and Toy (1990) model which describes a one-factor interest rate model and applies it to value Treasury bond options. The fundamental variable is the annualized one period interest rate, which is assumed to be log-normally distributed. Given this assumption, Black, Deman and Toy (BDT) derive the future one-period interest rates which match today's term structure of interest rates and yield volatilities.

Table 4.1 , which is borrowed from BDT, presents the figures of a fictitious term structure upon which all examples in this chapter are based. Under the riskmeutral measure the short-tem interest rate one period from now can be determined with the help of this table: Today's value of a zero coupon bond with a maturity of 2 years is equal to 81.16 $\left(=\frac{100}{(1+0.11)^{2}}\right)$. This must equal the expected price one period ahead, discounted back by using the one-period yield. BDT constrain interest rate fluctuations by use of a path- 
TABLE 4.1: A FICTITIOUS TEFM STRUCRTE

\begin{tabular}{ccc}
\hline $\begin{array}{c}\text { Maturity } \\
\text { (years) }\end{array}$ & $\begin{array}{c}\text { Yield } \\
(\%)\end{array}$ & $\begin{array}{c}\text { Yield Volatility } \\
(\%)\end{array}$ \\
\hline 1 & 10 & 20 \\
2 & 11 & 19 \\
3 & 12 & 18 \\
4 & 12.5 & 17 \\
5 & 13 & 16 \\
\hline
\end{tabular}

Source: Black, Derman and Tay (1990)

independent binomial lattice in which the short-term interest rate can only move up or down (with equal probability). Hence, the price one period in the future is either $P_{t a}$ or $P$, with $P$ being price and the subscripts indicating whether the interest rate moved up or down, respectively. This is illustrated in Figure $4.2 .^{3}$

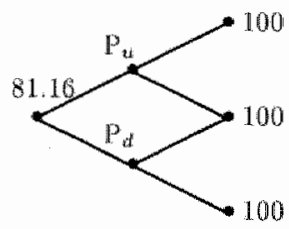

\section{FIGURE 4.2: THE SHORT-TERM INTEREST RATE IN THE NEXT PERIOD}

The present value of the expected bond price one period ahead must equal the present. value of a two-year zero coupon bond, such that:

$$
\frac{\frac{1}{2} P_{u}+\frac{1}{2} P_{e}}{1.10}=81,16
$$

where $P_{u}=\frac{\frac{1}{2} 100+\frac{1}{2} 100}{1+r_{u}}$ and $P_{d i}=\frac{\frac{1}{2} 100+\frac{1}{2} 100}{1+r_{d i}}$. Clearly, $v_{w}^{2}$ and $r_{d}$ reter to the movement in the short-term interest rate. Assuming that in continuous time the shot term interest rates are log-nomally distributed, the volatility of the two year yied in the applied binomial discreet approach must meet the following requirement:

$$
\sigma_{2}=\frac{1}{2} \ln \frac{r_{i k}}{r_{d}}=19 \%
$$

Equations (4.2) and (4.3) can be used to solve for the two unknown variables, $r_{z}=14.32$ and $r_{d}=9.79$. These results can be seen in Figare 4.3 .

The next step is to find the three possible short-term interest rates for the next year. Once again two equations similar to Equations (4.2) and (4.3) can be derived. Unfortunately, this time there are three unknown parameters to make it appear that an unique

\footnotetext{
${ }^{3}$ Note that the interest rates reported in Table 4.1 refer to observed rates such that no risk-adjustment is required.
} 


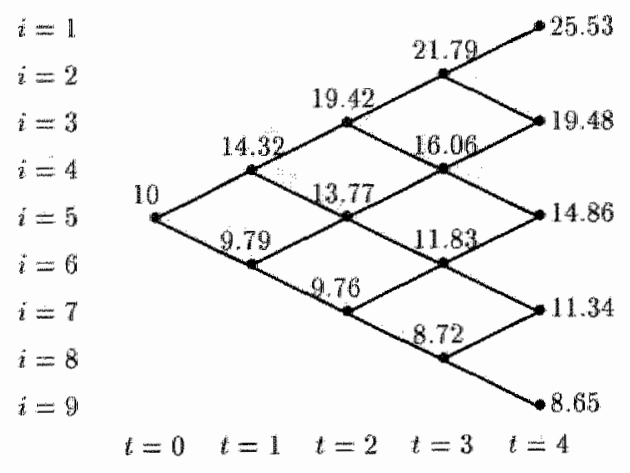

Figure 4.3: INTEREST RATE TREE

solution does not exist. However, the $\log$-normality assumption regarding the short-term interest rate tells us that the volatility only depends on time. Whether the short-term interest rate went up or down in the first period does not matter. The volatility when the interest rate rises is $\frac{1}{2} \ln \frac{r_{\text {mat }}}{r_{u, d}}$, while when the interest rate drops the volatility is $\frac{1}{2} \ln \frac{r_{d a}}{r_{d a}}$. Since these volatilities have to be similar we know that $\frac{r_{w d}}{r_{w d}}=\frac{r_{d u}}{r_{d a t}}$ "Because the interest ratie tree is assumed to recombine we know that $r_{u d}=r_{d u}$ and therefore $r_{u d i}^{2}=r_{u u^{r} d d^{2}}$. Hence the middle interest rate follows directly from the other two rates. This means that only two short-term interest rates have to match the two restrictions imposed by the three-year yield and volatility, the third one follows directly from this. Hence, a unique solution exists.

Applying this procedure to all nodes in different periods results in the interest rate tree plotted in Figure 4.3. This full tree of one-term interest rates corresponds with the term structure presented in Table $4.1{ }^{4}$

\subsection{Fixed-rate mortgages}

Fixed-rate annuity-mortgages are analyzed in this section, which builds upon the term structure of Table 4.1 and the dynamics of the short-term interest rate summarized in Figure 4.3. More precisely, the contract rate will be determined such that the value of the contract at origination equals the face value of the loan, which is assumed to be 100 . In this setting, the contract is an interest rate derivative with a zero net present value. By doing this for comparable callable and noncallable securities, the option-adjusted spread is found.

Let us first consider a 4 -year noncallable fixed-rate annuity-mortgage with an annual coupon of 11 percent. This example is graphically illustrated in the left diagram of Figure

\footnotetext{
${ }^{4}$ This section uses the Black, Derman, Toy approach to derive the interest rate tree. The same result thas been reached by other authors through tse of forward induction based on Arrow-Debreu securities. See for example Hull and White (1994).
} 
4.4. The mortgage prices embodied in Figure 4.4 represent the values immediately after the periodic payment has been made. This holds for all figures in this chapter.

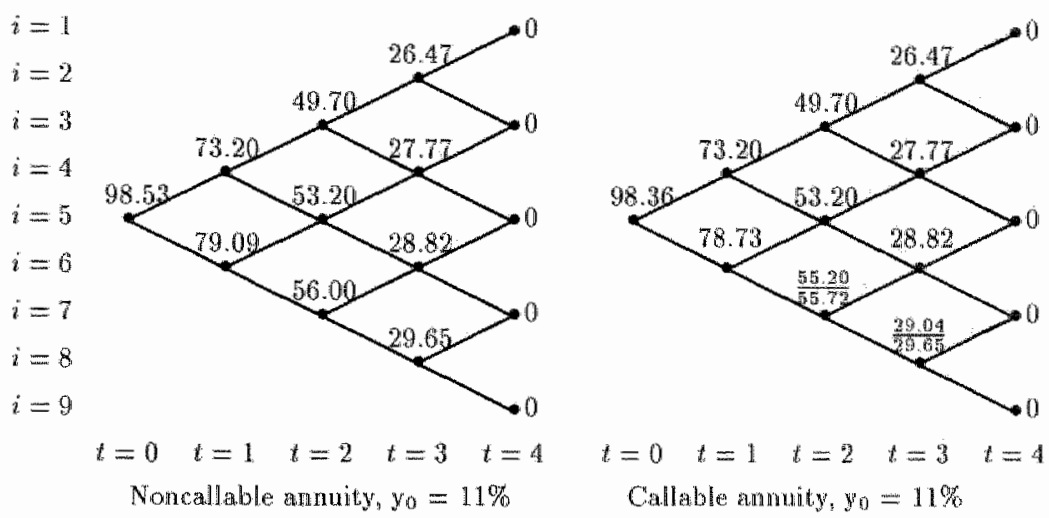

Figure 4.4: Annutty value

This figure compares the value of callable and noncallable anuuities. In the right diagram, prepayment is recommendabile in the nodes which contain two values. The lower number represents the present value of the future cash flows. The upper number reflects the unpaid baliance of the anuity loan. Since no prepayment costs are included this unpaid balance equals the price at which the annuity can be called.

Annuity-mortgage contracts have the characteristic that each periodical payment consists of both interest payments and principal repayments. Due to these redemptions, the unpaid principal, and hence the interest costs, decrease over time:

$$
U_{t+1}=\left(1+y_{0}\right) U_{t}-M_{0}
$$

where $U_{t}$ is the unpaid ballance at time $t, y_{0}$ is the contract rate at time $t=0$ which remains constant during the life of the contract, and $M_{0}$ represents the periodical costs. The amount which has to be paid in each period remains constant over the life of the contract. These periodical costs are a function of the time to matarity, the size of the principal, and the contract rate:

$$
M_{0}=U_{0} \frac{\left(1-v_{0}\right)}{v_{0}\left(1-v_{0}^{\gamma^{2}}\right)},
$$

where $U_{0}$ is the initial loan, $T$ is the time to maturity, and $v_{0}=\frac{1}{1+y_{0}}$. Given a contract rate of $11 \%$ and an initial loan of 100 , the periodical payment is equal to 32.23 . 
An annuity is a fully amortizing fixed-income security. The loan is completely repaid after four years. Hence, the mode values at time $t=4$ are zero in Figure 4 . 4 independent of the state of the economy at that time, $V(4)=0$ for all $i$.

To find the value at any specific node at time $t=3$, the expected value at $t=4$, given the node at $t=3$, has to be raised by the periodical payment paid at $t=4$. The resulting sum has to be discounted at rate $r$ which corresponds with the node under consideration for time $t=3$, w. the value of the noncallable annuity-mortgage at tirne $t=3$ in node $i=8$ is equal to $29.65\left(=\frac{\frac{1}{3} 0+\frac{2}{2} 0+32.23}{1+0.0872}\right)$. This must be done for all nodes at time $t=3$. Once these values are known, those at time $t=2$ can be found. By working all the way back through the tree the value of the security at origin is found. In essence, this is how the backward pricing method works. By doing this for various coupons the rate can be found at which the contract value at origin equals the principal value. For a noncallable annuty this is illustrated in the left diagram of Figure 4.5 .

The right diagrams of Figures 4.4 and 4.5 summarize the valuation procedure of a callable lixed-rate annuity-mortigage. Once again a backward technique is utilized. However, instead of feeding values at time $l$ straight into earlier ones, we now have to first check whether exercising the option is preferable to holding the contract. For this the calculated value has to be compared with the exercise price. Rather than staying constant over time, the exercise price is equal to the outstanding debt at each point in time provided no prepayment took place at an earlier stage.

To illustrate, let us once again look at the node corresponding with $i=8$ at time $t=3$ in Figure 4.4. As we just saw, the node value is equal to 29.65 when the contract rate is $11 \%$. However, the outstanding debt, and therefore the exercise price, at time $t=3$ is equal to 29.04. A wealth-maximizing borrower will thus prepay the loan so that the correct value in this node is 29.04 rather than 29.65 . This value of 29.04 must be used in the next step of the backward induction procedure. This is illustrated in the right hand diagram of Figure 4.4. Morling back like this through all nodes up until $t=0$ will bring us to the value al origin.

In the right hand diagram of Figure 4.5 the contract rate is derived which equals the walue at origin to the intiall loan. The endogenized contract rates at which the callable and noncalible annuties are zero net present value investments differ by 40 basis points in this example.

\subsection{Adjustable-rate mortgages}

An adjustable rate mortgage (ARM) is a loan whose contract rate is periodically reset. This petiodic adjustment reassigns part of the interest rate risk from the lender to the borrower. The borrower's uncertainty is often partially offset by cap and floor-features cmbodied in the ARM contract. These features restrict the degree by which the contract. rate can fuctuate between resel dates (periodic cap or floor) or during the entire life of 


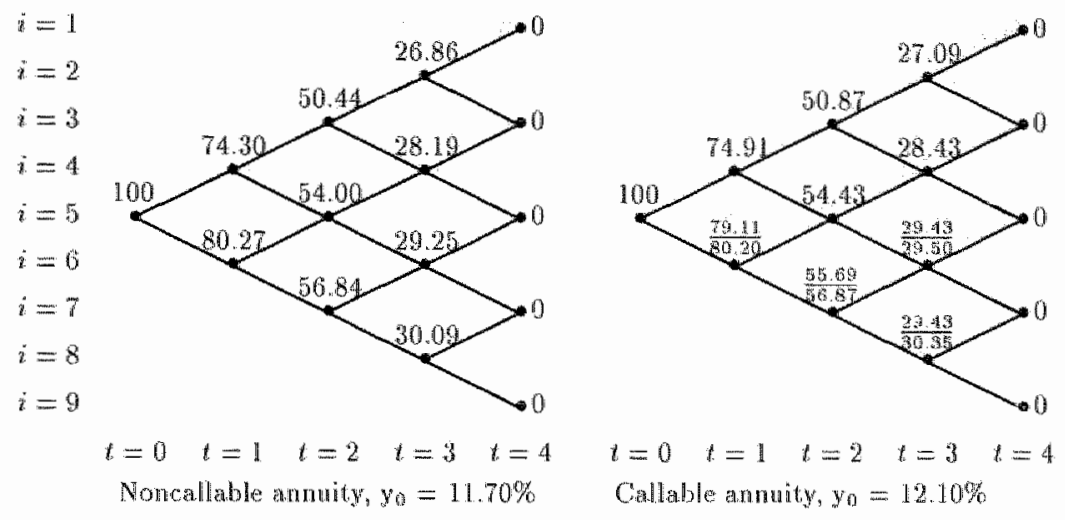

FIGURE 4.5: ANNUITY RATE

the mortgage (lifetime cap or floor). A further explanation of ARM characteristics is given in Chapter 3. In order to illustrate the ARM valuation procedure as introduced by hatu, Keenan, Muller and Epperson (1990, 1993), for the purposes of this section, let us look at an ARM contract both with and without a lifetime cap and floor. Periodic caps and Hoors are ignored in this four-period example. When the adjustment date is at time $t=2$, the new contract rate will depend both on the prevailing interest ratie at that time and, due to the embedded caps and floors, also on previous contract rates. These earlier rates camot be known by working backwards through the tree. However, Kau el al. (1990, 1993) observe that the value of the promised mortgage payments, the value of the prepayment option and therefore the value of the mortgage are homogeneous of degree one in the unpaid balance. Hence the problem can be solved for an arbitrary unpaid balance and rescaled as required.

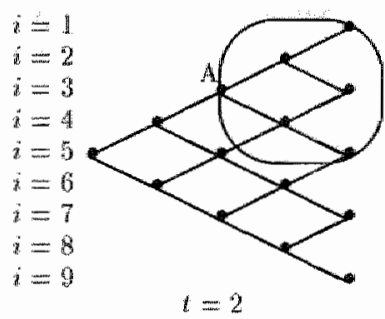

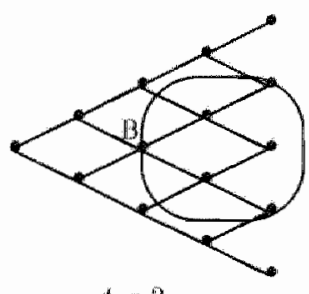

$t=2$

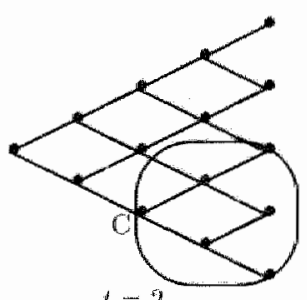

$t=2$

FIGURE 4.6: THE VALUATION OF AN ARM: STEP 1

A slightly adjusted procedure is followed in order to value the payments resulting from an annuity-mortgage whose contract rate is reset at time $t=2$. Let us start by assuming 
that the umpaid balance at the adjustment date is equal to 100 , which can later be rescaled if necessary. A contract rate is chosen successively for each node in the tree at $1=2$ such that the value of the annuity-mortgage is equal to one hundred in that node. This is illustrated in Figure 4.6. The sub-tree inside the ellipse of the let hand diagram determines the contract rate at which the annuty-mortgage is a zero net present value investment for node $A$ at the $t=2$. (See the previous section.) Once this is done for both node $A$, $B$ and $C$, we can continue with the second step in the pricing algorithm as illustrated in figure 4.7 .

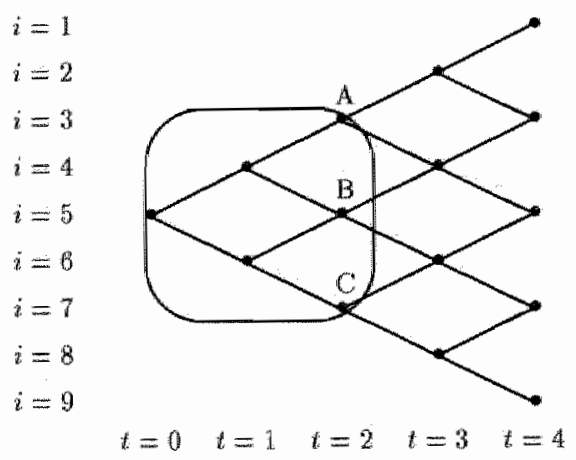

Figure 4.7: ThE VAldution OF AN ARM: SteP 2

The value of the contract at nodes $A, B$ and $C$ is discounted to $t=0$. It must be taken into account that prepaying is possible at time $t=1$. By doing this for various starting contract rates, or using an optimizing algorithm, these two steps will lead to the contract rate at origin which equals the value of the ARM contract to the loan.

Figure 4.8 illustrates the first step for valuing an adjustable-rate annuity-mortgage without cap or floor restrictions. When the new contract rate can freely be reset, the contrat, value on the adjustment date is at par. This par value is equal to what the outstanding loan would be at that point in time provided no prepayment took place at an carlier stage. It is not necessary to consider the periods after the reset date when valuing an ARM contract without caps and foors. Studying the first two periods and moving directly to the second step will suffice, as summarized in the left diagram of Figure 4.10. However, when cap and floor restrictions are imposed, the first step increases in importance. Now a valuation procedure is needed which can altemate between backward and forward solution techniques. First, the contract rate at $t=0$ has to be calculated as if no restrictions hold. The reset date must then be analyzed to see whether the cap or floor restrictions become binding. If so, the proposed contract rates in nodes $A, B$ and $C$ need to be adjusted. Next, the contract value at origin must be calculated. The initial contract rate has to be adjusted if this value is not equal to 100 and the whole procedure repeated. 

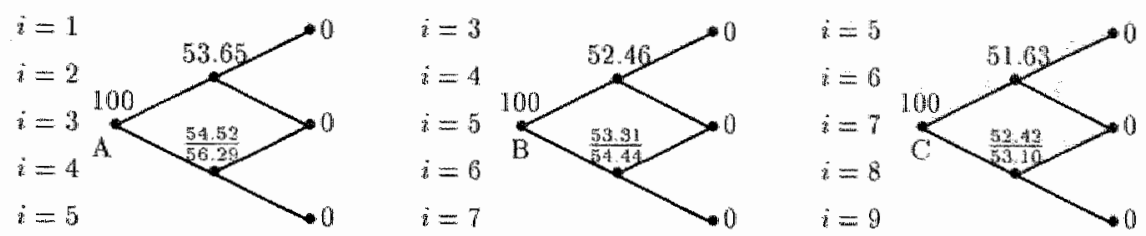

$$
\begin{aligned}
& t=2 \quad t=3 \quad t=4 \\
& y=A=19.85 \%
\end{aligned}
$$$$
t=2 \quad t=3 \quad t=4
$$$$
y_{2} \cdot k=14.20 \%
$$

$$
\begin{aligned}
& t=2 \quad t=1 \quad t=4 \\
& y_{2, c}=10.15 \%
\end{aligned}
$$

Figure 4.8: THE VAl,UATION OF AN ARM WITHOUT CAP OR FLOOR: STEP 1A

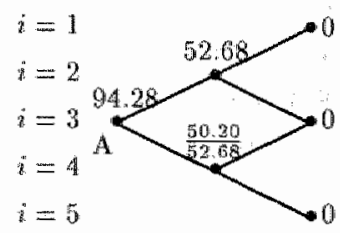

$t=2 \quad t=3 \quad t=4$

$y_{3} x_{4}=14.53 \%$

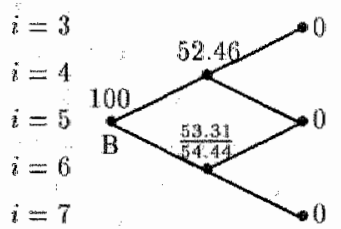

$t=2 \quad t=3 \quad t=4$

$y_{2}, 2=14.20 \%$

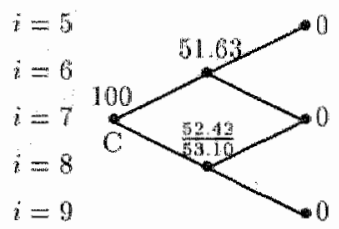

$t=2 \quad t=3 \quad t=4$

$y_{2, C}=10.15 \%$

FIGURE 4.9: The valuation OF AN ARM WTH A OAP OR FLOOR: STEP 1B

$$
\begin{aligned}
& i=3 \\
& i=4 \\
& i=5 \\
& i=6 \\
& i=7
\end{aligned}
$$
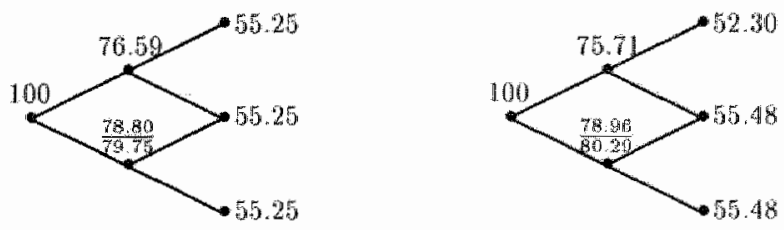

$$
t=0 \quad t=1 \quad t=2
$$$$
t=0 \quad t=1 \quad t=2
$$

Without a cap or floor, $y_{0}=11.11 \%$ With a cap and floor, $y_{0}=11.63 \%$

FIGURE 4.10: THE VALUATION OF AN ARM: STEP 2' 
The results of a lour period exanple are illustrated in Figure 4.9 and the right hand diagram of Figure 4.10. In this example, the contract rate is reset after two periods and the cap and floor restrictions require that the rate reset at the adjustment date may not exced 1.25 times the initial contract rate, while not decreasing beyond 0.75 times the initingl mate.

If an initial contract rate of $11.63 \%$ is chosen, the cap and floor restriction impose a contract rate reset at $t=2$ of between 14.33 and $8.73 \%$. If the contract rates could be freely reset at the adjustment date, the new rates would be $19.85,14.20$ and $10.15 \%$ for nodes $A, B$ and $C$, respectively. However, the cap requires that the new contract rate may not exceed $14.53 \%$, so that this latter percentage is now chosen for node $A$. As Figure 4.9 shows, this results in a below par walue for node $A$. Based on the initial contract rate of $11.63 \%$, the outstanding balance at time $t=2$ is equal to 55.48. Since the values at node $B$ and $C$ are equal to par, 55.48 is the correct corresponding value for these nodes. Node $A$ value is found by rescaling $(52.30=94.28 \% \times 55.48)$. The next step is now to discount these values plus the remaining cash flows (once again keeping prepayment opportunities in mind) for time $L=0$, the explanation for which is given in Section 4.4 .

It is evident that this procedure is computationally intensive. This imposes serious restrictions when a more realistic setting is chosen, such as a longer time to maturity, more than one reset date with periodic caps and floors, or a multi-factor interest rate model which requires much larger and finer interest rate grid. For example, Kau et al. (1990) utilize a 64 point grid for the interest rate and a 21 point grid for the lagged contract rate. In their 1993 paper which introduces the concept of default, an interest rate grid of 24 points is used to span the range of possible contract rates. Values lying in between these grid points are found by simple interpolation. This illustrates once again the computiational restrictions stressed in Section 4.2. By using a sophisticated model to link the mortgage rate to the short-tern interest rate, Kau et al. (1990, 1993) must make do with a small grid in their numerical solution procedure.

\subsection{Mortgages with limited prepayment options}

Most Dutch mortgages cannot be fully called without a penalty. Only 10 or 20 percent of the initial loan can commonly be prepaid in a calendan year without surcharge. Additional prepayments are settled at a cost. which is equal to the present value of the difference between the future monthly payments of a new contract and the existing mortgage. Due to the limited prepayment restriction, the path-dependence problem is even more profound in valuing these types of contracts than it was in the previously discussed adjustable-rate mortgages. Now the mortgage loan is no longer either fully prepaid or fully outstanding, various in-between stages are possible as well.

When a mortgage is partially prepaid, the periodical payments of the borrower must be adjusted for the smaller outstanding debt. The contract rate does not alter as a result 
of the prepayment. The newly determined periodical costs are therefore a function of the remaining outstanding debt and the remaining time to maturity. For fully amorlizing annuity-mortgage it thus malkes a substantial difference whether the mortgagor exercises the option to partially prepay the loan in Jantary or in December. This extra pathdependency makes a backward pricing technique very diffcult. Due to the computational complexity, a valuation technique which alternates between the backward and forward solution methods is also hard to implement. Figures 4.11 and 4.12 illustrate a four-period example. Even a small example like this shows the difficully involved in valuing this contract by using interest rate tree methods. ${ }^{5}$

Figure 4.11 plots a tree which illustrates the cash fows corresponding with a contract which will be partially prepaid whenever the prevaling interest rate is lower than the interest rate at origination. The time steps in Figure 4.11 represent calendar years. The month of prepayment is thus ignored in this example. In Figure 4.11, $M$ represents the periodical payment and the frst subscript indicates when the size of this payment was determined. Successive subscripts illustrate the path the interest rate takes up to the node where the mortgage was partially prepaid and a new periodic payment arranged. Once again $u$ means that the interest rate went up and $d$ illustrates a downward movement. Looking at the difference between $M_{3, \text { tod }}$ and $M_{3, \text { ddit }}$ will help clarify the notation. Both periodical payments are deternined at time $t=3$. However, the first follows from interest rates which first increased and then decreased twice in a row. Following this interest rate path, the first partial prepayment will be at $t=3$. The other periodical payment, $M_{3, \text { ad }}$, is based on an interest rate path which first went down twice in a row before rising again. So at time $t=1$ and $t=2$ the mortgage will also be partially prepaid. Following this latter interest rate path therefore results in a smaller periodical payment settled at time $t=3$ than when the first path is followed. This holds even though at time $t=3$ the same interest rate node is reached.

The wariable $b$ in Figure 4.11 illustrates that when the interest tate path reaches the corresponding node, the mortgage will be pantally prepaid. These nodes are indicalted by a circle. The anount indicated by variable $b$ lies between zero and $B$, where $B$ is equal to the maximum that can be prepaid without cost. As long as the outstanding loan $U_{t}$, is larger than $B$, the borrower will always prepay the maximum $B$. If the remaining debt is smaller than the allowed prepayment, the borrower will naturally only repay the outstanding debt, so that $b=\min \left(B, U_{t}\right)$. Hence, if the mortgage is completely prepaid in an earlicr stage, $b$ will be equall to zero. The same holds true for $M$ : if the contract is completely prepaid then $M$ becomes zero from that node on.

In Figure 4.12 a numerical example is introduced. The contract valued in Figure 4.12 is

\footnotetext{
5 Just before this thesis went to publication, reserarch being conducted by (houk and Vorst (logr) and

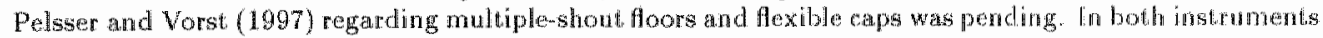
the holder has the right to exercise the derivative when it is in-the-money or to wait for another future situation wh wight be more profitable. These derivatives are priced with a wamerial nethod which in essence comes down to piling up interest rate trees. This layered approach may shed a new light on the valtation of mortgages with annual prepayment restrictions.
} 


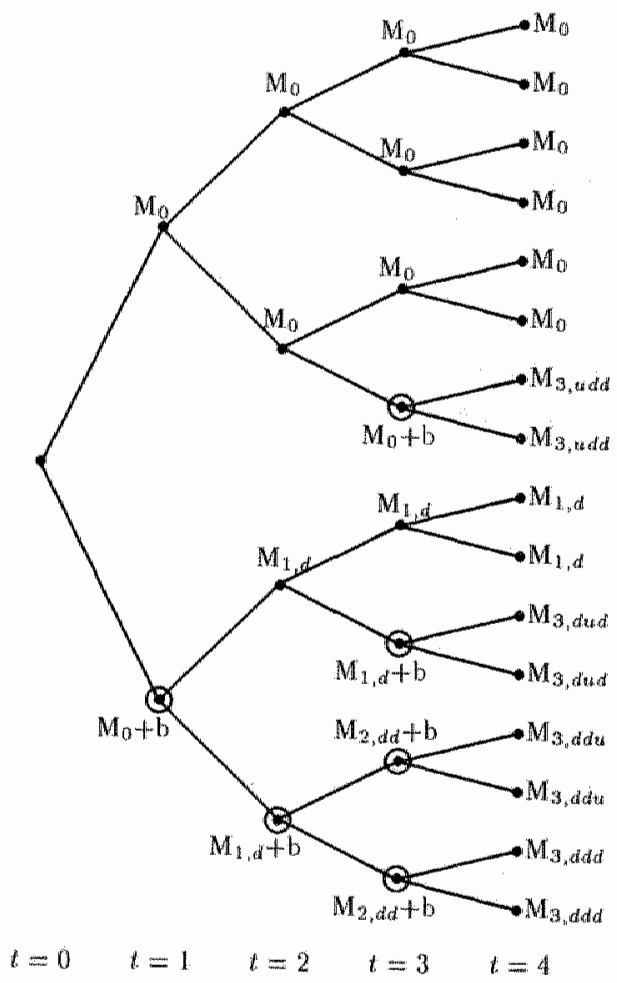

Figure 4.11: CASH Flow tree 


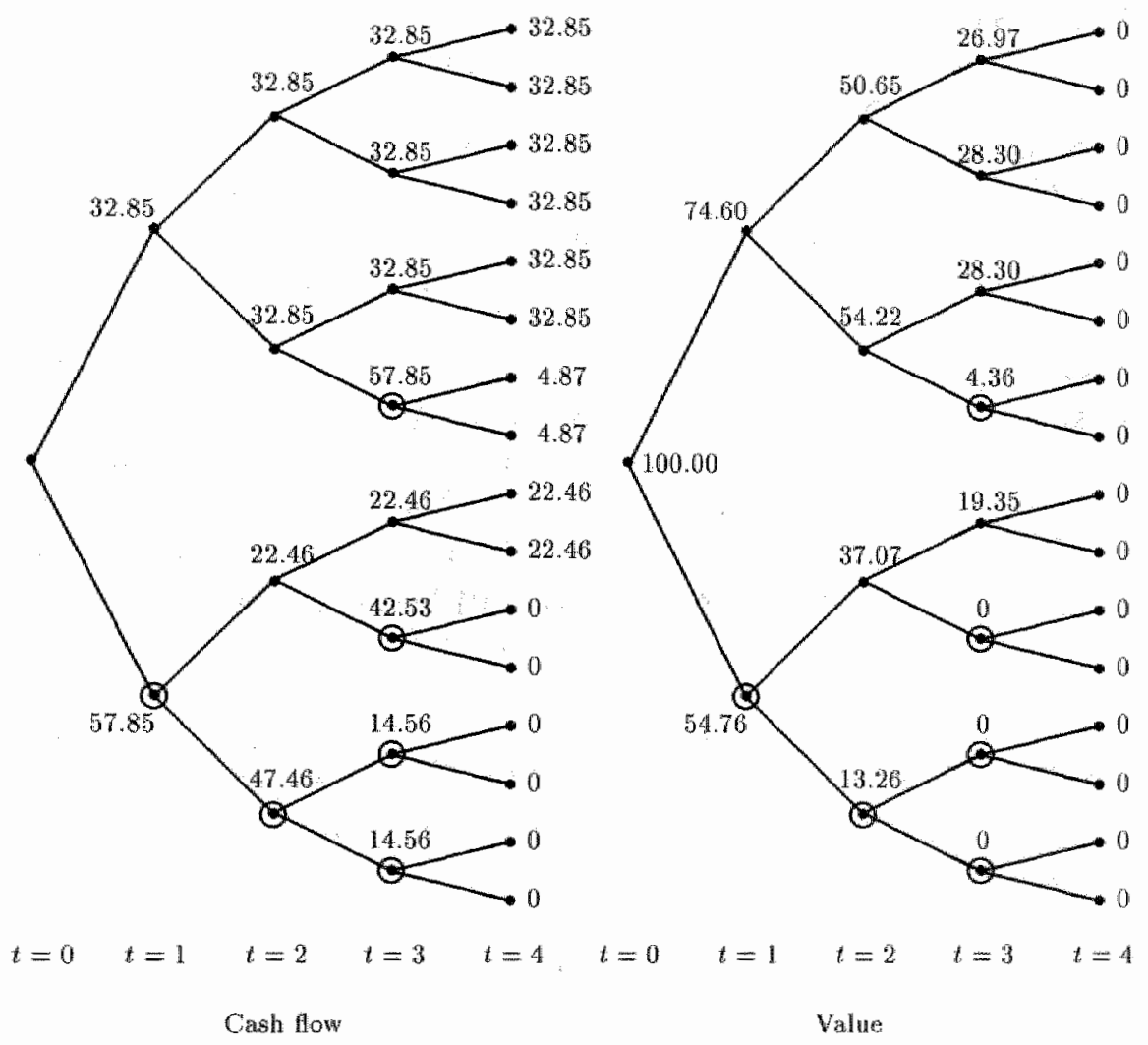

Figure 4.12: Cash flow and value taeE, $Y_{0}=11.89 \%$ 
an annuity mortgage loan of 100 , with a contract rate of $11.89 \%$ and a maturity of 4 -years. Only $25 \%$ of the initial loan is allowed to be prepaid each year. As long as the outstanding loan is larger than zero, the borrower will partially prepay the loan whenever the prevailing: interest rate is lower than the interest rate at origin.

The left diagram of Figure 4.12 shows the cash flows for each node following from this contract. In the right diagram, the siteam of possible payments is valued.

Let us first look at the tree illustrating the cash flows. By using the aforementioned numbers, in Equation (4.5) the periodical payment determined at origin, $M_{0}$, is equal to 32.85. When the interest rate goes up in the first period, the cash flow at time $t=1$ will be equal to 32.85 . In the branches proceeding from this up-node at $t=1$, only one node is found where the contract will partially be prepaid. Given the binomial tree, this node can be reached at time $t=3$ when the outstanding balance is equal to 29.36. Since the borrower can only prepay $25 \%$ of the initial loan, the cash flow in that node is equal to $57.85(=32.85+25)$. The debt that remains is equal to 4.36 , the remaining time to maturity is 1 year and the contract rate remains $11.89 \%$. It thus follows from Equation (4.5) that the periodical payment, $M_{3, \text { add }}$ is 4.87 . This resuls in the cash flow in the nodes caused by the sprouting branches.

Instead of moving upwards, the interest rate can also decrease in the first period. This will immediately result in partial prepayment such that the cash flow in the down-node at $t=1$ is equal to 57.85 . With no prepayment the outstanding debt alter one period would be 79.04. However, after the partial prepayment it becomes 54.04 so that the periodically required payment can be reduced to 22.46. From this down-node at $t=1$ the interest rate can move either up or down. In the former case no partial prepayment will occur, the cash. flow is 22.46, and the outstanding debt equals 38.01 . Continuing on from this node, the cash flow in the next period will equal either 22.46 or 42.53 . The latter cash flow consists of the periodical payment of 22.46 plus the partial prepayment. Since the outstanding debt is now only 20.07, the borrower will nepay exactly that amount. The mortgage being completely repaid, the cash flows in nodes on branches that proceed from here are now equal to zero.

A similar approach should be followed in the event the interest rate decreases in both the first and second period, so that the cash flow tree on the left hand side of Figure 4.12 can be completed. The cash flows shown in this iree were found by going forward through the tree. The next step is to discount the cash flows by going backwards through the tree. This is illustrated by the right hand diagram of Figure 4.12 .

\subsection{Conclusion}

The principles of mortgage valuation are explained in this chapter with the help of simplifed numerical examples based on bond option pricing techniques. The starting point is a description of the interest rate dynamics, which is assumed to be the single fundamental 
variable which drives all other interest rates. This assumption simplifies the description of: the term structure of interest rates and its dynamics. In this chapter, the Black, Derman and Toy (1990) interest rate model is applied. Given a fictitions term structure of interest rates, this model constructs a corresponding interest rate tree which is used for the examples included in this chapter.

First, noncallable and callable fixed-rate mortgage annuities are valued. These loan types can be valued with the techniques developed for bond options. It becomes more difficult when noncallable and callable adjustable-rate mortgages are priced. Kau, Keenan, Muller and Epperson (1990, 1993) introduced a pricing technique to value these kinds of mortgage contracts. Their technique is computationally intensive and therefore requires sacrifices in the accuracy of the interest rate process. In the last section a typical Dutch mortgage contract is studied, for which only a limited percentage of the initial loan can be annually prepaid. Due to the resulting path-dependency of the cash Hows, this loan type cannot be valued by backward induction only. Theoretically, a valuation method which alternates between the backward and forward solution technique as applied by the valuation of ARMs could solve this valuation problem. However, even more than is the case for ARMs, applying this method here causes even small examples to become unmanageable. Introducing an exogenous prepayment rule, as was done in this chapter, reduces the problem. In this case a forward solution technique can be applied to construct an interest rate and cash flow tree. Various things need to be known at each node: is prepaying recommendable, is it still allowed or has another prepayment occurred earlier in the same calendar year, what is the required periodical payment, and what is the outstanding debt? Only the first question is node-specific, the other three depend on the path of the interest rate. Due to this path-dependency, a recombining tree no longer suffices. However, the number of nodes in a non-recombining tree increases rapidly. When a binomial lattice is utilized the number of nodes double with each step. Consequently, introducing an exogenous prepayment rule is insufficient for addressing realistic valuation problems. For this we bave to resort to simulation techniques as done in Chapter 7 . 


\section{Chapter 5}

\section{Mortgage pricing under alternative prepayment behavior}

\subsection{Introduction}

The main difficulty in pricing mortgages lies within the prepayment behavior of the mortgagor. The literature distinguishes between optimal prepayment and exogenous prepay ment rules. Under optimal prepayments the valuation proceeds as for any callable bond by starting at the maturity date of the contract and working backwards in time under the assumption that, at each point in time, the borrower prepays when the value of the mortgage, if left nncalled, exceeds the outstanding debt plus any transaction costs associated with refinancing it.

Exogenous prepayment rules are empirically determined and based on observable variables like the age of the loan and the refinance incentive. ${ }^{1}$ As described in Chapters 3 and 9 , this refinance incentive captures the homeowners' decision to refinance their mortgage if the prevailing mortgage rates are lower than the coupon rate on their contract. This prepayment behavior can differ from the optimal call policy.

In this chapter we compare both approaches and examine how both prepayment rules affect the pricing of mortgages. First a valuation model is developed which ensures optimal prepayment behavior. Subsequently, a model is constructed in which the borrower prepays as soon as this reduces the future costs. Both approaches yield identical prepayment behavior as long as there are no market imperfections. As Kau and Keenan (1995) state: "If there were no up-front points or insurance, borrowers would prepay as soon as interest. rates fell". However, each approach might yield different prepayment behavior if market imperfections are introduced. In this chapter we concentrate on the impact transaction costs have on prepayment behavior and study the resulting differences of both approaches.

The optimal prepayment rule assumes that the mortgage market is a highly liquid and competitive market on which no intermediary has sufficient market power to charge

\footnotetext{
Examples are Richard and Roll (1989), Kang and Zenios (1992) and Golub and PohIman (1994).
} 
contract rates which exced its own cost of capital. This allows us to value a mortgage with no-arbitrage principles. For this we must impose that the mortgage is a zero net. present value investment, $i . c$. the value of a mortgage at origination has to equal the face value of the loan. To ensure that this holds, we have to endogenously derive the relation. between the mortgage vate and other interest rates. Such a nodel may otherwise prescribe prepayment at moments when the prevailing mortgage rate exceeds the contract rate on the current loan.

The prepayment rule which prescribes prepayment when the prepayment option is inthe-money depends explicitly on the mortgage rate at which the homeowner can refinance his Joan in the market. Whether this mortgage rate is endogenously or exogenously dettermined is not important. This approach automatically guarantees that prepayment only occurs if the prevaling mortgage rate is less than the current contract rate. As a shortcut to valuing mortgages we can therefore use empirically observed relations between mortigage rates and interest rates. In this chapter, for example, we use the historical relation betwen the mortgage rate and the short-term interest rate in the Netherlands and the US.

The main advantage of an exogenous relation between the mortgage rate and the shorterm interest rate is that it allows valuation models to cope with complicated pathdependency problems, detailed prepayment restrictions and complex interest rate environments. For example, the prepayment rule applied in this chapter is also utilized in Chapter 7, where the annual prepayment restrictions are amalyzed together with the minmum interest rate guarantee frequently embodied in the quotation offer preceding a Dutch mortgage contract. Within that chapter, a multi-factor interest rate model is used. Since the same forward-looking prepayment rule is used, we can compare the valuation results of Chapter 7 with the results proceeding from the valuation method of this chapter. A major limitation of this approach is that the exogenously defined prepayment rule does not automatically lead to optimal prepayment behavior in each theoretically possible settiug. Before we apply this prepayment rule in the simulation model we must therefore first examine its strengths and weaknesses. In this chapter we conduct an extensive analysis of the valuation model based on this rule and compare its results with those of a model which is based on the optimal prepayment rule.

The second topic that is central to this chapter is the impact interest rate processes have on mortgage pricing. Since a mortgage contract is an interest rate derivative with many option features, its valuation and risk measures could be very sensitive to the dynamic process of interest rates. For this reason we compare the results of three alternative endogenous single factor interest rate models, all estimated on Dutch short-term interest rate data.

The remainder of the chapter is organized as follows. Section 5.2 describes the mortgage contract and introduces the relevant components of an accurate mortgage valuation model. Section 5.3 elaborates on the valuation procedure and Section 5.4 studies the interest rate risk of a mortgage. The interest rate data used in this paper are summarized in Section 5.5. Section 5.6 contains an empirical analysis of the time series process of the short- 
tem interest rate. Section 5.7 discusses the empirical relation between the mortgage rate and the short-term interest rate. The valuation results based on the optimal prepayment rule follow in Section 5.8, while Section 5.9 presents the results from the suboptimal rule. Section 5.10 concludes.

\subsection{Mortgage valuation}

Many Dutch mortgages are annuities that pay a constant monthly cash flow consisting of: both interest and redemption. The most popular mortgage has a maturity of thirty years with the interest rate fixed for a five year period. After each five year period the contract rate is reset. No cap or foor restrictions apply on setting the new contract rate at the adjustment date. In the mortgage valuation models we therefore only consider the single fixed rate period. Interest rate risk faced by the lenders does not extend to periods after this adjustment.

A mortgage contract contains multiple embedded options. Most important is the pre payment option which allows the borrower to call the contract. We will consider a situation where the complete mortgage can be prepaid. However, prepayment is discouraged by the up-front fee for starting a new mortgage contract, necessary to refinance the existing contract. These costs are incurred by the borrower but not necessarily received by the investor.

A mortgage valuation model consists of four major components: a model of the term structure of interest rates, a model of interest rate dynamics, the relationship between mortgage rates and the term structure, and a prepayment behavior model.

\subsubsection{Term structure of interest rates}

In essence there are two approaches to model the term structure of interest rates, both of which are touched upon in Section 3.2. The general equabrim approach siarts by describing the underlying economy, the stochastic process of one or more exogenous state variables and the preferences of a typical investor. The term structure of interest rates is endogenously derived based on these elements, hence the term andogenous term structure models. The most famous model in this category is the Cox, Ingersoll and Ross model (1985a,b).

No-arbitrage models in the second approach take the initial yield curve as given and derive feasible subsequent term structure movements consistent with no-arbitrage opportunities. Examples include the Ho and Lee model (1986), the Black, Derman and Toy model (1990), and the model developed by Healh, Jarrow and Morton (1990, 1992). These models are often referred to as exogenous term stmeture models, because they take the term structure of interest rates as an input rather than producing it as an output.

The strength of the exogenous approach is that it utilizes the full information of the term structure observed on the valuation date. However, today's term structure is fitted at the expense of describing the general interest rate dynamics. Moreover, if the tem 
structure changes the next day, the interest rate diffusion process has to be readapted accordingly. In other words, the interest rate dynamics may change from day to day. In contrast, the parameters of endogenous models are assumed to be time-homogeneous. These endogenous models describe general interest rate dynamics whille no reference is made to the observed term structure at a specific valuation date. Ideally, the endogenous models should also fit today's term structure but this is not explicitly imposed.

The type of application determines which models are appropriate. Exogenous models, for example, are preferable in detemining today's value of a mortgage contract, while the time-invariant parameters of endogenous models make these models more suitable for analyzing the risk characteristics of a contract. This chapter focuses on the consequences of loosening prepayment restrictions. A bank which considers issuing freely callable mortgages in the near future will be interested in the risk characteristics of these loans. Since these mortgages will not be issued today, there is no reason to force the interest rate dynamics to be consistent with today's term structure. Instead, a more accurate description of the general interest rate dynamics is desirable. In this chapter we therefore utilize endogenous interest rate models to describe the term structure of interest rates.

\subsubsection{Short-term interest rates}

In this chapter we assume that the interest rate dynamics can be modelled by a one factor interest rate process. Most of the mortgage valuation literature uses the Cox, Ingersoll and Ross (CIR, 1985a, b) square root process for this. However, this model does not correspond well with the actual dynamics of the short-term interest rate. The volatility of interest rates is much more sensitive to the level of interest rates than in the CIR model. In addition, the drift is nonlinear, being almost zero at low interest rate levels and negative at high levels." Therefore, in this chapter we do not limit ourselwes to the Cox, Ingersoll and Ross model, but also use a nonlinear and a nonparametric model to describe the short-term interest rabe dymamics.

These dynamics aflect the value of the mortgage in three ways. First, they determine the term structure of interest rates and thus the discount factors of the periodic cash flows. Second, in an endogenous mortgage rate model the short-term interest rate process implies a dynamic process for the mortgage rate. Third, they affect the prepayment behavior.

In an endogenous one factor model the distribution of next month's interest rate depends only on today's interest rate. If the paraneters of the empirical interest rate model are time invariant, these interest rate processes are all Markovian. For computational reasons we approximate the different interest processes by a discrete time Markov chain with a finite number of states $i,(i=1, \ldots N) .^{3}$ A Markov chain can easily describe nonlinear

${ }^{3}$ See for example Chan, Karolyi, Longstaft and Sanders (1992), Ait-Sahalia (1996a, b), Pfann, Schotman and Tschernig (1996), Tauchen (1996), Koedijk, Nissen, Schotman and Wolft (1997), and Conley, Hansen, Luttmer and Scheinkman (1997).

${ }^{3}$ The theory of Markov chains can be found in many textbooks on stochastic processes, e.g. Ross (1993). 
time series behavior of the short-term interest rate. Details of the empirical spot rate processes are discussed in Section 5.6.

\subsubsection{Mortgage rates}

The model which relates the short-term interest rate dynamics to the nortgage rate determines the monthly payments and affects the opportunity casts for borrowers who consider refinancing. It therefore influences the prepayment behavior in the forward-looking valuatiton model.

In a single factor model, the short-term interest rate process involves the only uncertainty in the econony. The state of the economy depends therefore only on the level of the short-term interest rate. Each state corresponds with only one mortgage rate, such that the one-factor assumption implies that there is a one-on-one relationship between the short term interest rate $r$ and mortgage rate $y$.

We consider three specifications to relate the montgage rate to the short-term interest rate. Following Kau, Keenan, Muller and Epperson (1993) we derive two functionall relations $y=f(r)$ endogenously for both prepayment rules applied in this chapter. Hereby the mortgage rate is determined such that the value of the mortgage contract at origination is equal to the face value of the loan. As discussed in Section 5.2.4, in this setting a morigage is an interest rate derivative security with zero met present valne. To derive the endogenous relation it is assumed that mortgages are traded in a competitive market.

Alongside the endogenous relations, we also consider two exogenons specifications between the mortgage rate and the short-term interest rate. The firstis the empirical relation between the Dutch mortgage rate and the Dutch short-term interest rate. An advantage of this approach is that it is directly related to Dutch historical interest rate data. Despite this empirical justification, this relation is subject to the Lucas critique, us described in the introductory chapter, i.e. this relation describes the actual historical situation where prepayment was wery much restricted. Commonly, only 10 to 20 percent of the initial loan could be called within a calendar year without penally. Due to the increased competition, Dutch financial institutions are currently considering the consequences of loosening these anmual prepayment restrictions. In this chapter all prepayment restrictions are omitted such that the mortgage can be fully called. The Dutch historical premium is probably too small to cover this additional prepayment risk. Therefore, the second specification considers the empirical relation between the US mortgage rate and the US short-term interest rate. In the US, annual prepayment limitations are virtually unknown. Consectuently, the US relation shows a higher option premium, but depends on the US term structure, which can differ from the Dutch term structure. Section 5.7 provides details of the alternative empirical relations between the mortgage rate $y$ and the short-tem interest rate $r$. 


\subsubsection{Prepayment behavior}

The valuation models in this chapter closely follow the setup of Dunn and McConnell (1981a,b) and McConmell and Singh (1994). Dunn and McConnell (1981a,b) assume that the mortgage market is frictionless and that borrowers prepay their mortgage as soon as the walue of the mortgage; if left uncalled, exceeds the unpaid balance of the loan plus the transaction costs associated with refinancing it. McConnell and Singh (1994) axtend this waluation model and incorporate transaction costs into their rational valuation framework. At each pont in time they determine the critical interest rate below which it is rational to prepay the mortgage. The difficulty is in determining this boundary. McConmell and Singh's derivation of the boundary depends on the crucial assumptions that (a) the mortgagor can borrow money for the same costs as the mortgagee, and (b) the competition on the mortgage market is strong enough to ensure that lenders cannot charge a mortgage rate that exceeds their own cost of capital. If the latter assumption does not bold, it is possible that their prepayment rule prescribes prepayment even though the mortgage rate at which the borrower can refinance is higher than the contract rate of the current loan.

To see this, let us go back to the examples in Chapter 4 where the back ward valuation. technique was explained. As before, a borrower is assumed to prepay the loan when the present value of the loan exceeds the outstanding debt plus any transaction costs. An important property of this prepayment rule is that it is entirely determined by the spot wate process, without any reference to refinance alternatives open to the borrower, i.e. there is no role for the mortgage rate at which the homeowner can obtain a new mortgage loan.

Suppose that shorty after a mortgage contract is issued, the short-term interest rate decreases but that the intermediary has sufficient maket power to keep the mortgage rate at the old level. The decrease in the short-term interest rate causes the present value of the mortghge to rise. If this rise is large enough to trigger prepayment, the borrower will replace the existing contract by taking out a new loan and paying the corresponding transaction costs. Despite these costs, the borrower is lacing the same contract rate as before! This irrational prepayment behavior is excluded if the mortgage rate is endogenously determined as a function of the short-term interest rate, such that the value of the new mortgage at its origination is equal to the principal of the loan. Fxogenous relations between the mortgage rate and the short-term interest rate do not have to be consistent with this and can therefore not be incorporated in this framework.

In this chapter we relate the optimal prepayment ale to a suboptimal one which does not require the assumption that the mortgage has a zero net present value at origination. The suboptimal prepayment rute applied here assumes that the mortgage is replaced by a new contract if this reduces the total future costs for the borrower. Hence, the call policy depends explicitly on the mortgage rate at which the borrower can refinance in the market. "This is in sharp contrast to the optimal prepayment rule which depends only on the spot rate process. The suboptimal prepaynent rule allows the financial markets to be 
segmented such that the borrower does not have direct access to the capital market and can only obtain the funds to finance the purchase of a house through an intermediary. This intermediary may have sufficient market power to charge an interest rate which exceds its own cost of capital.

For this suboptimal prepayment rule we calculate a critical mortgage rate $y_{c}(t)$, for each month $t$, below which refinancing would reduce the future costs for the borrower. ${ }^{4}$ In computing the alternative costs we assume that the new mortgage loan is for the remaining time to maturity. To start a new mortgage, the borrower has to pay up-front costs equal to $c$ percent of the unpaid balance $U_{t}$ at time $t$. These costs discourage prepayment, and imply that the mortgage rate has to fall sufficiently below the initial contract rate. The refinancing costs can be interpreted as a premium on the unpaid balance $U_{t}$. Technically, the mortgage is callable at $(1+c)$ times its par value. Hence, a mortgagor who decides to replace the existing contract has to borrow $(1+c) U_{t}$ at the new mortgage rate The future monthly costs $M_{t}^{*}$ of the new loan are:

$$
\begin{aligned}
M_{i}^{*} & =(1+c) U_{t} \frac{\left(1-v_{t}\right)}{v_{t}\left(1-v_{t}^{T-t_{i}}\right)}, \\
& =(1+c) M_{t},
\end{aligned}
$$

where $v_{t}=\frac{1}{1+y(t)}$, with $y(t)$ representing the prevailing mortgage rate at time $t$. Since $T$ is the maturity of the original contract, $(T-t)$ reflects the remaining time to maturity in months. $M_{i}$ are the monthly payments resulting from an annuity with maturity $(T-t)$ issued at time $t$ without refinancing costs, $M_{*}^{*}$ does include these cosis.

The borrower can also decide to retain the original mortgage in which case the monthly costs remain:

$$
\begin{aligned}
M_{0} & =v_{0} \frac{\left(1-v_{0}\right)}{v_{0}\left(1-v_{0}^{T}\right)} \\
& =U_{t} \frac{\left(1-v_{0}\right)}{v_{0}\left(1-v_{0}^{J-i}\right)} .
\end{aligned}
$$

Hence, if the fixed-rate period is equal to the lifetme of the contract the prepayment rule reads:

$$
(1+c) M_{t}<M_{0}
$$

However, when the fixed-rate period is shorter than the time to maturity, this prepayment rule is a recessary, but no longer sufficient condition to ensure that refinancing results in lower future costs. For example, suppose that one month before the fixed rate period ends, Inequality (5.3) holds. Would you refinarce the contract and pay the transaction

\footnotetext{
4n order to avoid confusion regarding the states of the ecomomy, the time demarcations for mortgage

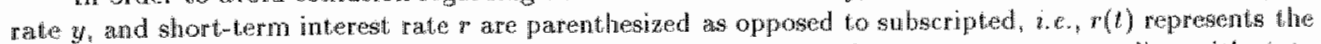
short-term interest rate at time $t$, while $r_{i}$ indicates the short-term interest rate corresponding with state i. For all onder wathes the time demarcation remains subscripted.
} 
costs? Or would you wait one more month and get the contract rate adjusted to the then prevalling mortgage wate for free? You will probably only replace your mortgage if the resulting savings on the periodical payment exceed the transaction costs. Or more generally, homeowners will only replace their mortgage if the resulting savings on their periodical payments during the fixed-rate period justify the transaction costs. To determine this, we compare the outstanding debt on the adjustment date of an uncalled mortgage with the outstanding debt of the new mortgage loan on that reset date. With mortgage rate $y(t)$ prevalling at time $t$ and the corresponding new periodic cash flow $M_{i}^{*}$, the unpaid balance on the adjustment date $\tau$ of a new contract issued at time $t$ is:

$$
\tilde{U}_{\mathrm{T}}=\frac{U_{t}(1+c)}{1-\left(\frac{1}{1+y\left(t_{1}\right.}\right)^{T-t}} \times\left[1-\frac{(\mathbb{1}+y(t))^{T-t}}{(1+y(t))^{T-i}}\right]
$$

with $t<\tau<T$. This outstanding debt is compared with the debt on that same date if the mortgage is not called:

$$
U_{\tau}=\frac{U_{t}}{1-\left(\frac{1}{1+y(0)}\right)^{T-t}} \times\left[1-\frac{(1+y(0))^{T-t}}{(1+y(0))^{T-t}}\right] .
$$

Let us look at a mortigagor who replaces the contract at time $t$ with a new loan which demands lower monthly payments. Each month, until the reset, date, the individual saves $\left(M_{0}-M_{t}^{*}\right)$. If the homeowner deposits these savings each month on a bank account on which he earns interest, he will have an amount $S_{+}$at his disposal at time $\tau$.

Due to the refinancing costs the debt initially increases. On the adjustment date $T_{\text {. }}$ the outstanding debt of the new loan can therefore be larger than what the debt would be if the contract is left uncalled. A borrower is indifferent between refinancing the contract and holding on to it if $S_{r}$, the present value of the savings at time $\tau$, is large enough to ofset the potential bigher debt on the reset date. ${ }^{5}$ Mathematically, the prepayment option is in-the money if:

$$
\tilde{U}_{T}-S_{T}<U_{r}
$$

where $S_{r}$ is the value of all monthly savings expressed in dollars of time $\tau$. To calculate $S_{r}$ we must use the short-term interest rates between time t and $\tau$. However, these rates are unknown at time twen the prepayment decision is made. Given the state of the economy at time $t$, we can use the interest rate grid and Markov transition probabilities to calculate the expected short-term interest rate for each month. Hence, the expected value of $S_{\mathrm{r}}$ can be determined.

The critical mortgage rate $y_{c}(t)$ at which $\hat{U}_{T}-S_{r}=U_{r}$ defines an upper boundary for the mortgage rate above which prepayment will not occur. This boundary depends on both the underlying process of the interest rate dynamics and the model which relates the

\footnotetext{
5 A typical butch mortgage can be prepaid without a penalty on the reset date such that $S_{x}$ can be used to reduce the unpaid balance att time $\tau$.
} 
short-term interest rates to the mortgage rate. If $\tilde{U}_{T}-S_{r}<U_{r}$ refinancing reduces the future costs from time $T$ onwards due to the fact that the new periodic payments are based on a lower principal amount at the reset date.

The nature of the prepayment rule is such that it may prescribe prepayment during stages when waiting may have been more profitable. However, the value of the prepayment option diminishes with the lapse of time, ceteris parbus. At maturity this option watue is, with certainty, equal to zero. In the Netherlands where the conbract rate is freely resel after a fixed-rate period, the time value of the prepayment option vaporizes even faster. A borrower who decides to wait to prepay the mortgage is weighing this decrease in value against the possible gain that can be achieved by postponing to exercise the prepayment option. However, this decision to wait is not without costs. Not only will the option value decrease with the lapse of time, the mortgagor is also saddled with higher monttly costs during the time he is waiting for a possible decrease in the mortgage rate. For these reasons we do not expect large differences between the optimal and suboptimal prepayment rule.

\subsection{Valuation procedure}

In Chapter 4 an interest rate tree was constructed to model the dynamics of a one-factor model. There, a binomial tree was used for illustrative purposes. In this chapter we apply a multinomial recombining tree which immediately branches out to its fuil size. The main advantage of such a multinomial interest rate tree is that it can capture the characteristics of more general interest rate processes without the number of nodes growing exponentially with the number of time steps. ${ }^{6}$ The transition probabilities of the recombining interest rate tree are stored in the Markov transition matrix $A$. Fach element $a_{i j}$ of this transition matrix contains the probability that the interest rate process moves from state $i$ at time $t$ to state $j$ at time $t+1$, conditional on the interest rate process being in state $i$ at hime $t$.

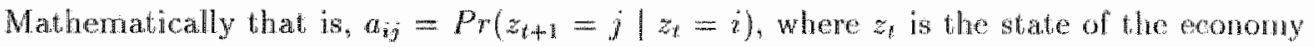
at timet.

From the empirical time series analysis of the short-term interest rate we obtain the actual matrix $\mathbf{A}$ of transition probabilities. However, to vallue a mortgage contract we have to use risk-nentral probabilities associated with the interest rate process, and not the actual transition probabilities. This requires an assumption about the market price of risk, whicli can be derived implicitly from the term structure of interest rates. ${ }^{7}$ We assume that the spot rate follows a stitionary process which implies that the infinite horizon yield converges to a constant $R_{\infty}$ independent of both time and the current spot rate r(1). Setting $R_{\infty}$ at a. particular value, say $R_{\infty}=8 \%$, we can solve for the market price of risk and thereby obtain the risk-neutral Markov transition matrix $\tilde{\mathbf{A}}$.

To do this, the elements in each row of $\mathbf{A}$ are shifted to the left (lower states, higher

\footnotetext{
See Hull and White (1990, 1999) and Nelson and Ramaswamy (1990) for an elaborated dincuision on this topic.

T See Duffie, Chapter 3, 1900 .
} 
interest rates) by $\delta_{i}$ positions. The open positions at the right of each row are filled with zeros and the entire row is rescaled such that the probabilities on row sum to one." The resulting transition distributions differ from the original vectors of transition probabilityes only by their drift. All other aspects of the distribution are preserved as much as possible. The vumbers $\delta_{i}$ are obtajned by wal and error; such that the implied infinite horizon yield $R_{\infty}$ equals $8 \%$ irrespective of the intial spot rate. For this we define an $(N \times \pi)$ vector $\Lambda_{\text {. }}$ with an element $\Lambda_{i \tau}$ being the price of a zero-coupon bond with maturity $\tau$ when the spot vate is equal to $r_{\mathrm{i}}$. These bond prices can be computed as:

$$
\mathbf{\Lambda}_{+}=\mathbf{B}^{\dot{\tau}} \boldsymbol{\imath}
$$

where $\boldsymbol{c}$ is a vector of ones and the elements in the matrix $\mathbf{B}$ are discounted risk-neutral probabilities: $b_{i j}=\frac{\vec{a}_{i j}}{\left(1+r_{i j}\right)}$. The vector of yields corresponding with the bond prices bas elements $R_{i}=\Lambda_{i r^{*}}^{-\frac{1}{4}}-1$. We determine the shift parameters $\delta_{i}$ such that

$$
\lim _{\pi \rightarrow \infty}\left(\Lambda_{i r}^{-\frac{1}{x}}-1\right)=R_{\infty}=8 \%
$$

for all $i=1,2, \ldots, N$. Equations (5.8) are solved simultaneously for all

For the special case that the interest rate dynamics are modelled as the CIR square root process the transformation from the actual to the risk-nentral probability measure can be performed analytically. See Section 5.6 .1 below.

\subsubsection{Optimal prepayments}

Optimal prepayment rules lead to dynamic programming problems which must be solved backwards. We start at the end of a valuation tree and work back through all nodes until the value of the contract at the moment of origination is found. In each node of the valuation tree, the mortgagor checks whether replacing the mortgage is preferable to holding the contract. In order to detemine this, the present value of the future cash fows of the existing contract is compared with the principal value of the new loan the borrower lias to take out, to prepay the existing one. Starting a new contract implies incurring new up-front costs, such that the prepayment decision is not just based on the unpaid balance of the old contract at that time, $U_{t}$, but also on the refinance costs, $c$. These costs are commonly proportional to the unpaid balance. Consequently, the mortgage will be prepaid if $V_{k}(1+c)$ is smaller than the present value of the existing contract. If this is the case in a particular node of the valuation tree, the value fed into the corresponding node becomes $V_{1}(1+c)$ mather than the present value of future payments. The mortgagee, however, receives only $U_{t}$ and not $U_{t}(1+c)$. The value of the matching node in the mortgagee's valuation tree is therefore equal to $U_{t}$.

We introduce the following notations to value the contract studied in this chapter:

\footnotetext{
The amount of shift is always small, so that more than $2.5 \%$ of the original probability mass is never pushed out of the matrix at the lefthand side. Since the number of grid points $M$ is large $(N=226)$, the transition densities are only minimally disturbed.
} 


$$
\begin{aligned}
N= & \text { number of states, } \\
v_{i}^{*}= & a(N \times \mathbb{1}) \text { vector containing the mortgage value for the mortgagor at } \\
& \text { time } t \text { before the prepayment decision is made, } \\
v_{t}= & a(N \times I) \text { vector containing the mortgage value for the mortgagor at } \\
& \text { time } t \text { after the prepayment decision is made, } \\
w_{*}^{*}= & a(N \times 1) \text { vector containing the mortgage value for the mortgagee at } \\
& \text { time } t \text { before the prepayment decision is made, } \\
w_{t}= & \text { a }(N \times 1) \text { vector containing the mortgage value for the mortgagee at } \\
& \text { time } t \text { after the prepayment decision is made. }
\end{aligned}
$$

The mortgage contract studied in this chapter has a maturity of thirty years, and an interest rate fxed for a 60 month period. The backward pricing method therefore starts in the interest rate tree at time $t=60^{9}$ The value at time $t=60$ equals $U_{60}$ with certainty. $\mathrm{At}$ the adjustment date, the mortgagor can freely reset the contract, such that this mortigage vallue holds for both the mortgagor and the mortgagee. Hence, the elements in both vou and $w_{60}$ are equal to $V_{60}$.

Given $v_{60}$ and $w_{60}$ we can calculate the present value of future payments one period earlier by using the matrix $\mathbf{B}$, which contains the rish-adjusted discounted transtion probabilities as derived before. More generally, to derive $v_{i}$ and $w_{t}$ given $v_{i+1}$ and $w_{t+1}$, we must first determine the mortgage value for the mortgagor at time $t$ befort the prepayment decision is made:

$$
\mathrm{v}_{i}^{*}=\mathbf{B}\left(\mathrm{v}_{i+1}+c M_{0}\right)
$$

where $\iota$ is a vector of ones and $M_{0}$ is the monthly required payment. Each clement $v_{j t}^{*}$ is compared with $U_{t}(1+c)$ and the mortgage is prepaid if $U_{t}(1+c)<v_{j t}^{*}$. This prepayment. behavior at time $t$ is captured by the diagonal matrix $\varphi_{t}$ where the $j^{\text {th }}$ element on the diagonal position is equal to:

$$
\varphi_{j t}= \begin{cases}1 & \text { if } \quad v_{t}(1+c)<v_{j t}^{*}, \\ 0 & \text { if } \quad v_{t}(1+c) \geq v_{j t}^{*}\end{cases}
$$

The contract walue at thmet for the mortigagor can now be calculated by:

$$
\mathrm{v}_{t}=\mathrm{v}_{t}^{*}+\varphi_{i}\left(\iota U_{t}(1+c)-\mathrm{v}_{t}^{*}\right)
$$

\footnotetext{
The time steps in this section, as well as in the emander of this chapter, are equal to one morth. The dezrihed method, however, wso allows other times steps.
} 
The same argument applies for the mortgage with one exception: whenever the mortgagor prepays the contract, the value $U_{i}$, is used instead of $U_{t}(1+c)$. The contract value for the mortgagee can consequently be calculated by"

$$
\begin{gathered}
w_{i t}^{*}=\mathbf{B}\left(w_{t-1}+\iota M_{0}\right), \\
w_{t}=w_{t}^{*}+\varphi_{t}\left(\iota U_{t}-w_{t}^{*}\right) .
\end{gathered}
$$

This backward moving process will eventually bring us to the value at origin. The present value of the contract for the mortgagor and mortgagee is found by selecting the $i^{\text {th }}$ dement of $v_{0}$ and $w_{0}$, respectively, where $i$ corresponds with the state of the economy at origination.

An important property of the prepayment boundary in Equation (5.10) is that it is entirely determined by the spot rate process, without any reference to refinance alternatives open to the borrower at time 4 . And because the term structure only depends on the spot rate in this one-factor economy, there is no role for the mortgage rate $y(t)$ at which the borrower can obtain a new mortgage loan for the remaining time to the reset date. In fact; the new mortgage rate $y(t)$ must be a function of the short-term interest rate $r(t)$, such that the new mortgage has a value equal to the principal amount.

\subsubsection{Moneyness boundary}

The suboptimal prepayment lule applied in this chapter assumes that the mortgage will be prepaid as soon as this reduces the total future costs fot the borrower. This prepayment behavior is explained in detail in Section 5.2.4: There we also explained how the critical mort.gage rate $y_{0}(t)$ can be determined for each initial mortgage rate $y(0)$. If the mortgage rate is below the critical rate for particular month we assume that the mortgage will be prepaid and the value $t_{t}$ is fed into the corresponding node of the interest rate tree. Hence, we do not have to make a distinction between the contract value for the mortgagor and mortgagee. Instead, we can directly form the diagonal prepayment matrix $\varphi_{i}$ where the $j^{\text {th }}$ element on the diagonal position is equal to:

$$
\varphi_{j *}=\left\{\begin{array}{lll}
1 & \text { if } & y_{i}(t)<y_{c}(t) \\
0 & \text { if } & y_{i}(t) \geq y_{i}(t) .
\end{array}\right.
$$

Subsequently, the mortgage value can be determined by using Equations (5.12) and (5.13). 


\subsection{Interest rate risk}

The interest rate risk is measured by the effective duration $\Delta$ which is defined as the semi-elasticity of the mortgage value with respect to the spot interest rate: ${ }^{i 0}$

$$
\Delta\left(r_{j}, y_{j}\right)=-\frac{v\left(r_{j+1}, y_{j}\right)-v\left(r_{j-1}, y_{j}\right)}{\left(r_{j+1}-r_{j-1}\right) v\left(r_{j}, y_{j}\right)} \times 100 .
$$

We adjusted the notation for the mortgage value to emphasize that the initial short term interest rate is adjusted while the mortgage rate remains untouched. In Equation $(5.15), v\left(r_{j+1}, y_{j}\right)$ represents the mortgage value at time $t=0$ issued whith a contract date corresponding with state $j$, while the discount rate corresponds with state $j+1$.

The effective duration is a better measure of the interest rate sensitivity of a callable contract than the duration. ${ }^{11}$ However, the duration still gives us a good idea about the weighted time to maturity, which is important to know for the funding of a mortgage. Therefore we also report the duration measure in this chapter.

Duration analysis was first described by Macaulay (1938) using the present value of the cash flows as weights, such that:

$$
D=\frac{\sum_{t=1}^{T} \frac{t C_{t}}{(1+r)^{i}}}{\sum_{t=1}^{T} \frac{C_{t}}{(1+\cdots)^{i}}}
$$

where $D$ is the duration, $T$ is the time to maturity, $C_{t}$ is the cash flow at time $t$ and $(1+r)^{t}$ is the relevant discount factor. The denominator is simply the price of the mortgage, while the numerator is the present value of the cash flows weighted according to the time to cash receipt. This numerator can be determined simultaneously with the value of the contract. In Figure 5.1, a two-period example is worked out to illustrate this. There we assume that the mortgage will be prepaid at time $t=1$ if state $i=4$ occurs. The cash flow at time $t=2$ is equal to $M_{0}$, such that the weighted values in the corresponding nodes become $2 M_{0}$. If we move one period back and consider node $i=2$ we know that the mortgage is not prepaid such that the cash fow is equal to $M_{0}$. And of course we have to take the weighted present value of future cash flows into consideration. In node $i=4$ at time $t=1$ the mortgage is called and the lender receives $\left(M_{0}+U_{1}\right)$. Future cash flows are not relevant anymore and the corresponding value in this node becomes $1\left(M_{0}+U_{1}\right)$. To derive the value of the numerator of Equation (5.16) at origination, we have to make one additional step. backwards from both nodes at time $t=1$ to node $i=3$ at time $t=0$. Since no payment is made at $t=0$ we only have to discount the expected walues of time $t=1$.

In Appendix 5.A we present an alternative algorithm to derive the duration of a callable mortgage contract. That algorithm malkes explicit use of the probability that the mortgage has or has not been called prior to the time period under consideration, such that also the "life expectations "of a mortgage contract can be determined.

\footnotetext{
10 See Fabozzi and Modigliani, Chapter 13 (1992).

11 The duration is inappropriate because the expected cast flows of a mortgage change an interesta rates fuctuate. See DeRosa, Goodman and Zazarino (1993) and Choi (1996) for anore detaited discusion on this topica.
} 


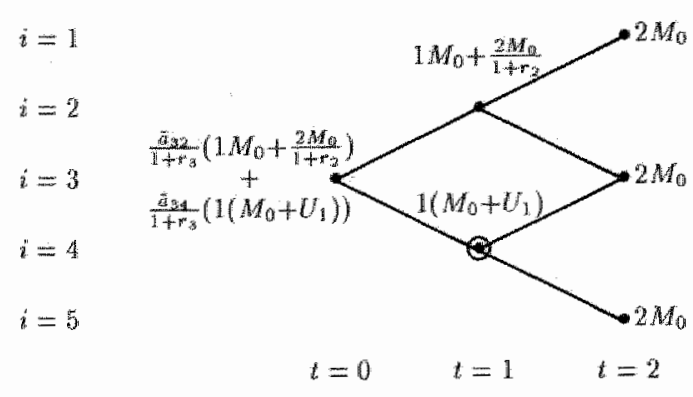

Figure, 5.1.: DURATION CALCULATION

\subsection{Description of the data}

The Dutch interest rates we use in this paper are end-of-month observations obtained from Datastream. The data are used to model the interest rate dynamics and the relation between short-term interest rates and mortgages rates. Data for the Dutch one-month Holland Interbank rate are available beginning January 1981. The five-year yield on govermment bonds and the Dutch mortgage rate are available from Jantary 1975 and January 1974, respectively. The mortgage yield is the average yield on annuity-mortgages whose contract rates are fixed for a 5 -year period. Figure 5.2 plots the different interest rates for the overlapping period; summary statistics are reported in Table 5.1.

\section{TABLE 5.1: SUMMARY STATISTLCS OF DUTCH INTEREST RATES}

\begin{tabular}{lcrrr}
\hline Series & Mean & Des. & Max. & Min. \\
\hline Interbank (a) & 7.10 & 2.07 & 13.81 & 3.81 \\
5-year bond (b) & 7.71 & 1.68 & 12.47 & 4.90 \\
Mortgage Rate (c) & 8.86 & 1.61 & 13.45 & 6.51 \\
Spread (b-a) & 0.61 & 1.28 & 4.00 & -1.89 \\
Spread (c-a) & 1.76 & 1.19 & 4.71 & -0.83 \\
Spread (c-b) & 1.15 & 0.33 & 1.90 & 0.32 \\
\hline \multicolumn{4}{c}{ Sample period: Jantary 1981 - December } & 1994
\end{tabular}

The Dutch yield curve is relatively flat with an average spread of only 61 basis points. The mortgage rate commands a 115 basis point spread over the five year government bond yield. The five year government yield and the mortgage rate follow each other closely, except at times when the government yield rises shamply.

To estimate the empirical relation between the American mortgage rate and the short- 

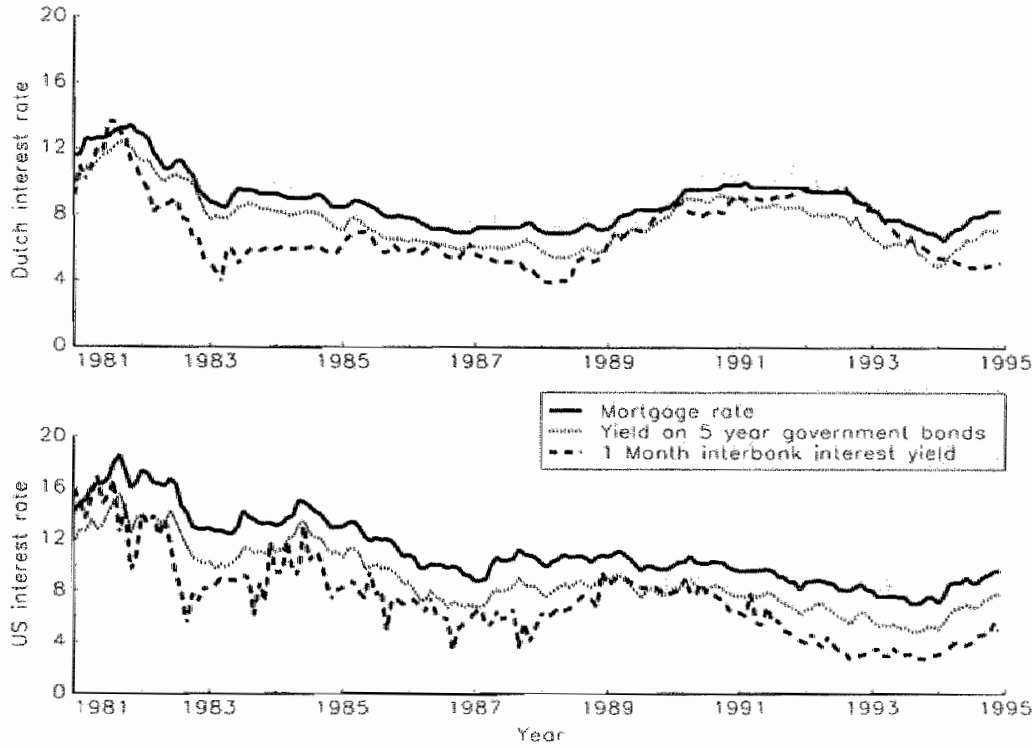

Frgure 5.2: Time series of Dutch and American interest rates The Dutch interest rates and US mortgage rates are end-of month observations obtained from DataStrean. For the other US data we have used bond prices available on CRSP Lapes. 
TABLE 5.2: SUMMAY STATSTICS OF AMERICAN INTEREST RATES

\begin{tabular}{lcccc}
\hline Series & Nean & Dew. & Max. & Min. \\
\hline 1-month bond (a) & 7.28 & 3.20 & 16.97 & 2.59 \\
5 -year bond (b) & 8.88 & 2.50 & 15.50 & 4.80 \\
Mortgage Rate (c) & 11.11 & 2.67 & 18.55 & 7.02 \\
Spread (bua) & 1.59 & 1.53 & 6.01 & -4.20 \\
Spread (c-a) & 3.83 & 1.56 & 8.68 & -1.66 \\
Spread (c-b) & 2.24 & 0.38 & 3.66 & 1.52 \\
\hline Sample period: January 1981 -December & 1994
\end{tabular}

term interest rate we have ased US bond data, avaiable from CRSP tapes for the period January 1970 until December 1994. The data, which awe summarized in Table 5.2, were collected on a monthy busis. The US mortgage rate is obtained from Datastream. This mortgage rate is an average of the secondary market yields on FHA ( - Federal Housing Associations) mortigages. It is an average of all yields to maturity for diferent mortgages.

Comparing both tables we see that the American interest rates are more volatile than their Dutch counterparts. Additionally, the historical spread between the mortgage rate and the 5 year yield is almost $95 \%$ larger in the US than in the Netherlands. And also the spread between the mortgage rate and the short-term interest rate is much larger in the US than in the Netherlands. This latter is illustrated in Figure 5.3.

\subsection{Spot rate dynamics}

Here we consider three specifications for the dynamics of the spot rate: the now familiar CIR square root process, a flexible nonlinear time series model and a non parametric model. All three processes will be used in the mortgage waluation to study the sensitivity of the results for the underlyng interest rate model.

\subsubsection{The CIR model}

The starting point for modelling interest rate derivative securities is usually a diffusion procese of the form:

$$
d r=\mu(r, t) d t+\sigma(r, t) d z_{3}
$$

where the functions $\mu(\cdot)$ and $\sigma(\cdot)$ are the instantaneous proportional drift and the volatility of the interest rate, respectively, and $d z$ is a Wiener process. The CIR model is the most, widely-applied term structure model. It is a mean-reverting model where the speed-ofadjustment to the unconditional mean, $\theta$, in an interval dt is measured by $k$. The variance 

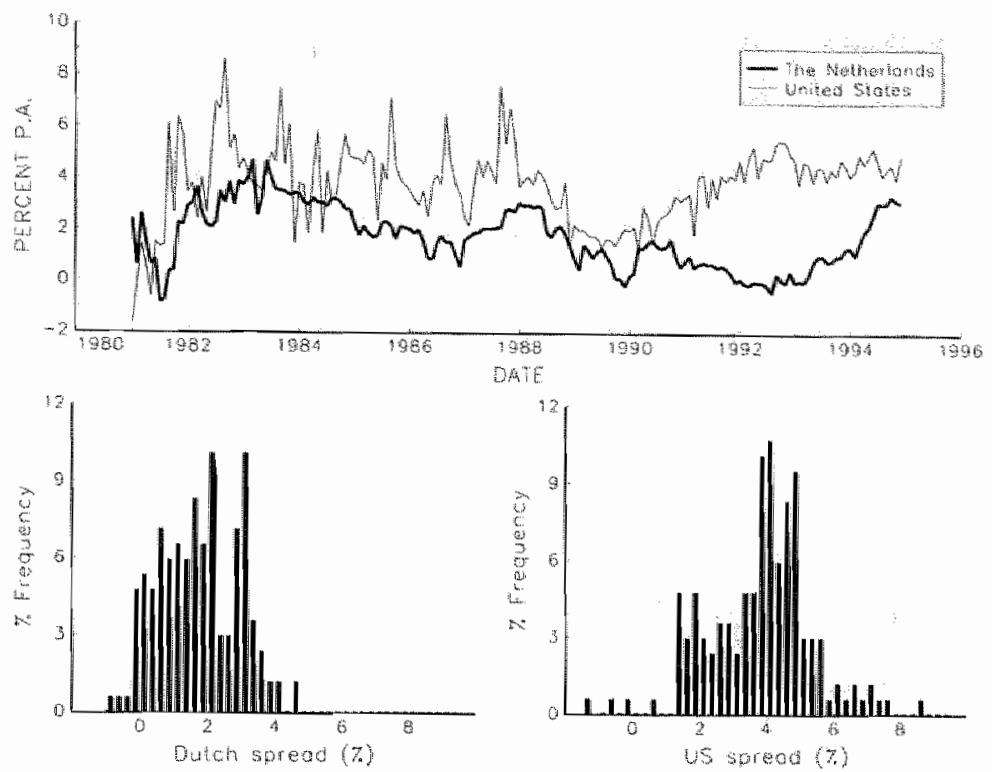

FIGURE 5.3: MORTAAGE SPREAD

The upper diagram of this figure shows the historical spread between the mortgage rate and the short-term interest rate in the Netherlands and the United States, respectively. The lower diagrams show the frequency distributions of these spreads.

in this model is proportional to the level of the instantaneous risk-free rate:

$$
d r=r(\theta-r(t)) d t+\sigma \sqrt{r(t)} d z .
$$

The empirical problem is to estimate these parameters for the CHR interest model. The asual procedure to do this is by time series analysis. Chan, Karolyi, Longstaff and Sanders (1992) give an empirical overview of the results of time series methods. Fere the parameters are estimated by Maximum Likelitiood using the time series data for the onemonth Interbank rate between January 1981 and December $1994 .{ }^{12}$ Table 5.3 contains the estimated parameters for the CIR model.

The conversion of the continuous time CIR model into a discrete, finte Markov chain has been introduced by Hull and White (1990) and is summarized in Appendix 5. B.

The risk-neutral parameters depend on the assumption on the market price of risk $\lambda$, which can be identified through the infinite horizon yield. This constant is independent of the current spot rate:

12 The CIR process is based on the instantaneous riak-free rate which cannot be observed. For the closest approximation the onemonth interest rate is used. A discrete time representation of the spot rate process is utilized to estimate the CIR parameters for the the time series process of the one-month interest rate; see $\mathbb{D e}$ Munnik and Schotman (1994). 
TABLE 5.3: CIR PAPAMETERS

\begin{tabular}{cccc}
\hline & $\kappa$ & $\theta$ & $\sigma$ \\
\hline Fstimate & 0.38 & 6.33 & 0.49 \\
t-statistic & 1.77 & 4.34 & 3.62 \\
\hline Sample: Jan. $1981-$ Dec. & 1994
\end{tabular}

$$
R_{\infty}=\frac{2 \kappa \theta}{\kappa+\left(\kappa^{2}+2 \sigma^{2}\right)^{\frac{1}{2}}}
$$

where $\tilde{\kappa}=\kappa+\lambda$ (see Cox, Irgersoll and Ross, 1985b). We compute $\lambda$ and thus $\tilde{z}$ by setting $R_{\infty}=8 \%$

\subsubsection{A nonlinear model}

A more general specification of the interest rate process is the parametric one-factor model based on Ait-Sahalia $(1996 a, b)$. The Euler discretization of the continuous time model developed by Ait Sahalia reads:

$$
r(t+1)=\alpha_{0}+\alpha_{1} r(t)+\alpha_{2} r(t)^{2}+\alpha_{3} \frac{1}{r(t)}+\sqrt{s_{0}+s_{1} r(t)} \epsilon_{t+1}
$$

The model allows for heteroskedasticity of the constant elasticity of variance (CEV) type, and is mean-reverting if either $\alpha_{2}=0$ and $\alpha_{1}<0$ or $\alpha_{2} \leq 0$. In the latter case the model is strongly mean-reverting at high interest rate levels. With $\alpha_{3}>0$ the interest rate has a strong upward drift close to zero, thus excluding negative interest rates. Maximum likelihood parameter estimates for the Dutch time series are presented in Table 5.4.

TABLE: 5.4: NONLINEAR PARAMETERS

\begin{tabular}{ccccccc} 
& $\alpha_{0}$ & $\alpha_{1}$ & $\alpha_{2}$ & $\alpha_{3}$ & $s_{0}$ & $s_{1}$ \\
\hline Estimate & -8.693 & 1.120 & -0.047 & 21.42 & 0.109 & 0.00191 \\
|t|-statistic & 2.76 & 4.76 & 2.35 & 3.08 & 4.06 & 3.91 \\
\hline \multicolumn{6}{c}{ Sample period: January } & $1981-$ December 1994
\end{tabular}

The parameter estimates are not very informative about the implications of this process. Since the model has nonlinear dynamics, its properties can not be established by analytical methods. Numerical methods for analyzing this model include a long simulation and discretization of the probability space.

The latter method involves dividing the range of possible values of the interest rate into a (large) number of intervals. Stanting from each interval we can compute the probability of the interest rate moving to any other interwal. The result is a discrete time Markov chain, which lends itself to the analysis of the dynamics of the interest rate as well as to the valuation of a mortgage. Pfan, Schotman and Tschernig (1996) apply this method to 
a. nonlinear model of the US term structure, while Benninga and Protopapadakis (1994) use it for pricing interest rate futures. Taking the number of states in the CIR model into account, we fixed the number of states for the nonlinear model at $N=226$.

The nombinear interest rate model implies a mean interest rate of $6.3 \%$, and a volatility of $1.9 \%$. (Note that this is before the market price of risk is included.) The drift of the model is plotted in Figure 5.4 .

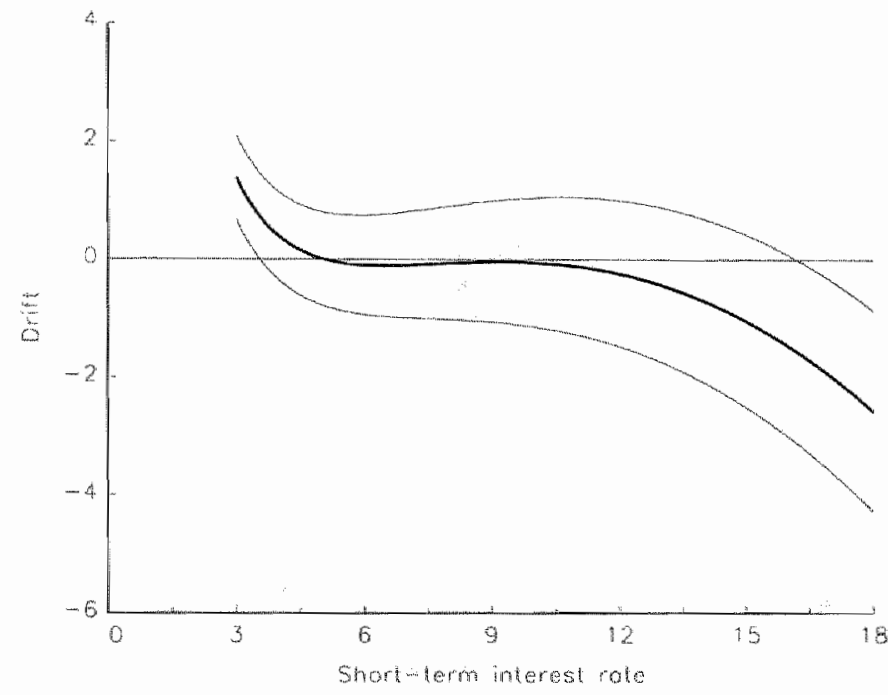

\section{Figure 5.4: The NONLINeAR MEAN-REverting DAIFT}

The bold line in this figure shows the drift resulting from the nonlinear ine terest rate model estimated on Dutch data. The thin lines illustrate the $95 \%$ confidence interwal.

Figure 5.4 shows that there is almost no mexn-reversion when the spot rate is in the range of 5 to $10 \%$. In this region the spot rate behaves manly like a random walk. When the spot rate is outside this region the mean-reverting drift gets strong and pulls the rate back into the 5 to $10 \%$ range. These findings are consistent with the resulls found by Ait Sahalia (1996a,b) for the American spot rate. Unlike Ait-Sahalia's American data, where the highest spot rate was about $24 \%$, our Dutch spot rate time series does not contain rates higher than $13.81 \%$. Our nonlinear model should therefore be carefully approached at high interest rates.

As discussed in Section 5.3, to include the market price of risk we adjust the drift such that the implied infinite horizon yield $R_{\infty}$ equals $8 \%$. This results in an interest rate model which has a bimodal distribution as can be seen in the bottom right quarter of Figure 5.5 .

The top balf of this figure displays the speed at which different interest rates converge 

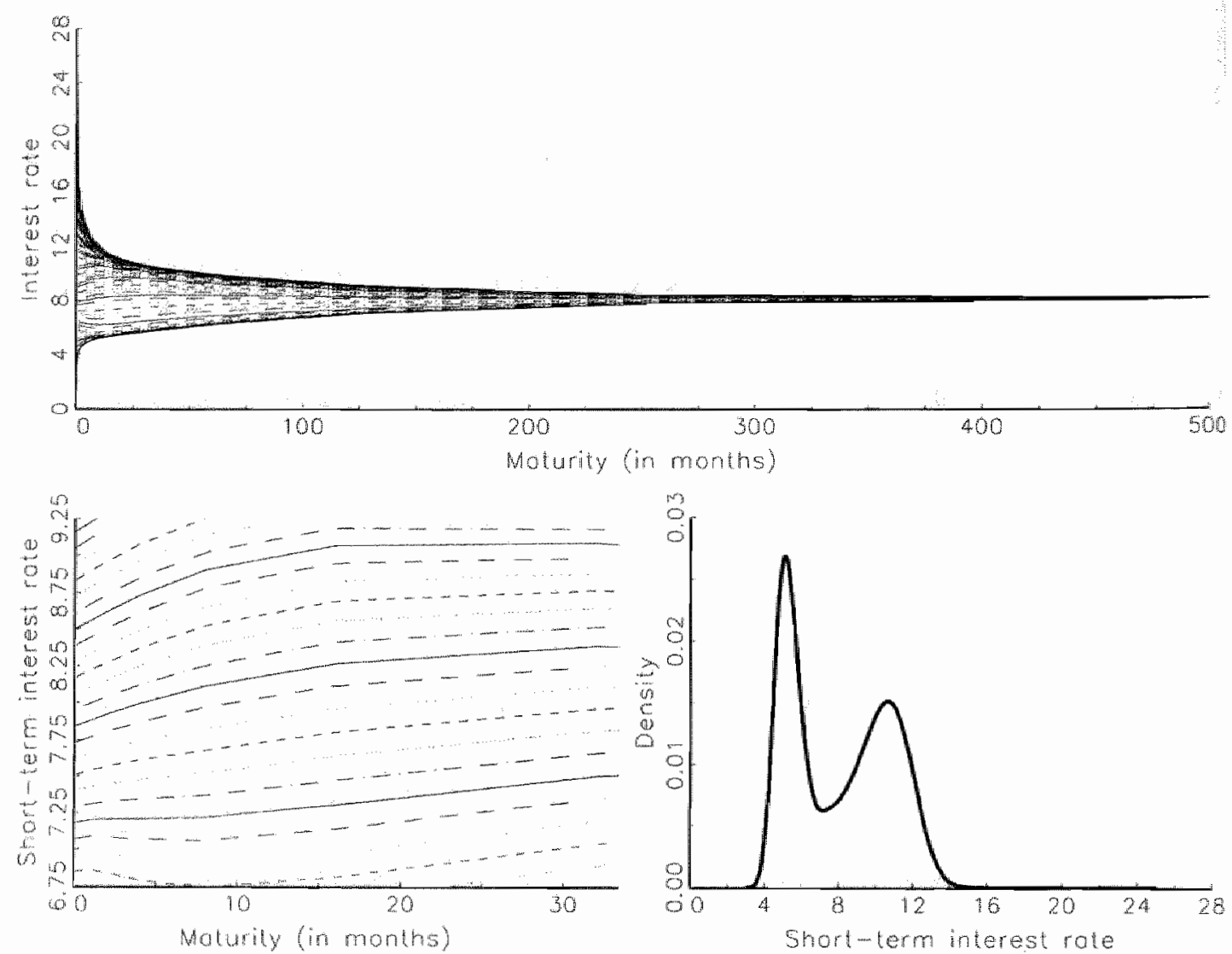

FIGURE 5.5: Characterdstios of THE NONLINEAR INTEREST RATE MOdEL

The uppes" diagram of this figure shows the term structure of interest rates for different starting tates. The boltom left quartier yields a close up look of the top figure. The bottom right plots the risk-neut ral unconditional distribution. 
to the long-tem mean. We see that extreme interest rates are firmly pulled back into the middle range after which the speed of mean-peversion decreases. In the bottom left quarter of Figure 5.5 we take a close up look of the top figure. This enlargement summerizes both other figures. A trend towards a short-term interest rate of 8 percent is observable. At the same time we see that small deviations in the starting rate make a large difference in the path the process is expected to follow afterwards. Starting at a spot rate of 7.5 percent the process is expected to follow a concave path towards the long-tern mean, while starting at 7 percent the expected path has a convex beginning. The difference between a concave and a convex interest path is of major importance for the prepayment likelihood so that even small differences in the starting spot rate can yield serious deviations in the mortgge values.

\subsubsection{A nonparametric density estimation}

For the nonparametric approach, no assumptions need to be nude regarding the functional form of the probability density function (except for some regularity conditions on smootl. ness of the density). In principle, model misspecification is excluded, however, estimation error is unavoidable.

Following the approach of Ait-Sahalia (1996a,b) a kernel method is used to obtain the conditional transition density of the spot rate. ${ }^{13}$ One can compare kernel estimation with smoothing a histogram. The density at a point is estimated as the average of densities centered around that point. Observations farther away from the estimation point still contribute to the estimated density but to a lesser degree than observations closer to this estimation point. As a result, the density will be highest near concentrations of observations, while the density will be low when observations are scarce.

The nonparametric kernel estimator of the marginal density reads:

$$
\hat{\pi}(u) \equiv \frac{1}{T} \sum_{t=1}^{T} \frac{1}{h_{T}} K\left(\frac{u-r(d)}{h_{T}}\right),
$$

where $h \mathrm{r}$ is the bandwidth, also called the whadow width or smoothing parameter. The basio idea behind kernel smoothing is to find a probability density function for $K(\cdot)$ that de scribes the diffusion process well. Here, we choose a Gaussian kernel $K(u)=\frac{1}{\sqrt{2 \pi}} \exp \left(-\frac{1}{2} u^{2}\right)$ to smooth the densities. The quality of the density estimator is highly dependent on the choice of the bandwidth. Following Härdle (1.993), the bandwidth is defined as $h_{T}=d_{r} T^{\frac{-3}{5}}$ where $T$ is the number of observations in our time series, and $d x$ equals $d$ times the stan. dard deviation of the spot rate time series. The smoothing parameter $d$ is chosen by cross-validation to minimize the integrated squared error of the estimator. The smoothing parameter regulates the size of the neighborhood around the dependent variable. When

13 Tardle (1990), Scott (1992) and Silverman (1986) provide an extensive explanation of kernel estimation. 
this neighborlood is too largo, an oversmoothed transition matrix is constucted, while too small at neighborhood will result in undersmoothing.

Bayes" whe tells ws that

$$
\hat{p}(w \mid v) \equiv \frac{\hat{p}(w, v)}{\hat{\pi}(v)},
$$

where $v$ aind $w$ arre class midpoints. The joint density of observations is written as $p(w, v)$. In the above equation this is replaced by its kernel estimator $\hat{p}(w, v)$. Similarly, $\hat{p}(w \mid w)$ is the kernel estimator of the conditional transition probability. As shown by Ait-Sahalia (1996a), Equation 5.22 can be replaced by its kemel estimator:

$$
\hat{p}(w \mid w)=\frac{\frac{1}{T} \sum_{t=1}^{T} \frac{1}{h_{T}^{2}} K\left(\frac{v-r(u)}{h_{T}}\right) K\left(\frac{w-r(t+1)}{h_{T}}\right)}{\frac{1}{T} \sum_{t=1}^{T} \frac{1}{h_{T}} K\left(\frac{v-r(t)}{h_{T}}\right)} .
$$

Figure 5.6 shows the conditional density as it results from the nonparametric approach. Between January 1981 and December 1994 the one-month interest rate did not rise above 14 percent. In a nonparametric setting this results in a strong mean-reversion force at high interest taths, as becomes obvious in Figure 5.7.

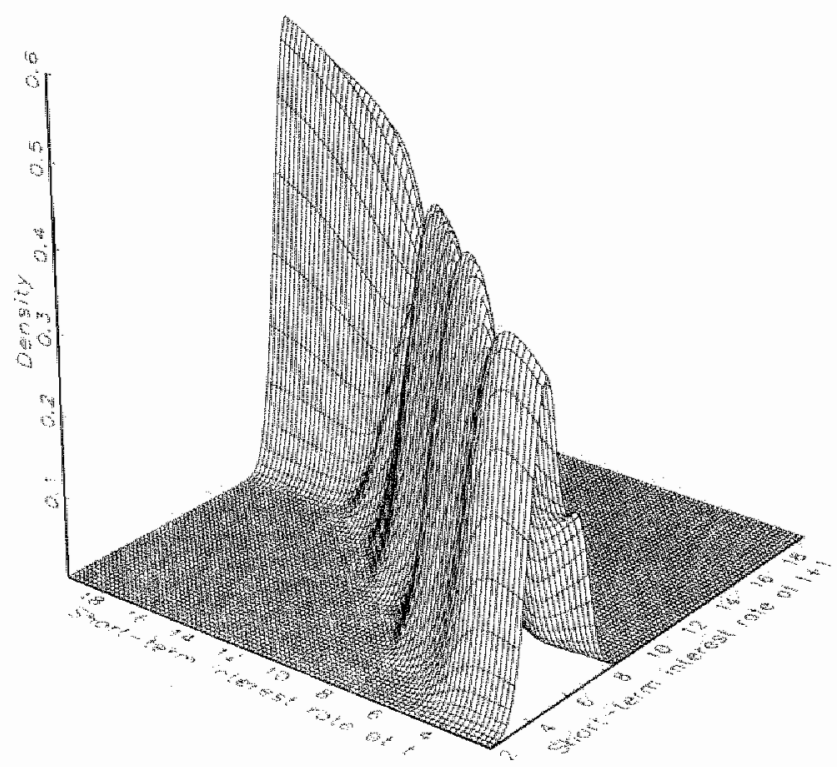

FIGURE 5.6: NONPARAMETRIO TRANGITION DENSITIES

The upper diagram of Figure 5.7 displays the contours of the conditional density; the lower dagram plots the dritt. This lower diagram clearly shows that high interest rates are firmly pulled back into a range between 6 and $12 \%$, while in this range the mean-reversion is negligible. A similar result was foud for the nonlinear model. 

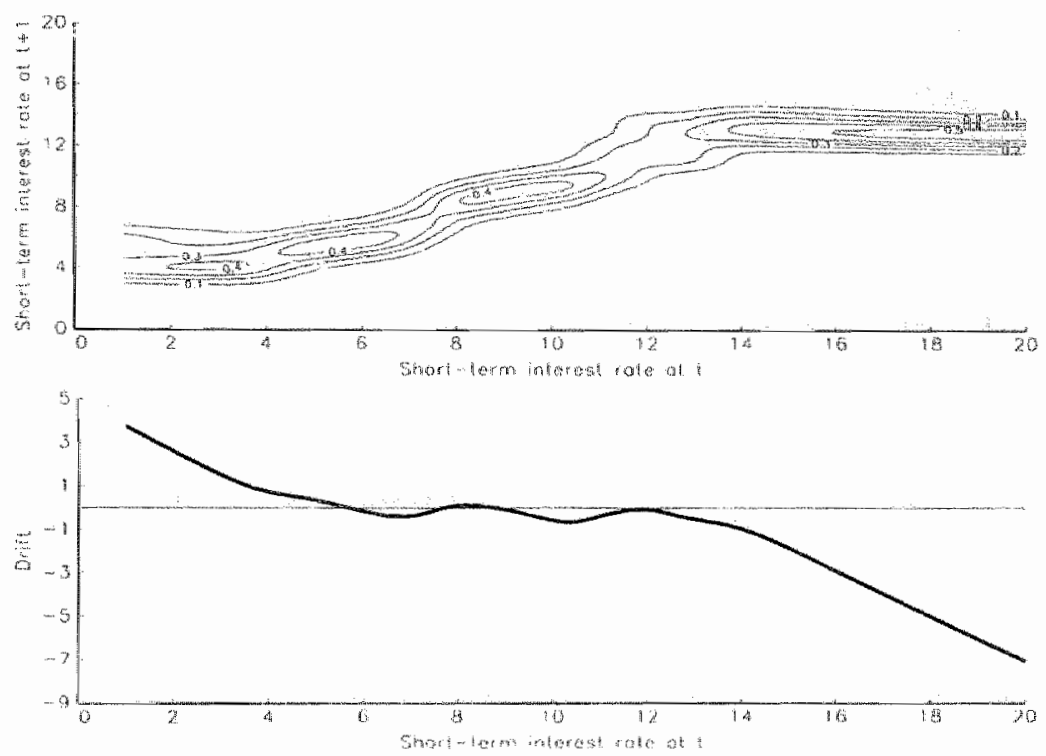

FlGURE 5.7: CHARACTERISTICS OF THE NONPARAMETRIO INTEREST MODEL

The upper diagram of this figure shows the contours of the nomparametric transition densities. In the lower diagram the nonparametrie drift is plof ted. 


\subsection{Mortgage rate dynamics}

The importance of the mortgage rate dynarics was already stressed in Section 5.2.3. The relation between the mortgage rate and short-term interest rate is endogemously derived for both the backward and forward valuation method. In the forward-looking valuation approach we also consider two empirical relations between the spot rate and the mortgage rate.

We start with an estimation of the empirical relation between the mortgage rate and the short-term interest rate in the Netherlands. The idea is to fit a function

$$
y(t)=f(r(t))
$$

where $y(t)$ is the mortgage rate and $x(t)$ the short-term interest rate at time $t$. The function $f(r(t))$ can be highly nonlinear and is therefore estimated nonparametrically. The left diagram of Figure 5.8 shows the result for the Netherlands. The thick line in the figure will be used as the empirical equilibrium relation between the mortgage rate and the spot interest rate.
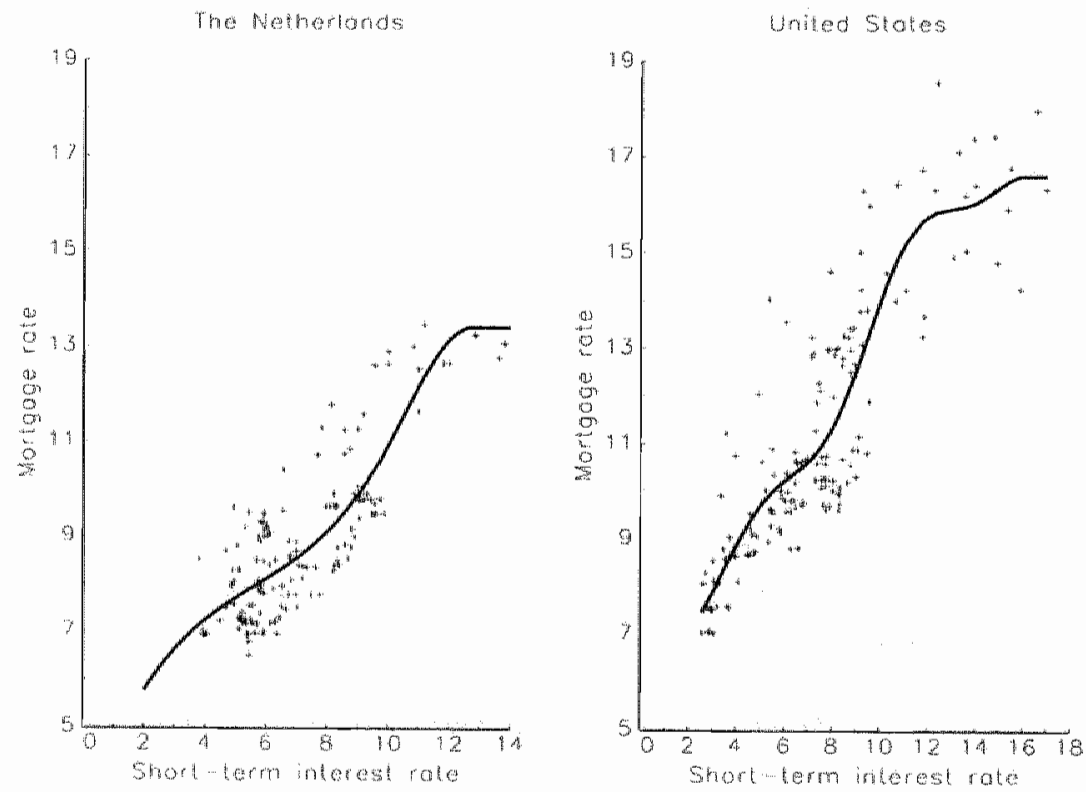

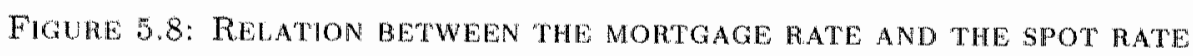

This figure shows the relation between short-tem interest rates and mortgage rates for both the Netherlands and the US. "The "crosses" depict a scatter of the observations. The solid lines are the estimated functional relations.

The Dutch curve shows that the mortgage premium over the short-tem interest rate is more than 300 basis points at low levels of $r$, and drops to about 110 basis points at 
interest rates above $10 \%$. The premium consists among others of a compensation for the prepayment risk embedded in Dutch mortgages. However, these mortgages have very rigid prepayment restrictions which are undoubtedly refected in the bistorical spread. In this chapter we analyze what would happen if these restrictions would be abandoned. The histonical premium might therefore be too small to cover the risks involved in the contracts studied. American mortgages have less restrictions on prepayment so that the historical American relation between the short-tern interest rate and mortgage rate might be more appropriate here. However, this relation refects the US interest rate dynamics which might substiantially differ from the Duteh dynamics.

In keeping with Tables 5.1 and 5.2 , the diagrams in Figure 5.8 illustrate that American interest rates attained higher levels than their Dutch connterparts in the considered period. Consistent with the less restricted prepayment options, the US mortgage spread is higher than the Dutch spread.

Both the Dutch and American figure will be used to describe the mortgage rate dy. namics underlying our valuation model. Furthemore, we will endogenously determine the contract rate which makes a mortgage a derivative security with a zero net present value. This is essentially the approach taken by Kau, Keenan, Muller and Epperson (1993).

\subsection{Optimal prepayment results}

This section presents the results of the valuation procedure based on the optimal prepayment rule. We start with the derivation of the mortgage rate which equals the mortgage walue at origination to the principal of the loan. Recall that in this chapter we study a mortgage which can be completely called. However, prepayment is discouraged by the up-front costs for starting a new loan necessary to refinance the existing contract. These up-front costs are assumed to be $1 \%$ of the outstanding ballance.

The endogenous relationship between the mortgage rate and the short term interest. rate is cletermined with the CIR, the nonlinear and the nonparametric models describing the underlying short-term interest rate dynamics. The results are shown in Figure 5.9. This figure shows that the CIR model results in an endogenons relation between the mortgage rate and the short-term interest rate which is close to linear, while for both alternative models a nontinear relation comes out. The impact of the alternalive single factor models is most obvious at low interest rates. The differences are caused by the different drit terms in the models. For example, Figures 5.4 and 5.7 show that low spot rates ane firmly pulled back into a range of between 6 and 10 percent by both the nonlinear interest rate model and the nonparametric model. The exact size of this upward drit depends on the underlying model. It is therefore not surprising that the various endogenous relations converge at rates below $6 \%$. The upward drift is strongest in the nonparametric model and therefore this model implies the highest mortgage rates at low short-term interest rates.

The crosses in the left diagram of Figure 5.9 depict a scatter of observations in the 
The Netherionds

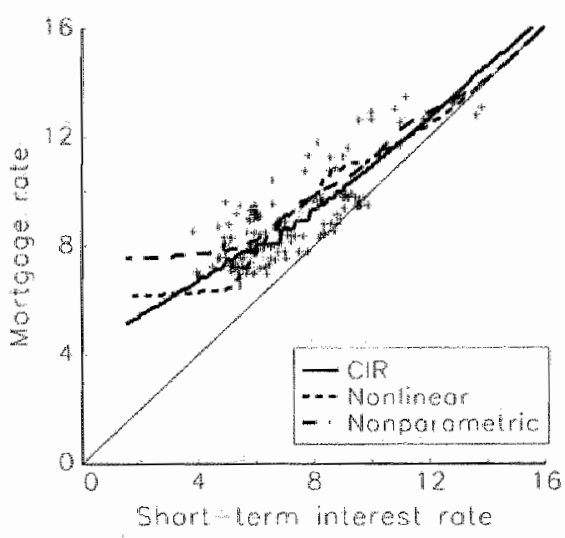

United Slotes

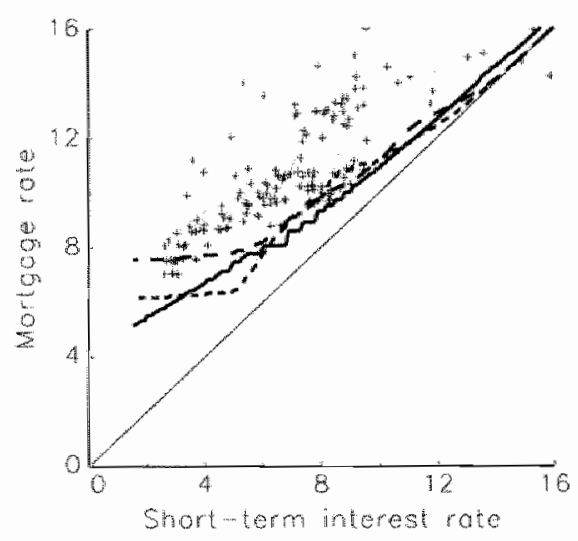

\section{Figure 5.9: Endogenous mortgage Rates}

The mortgage rates plotted in this figure are endogenously derived such that the value of the mortgage contract equals the face value of the loan. In this setting a mortgage is an investment wh an expected net present value of zero. The optimal prepayment rule is used to model the prepament behavon. "The endogenous relatons are shown lor alternative specifications of the underlying interest rate dynamics. The crosses in the left diagram depict as ster of observations in the Netherlards, in the right diagram they represent US obsenvations. The endogenous relations presented in both diagrams are based on Dutch interest rabe dymanics. 
Netherlands. Note that these observed mortgage rates refer to contracts with amnual prepayment restrictions. The endogenous relation, on the other hand, is based on the assumption that the mortgage can be completely called each month. One would therefore expect that the observed mortgage rates would all be below the various endogenous rela tions. But Figure 5.9 shows that the observations are scattered around the endogenously derived relations which suggest that a typical Dutch mortgage contract is not a zero net present value investment.

American mortgages have less prepayment restrictions and therefore resemble the contract studied here. In the right diagram of Figure 5.9 we compare the endogenous relations with US observations. This time we expect the crosses to be scattered around the various endogenous relations, but Figure 5.9 shows that almost all US mortigage rates observed between January 1981 and December 1994 exceed the endogenously derived rates. Note that the endogenous relations are based on Dutch interest rate dynamics while the US observations are of course based on American dynamics. As Table 5.2 in Section 5.5 shows, the volatility of the American interest rates is relatively high compared with their Dutch counterparts. Apparently this has a substantial impact on the spread between mortgage rates and short-term interest rates, such that we have to be reserved to use American interest rate relations to value Dutch contracts.

In Figure 5.10 we used the endogenously derived mortgage rates to determine the refinancing boundaries. These boundaries depend on the interest rate process underlying the backward valuation algorithm. Hence, Figure 5.10 displays the critical boundaries for the CIR, nonlinear and nonparametric model. The results are shown for initial short-term interest rates of 4,8 and 12 percent and for five levels of refinancing costs.

In keeping with economic theory, Figure 5.10 shows that the critical boundary increases as the refinancing cost decreases. Similar to McConnell and Singh (1994) we find that the critical boundary increases through time when there are no transaction costs:

...for the zero refinancing cost category, the critical boundary traces the level of the short-term interest rate that gives the eurrent coupon mowgage rate for a martgage with a term to maturity equal to the remaining term of the original mortgage. As the remaining term to maturity declines, the current coupan rate approaches the short-term rate. At malurity, the critical refinancing rate equals the original coupon rate.

For positive transaction costs we see that eventually the critical rate declines to zero. This means that, independent of the prevaling interest rate, the remaining time to the reset, date is too short for the savings on the monthly payments to make up for the transaction costs.

Table 5.5 examines a mortgage contract for which the only discouragement to prepay arises from one percent refinancing costs. The table presents the results for a noncallable annuity and a mortgage contract. Given the underlying interest rate process, the mortgage rate is endogenously derived such that the value of the mortgage contract at origination 
CIP

$r=4 \%$
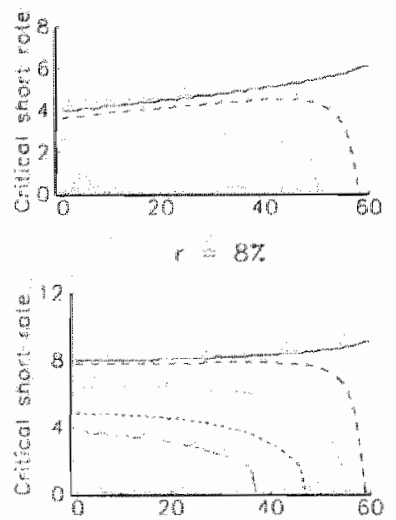

$r=12 \%$

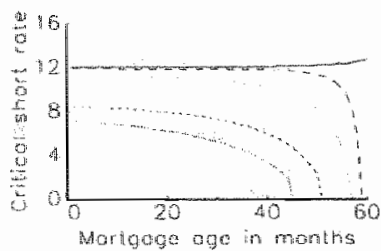

thonlines

$r=4 \%$

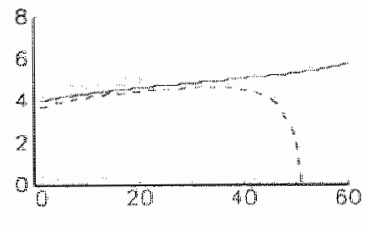

$r=8 \%$

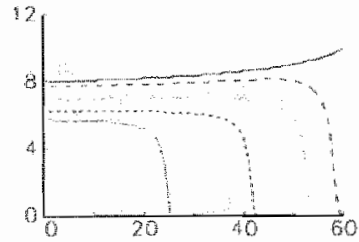

$r=12 \%$

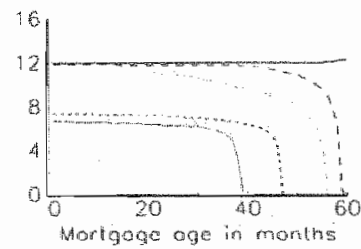

Nonoprometric

$r=4 \%$
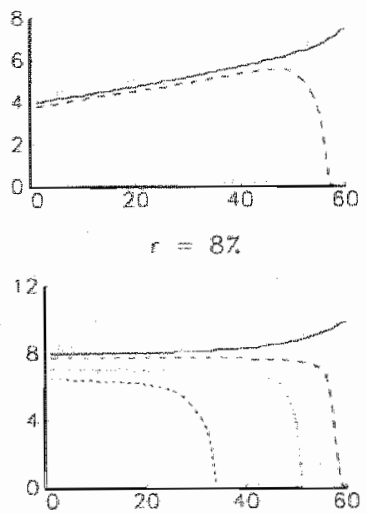

$r=12 \%$

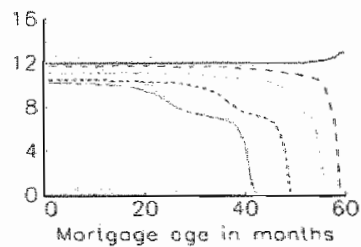

FrGURE 5. 10: CRITICAL SHORT-TERM INTEREST RATES

This figne plots the critical shorterm interest rates as derived under the optimal prepayment rulde. The results are based on the andogenously derived mortgage rates cormesponding with shortherm interest rates of 4,8 , and 12 percent, respectively. The diagrams in the first column are based on the CIR modet, whill the second and third colum are based on the nonlinear and honparametric interest pate process, respectively. The refunacing costs as a, percentage of the outstanding balame are, from the highest to the lowest boundary, $0,1,3$, 6 and 9 pretert, nepectivisly. 
TABLE 5.5: OPTIMAL PREPAYMENT RESULTS

\begin{tabular}{|c|c|c|c|}
\hline Spot Rate & $4 \%$ & $8 \%$ & $12 \%$ \\
\hline & \multicolumn{3}{|c|}{ CIR model } \\
\hline Anmuity value & 103.56 & 104.96 & 108.53 \\
\hline Duration annuity & 50.04 & 48.09 & 45.83 \\
\hline Duration mortgage & 30.15 & 8.82 & 3.54 \\
\hline$\Delta$ anmuity & 2.18 & 2.06 & 1.94 \\
\hline \multirow[t]{2}{*}{$\Delta$ mortgage } & 0.05 & 0.18 & 0.20 \\
\hline & \multicolumn{3}{|c|}{ Nonlinear model } \\
\hline Annuity value & 1.02 .80 & 105.71 & 106.99 \\
\hline Duration annuity & 50.41 & 47.76 & 45.86 \\
\hline Duration mortgage & 23.23 & 13.92 & 2.48 \\
\hline$\Delta$ annuity & 0.26 & 3.94 & 0.73 \\
\hline \multirow[t]{2}{*}{$\Delta$ mortgage } & 0.09 & 0.50 & 0.12 \\
\hline & \multicolumn{3}{|c|}{ Nonparametric model } \\
\hline Annuity value & 102.12 & 106.82 & 113.91 \\
\hline Duration annuity & 49.11 & 47.85 & 46.11 \\
\hline Duration mortgage & 19.91 & 8.90 & 3.70 \\
\hline$\Delta$ annuity & 0.24 & 1.42 & 0.85 \\
\hline$\Delta$ mortigage & 0.13 & 0.24 & 0.11 \\
\hline \multicolumn{4}{|c|}{ 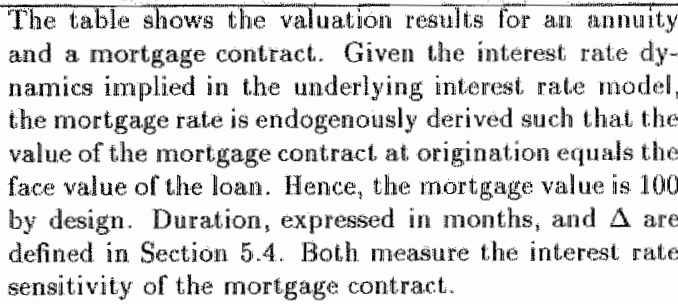 } \\
\hline
\end{tabular}


equals the taxe value of the loan. Hence, the mortgige value is 100 by design and not presented in the table. The value of the prepayment option is also not shown because it can be found by simply subtracting the value of lhe morlgage from the value of the annuity contract.

Table 5.5 show that the different underlying interest rate processes yield very similar watuation results. Even though the exact figures differ slightly, similar patterns may be recognized. For example, the value of the annuity and prepayment option increase along wh the short-term interest rate, while the duration decreases with increasing interest rates. The $\Delta$ meastires show varying patterns depending on the model used. The linear dritit in the CIR model keeps the $\Delta$ measures more or less the same for different initial short-term interest rates. The nonlinear and nonparametric models, on the other hand, have a nonlinear drift which pults high and low interest rates firmly back into a range of between 6 and 10 percent. Within this range, the interest rates behave like a random walk and this uncertainty is reflected by the relatively high interest rate sensitivity of the mortgage contract at: the 8 percent interest rate level.

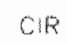

$r \approx 4 \%$

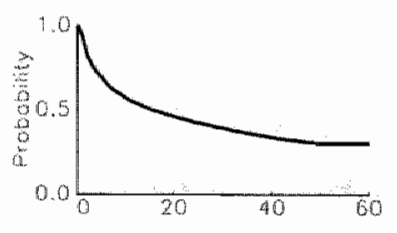

$f^{\prime}=8 \%$

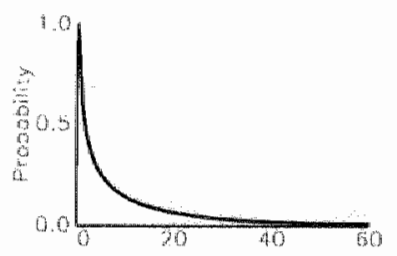

$12 \%$

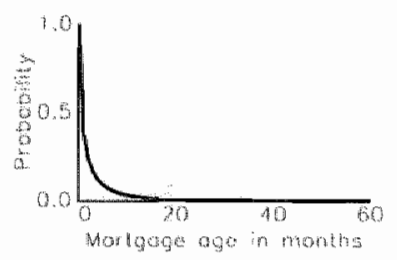

Morititam $5=4 \%$
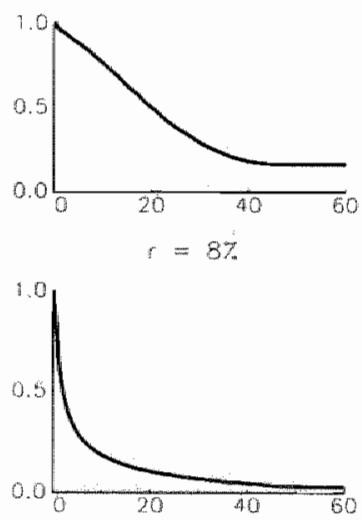

$r=12 \%$

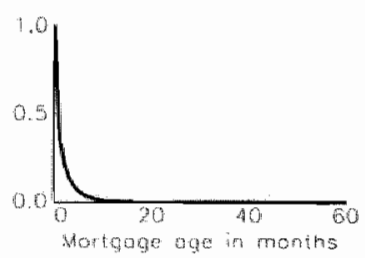

Norporomatric $r=4 \%$

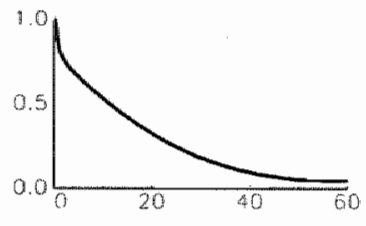

if $=8 \%$

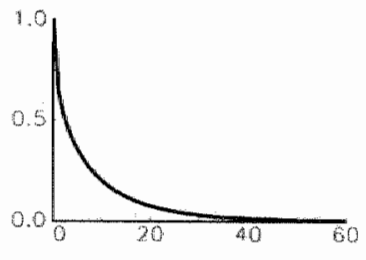

$r=12 \%$

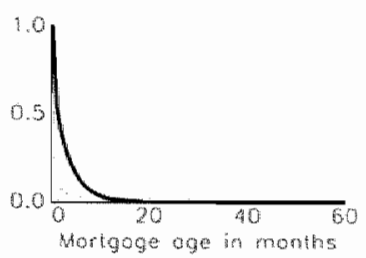

Figure 5.11: Probability of Not Being prepaid

These figures show the probability that the mortgage has not been prepaid at a specific age of the contract. The refinancing costs are assumed to equal 1 percent of the outstanding balance. 
The interest rate risk faced by the lender is closely linked to the uncertainty as to when the money will be received: Will the borrower follow the periodic principal repayments scheduled over the entire time to maturity, or will the mortgage be called prematurely? In Figure 5.11 we study this by looking at the probability that a mortgage has not been prepaid at a specific age of the contract. The results are shown for the three altemative underlying interest rate models at spot rates of 4,8 and 12 percent, respectively. Even though the "life expectations" of a mortgage contract depend on the underlying stochastic interest rate process, Figure 5.11 shows that at moderate and high interest rates it is almost certain that a mortgage will be prepaid before the fixed-rate period of 5 years ends. Also at lower interest rates the various single factor models agree that there is a significant. probability that the mortgage is prepaid before the reset date.

\subsection{Suboptimal prepayment results}

This section presents the valuation results based on the suboptimal rule where prepayment is triggered as soon as refinancing reduces the future costs for the borrower. The results are presented for the three alternative one-factor interest rate models. The one-factor assumption implies a one-to-one correspondence between the spot rate and the mortgage rate. We will discuss three specifications for this functional relation. Two exogenous relations will be considered, while for the third specification the mortgage rate is endogenously determined.

\subsubsection{Exogenous interest rate relations}

Table 5.6 shows the computed value at origination of the mortgage contract, the value of the prepayment option, and two measures of interest rate risk: duration and $\Delta$. For straight bonds, duration and $\Delta$ both measure the sensitivity to interest rate changes and are readily interchangeable. For a mortgage, the two concepts have very different properties. For comparison purposes, the resul ts of a noncallable annuty are also inchuded. The results are presented for the 4,8 and 12 percent level of the spot rate. The matching contract rates are based on both the Dutch and American empirical relation between the short-term interest rate and mortgage rate, as described in Section 5.7 .

The results presented in the upper panel of Table 5.6 are calculated with the Cox, Ingersoll and Ross model describing the underlying short-term interest rate dynamics. Because of the mean-reversion implied in the CIR model, the nomcallable annuity is expected to increase with interest rates. However, when the historical Dutch relation between the short-term interest rate and the mortgage rate is used, Table 5.6 shows that the anruity value is higher when the short-term interest rate is 4 percent than when it equals 8 per cent. This is caused by the different margins between the short-tem interest rate and the mortgage rate. As illustrated in Figure 5.8, the margin rapidly decreases from 300 to 110 basis points when the short-term interest rate increases from 4 to 8 percent, while for rates above 8 percent the margin stays around 170 basis points. 
TABLE 5.6. Mortgage VAlues and the INTEREST Rate process

\begin{tabular}{|c|c|c|c|c|c|c|}
\hline \multirow{2}{*}{$\begin{array}{l}\text { Empirical Spread } \\
\text { Spot Rates }\end{array}$} & \multicolumn{3}{|c|}{ Dutch } & \multicolumn{3}{|c|}{ American } \\
\hline & $4 \%$ & $8 \%$ & $12 \%$ & $4 \%$ & $8 \%$ & $12 \%$ \\
\hline & \multicolumn{6}{|c|}{ CIR model } \\
\hline Annuity value & 105.75 & 104.07 & 110.12 & 111.19 & 113.77 & 116.78 \\
\hline Mortgage value & 104.38 & 100.29 & 100.26 & 109.44 & 102.78 & 101.25 \\
\hline Option value & 1.38 & 3.78 & 9.86 & 1.75 & 10.99 & 15.53 \\
\hline Duration amnuity & 49.72 & 48.22 & 45.61 & 48.95 & 46.84 & 44.72 \\
\hline Duration mortgage & 41.16 & 16.38 & 5.85 & 43.10 & 13.62 & 6.66 \\
\hline$\Delta$ annuity & 2.17 & 2.07 & $\mathbb{1 . 9 4}$ & 2.14 & 2.02 & 1.91 \\
\hline \multirow[t]{2}{*}{$\Delta$ morlgage } & -1.01 & 0.14 & -0.09 & -1.88 & -3.06 & -1.14 \\
\hline & \multicolumn{6}{|c|}{ Nonlinear model } \\
\hline Annuity value & 106.78 & 103.08 & 109.40 & 112.24 & 112.72 & 116.05 \\
\hline Mortgage value & 106.56 & 99.20 & 1.00 .23 & 112.04 & 102.51 & 100.85 \\
\hline Option value & 0.22 & 3.88 & 9.18 & 0.19 & 10.21 & 15.20 \\
\hline Duration annuity & 49.84 & 48.15 & 45.52 & 49.07 & 46.76 & 44.62 \\
\hline Duration mortgage & 48.35 & 19.01 & 3.75 & 48.40 & 16.91 & 4.20 \\
\hline$\Delta$ anmuily & 0.26 & 3.97 & 0.73 & 0.26 & 3.86 & 0.72 \\
\hline \multirow[t]{2}{*}{$\Delta$ mortgage } & 0.02 & 1.42 & -0.03 & 0.09 & -2.37 & -0.45 \\
\hline & \multicolumn{6}{|c|}{ Nonparametric model } \\
\hline Annuity value & 100.25 & 104.17 & 114.77 & 105.48 & 113.86 & 121.60 \\
\hline Mortgage value & 100.06 & 99.47 & 100.08 & 109.24 & 101.47 & 100.69 \\
\hline Option value & 0.19 & 4.69 & 1.4 .69 & 1.24 & 12.39 & 20.91 \\
\hline Duration anmuity & 49.40 & 48.24 & 46.00 & 48.62 & 46.85 & 45.12 \\
\hline Duration mortgage & 36.90 & 11.23 & 4.08 & 38.91 & 10.20 & 4.33 \\
\hline$\Delta$ annujiy & 0.24 & 1.42 & 0.85 & 0.24 & 1.41 & 0.84 \\
\hline$\Delta$ mortgage & 0.21 & 0.57 & 0.08 & -0.1 .5 & -0.68 & -0.13 \\
\hline
\end{tabular}

The table shows valuation resulis for the three alternative short-term interest rate processes described in Section 5.6. For the spread between the short-term interest rate and the mortgage rate we used both the Dutch and American historical relation between these two rates. Duration, expressed in months, and $\Delta$ are defined in Section 5.4. Both neasure the interest rate sensitivity of the mortgage contract. 
At the 4 percent level the probability that the mortgage will be prepajd is small. Consequenty, the mortgage contract studied here is similar to the contracts issued historically in the Natherlands. The historical Duich premium might therefore be appropriate at this low interest rate. However, as the initial interest rate increases, the prepayment probability increases. The historical spread, based on restrictive contracts, might not be large enough to cover this prepayment risk. In that light it is surprising that, even if the relation between the spot rate and the mortgage rate is based on Dutch historical data, the model based on the CIR process still yields mortgage values above par for both the 8 and 12 percent spot rate. ${ }^{14}$

Contrary to the CIR model, the nonlinear and nonparametric interest rate models yield mortgage values below par. This would mean that the issuing party is accepting a loss. A more reasonable interpretation is that the Dutch historical premium is not appropriate. Therefore we also consider the empirical relation between the mortgage rate and the shortterm interest rate in the US, where anmual prepayment restrictions are virtually unknown. At moderate and high interest rates, the US relation shows a higher option premium which, as Table 5.6 shows, results in higher values for the annuity, the mortgage and the prepayment option. Furthermore, the mortgages all value above par.

Does this mean that the consequences of loosening the prepayment restrictions in Dutch mortigage contracts can correctly be analyzed by applying the empirical US relation? No. The negative $\Delta$ 's reported in Table 5.6 reveal that the American empirical relation between the mortgage rate and the short-term interest rate is not appropriate for this purpose. A negative $\Delta$ measure indicates that the contract walue decreases with decreasing interest rates!

Decreasing short-term interest rates result in decreasing discount rates. At the same time, the prepayment probability increases. Due to these callable features, the value of a mortgage contract will not increase as much as the value of a noncallable annuity, for example. One would expect that the value of a montgage increases with decreasing interest rates until a value equal to the par value plus transaction costs is reached. Additional interest rate decreases would have no effect anymore. However, this is only the case when low initial short-term interest rates (and therefore low prepayment probabilities) are considered or when the mortgage value at origination is below or close to par. Otherwise the mortgage value decreases with decreasing interest mates. This is illustrated in Table 5.6 where mortgage values above par and moderate and high interest rates go hand in hand with negative $\Delta$ measures. These negative $\Delta$ 's clearly reveal the shortcomings of exogenous approaches to relate the mortgage rate to the short-term interest rate.

14 Anstead of only implementing our point estimators for the mean-reverting and volatility patrinnetrer in the CIR model, we also studied the sensitwity of the mortgage vallue and its prapayment option for

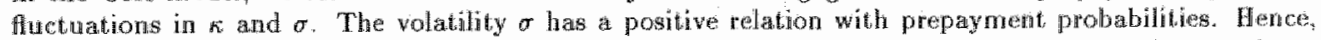
an increase in $\sigma$ results in an increase in the option value. Howewer, this is only noticeable at a term interest rate of $8 \%$. At interest rates of 4 and $12 \%$, the speed-of adjusthent factor donirates the volatility factor. Independent of these adjustments, the general results are very similar to the ones. presented in the top panel of Table 5.6. 


\subsubsection{Endogenous interest rate relations}

The endogenous relation between the mortgage rate and the short-term interest rate derived in Section 5.8 is based on the optimal prepayment rule. These mortgage rates are used in this subsection to value the mortgage contract in a framework where prepayment is triggered when this reduces the future costs for the borrower. Later we also derive the mortigage rates endogenously in this tramework.

TABLE 5.7: VALUATION RESULTS

\begin{tabular}{|c|c|c|c|}
\hline Spot Rate & $4 \%$ & $8 \%$ & $12 \%$ \\
\hline & \multicolumn{3}{|c|}{ CIR model } \\
\hline Annuity value & 103.56 & 104.96 & 108.53 \\
\hline Mortage value & 102.38 & 100.23 & 100.06 \\
\hline Duration annuity & 50.04 & 48.09 & 45.83 \\
\hline Duration mortgage & 38.82 & 9.46 & 5.63 \\
\hline$\Delta$ annuity & 2.18 & 2.06 & 1.94 \\
\hline \multirow[t]{2}{*}{$\Delta$ mortgage } & -0.63 & -0.02 & 0.16 \\
\hline & \multicolumn{3}{|c|}{ Nonlinear model } \\
\hline Annuity value & 102.80 & 105.71 & 106.99 \\
\hline Mortgage value & 102.80 & 100.12 & 100.06 \\
\hline Duration annuity & 50.41 & 47.76 & 45.86 \\
\hline Duration mortgage & 50.41 & 16.79 & 4.64: \\
\hline$\Delta$ annulity & 0.26 & 3.94 & 0.73 \\
\hline \multirow[t]{2}{*}{$\Delta$ mortgage } & 0.26 & 0.40 & 0.11 \\
\hline & \multicolumn{3}{|c|}{ Nonparametric model } \\
\hline Annuity value & 102.12 & 106.82 & 113.91 \\
\hline Mortage value & 102.12 & 100.07 & 100.02 \\
\hline Duration annuity & 49.11 & 47.85 & 46.11 \\
\hline Duration mortgage & 49.11.1 & 11.66 & 4.67 \\
\hline$\Delta$ anmuity & 0.24 & 1.42 & 0.85 \\
\hline$\Delta$ montgage & 0.24 & 0.21 & 0.10 \\
\hline \multicolumn{4}{|c|}{ 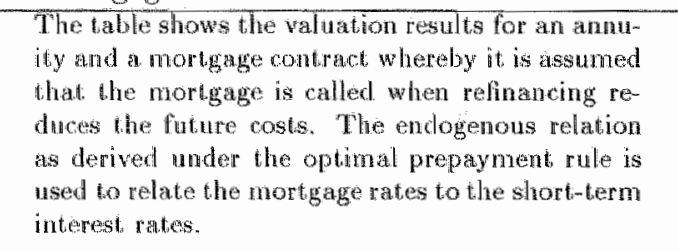 } \\
\hline
\end{tabular}

Table 5.7 presents the valuation results of a mortgage contract which is assumed to be called as soon as this reduces the future costs for the borrower. The relationship between the mortgage rate and the shorterm interest rate is endogenously derived under the optimal prepayment rule as described in Section 5.8. The most eye-catching results in Table 5.7 are the relatively high durations compared to their counterparts in Table 5.5. 
This results in the counter intuitive ontcome that the prepayment likelibood is lower when the in-the-money mle is applied rather than the optimal prepayment rule! The explanation For this can be found in Figure 5.9 , where the endogenously derived mortgage rates are plotted as a function of the short-tem interest rate. Figure 5.9 shows that, regardless of the underlying interest rate process, the regression coefficients of the tangent lines at short-term interest rates of 4,8 and 12 percent are smaller than the regression coeficient of a $45^{\circ}$ line. This indicates that a one basis point decrease of the short-term interest rate corresponds with a decrease of the mortgage rate which is smaller than one basis point. This characteristic has a major impact on the prepayment behavior modelled by both approaches.

Recall that the prepayment boundary under the optimal prepayment rule is entirely determined by the spot rate, whille the suboptimal prepayment boundary solely depends on the mortgage rate at which the borrower can refinance the loan. This distinction infuences the prepayment behavior substantially. To see this let us consider a situation where the short-term interest rate drops with 100 basis points from 4 to 3 percent. The probability that this drop in the spot rate triggers prepayment when the optimal rule is used is substantial. The likelibood that the suboptimal rule prescribes prepayment is, however, much smaller. For example, when the nonlinear or nonparametric model is used, the adjustment in the mortgage rate is almost negligible, such that the probability that the mortgage is called is very small. This is also reflected by the higher duration measures. The same argumentation holds for short-term interest rate levels of 8 and 12 percent.

The prepayment boundary under the optimal prepayment rulle does not depend on the refinance opportunities open to the individual. Hence, the mortgage rate corresponding to a particular short-term interest rate can be derived without reference to mortgage rates matching the other short-term interest rates. This is more complicated when the suboptimal prepayment rule is used. For example, suppose that the short-term interest rate at origination equals $r_{i}$, which is the short-tem interest rate corresponding with shade i. From this state $i$ the short-term interest wate process can reach each statc $j$ in the next period. The mortgage rate matching this state $j$ will in fuence the prepayment behavior regarding a contract issued at time $t$ in state $i$. This means that the mortgage rate corresponding with state i should be derived simultaneously with the mortgage rates connected with all possible states $j$. The results are shown in Figure 5.12 , which compares the endogenous relations based on the suboptimal prepayment rule with those of the optimal rule. Regardless of the underlying interest rate process, Figure 5.12 shows that the suboptimal prepayment rule results in mortgage rates which are lower than when the optimal rule is. utilized. The reason for this is straight forward. The bank can settle for lower contract rates if borrowers prepay suboptimally.

When the CIR model underlies the valuation model, both prepayment rules result in a linear relation between the mortgage rate and the short-term interest rate. The functional relation proceeding from the suboptimal rule is not only below the one arising from the optimal prepayment rule, it is also less steep. For moderate and high interest: 

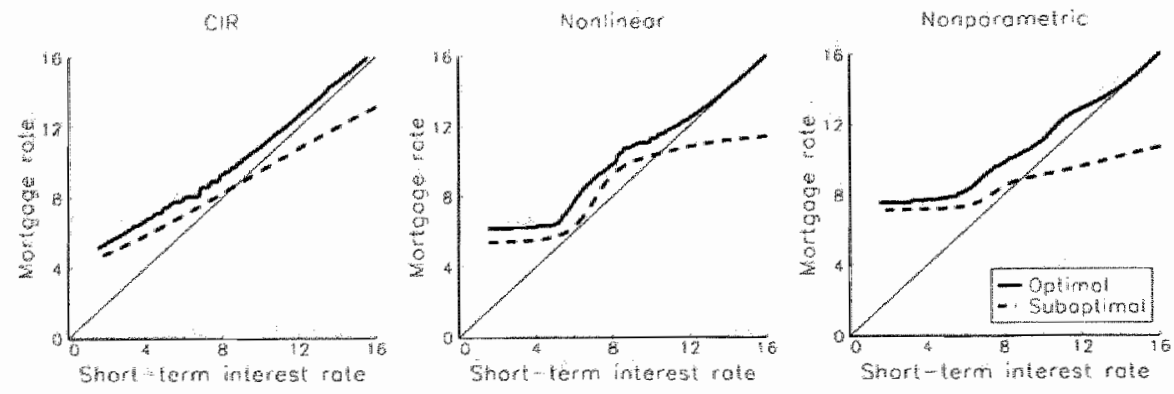

FIGURE 5.12: Endogenous mortGaGe rates

The mortgage rates plotted in this figure are endogenously derived such that the value of the mortgage contract equalls the face value of the loan. The results are shown for both the optirnal and suboptimall prepayment. cule.

rates this also tholds when the nonlinear or nonparametric interest rate process underlies the valuation algorithm. To explain this, we must look at the interest rate which determines the prepayment behavior. As mentioned earlier, the prepayment boundary under the optimal rule is determined by the spot rate, while the prepayment behavior under the suboptimal rule is based on the prevailing mortgage rate. This distinction is especially important when the underlying interest rate process has a strong mean-reverting drift and the short-term interest rate is outside the middle range. For example, high short-term interest rates are firmly pulled back into the middle range by both the nonlinear and nonparametric model. Since the prepayment behavior modelled by the optimal rule is based on this short-term interest rate, there is a substantial probability that the mortgage will be prepaid. The lender wants to be reimbursed for this prepayment risk and requires a relatively high morlgage rate. When we start with lower short-term interest rates, the prepayment likelihood drops and the contract rate required by the mortgagee decreases. At first the mortgage rate decreases at the same rate as the short-term interest rate. Later, the mortgage rate decreases less rapidly than the short-term interest rate.

When the nonlinear or nonparametric model is used, Figure 5.12 shows that the mortgage rate hardly decreases any further once the short-term interest rate is below 5 percent. At those low rates, both models have a strong upward drift which causes the discount factor to rise. The spread between the short-term interest rate and the long-term mortgage rate refers, at those levels, to the expected increase in the discount factor, and somewhat less to the prepayment risk faced by the mortgagee. This holds for endogenously derived relations based on both the optimal and suboptimal prepayment rule.

At higher raties, on the other hand, a discrepancy occurs between the two prepayment methods. As opposed to the relation proceeding from the optimal prepayment rulle, the 
relation between both interest rates levels out when the suboptimal rulle is used in combination with the nonlinear or nonparametric model. This the the prepayment decision is based on the prevalling mortgage rate rather than on the short-term interest rate. Rapidy decreasing short-term interest rates have therefore a much less pronounced effect on the prepayment behavior than when the optimal prepayment rule is applied. The flat fela thon between the mortgage rate and high short tem interest rates prevent the prepayment activity from increasing rapidy when the shortterm interest rate decreases. Despite this limited effect on the prepayment behavior, the mortgage value atters due to the decreasing discount factors. In other words, the mortgage value increases when the short-term interest rate decreases, while the prepayment risk faced by the lender hardly changes. Consequently, the lender can make do with lower contract rates.

TABLE 5.8: SUBOPTIMAL PREPAYMENT RESULTS

\begin{tabular}{lrrr}
\hline Spot Rate & $4 \%$ & $8 \%$ & $12 \%$ \\
\hline & \multicolumn{3}{c}{ CIR model } \\
Annuity value & 100.19 & 100.90 & 101.93 \\
Duration annuity & 50.54 & 48.70 & 46.81 \\
Duration mortgage & 41.41 & 15.65 & 6.60 \\
$\Delta$ arnuity & 2.19 & 2.08 & 1.97 \\
$\Delta$ mortgage & 1.43 & 1.32 & 1.19 \\
\hline & Nonlinear model \\
Annuity value & 100.00 & 103.59 & 101.33 \\
Duration annuity & 50.84 & 48.07 & 46.70 \\
Duration mortgage & 50.84 & 14.48 & 10.64 \\
$\Delta$ annuity & 0.26 & 3.96 & 0.74 \\
$\Delta$ mortgage & 0.26 & 1.30 & 0.50 \\
\hline & Nonparametric model \\
Annuity value & 100.00 & 101.83 & 102.03 \\
Duration annuity & 49.44 & 48.59 & 4.83 \\
Duration mortigage & 49.44 & 10.64 & 6.46 \\
$\Delta$ annuity & 0.24 & 1.43 & 0.86 \\
$\Delta$ mortgage & 0.24 & 0.89 & 0.61 \\
\hline
\end{tabular}

The table shows the valuation results for an annuity and a mortgage contract which will be prepaid when this reduces the future costs lor the bortrower. Given the interest rate dynamics implied in the underlying interest rate model, the mortgage rate is endogenously deriwed such that the value of the mortgage contract at origination equals the face value of the loan. Hence, the mortgage value is 100 by design.

The fact that the functional relation between the mortgage rate and the shorteterm interest rate levels out when the suboptimal prepayment rule is applied, is also reflected 
in the valuation results presented in Table 5.8. The results in that table are based on the endogenous relation as derived under the suboptimal prepayment rule. This is in contrast to Thble 5.7, where the applied mortgage rates are endogenously derived given the optimal prepayment rule. However, the results in both tables are based on the same valuation agoritum which assumes that the mortgage is refmanced as soon as this reduces the future costs for the borrower. The differences between both tables can best be explained with the help of Figure 5.12. For example, the left diagram of Figure 5.12 illustrates that in the CIR setting, the endogenous relation between the mortgage rate and the shortiten interest rate is tatter when the suboptimal rule is used rather than the optimal rule. Whis results in lower intial contract rates and lower prepayment probabilities as shown by the higher duration measures. When the nonlinear or nonparametric model is utilized we have to distinguish between low, moderate and high interest rates. At low rates, both the optimal and suboptimal prepayment rules result in an almost fat relation between the mortgage rate and the short-term interest rate. The prepayment likelihood is therefore wery similar in both settings. As a consequence the duration measures hardly differ. At an intial short-term interest rate of $8 \%$ we see that the tangent line of the endogenous relation based on the suboptimal prepayment rule is steeper than the tangent line of the relation based on the optimal rule. Consequently, the duration measure presented in Table 5.8 is shorter than its counterpart in Table 5.5. Since the relation based on the suboptimal prepayment rule levels out, the opposite holds at an initial short-term interest rate of $12 \%$.

To summarize, the functionall relation between the mortgage rate and the short-term interest rate depends substantially on the underlying prepayment rule. As Tables 5.5, 5.7 and 5.8 show, the choice for a particular endogenous specification of the relation between the mortgage rate and short-term interest rate influences the valuation results. Especially the interest rate risk measures are found to be sensitiwe to this choice.

\subsection{Conclusion}

This chapter considers the impact alternative prepayment rules have on mortgage pricing. We distinguish between an optimal prepayment rule and a suboptimal rulle. Under the optimal rule, mortgages are prepaid when the vallue of the mortgage, if left uncalled, exceeds the outstanding debt plus any transaction costs associated with refinancing the loan. The corresponding prepayment behavior is entirely determined by the dynamic process of the discount rate. This is in sharp contrast to the suboptimal moneyness boundary which states that the mortgage is prepaid as soon as this reduces the future costs for the borrower. This rule depends explicitly on the mortgage rate at which the individual can refinance his loan in the market.

The second topic this chapter concentrates on is the effect of alternative interest rate processes on the waluation results. For this purpose we specify three empirical one-factor mordels. Alongside the widely-applied Cox, Ingersoll and Ross model, we use a nonlinear 
and a nomparametric model. We find that the choice for a specific interest rate process wifluences the valuation results. In particular the duration and the effective duration $\Delta$, which both measure the interest rate sensitivity of the contract, are sensitive to the underlying interest rate process.

Another important component of a mortgage valuation model is the function which relates the mortgage rate to the short-term interest rate. Optimal prepayment; rules can only be used when this relation is endogenously derived, while the moneyness boundary allows exogenously specified relations between both interest rates. The exogenous relations used in this chapter are based on historical observations in the Netherlands and the US. The results, however, indicate that these empirical relations have serious drawbacks when they are used to value a contract not yet issued on the Dutch montgage market. We therefore also endogenously determine the relation between the mortgage rate and the short-term interest rate for the suboptimal prepayment rule. We find that the exact shape of the endogenous relation depends not only on the applied prepayment rule but also on the underlying interest rate process. Different combinations of prepayment rules and underlying interest rate processes yield different valuation results. Again, we find that the interest rate risk measures are especially sensitive to this. 


\section{Appendix 5.A: Duration and "life expectations" of a mortgage contract}

In this appendix we present an alternative way to calculate the duration of a mortgage contract. The techniques applied here to determine the duration of a callable mortgage contract are also utilized to calculate the probability that the mortgage has not been prepaid at apeiflc age of the contract.

To determine the duration we need to know the present walue of the expected cash flow in each month. Given the prepayment behavior described in Section 5.3 , the conditional cash flows in each node $(i, t)$ can take two values:

$$
C_{i t}=\left\{\begin{array}{ccc}
M & \text { if } \quad z_{i}<k_{i} \\
M+U_{t} & \text { if } \quad z_{i} \geq k_{i}
\end{array}\right.
$$

where $z_{\|}$reflects the state of the economy at time $t$, i.e. $\left.z_{t} \in\left\{i_{2}\right] \leq i \leq N\right\}$ and $k_{t}$ is the critical node at time $t$. If the interest rate process moves below this critical node, the mortgage will be prepaid. Note that interest rates are ordered from high to low: $r_{i}>r_{i+1}$, so $r_{i}<r_{k}$ if $i>k_{t}$. The first line in Equation (5.25) reflects the regular monthly payments. The second line displays the prepayment betavior.

The cash flows described in Equation (5.25) are conditional on the mortgage not having been prepaid in an earlier gtage. To derive the present value of the expected cash flow at time we must therefore use a discount factor which takes the possibility that the mortgage has already been prepaid into account. For this we introduce an elementary security that pays one if state $i$ occurs at time $t$ conditional on the interest rate path having been above the critical boundary at all times $s<t$. The valuation of such a security proceeds analogous to the derivation of state prices for Arrow-Debreu securities (see Duffie, 1996). We illustrate the procedure using Figure 5.13 .

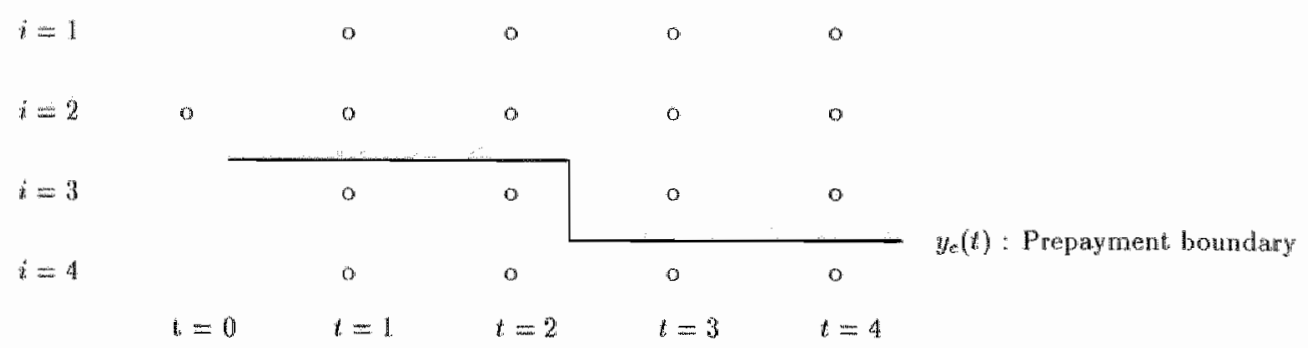

\section{Figure 5.13: Interest rate Grid}

Consider the valuation of a security $x_{34}$ that pays 1 in state 3 at time 4 , conditional on the interest rate having always been above the prepayment boundary. Its value at each of 
Whe states at time 3 is given by

$$
\begin{aligned}
& h_{13}=\frac{\tilde{a}_{13}}{1+r_{1}} \equiv b_{13}, \\
& h_{23}=\frac{\tilde{a}_{23}}{1+r_{2}} \equiv b_{23}, \\
& h_{33}=\frac{\tilde{a}_{33}}{1+r_{3}} \equiv b_{33}, \\
& h_{43}=0 \equiv b_{43},
\end{aligned}
$$

where $\tilde{a}_{i j}$ are the risk-nentral transition probabilities of the Markov chain. The elements $b_{i j}=\frac{a_{i_{3}}}{\left(1+r_{i}\right)}$ are discounted probabilities and stored in the matrix $\mathbf{B}$, as discussed in Section 5.3. Continuing the pricing algorithm, the value of the elementary security at time 2 follows as:

$$
h_{i 2}= \begin{cases}\sum_{j=1}^{3} b_{i j} h_{j 3} & i=1,2 \\ 0 & i=3,4\end{cases}
$$

and for $t=1$ :

$$
h_{i 1}= \begin{cases}\sum_{j=1}^{2} b_{i j} h_{j 2} & i=1,2, \\ 0 & i=3,4 .\end{cases}
$$

Finally the "conditional state price" $q_{34}$ can be calculated as the value of this security at: time $t=0$. Since the tree starts from the initial condition $z_{0}=2$, we have

$$
q_{34}=\sum_{j=1}^{2} b_{2 j} h_{j 1}
$$

To derive the general formula for all conditional state prices $q_{i t}(i=1, \ldots, N, t=1, \ldots, T)$, first consider pricing all elementary securities $x_{i 4}$ at time $t=4$. Going backwards, their value at time $t=3$ can be stored in the $(4 \times 4)$ matrix $\mathbf{H}_{3}$, which is given by

$$
\mathbf{H}_{3}=\mathbf{J}_{3} \mathbf{B}
$$

where $\mathbf{J}_{3}$ is the selection matrix that takes the first $k_{3}$ rows from $\mathbf{B}$, and sets the rentaing rows equal to zero,

$$
\mathbf{J}_{3}=\left(\begin{array}{ll}
\mathbf{I}_{k, 3} & 0 \\
0 & 0
\end{array}\right),
$$

where $I_{k_{3}}$ is the identity matrix of order $k_{3}$. The vector of state prices $q_{4}=\left(q_{14}, \ldots, q_{44}\right)^{\prime}$ is found by the backward recursion illustrated above,

$$
q_{4}^{\prime}=e_{2}^{\prime} B\left(\prod_{s=1}^{3} j_{s} \cdot B\right)
$$

where $\mathbf{e}_{2}$ is the vector $(0,1,0,0)^{\prime}$, and all $\mathbf{J}_{s}$ are defined analogous to the selection matrix $\mathbf{J}_{3}$ abowe, selecting the first $k_{s}$ rows from $\mathbf{B}$ and filling the remaining rows with zeros. In general, in a tree with $N$ states, the vector of state prices for period $t$ can be written as: 


$$
\mathrm{q}_{i}^{\prime}=\mathbf{e}_{z_{0}}^{\prime} \mathbf{B}\left(\prod_{k=1}^{t-1} \mathbf{J}_{s} \mathbf{B}\right),
$$

where $e_{s,}$ is $(N \times 1)$ vector with a one in position $z_{0}$ and zeros elsewhere. Equation $(5.33)$ can be transformed to the forward recurision to derive conditional state prices:

$$
\begin{aligned}
\mathbf{q}_{t+1}^{\prime} & =\mathbf{e}_{z, j}^{\prime} \mathbf{B}\left(\prod_{s=1}^{i} \mathbf{J}_{s} \mathbf{B}\right) \\
& =\mathbf{q}_{t}^{\prime} \mathbf{J}_{t} \mathbf{B} .
\end{aligned}
$$

Equation (5.34) defines a forward recursion for the valuation of the conditional cash flows $C_{\text {it }}$ in state $i$ at time 1 . These conditional state prices $q$ can be used to determine the vallue and the duration a mortgage contract. For example, the value of the mortgage in state $j$ at time 0 , represented by $v_{j 0}$, is defined as the present value of the future cash flows:

$$
v_{j 0}=\sum_{i=1}^{T} \sum_{i=1}^{N} O_{i t} q_{i t}
$$

Note that we hereby assume that the critical boundary is known. Based on this setup we define duration as:

$$
D_{j 0}=\frac{1}{v_{j 0}} \sum_{t=1}^{T} \sum_{i=1}^{N} t C_{i t} q_{i t}
$$

where $D_{j 0}$ is the duration of a mortgage whose contract rate $y_{j}$ is based on the short-term interest rate $r_{j}$, and $v_{j 0}$ is the corresponding mortgage value. Furthermore, $C_{i t}$ is the conditional cast flow at node $(i, t)$ of the tree and $q_{i t}$ is the conditional state price at that node corresponding to the risk-neutral probabilities. Note that both $C_{i t}$ and $q_{i t}$ depend on state $j$ al time $t=0$.

Similar to the derivation of the conditional state prices we can determine the probability that a mortgage has not been prepaid at a specific age of the contract. For this we have to replace the matrix $\mathbf{B}$ in Equation (5.3) by the matrix $\mathbf{A}$ which contains the transition probabilities of the underlying interest rate process. Since we are calculating the "life expectations" of the mortgage rather than its value we must use the matrix $\mathbf{A}$ instead ofl its risk-neutrall counterpart. $\tilde{\mathbf{A}}$. Hence, the probability that the mortgage has not been prepeid at time $t$ can be calculated by the forward recursion:

$$
\mathrm{l}_{t}^{\prime}=\mathrm{I}_{t-1}^{\prime} \mathbf{J}_{t-1-1} \mathbf{A}
$$

where $l_{\text {t }}$ is an $(n \times 1)$ vector with an element $l_{i t}$ being the probability that interest rate process arrives in node $i$ at time $t$ and that the followed interest rate path las been above the critical boundary at all times $s<t$. In other words, the mortgage has not been prepaid in an earlier stage. The matrix $\mathbf{J}_{t-1}$ is defined analogous to the selection matrix $\mathbf{J}_{3}$ in Equation (5.31). 


\section{Appendix 5.B: The Markov transition matrix for the CIR model}

In this appendix the explicit finite difference method will be used to construct a Markov transition matrix which describes the short-term interest rate process based on the CIR interest rate model:

$$
d r=\kappa(\theta-r(t)) d t+\sigma \sqrt{r(t)} d z .
$$

This appendix borrows heavily from Hull and White (1990a, 1990b, 1993). The transformation described here can also be used for the Vasicek model, however, in that case there is no reason to apply the change of variable technique.

Instead of using the short-term interest rate as the state variable, Hull and White define a new state variable $x(r, t)$, which has a constant instantaneous standard deviation. From Ito's Lemma we know that the process followed by $x(r, l)$ can be described as:

$$
d x=\left(\mu(r, t) \frac{\partial x}{\partial r}+\frac{\partial x}{\partial t}+\frac{1}{2} \frac{\partial^{2} x}{\partial r^{2}} \sigma^{2}(r, t)\right) d t+\sigma(r, t) \frac{\partial x}{\partial r} d z
$$

where $\mu(r, t)$ and $\sigma(r, t)$ are the drift and volatility, respectively, as defined in the CIR model. We wish to find a transformation from $r$, the interest rate, to the new state variable, $x$, that has a constant volatility, therefore:

$$
\sigma(r, t) \frac{\partial x}{\partial r}=v
$$

where $v$ is a constant and $\sigma(r, t)=\sigma \sqrt{r(t)}$ as in the CIR model. For the standard deviation to be constant, the stochastic process $x(r, t)$ has to be a linear function of $\sqrt{r(t)}$ :

$$
x(r, t)=\frac{2 v}{\sigma} \sqrt{r(t)}
$$

If we choose $v=\frac{1}{2} \sigma$ then $x(r, t)=\sqrt{r(t)}$. The process described by Equalion (5.39) can now be written as :

$$
d x=g d t+v d z
$$

where

$$
\begin{aligned}
v & =\frac{1}{2} \sigma \\
g & =\mu(r, t) \frac{\partial x}{\partial r}+\frac{\partial x}{\partial t}+\frac{1}{2} \frac{\partial^{2} x}{\partial r^{2}} \sigma^{2}(r, t) \\
& =\frac{\alpha_{1}}{x}-\alpha_{2} x
\end{aligned}
$$

with $\alpha_{1}=\frac{4 n \theta-\sigma^{2}}{8}$ and $\alpha_{2}=\frac{1}{2} *$

The discretization of this stochastic process can proceed in two alternative ways (sec Figure 5.14). The first is the explicit finite difference method, this method relates the value 
at time to three walues at time $t+\Delta t$. On the other hand, the implicit finite difference method relates the value at time $t$ to thre values at time $t-\Delta t$.

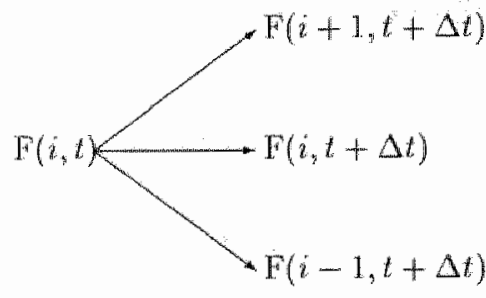

Explicit Finite Difference Method

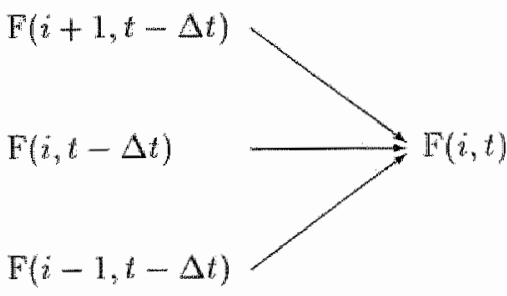

Implicit Finite Difference Method

\section{Figune 5.14: Finite Difference Method}

In both cases the value at a specific time is related to three values at time $t+\Delta t$ (explicit) or at time $t-\Delta t$ (implicit). This is done because, as shown by Brennan and Schwartz (1978), the explicit finite difference method is equivalent to a trinomial lattice approach, while the implicit finite difference method is equivalent to a multinomial lattice approach.

To model the interest rate dynamics we use the explicit finite difference methoc. The results from this lattice or tree approach will be combined in a Markov chain model of interest rates. In order to be sure that the Markov process yields a similar unconditional density distribution as the original continuous time model, the first and second moments of each model have to be equal in the limit $\Delta t \rightarrow 0$. This means that for a mean-reverting interest process we can no longer insist that the process moves from state $i$ to one of $i+1$, i or $i-1$ as was graphically represented in Figure 5.14. By introducing an integer $m$, we allow bigger fluctuations towards $m+1, m$ or $m-1$, where $m$ may or may not be equal to : The alternative branching possibilities are shown in Figure 5.15.

It can be shown that in Figure $5.15 i=m$ when:

$$
-\frac{1}{2} \leq\left(\frac{\alpha_{1}}{x}-\alpha_{2} x\right) \frac{\Delta t}{\Delta x} \leq \frac{1}{2}
$$

with $\alpha_{1}$ and $\alpha_{2}$ defined as before. If these two parameters are positive, Equation (5.45) can be written as:

$$
x_{m i n z} \leq x \leq x_{m a x}
$$

where

$$
\begin{aligned}
& x_{\text {man }}=\frac{1}{2 \alpha_{2}}\left(-\beta+\sqrt{\beta^{2}+4 \alpha_{1} \alpha_{2}}\right), \\
& x_{\text {mat }}=\frac{1}{2 \alpha_{2}}\left(\beta+\sqrt{\beta^{2}+4 \alpha_{1} \alpha_{2}}\right),
\end{aligned}
$$




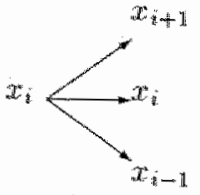

(a.)

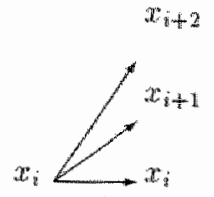

(b)

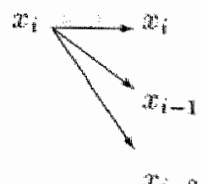

(c)
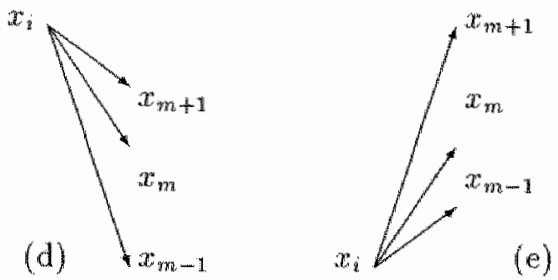

Source: Hull and White (1990a)

Figure 5.15: Mean-reverting possibilities

$$
\beta=\frac{\Delta x}{2 \Delta t} \text {. }
$$

If $x<x_{\min }$, the tree from Figure $5.15 \mathrm{~b}$ will be used. And if $x>x_{\max }$. Figure $5.15 \mathrm{c}$ will be chosen. By using these two trees when $x$ is imminent to become either too small or too large, $g$ is bounded and the estimated value converges to its true value.

The integer $m$ has to be chosen such that the first and second moments of the change in $x$ are correct during the time interval $\Delta t \rightarrow 0$. In this limit $\Delta t \rightarrow 0$ the discrete approximation becomes its own original continuous time model. The first and second moment will be accurate if the following equations are satisfied:

$$
\begin{aligned}
p_{i, m-1}(m-1) \Delta x+p_{i, m} m \Delta x+p_{i, m+1}(m+1) \Delta x & =E(x) \\
p_{i, m-1}(m-1)^{2} \Delta x^{2}+p_{i, m} m^{2} \Delta x^{2}+p_{i, m+1}(m+1)^{2} \Delta x^{2} & =v^{2} \Delta t+E(x)^{2}, \\
p_{i, m-1}+p_{i, m}+p_{i, m_{2}+1} & =1
\end{aligned}
$$

where $E(x)=g$ is the drift rate after changing the state variable and $p_{i, j}$ represents the probability that the process moves from state $i$ to state $j$ in the time interval $\Delta t$. As presented by Hull and White (1990) the solution of these equations is:

$$
\begin{aligned}
p_{i, m-1} & =\frac{1}{2}\left(m^{2}+m-(1+2 m) \frac{E(x)}{\Delta x}+\frac{E(x)^{2}}{\Delta x^{2}}+\frac{v^{2} \Delta t}{\Delta x^{2}}\right) \\
p_{i, m} & =1-m^{2}+\frac{2 m E(x)}{\Delta x}-\frac{E(x)^{2}}{\Delta x^{2}}-\frac{v^{2} \Delta t}{\Delta x^{2}}
\end{aligned}
$$




$$
p_{t, n+1}=\frac{1}{2}\left(m^{2}-m+(1-2 m) \frac{E(x)}{\Delta x}+\frac{E(x)^{2}}{\Delta x^{2}}+\frac{v^{2} \Delta t}{\Delta x^{2}}\right)
$$

hereby is noted that the explicit finte difference method prowides one degree of freedom: the choice of $\frac{y^{2} \Delta t}{\Delta x^{2}}$. However, the choice for this ratio is not completely without bounds: It is necessary that $p_{i, m-1}, p_{i, m}$ and $p_{i, m+1}$ are positive and smaller than or equal to one. This implies that $0.25<\frac{v^{2} \Delta t}{\Delta x^{2}}<0.75$.

Proof: If we look at one time interval $\Delta t$, the interest process can move from state $x_{i}$ to one of $x_{1}, x_{2}$ or $x_{3}$ with probabilities $p_{i, 1}, p_{i, 2}$ and $p_{i, 3}$, respectively, where the subscripts 1,2 and 3 are randomly chosen, they can represent each possible branching process from Figure 5.15. The relations between $x_{1}, x_{2}$ and $x_{3}$ are $x_{1}=x_{2}+\Delta x$ and $x_{3}=x_{2}-\Delta x_{\text {s }}$ so that $E(x)=x_{2}+\infty \Delta x$ where $-1 \leq w \leq 1$. The first moment condition demands that

$$
p_{i, 1} x_{1}+p_{i, 2} x_{2}+p_{i, 3} x_{3}=x_{2}+\hbar \Delta x
$$

Taking into account that the probabilities have to sum to one, the first moment condition tells us that $p_{i, 1}-p_{i, 3}=\sigma$. The second moment constraint requires that

$$
p_{i, 1} x_{1}^{2}+p_{i, 2} x_{2}^{2}+p_{i, 3} x_{3}^{2}=v^{2} \Delta t+\left(x_{2}+\omega \Delta x\right)^{2} .
$$

Combining this second moment constraint with the relations between $x_{1}, x_{2}$ and $x_{3}$ yields:

$$
\begin{aligned}
& p_{i, 1}=\frac{1}{2}\left(\varpi^{2}+\varpi+\frac{y^{2} \Delta t}{\Delta x^{2}}\right) \\
& p_{i, 2}=1-\varpi^{2}-\frac{u^{2} \Delta t}{\Delta x^{2}} \\
& p_{i, 3}=\frac{1}{2}\left(\varpi^{2}-\varpi+\frac{y^{2} \Delta t}{\Delta x^{2}}\right)
\end{aligned}
$$

\begin{tabular}{|c|c|c|c|}
\hline & $\pi=-\frac{1}{2}$ & $\pi=0$ & $\infty=\frac{1}{2}$ \\
\hline$p_{n, 1}$ & $\frac{v^{2} \Delta t}{\Delta x^{2}} \geq \frac{1}{4}$ & $0 \leq \frac{v^{2} \Delta t}{\Delta x^{2}} \leq 2$ & $0 \leq \frac{y^{2} \Delta t}{\Delta x^{2}} \leq \frac{5}{4}$ \\
\hline$p_{i, 2}$ & $0 \leq \frac{\eta^{2} \Delta t}{\Delta x^{2}} \leq \frac{3}{4}$ & $0 \leq \frac{v^{2} \Delta t}{\Delta x^{2}} \leq 1$ & \\
\hline$p_{i, 3}$ & $0 \leq \frac{y^{2} \Delta}{\Delta x^{2}} \leq \frac{4}{4}$ & $0 \leq \frac{u^{2} \Delta i}{\Delta x^{2}} \leq 2$ & $0 \leq \frac{\nu^{2} \Delta t}{\Delta x^{2}}$ \\
\hline
\end{tabular}

The probabilities $p_{i, 1}$ and $p_{i, 3}$ are mimimal when $w$ is $-\frac{1}{2}$ and $\frac{1}{2}$, respectively, while $p_{i, 2}$ has its maximum value when $\approx=0$. These values for $w$ result in the following constraints for the different probabilities:

Taking the relevant constraints we find that $\frac{1}{4} \leq \frac{y^{2} \Delta t}{\Delta x^{2}} \leq \frac{3}{4}$. Q.E.D.

Hull and white suggest a value of $\frac{1}{3}$ for $\frac{v^{2} \Delta t}{\Delta x^{2}}$ which means that $\Delta x=v \sqrt{3 \Delta t}$. The constraint that just has been derived requires $\frac{1}{2} \Delta x \leq v \sqrt{\Delta l} \leq \frac{1}{2} \sqrt{3} \Delta x$ which means that $\frac{2 w \sqrt{\Delta t}}{\sqrt{3}} \leq \Delta x \leq 2 v \sqrt{\Delta t}$. Hull and White's choice satisfes this condition. We will use the same value for $\frac{r^{2} \Delta t}{\Delta x^{2}}$ to define a finite state Markov chain with Equation (5.46) indicating the borders. These boundaries, together with the transform probabilities as defined in Equations (5.53), (5.54) and (5.55) describe the Markov process. 


\section{Chapter 6}

\section{A VAR analysis of interest rates in the Netherlands}

\subsection{Introduction}

Mortgage valuation models are commonly based on one-factor interest rate models. For example, Dunn and McConnell (1981a,b), Hendershoti and Van Order (1987) and Kau, Keenan, Muller and Epperson (1990) all use the Cox, Ingetsoll and Ross (1985b) square root process to model the term structure. The effect of alternative one factor interest rate models on the value and risk characteristics of mortgages was studied in the previous chapter.

Various authors argue that a single factor model is not sufficient to describe the entire term structure. For example, Longstaff and Schwartz (1992) advocate a two-factor model which includes the spot rate volatility along the short-term interest rate. Brennan and Schwartz (1985) include the long-term yield as a second factor. In keeping with this, Schwartz and Torous (1989) and Boudoukh, Richardson, Stanton and Whitelaw (1997) base their mortgage pricing models on two factors and find that introducing the long-term interest rate as a second wariable irriproves the waluation results for US Morlgage-Backed Secunities.

Alongside both term structure variables, a third factor related to the mortgage market. might be required to model the mortgage rate dynamics accurately. This assumplion appears reasonable for countries without a well-developed secondary market in MortgageBacked Securities like the Netherlands.

This chapter addresses the question how many factors are needed to describe the mortgage rate dynamics correctly. For this we study the empirical relation between the onemonth interest rate, the long-term interest rate and the mortgage rate in the Netherlands.

Vector AutoRegressive (VAR) techniques are used to analyze the dynamic interactions between the variables. This chapter presents the results for both at stionary and ant root specification of the VAR model. The former specification is consistent with meanreverting interest rate models, the latter models a random wajk. 
This chapter is organized as follows: In Section 6.2 the vector a toregressive technique is introduced and briefy explanted. Section 6.3 describes the interest rate data used in this paper. The actual analysis is done in Section 6.4. First, the number of lags included in the VAR analyses is determined in Subsection 6.4.1. Granger cansality tests are applied in Subsection 6.4 .2 , and impulse response functions and variance decompositions are estimated in Subsections 6.4.3 and 6.4.4. The main conclusions are summarized in Section 6.5.

\subsection{Methodology}

In order to analyze the relations between the short-term interest rate, the long-term interest rate and the mortgage rate in the Netherlands a Vector AutoRegressive (VAR) model is utilized. A VAR nodel, as introduced by Sims (1980), is well suited for analyring the joint linear dynamics in as system of time series. Within a vector autoregressiwe model, variables are regressed on a constant and $p$ of their own lags, as well as on $p$ lags of all other variables in the system. A $p^{\text {th }}$ order vector autoregression, denoted by $\operatorname{VAR}(p)$, is at vector gencralization of a $p^{t / h}$ order autoregression, AR(p), ard reads:

$$
\mathbf{x}_{i}=\mathbf{c}+\Phi_{1} \mathbf{x}_{t-1}+\Phi_{2} \mathbf{x}_{t-1}+\ldots+\Phi_{p} \mathbf{x}_{t-p}+\epsilon_{t}
$$

The vector $\mathrm{x}_{t}$ contains the observed values at time $t$ of $n$ variables. Furthermore, $\mathrm{c}$ is a $(n \times 1)$ vector of constants, and $\boldsymbol{\Phi}_{j}$ denotes a $(n \times n)$ matrix of autoregressive coefficients for $j=1,2, \ldots p$. The error terms in Equation $(6.1), \epsilon_{i,}$ are serially uncorrelated, with mean zero, and covariance matrix $\mathbf{\Sigma}$. Without restrictions on the parameters, this vector autoregression can be estimated with $n$ Ordinary Least Squares regressions where each regression has the same set of explanatory variables. ${ }^{1}$

The validity of the VAR analysis depends on the stationarity of the time series. If a time serics has a unit root, one can take first differences before including it in the VAR model. Alternatively, if two unit root processes are cointegrated, a stationary linear combination of these variables can be found which can be included in the VAR model. ${ }^{2}$ See Engle and Granger (1987), Johansen (1988) and Hamilton (1994) for a discussion on cointegration and unit roots. Campbell and Perron (1991) is as useful, non-technical primer on these issues.

In this chapter, we do not report the estimated VAR parameters because the linear dynauics of a VAR model are better illustrated with impulse response functions and variance decompositions.

An impulse response function describes the reaction of all included variables to a shock in one of them. To derive the impulse response function it is helpful to first rewrite the

\footnotetext{
TFor a more detailed explanation of vector autoregressions see familton (1994).

${ }^{2}$ The cointegrating vectors of the interest rates analyged in this chapter are of the form $(1,-1)$, such that the spreads are stationary. The permanent effect of a shock in one of the variables is therefore the same for each variable.
} 
VAR $(p)$ process in its companion form. ${ }^{2}$ Suppressing constiants the companion form reads:

$$
\begin{aligned}
\boldsymbol{\xi}_{t} & =\mathbf{F} \boldsymbol{\xi}_{-t-1}+\mathbf{G} \boldsymbol{\varepsilon}_{t,} \\
\mathbf{x}_{t} & =\mathbf{H} \boldsymbol{\xi}_{t},
\end{aligned}
$$

where

$$
\begin{aligned}
& \underset{(n p \times 1)}{\boldsymbol{\xi}_{t}} \equiv\left(\begin{array}{l}
\mathrm{x}_{t} \\
\mathrm{x}_{t-1} \\
\vdots \\
\mathrm{x}_{t-p+1}
\end{array}\right) \\
& \underset{\left(m p \times n_{p}\right)}{\mathbf{F}} \equiv\left(\begin{array}{llllll}
\boldsymbol{\Phi}_{1} & \boldsymbol{\Phi}_{2} & \boldsymbol{\Phi}_{3} & \cdots & \boldsymbol{\Phi}_{p-1} & \boldsymbol{\Phi}_{p} \\
\mathbf{I}_{n} & 0 & 0 & \cdots & 0 & 0 \\
0 & \mathbf{I}_{n} & 0 & \cdots & 0 & 0 \\
\vdots & \vdots & \vdots & \ddots & \vdots & \vdots \\
0 & 0 & 0 & \cdots & \mathbf{I}_{n} & 0
\end{array}\right), \\
& \underset{(n p \times n)}{\mathbf{G}_{n \rightarrow}} \equiv\left(\begin{array}{c}
\mathbf{I} \\
\mathbf{0} \\
\vdots \\
0
\end{array}\right) \\
& \underset{(n \times n p)}{\mathbf{H}} \equiv\left(\begin{array}{llll}
\mathbf{I} & 0 & \cdots & 0
\end{array}\right),
\end{aligned}
$$

and $\varepsilon_{t}$ is an $(n \times 1)$ vector of residuals. By recursive substitution, Equation (6.2) can be brought to:

$$
\boldsymbol{\xi}_{t+s}=\mathbf{G} \varepsilon_{t+s}+\mathbf{F G} \varepsilon_{i+s-1}+\mathbf{F}^{2} \mathbf{G} \varepsilon_{t+s-2}+\ldots+\mathbf{F}^{s-1} \mathbf{G} \varepsilon_{t+1}+\mathbf{F}^{s} \boldsymbol{\xi}_{i} .
$$

If the eigenvalues of $\mathbf{F}$ are all inside the unit circle, then $\lim _{s \rightarrow \infty} \mathbf{F}^{s} \rightarrow 0$ and the VAR model can be written as an infinite order Moving Average process:

$$
\begin{aligned}
\mathbf{x}_{t} & =\varepsilon_{t}+\tilde{\mathbf{\Psi}}_{1} \varepsilon_{t-1}+\tilde{\mathbf{\Psi}}_{2} \varepsilon_{t-2}+\tilde{\boldsymbol{\Psi}}_{3} \varepsilon_{t-3}+\ldots \\
& =\sum_{s=0}^{\infty} \tilde{\mathbf{\Psi}}_{s} \varepsilon_{t-s} \\
& =\sum_{s=0}^{\infty}\left(\tilde{\boldsymbol{\Psi}}_{s} \mathbf{L}\right) \boldsymbol{\eta}_{t-s t} \\
& =\sum_{s=0}^{\infty} \boldsymbol{\Psi}_{s} \boldsymbol{\eta}_{t-s}
\end{aligned}
$$

\footnotetext{
${ }^{3}$ Before rewriting the unit root specification we imposed an additional restriction on the constant tems of the VAR model to exclude dirifts in the interest rates.
} 
where

$$
\begin{aligned}
\varepsilon_{t-s} & =\mathbf{L} \eta_{t-s}, \\
\boldsymbol{\Psi}_{s} & =\tilde{\boldsymbol{\Psi}}_{s} \mathbf{L}_{s} \\
E\left[\boldsymbol{\eta}_{t-s} \boldsymbol{\eta}_{t-s}^{\prime} \mid\right. & =\mathbf{I}
\end{aligned}
$$

and the matrix $\mathbf{L}$ is the Choleski decomposition of the estimated covariance matrix: $\tilde{\Sigma}(p)=$ $\mathbf{L} L^{\prime}$, with $\mathbf{L}$ being a lower triangular matrix. Since $\mathrm{L}$ is a lower triangular matrix the ordering of the variables is of great importance. Changing the order results in a different

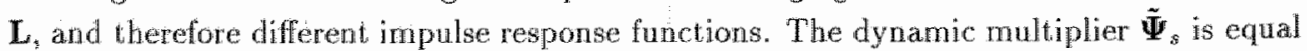
to $\mathrm{HF}^{y} \mathrm{G}$. Element $(i, j)$ of the matrix $\boldsymbol{\Psi}_{s}$ is the response of the $z^{t / h}$ element of $\mathrm{x}_{t+s}$ on an increase in the $j^{\text {th }}$ element of $\eta_{t}$. A plot of this element as a function of $s$ is referred to as the impulse response function.

The key question that can be addressed with impulse response functions is how ank unexpected shock in one variable at time $t$ will cause us to revise the predictions for the future values of the separate variables. More formally, we are estimating:

$$
\boldsymbol{\Psi}_{s,}\left(i_{i} j\right)=\frac{\partial E\left(x_{i, t+s} \mid \boldsymbol{\eta}_{\left.\mathrm{j}, t, \mathbf{I}_{\mathrm{t}-\mathbf{1}}\right)}\right.}{\partial \boldsymbol{\eta}_{\mathrm{j}, \mathrm{t}}}
$$

Here $\boldsymbol{\Psi}_{a}(i, j)$ is element $(i, j)$ of the matrix $\boldsymbol{\Psi}_{s,} i$ is the variable whose response to the unexpected change of shock $j$ is analyzed, with $i, j \in \mathbb{1}, \ldots n . \mathbf{I}_{i-1}$ is the set of information at time $t-1$ on which the expectations of $x_{j, t}$ were based. This intormation set does include the lagged history of $x_{t}$.

The representation of the VAR model applied in the impulse response analysis provides another way to analyze the inter-relationships within a system of variables. Given Equation (6.11), the error in forecasting a VAR model s periods-ahead can be assigned to innovations in specific variables. By decomposing the variance in this way, we get more insight into the retitive importance of the random shocks.

The erro" of the s periods-ahead torecast in a VAR model is:

$$
\mathbf{x}_{t+s+s}-\hat{\mathbf{x}}_{t+s}=\varepsilon_{t+s}+\boldsymbol{\Psi}_{1} \varepsilon_{t+s-1}+\boldsymbol{\Psi}_{2} \varepsilon_{t+s-2}+\mathbf{\Psi}_{3} \varepsilon_{t+s-3}+\ldots+\boldsymbol{\Psi}_{s-1} \varepsilon_{t+1}
$$

such that the Mean Squared Error of this forecast is:

$$
\begin{aligned}
\operatorname{MSE}\left(\hat{\mathbf{x}}_{t+s}\right) & =E\left[\left(\mathbf{x}_{t+s}-\hat{\mathbf{x}}_{t+s}\right)\left(\mathbf{x}_{t+s}-\hat{\mathbf{x}}_{t+s}\right)^{\prime}\right] \\
& =\Sigma+\boldsymbol{\Psi}_{1} \Sigma \boldsymbol{\Psi}_{1}^{\prime}+\boldsymbol{\Psi}_{2} \mathbf{\Sigma} \mathbf{\Psi}_{2}^{\prime}+\ldots+\boldsymbol{\Psi}_{s-1} \mathbf{\Sigma} \boldsymbol{\Psi}_{s-1}^{\prime} .
\end{aligned}
$$

Since $\mathbf{\Sigma}=\mathbf{L} \mathbf{L}^{\prime}$ Equation $(6.17)$ can be rewritten as:

$$
\begin{aligned}
\operatorname{MSE}\left(\hat{\mathbf{x}}_{t+s}\right) & =\sum_{j=1}^{n} l_{j} l_{j}^{\prime}+\boldsymbol{\Psi}_{1} l_{j} l_{j}^{\prime} \boldsymbol{\Psi}_{1}^{\prime}+\mathbf{\Psi}_{2} l_{j} l_{j}^{\prime} \mathbf{\Psi}_{2}^{\prime}+\ldots+\mathbf{\Psi}_{5-1} l_{j} l_{j}^{\prime} \mathbf{\Psi}_{s-1}^{\prime}, \\
& =\sum_{t=0}^{s-1} \sum_{j=1}^{n} \boldsymbol{\Psi}_{t} l_{j} l_{j}^{\prime} \mathbf{\Psi}_{i}^{\prime}
\end{aligned}
$$


where $l_{j}$ is the $j^{\text {th }}$ column of the lower triangular matrix $\mathbf{L}$. The $m^{\text {th }}$ diagonal elenent of this matrix $\operatorname{MSE}\left(\hat{\mathbf{x}}_{t+s}\right)$ is the variance of the s periods ahead forecast of variable $m$. The contribution of innovations in the $k^{\text {th }}$ variable to this variance is given by the $m^{\text {th }}$ diagonal element $\sum_{t=0}^{s-1} \mathbf{\Psi}_{t} l_{k} l_{k}^{r} \mathbf{\Psi}_{t}^{\prime}$. This way the forecast error variance can be decomposed into the components accounted for by shocks in the individual variables.

\subsection{Description of the data}

The empirical analysis in this paper is based on a system of time serves of the shortterm interest rate, the long-term interest rate and the mortgage rate. The perjod under investigation runs from January 1972 to December 1995.

From Jaruary 1972 to April 1980 , the return on one-month loans to local authorities is used as the short-term interest rate." From April 1980 on, the one-momth Holland Interbank rate is used. Both time series are end-of-month observations and are identical during the period for which we have data on both tirne series. The long-term interest rate is the yield on government bonds with a remaining time to maturity of 5 to 8 years. This time to maturity resembles the period during which the contract rate of most Dutch mortgages is fixed. For the mortgage rate we consider annuity-mortgage contracts whose contract rates are fixed for 5 years while the maturities are equal to 30 years. The Holland Interbank rate, the yield on government bonds and the mortgage rates are obtained from Datastream.

The time series are plotted on the left-hand side of Figure 6.1. As can be seen from the top left drawing, the short-term interest rate time series has two outliers. In September and October 1976 the one-month interest rate reached a level of 18 percent white shorty before and after these two months the interest rate was at a more normal, and therefore lower, level. As reported by Schotman (1989), these months are known for the tunult on the European exchange markets.

Additionally, it can be deduced from the right-hand diagrams of Figure 6.1 that the yield curve was frequently inverse in the late seventies and early eighties. This phenomenon also occurred in the early nineties. In those periods with inverse term structures, whe short term interest rate was occasionally even higher than the morlgage rate. In the 24 years with monthly observations, the short-term interest rate exceds the mortgage rate in 26 months. Especially remarkable in this respect is 1992 . During most of that year, the levels of the short-term interest rate and the mortgage rate followed each other closely. The long-term interest rate, however, was often a most I percentage point below that level. Besides these periods with inverse term structures, we observe that in May and June 1976 the long-term interest rate was higher than the mortgage rate.

The top right conner of Figure 6.1 suggests heteroskedasticity in the volatility of the first differences of the short-term interest rate. This can result in an inconsistent estimation

4he time series of the return on one-month loans to local authorities has been constructed by fian and Rowwenhorst (1985) and was analyzed in depth by Schotman (1989). 
Nominol onemonth interest rote

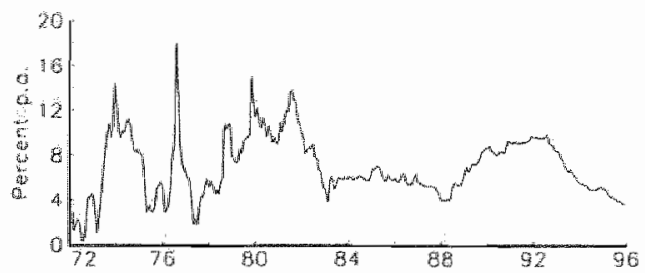

rield on bonds with molurity $5-8$ years
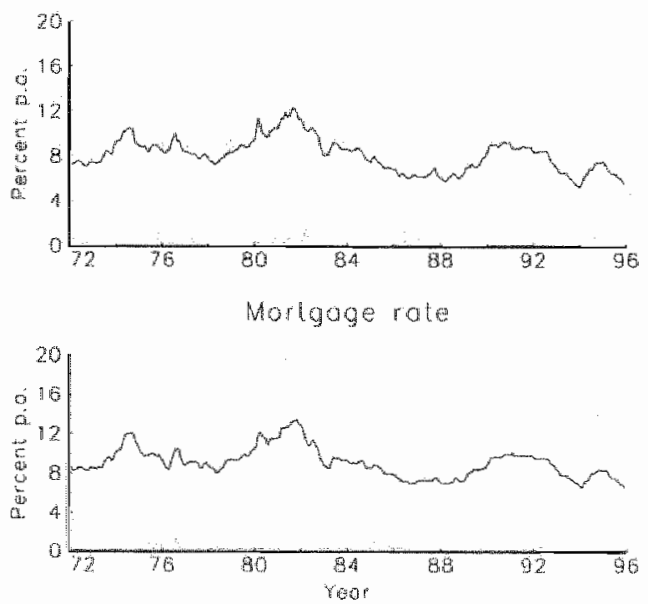

change in one-month interest rote

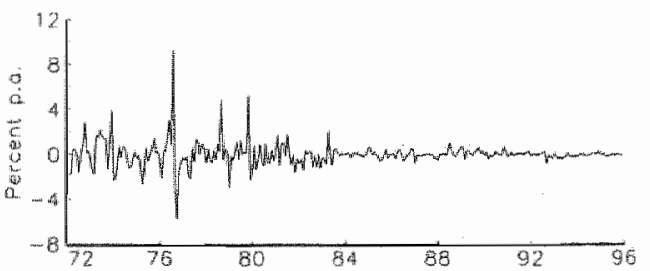

Bond spreod
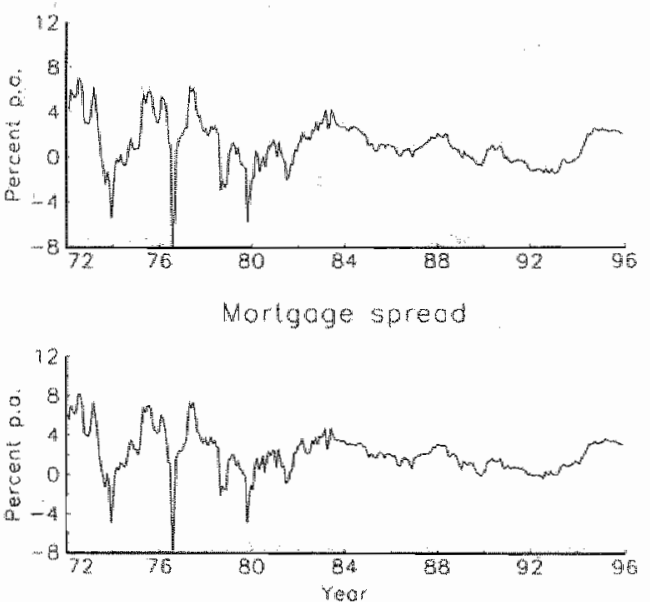

\section{FigURE 6.1: TIME SERIES OF INTEREST RATES}

The lefthand diagrans of this figure show the short-term, long-term and mortgage interest rates, respectively. The right-hand diagrams illustrate the monthly fluctuations in the short-term interest rate, the differences betweell the long-term sind short-term interest rates and the spread between the mortgage rate and the short-term interest rate. 
TABLE 6.1: SUMMARY STATISTICS OF INTEREST RATES, JAN.1972-DEC.1995

\begin{tabular}{lcccccc}
\hline & $r$ & $l$ & $y$ & $\Delta r$ & $l-r$ & $y-r$ \\
\hline Mean & 6.95 & 8.12 & 9.08 & -0.01 & 1.17 & 2.13 \\
Maximum & 18.00 & 12.30 & 13.45 & 9.25 & 7.10 & 8.13 \\
Mimimum & 0.38 & 5.27 & 6.51 & -5.75 & -7.97 & -7.75 \\
Stiand. Dev. & 2.77 & 1.47 & 1.49 & 1.15 & 2.14 & 2.11 \\
Skewness & 0.47 & 0.43 & 0.73 & 1.99 & -0.07 & -0.14 \\
Kurtosis & 3.49 & 2.86 & 3.24 & 21.96 & 4.54 & 5.37 \\
ADF & $-4.10^{* * *}$ & -1.90 & -2.02 & $-9.96^{* * *}$ & $-4.94^{* * * *}$ & $-5.05^{* * * *}$
\end{tabular}

The first thee columns report whe statistics of the short-term interest rate, the long-term interest rate and the mortgage rate, pespectively. These rates are expressed in percentages per annum. The fourth column presents the statistics of the first differences of the short-term interest rate, while for the following two columns the short-term interest rate is subtracted from the longterm interest rate and the mortgage rate, respectively. The skewness of a series $x_{t}$ is calculated as $S K=\frac{1}{\sigma_{x}^{3}} \frac{1}{T} \sum_{t=0}^{T}\left[\left(x_{t}-\tilde{x}\right)^{3}\right]$, where $T$ is the number of observations. The thickness of the tails is measured by the kurtosis: $K V=$ $\frac{1}{0_{N}^{4}} \frac{1}{T} \sum_{t=0}^{T}\left[\left(x_{t}-\dot{x}\right)^{4}\right]$. The Augmented Dickey-Fuller (ADF) test is applied two test for the null hypothesis of a unit root. One asterisk denoties significance at a $10 \%$ level, two asterisks at a $5 \%$ level and three at a $1 \%$ level.

of the standard errors of the parameters in the VAR system. In order to correct for this a White procedure is applied.

The bottom right corner of Figure 6.1 shows the historical spread between the mortgage rate and the short-term interest rates in the Netherlands. For the period 1981-1994, this spread is compared with its American counterpart in Figure 5.3 of Section 5.5 . There we also present the summary statistics of this spread for both countries.

Table 6.1 provides descriptive statistics for each of the series. In this paper the Aug mented Dickey-Fuller (ADF) test is applied to test for the null hypothesis of a unit root." If the absolute value of the ADF-statistic is larger than the critical value the hypothesis of a unit root can be rejected. If we concentrate on the level of the interest rates, Table 6.1 shows that the non-stationarity hypothesis can be rejected for the one-month interest rate, but not for the other interest rates. Table 6.1 also reports the ADF-statistics of time series after transformation. As shown by Camplell and Shillen (1.987), simple first differencing of all variables can lead to econometric problems. Hence, we utilize the spreads between the different yields rather than the first differences of the long-term interest rate and mortgage rate. This assumes that the lewels of $y$ and $r$ are cointegrated.

The unit root tests summarized by the ADF-statistics in Tabile 6.1 are inconsistent with each other. A linear transformation of two stationary processes has to be stationary as well. Since we find that the short-term interest rate is a stationary process, just like the

5 Figure 6.1 suggest that structiral breaks may have occured in both the inberest atse levels and apreads. "This might bias the ADF tesi. See Perron $(1989,1993)$ for a discusion on this topic. 
spread between the different yields and the short-term interest rate, we would expect the different yelds to be stationary as well. This does not conform with the results in Table 6.1, however. Unit roots lests like the Augmented Dickey-Fuller test have frequently been questioned in the literature. For example, Cochrane (1991) warns against an excessively strict application of these kinds of tests such that we have to be careful with drawing strong conclusions based on the ADP statistics.

TABLE 6.2: CORRELATION MATRIX OF INTEREST ITATES, JAN. 1972-DEC 1995

\begin{tabular}{lccccccccc}
\hline & $r$ & $\Delta r$ & $l$ & $\Delta l$ & $y$ & $\Delta y$ & $l-r$ & $\Delta(l-r)$ & $y-r$ \\
\hline$r$ & 1 & & & & & & & & \\
$\Delta r$ & 0.20 & 1 & & & & & & \\
$l$ & 0.64 & -0.00 & 1 & & & & & & \\
$\Delta l$ & 0.16 & 0.31 & 0.12 & 1 & & & & & \\
$y$ & 0.66 & -0.06 & 0.97 & -0.01 & 1 & & & & \\
$\Delta y$ & 0.24 & 0.14 & 0.18 & 0.57 & 0.12 & 1 & & & \\
$l-r$ & -0.85 & -0.27 & -0.15 & -0.12 & -0.19 & -0.19 & 1 & & \\
$\Delta(l-r)$ & -0.17 & -0.97 & 0.03 & -0.07 & 0.06 & 0.00 & 0.25 & 1 & \\
$y-r$ & -0.85 & -0.31 & -0.16 & -0.21 & -0.16 & -0.23 & 0.99 & 0.27 & 1 \\
$\Delta(y-r)$ & -0.15 & -0.97 & 0.04 & -0.18 & 0.09 & 0.09 & 0.23 & 0.98 & 0.26
\end{tabular}

The table reports the correl ation coefficients between the interest rates in different specifications.

Table 6.2 reports the correlation coefficients between the variables, their first differences and the spreads between the long and short-term interest rate and the mortgage rate and short-term interest rate. Table 6.2 illustrates the higly correlation between the level of the short-tem interest rate, the long-term interest rate and the mortgage rate. It especially appears that the long-term interest rate and the mortgage rate follow each other closely. When looking at the first differences we see that the correlations of the short-term interest rate with both the long-term interest rate and mortgage rate decrease considerably, while 1he cortation coefficient of the long term interest rate and mortgage rate remains high. Table 6.2 therefore indicates that monthly fuctuations of the long-term interest rates and morkgage rates are more or less independent of changes in the short-term interest rate. This suggests that a second factor is needed to model the mortgage rate dynamics accurately.

As there is some cloubt about the stationarity of a levels specification, we analyze a VAR model in levels as well as a cointegrated system. In the first specification we include the level of the short-lerm interest rate and the spread between the yield on govermment bonds with a raturity of 5 to 8 years and the shorterm interest rate, wh well as the spread between the mortgage rate and the short-term interest rate. We refer to this VAR model as lhe stationary specifaction. This specification corresponds with the mean-reversion literature which states that shocks in the short-term interest rate have no permanent effect. The short-term interest rate returns eventually to its unconditional mean. This first specification can be rewritten in a VAR system based on the levels of the three interest rates. 
In the second version of the model, the spreads are analyzed together with the first diferences in the short-tem interest rate. A shock in this latter variable has a permanent effect on the level of the short-term interest rate. Once the shock to $\Delta r$ is died out, $\Delta r$ will return to its equilibrium, while the level of $r$ has undergone a permanent shift, c.g. in the new equilibrium there are no further changes in $x$ but the cumulative change $\sum_{t=0}^{r} \Delta r_{t}$ is not zero. Hence, this model has a unit nook and two cointegrating vectors and is referred to as the whit root specification. Other models which allow for a greater number of unit roots are empirically rejected in Table 6.1. The spreads are already stationary so that checking for more unit roots is superfluous. Moreover, those models are less relevant from an economic point of view, and are therefore left out of this analysis.

\subsection{VAR analysis}

\subsubsection{Determining the order}

A VAR analysis starts with the determination of the number of lags that have to be included in the system. Here we determine the optimal order $p$ by minimizing the Akaike's information criterion $A I C$ :

$$
A I C(p)=\ln |\tilde{\Sigma}(p)|+\frac{2 n^{2} p}{T}
$$

were $\tilde{\mathbf{\Sigma}}(p)$ is the maximum likelihood estimator of the error covariance matrix, $n$ is the number of variables in the system, and $T$ is the number of observations. For the stationary specification of the VAR model we found that the optimal order p equals 2 , for the unit root specification the order was found to be $p=3$.

\subsubsection{Granger causality}

The first test we apply to study the dynamic interactions between the interest rate variables is the Granger causality test. With this test we survey whether only the short term interest rate has explanatory power or that fluctuations in the short-term interest rate can be explained by information regarding the long-term interest rate and the mortgage rate. In other words, the direction of causality between variables is investigated. Does the shortterm interest rate cause the mortgage rate? Does the mortgage rate cause the short-term interest rate? $\mathrm{Or}$ is it the long-term interest rate that causes the mortigage vate? Question like these can be studied with the causality test developed by Granger (1969), hence the term Granger causclity.

A variable $w_{2}$ is said to be Grangerwansed by a variable $z_{\text {, }}$ if the predictions of we can be improwed by including the history of $z_{t}$ in the information set used for the prediction of $w_{*}$. More formally, the variable $z_{t}$ is Granger-casal for the variable $w_{t}$ if

$$
\sigma^{2}\left(w_{t} \mid \mathbf{X}_{t}, \mathbf{Z}_{t}\right)<\sigma^{2}\left(w_{t} \mid \mathbf{X}_{t}\right)
$$


where

$$
\begin{aligned}
& \mathbf{X}_{t}=\left\{x_{i}, x_{t-1}, \ldots\right\} \\
& \mathbf{Z}_{t}=\left\{z_{t}, z_{t-1}, \ldots\right\} \\
& \mathbf{Z}_{t} \neq \mathbf{X}_{t}
\end{aligned}
$$

and $\sigma^{2}$ represents the conditional wariance of $w_{i}$.

In a VAR framework testing for Granger causality comes down to a joint test for the estimated coeficients in the VAR system to be equal to zero. That is, to analyze if the first variable in the VAR model Granger-causes the second variable, we have to test the null hypothesis that the parameters corresponding with the first variable in the second OLS regression in the VAR system, are equal to zero. The test statistic is a Wald test with $p$ and $T-p n-1$ degrees of freedom.

The results of the Granger causality tests are summarized in Table 6.3. Since the level of the short-term interest rate and the first differences of this rate are not included in the same specification of the VAR model, there are no results available for the Granger

\begin{tabular}{|c|c|c|c|c|c|}
\hline \multicolumn{2}{|c|}{ Jan.72-Dec.95 } & \multicolumn{4}{|c|}{ to } \\
\hline & & $r$ & $\Delta r$ & $1-r$ & $y-r^{\prime \prime}$ \\
\hline \multirow{4}{*}{ from } & $r$ & $\bullet$ & N.A. & 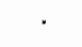 & $\cdot$ \\
\hline & $\Delta r$ & N.A. & $\varnothing$ & . & . \\
\hline & $l-r$ & $\cdot$ & . & - & $\theta$ \\
\hline & $y-r$ & 0 & . & $?$ & $\bullet$ \\
\hline
\end{tabular}
causality test between these two variables.

TABLE 6.3: GPANGER CAUSALITY TESTS

The tables show the results of the Granger causality $A$ dot undicates that in both VAR-models the row-variable Grangercauses the column-wariale at a significance level of $1 \%$, a dianond denotes significance at a $10 \%$ level. The question mark denotes that the test results differ between the two VARmoclets, and a period means that the row-variatile Grangercauses the column-variable in neither VAP model.

Table 6.3 sthows that the history of each variable contains information that can help to improve the forccast of its own current value. "The mutual relations between the economic variables are less unequivocal. In the stationary specification of the VAR model, the spread between the mortgage rate and the short-term interest rate Granger-causes the spread on long-term government bonds. However, this Granger causality is non-existing in the unit root specification. At a $10 \%$ significance level the tem structure spread Granger-causes the mortgage spread, while in its turn the spread on mortgages Granger-causes the shortterm interest rates. Hence, the spread on long-term government bonds might indirectly Granger-cause the short-term interest rate. Impulse response functions are well-suited to analyze such indirect interactions among variables. 


\subsubsection{Impulse response functions}

An impulse response function examines the effect a shock to one of the endogenous pariables has on current and future values of all variables in the system. By studying successive shocks in the three variables we can address the question whether the dynamics of the mortgage rate can correctly be described by a one-factor interest rate model.

TABLE 6.4: OVERVIEW

\begin{tabular}{cl}
\hline Shock in & Line Type \\
\hline$r$ & solid \\
$l$ & broken \\
$y$ & dots and dashes \\
\hline
\end{tabular}

The table shows the line types corresponding with the variables as applied in the impulse response functions and the variance decompositions illiustrated in the Figures 6.2 through 6.7 .

Figure 6.2 relates to the stationary specification of the VAR model. In this impulse response analysis the first shock occurs in the short-term interest rate. The size of this shock equals the standard deviation of the residuals in the short-term interest rates, which remain unexplained by the VAR model. Note that each graph in Figure 6.2 has its own scale on the vertical axis for visual clarity.

The solid line in the upper diagram of Figure 6.2 reflects the effect a shock in the shortterm interest has on the rate itself. The mean-reversion characteristics of the short-term interest rate are obvious. The half life of a shock is 6 months. After these 6 months the shock fades further until it completely dies out. The responsiveness to the innowation in the shortwerm interest rate differs substantialy between the long-term interest rate and the mortgage rate. The mortgage rate turns out to be more sensilive to shocks in the short-term interest rate than the long-term interest rate. It holds for both interest rates that the instantaneous response is rather small, their impulse response functions reach their maximums after 2 months, while the shorterm interest rate peaks one month atter the occurrence of the shock. This lagged response is in contrast with the one-factor interest rate models which imply that the longterm interest rate and the mortgage rate should immediately move in the same direction as the short-term interest rate.

Contrary to the single factor assumption, the broken line in the lower diagram of Figure 6.2 shows that an additional shock in the long-term interest rate has an substantial effect on the level of the mortgage rate. Apparently, the long-term interest rate contains information about the mortgage rate dynamics which is not embodied in the short-term interest rate.

An additional innovation in the mortgage rate has an effect on itself but fades guickly. Since this shock occurs after the innovations in both the short and long-term interest rate have been absorbed, it is unrelated to the term structure. This shock in the mortgage rats 
Pesponse of the shom-lem interest rote

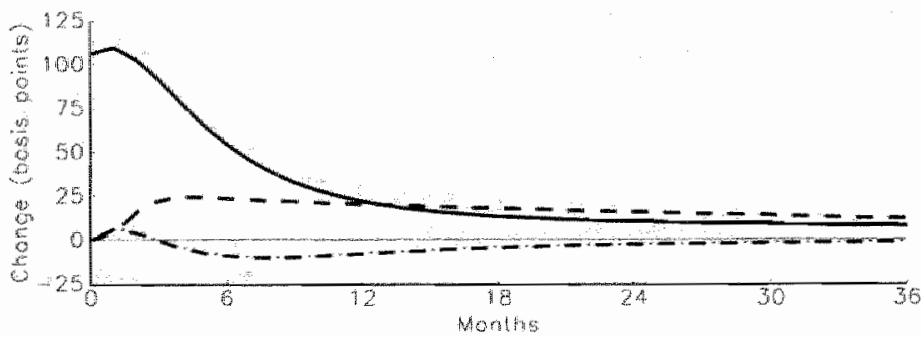

Response of the tong-lerm interest rote

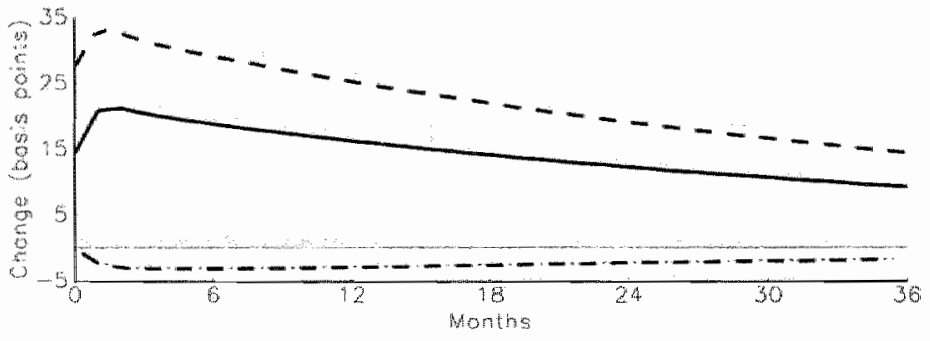

Response of the mortgoge rote

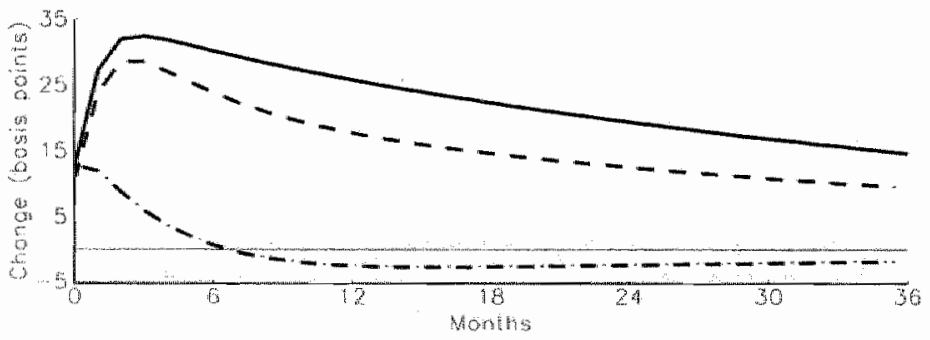

Figure 6.2: Impulse REsponse Funotions, ORdering: $r \rightarrow 1 \rightarrow y$

The sold line in the upper diagman refects the fect a shock in the short-term interest rate has on the shont-tem interest rate itself. Hn the midlle diagram, this solid line ilustrates the offect a shock in the short-term intarest ate has on the long-tern interest rate, whild in the bothom diagram the efect on the mortgage rate is ithotrated. The broken line in the upper diagram shows the response of the short-term interest rate to a subsequent shock in the long-term interestitite. The line which consists of dots and dashes illustrates the response of the short-term interest rate to ghock in the mortgage rate. The lines in the middle and bottom diagrams can be interpreted similarly. This ligure is based on the stationary specincation of the WAR nodel. 
initially has a small positive effect on the short-term interest rate. However, as soon as one month later, the effect becomes negative and eventually dies out. The long-term interest rate decreases as a consequence of the shock, but the negative effect is very small.

Figure 6.2 shows the shortcomings of a single factor model to model the mortgage rate dynamics. The long-term interest rate turns ont to contain additional inlormation regarding mortgage rate fluctuations. The impact of additional inmowations in the mortgage rate itself is much smaller. These resultis can be interpreted as support for a two-factor model.

In Figure 6.2, a shock in the short-term interest rate was orthogonalized first. Often, however, economists argue that mortgage rates are related to long-term interest rates rather than short-term interest rates. To check whether a single factor model based on the longterm interest rate can correctly model the mortgage rate dynamics, we consider a second ordering. In Figure 6.3 the impulse response functions are plotted such that the innovation in the long-term interest rate is analyzed first. A shock in the short-term interest rate is analyzed second, and finally, the effects of an additional shock in the mortgage rate are studied.

The broken line in the upper pand shows that a shock in the long-term interest rate has a substantial instantaneous effect on the short-term interest rate. The long-term interest rate itself increases much less than the short-term interest ratie. The mortgage rate reacts to the shock in a similar manner as the long-term interest rate: the ffect is at its maximum two months after the shock occurred. Past this point it fades slowly, but the mortgage rate is still more than 18 basis points above its initial level after 36 months.

The solid line in the upper diagram of Figure 6.3 demonstrates that a successive innovation in the short-term interest rate has a serious effect on the short-term interest rate. The effect on the long-term interest rate is rather small and the instantaneous effect on the mortgage rate is also limited. As the lower diagram of Figure 6.3 shows, the mortgage rate reacts with a lag on an additional shock in the short-term interest ratie. Finally, in this ordering of the variables, the effects of a shock in the mortgage rate are similar to the effects such a shock had in the previous ordering.

The results suggest that significant improvements can be achieved by using a two-factor model to describe the mortgage rate dynamics.

In Figure 6.4, the impulse response functions are plotted for the unit rool specificalion of the VAR model. A shock in the short-term interest rate has a permanent effect on its level. By construction it also has a permanent effect of the same size on the level of both the long-term interest rate and the mortgage rate. The innovation in the short-term interest rate results therefore in an increase of each of the three interest rates by almost. 18 basis points.

The solid lines in the middle and bottom graphs clearly illustrate the lagged response of the long term interest rate and the mortgage rate on shocks in the short-tern interest rate. A one factor model thus los serious shortcomings in this setting as well. This is also demonstrated by the broken lines in Figure 6.4, which show the responses of an additional 


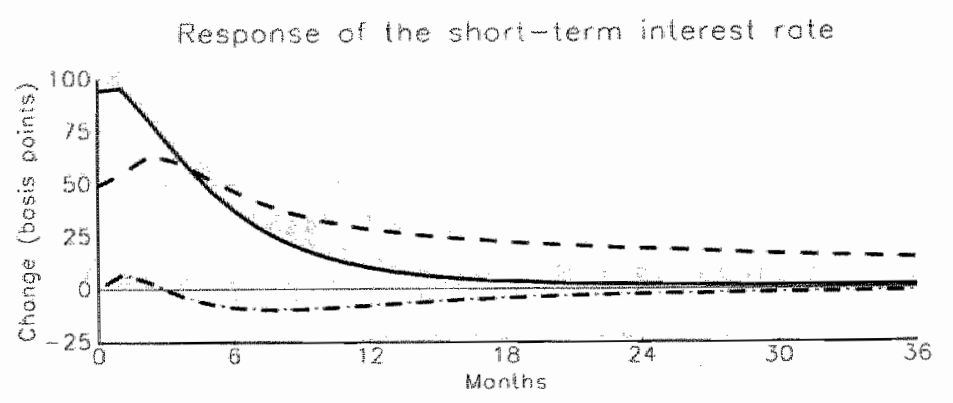

Response of the long-term interest rote

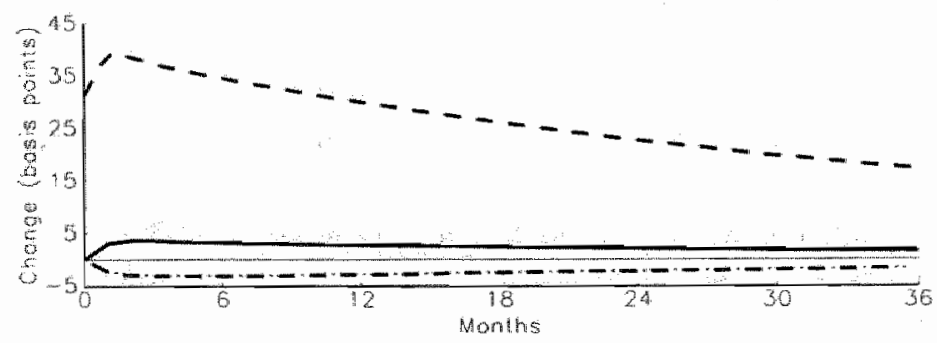

Response of the mortgage rote

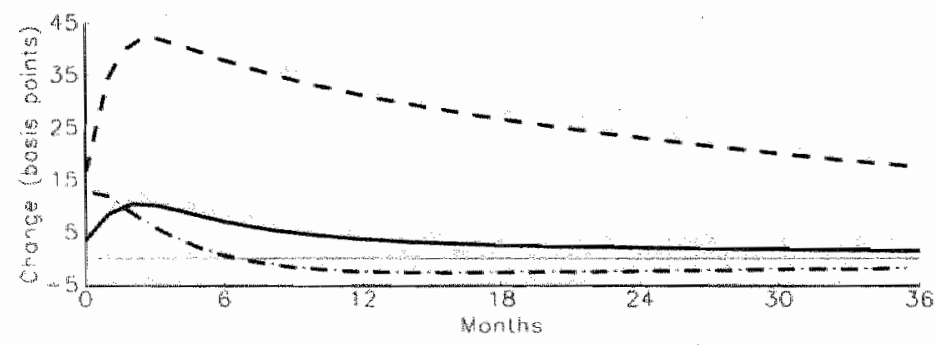

Figune 6.3: ImPULSE RESPONSE FUNCTIONS, ORDERING: $l \rightarrow r \rightarrow y$

For an explatution of the lines see Table 6.4 and Figure 6.2. Note that hert ine wariables are ordered differently. This figure is based on the stationary specification of the VAR nodel. 

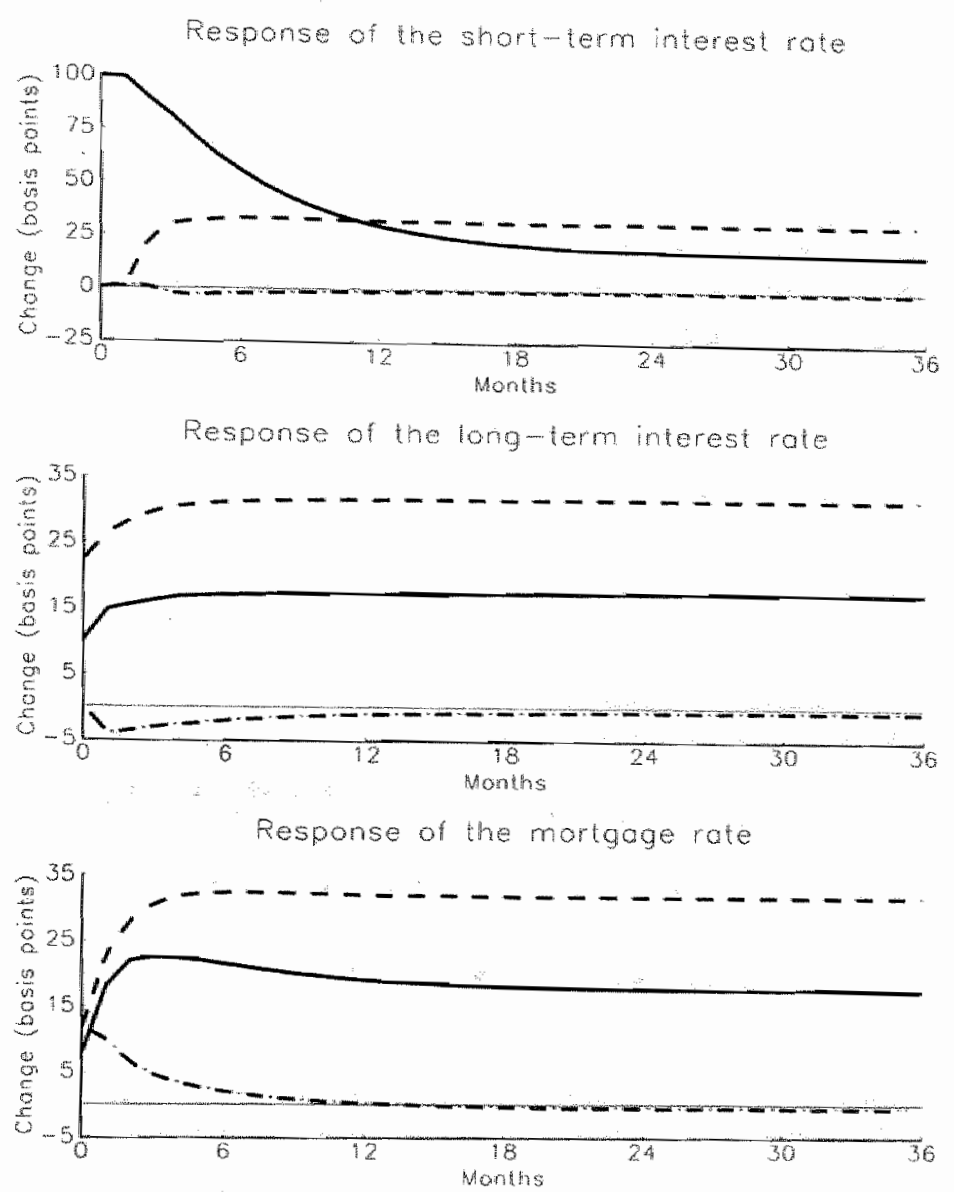

Figure 6.4: ImpUlse Response Functons, ordening: $r \rightarrow 1 \rightarrow y$

The solid line in the upper diagram reflects the effect a shock in the first diffurences of the short-term interest rate has on the level of the shortim interest rate. In the middle diagram, this solid line jlustrates the effect such a sock has on the long-tern interest rate, while in the bottom diagram the effect on the mortgage rate is illustrated. The broken line in the upper diagram shows the response of the short-term iruterest rate to a subsequent shock in the long-term interest rate. The line which consists of dots and dashes illustrates the response of the short-term interest rate to a shock in the morgage rate. The lines in the middle and bottom diagrams can be interpreted similarly. This figure is based on the unit root specification of the VAll model. 
shock in the long-term interest rate. This successive shock has a substantial and permanent effect on all three interest rates, thereby stressing the importance of a second factor.

A thind shock, this time in the mortgage rate, has only a temporary effect. After one year the effects of this shock almost completely die out for all three interest rates.

Pesponse of he short-term interest rate

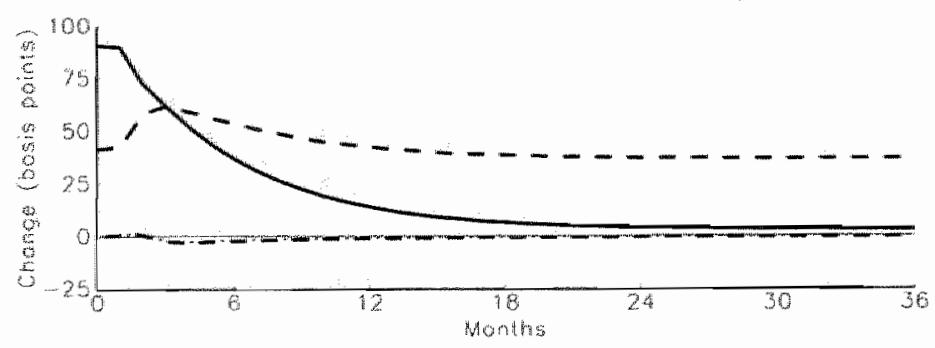

Response of the long-ierm interest rote

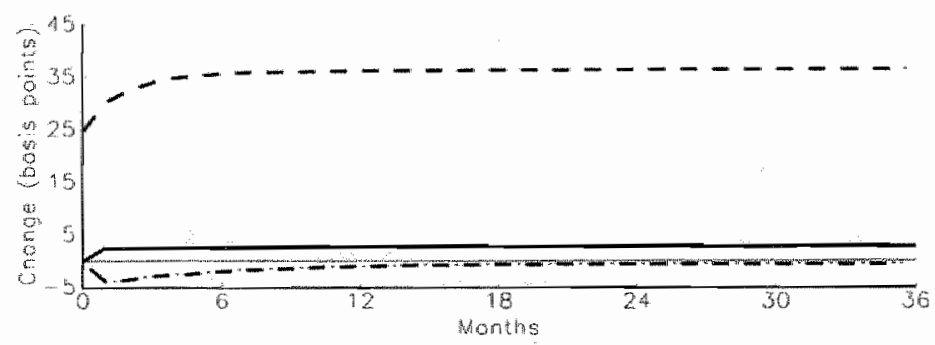

Response of the mortgage rote

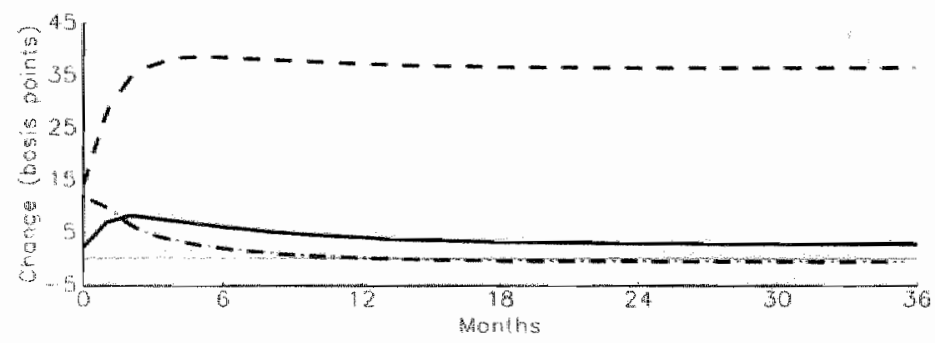

FIGURE 6.5: IMPULSE RESPONSE FUnCTIONS, ORdering: $l \rightarrow r \rightarrow y$

For an explanation of the lines see Table 6.4 and Figure 6.4. Note that here the wariables are ordered differentily. This figure is based on the unit root specification of the VAR model.

Changing the order in which shocks occur in the unit root specification of the VAR model results in the impulse response functions plotted in Figure 6.5. Here a shock in the long-tem interest rate is orthogonalized first. The broken lines in Figure 6.5 represent the effects this shock thas on the endogenous variables. As a results of this innovation the three 
interest rates increase by 36 basis points. This new level is reached rather quichly by the separate interest rates. The fuctuation in the mortgage rate due to the initial shock in the long-term interest rate is quite small after 6 months.

The long run effect of a successive shock in the short-term interest rate is much smaller. Initially, the short-term interest rate increases substantially. This effect fades fast, however, and after three years the remaining impact is less than 3 basis points. The long run effects of a shock in the mortgage rate are even smaller: 40.6 basis points.

In this specification of the VAR model, a one-factor model with the long-term interest rate as the leading indicator seems to describe the long run dymamics of the mortgage tate rather well. However, as Figure 6.5 illustrates, over the short run the effects of a luctuating short-term interest rate can not be neglected.

To conclude, even though one-factor interest rate models allow mathenatical deriva." tions of deterministic equations to price interest rate derivatives, the results in this subsection indicate that a single factor does not correctly describe the dynamics of the interest rate term structure and that more factors should be inchuded.

\subsubsection{Variance decompositions}

Variance decompositions isolate the relative importance of random shocks to the forecast errors of the wariables. Given Equation 6.18, the error variance of the s periods-abeacl forecast of a variable can be decomposed into the components accounted for by shocks in the individual variables. In other words, the forecast uncertainty is assigned to the separate variables in the system. The single factor assumption prescribes that the forecast errors of the interest rates included in our VAR system depend solely on the short-term interest. rate. Whether this is true or not is studied in this subsection.

Similar to the impulse response functions, the variance decomposition analysis depends heavily on the ordering of the variables. The orderings worked out in Figures 6.6 and 6.7 are summarized in Table 6.5 .

Table 6.5: Ordering

\begin{tabular}{ccc} 
Graphs & \multicolumn{2}{c}{ Ordering } \\
\hline Left columns & $r \rightarrow l \rightarrow y$ \\
Right columns & $l \rightarrow r \rightarrow y$ \\
\hline
\end{tabular}

The tablo shows the ondering of the variables as applied in the wariance decompositions illustrated in the Figures 6.6 and 6.7 .

The variance decompositions summarized in Figure 6.6 are based on the stationary specification of the VAR model. The graphs on the left-hand side of this figure illustrate the variance decompositions when a shock in the short-term interest rate is followed by 

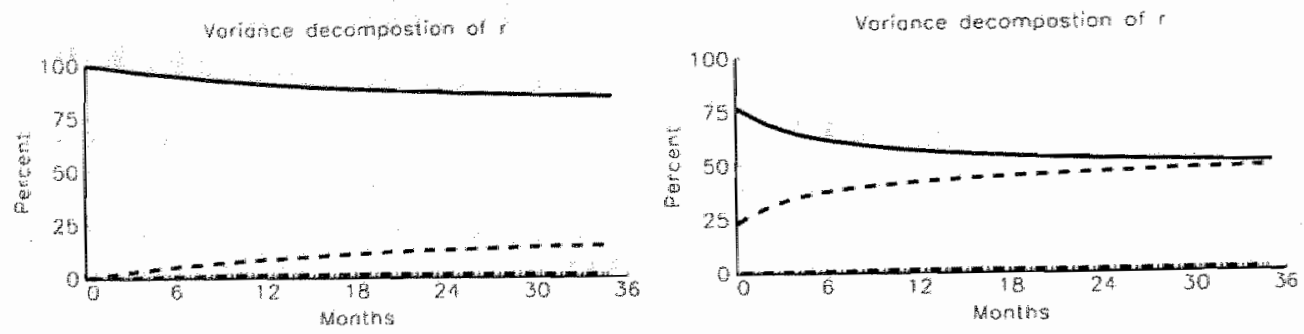

vertonce decompostion of a
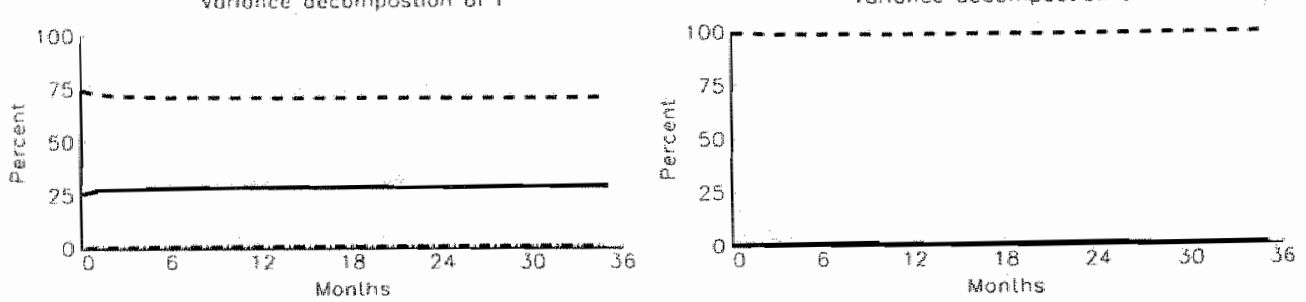

Voriunce decomposition of
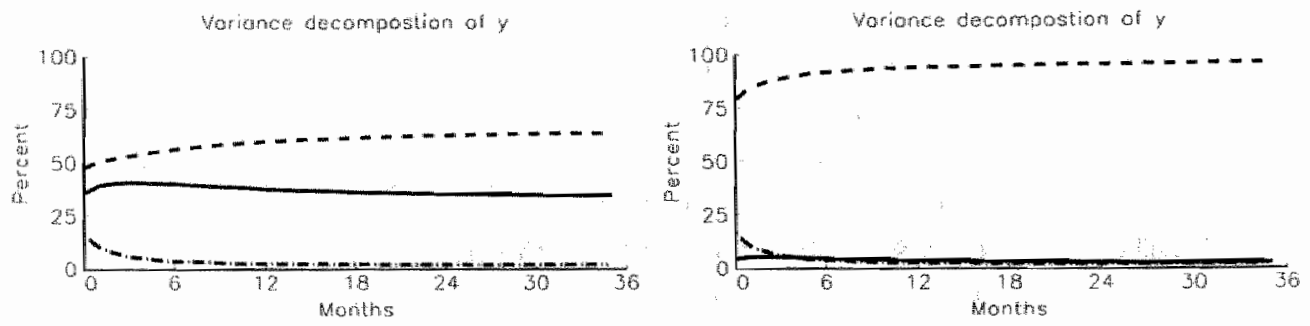

FIGURE 6.6: VARANCE DECOMPOSITION, STATIONARY PROCESS

The grath on the left-hand side of this figure illustrate the variande decompositions: when shock in the short-term interest rate is followed by an innovation in the longlem anterest rate, and suhsequenty by a shock th the mortgage rate. The right disgrans show the variane decompositions wher a shock in the long-term interest rabe is followed by an inthowation in the shorterm interest rate, and sabsequently by a shock in the rortighge rate. In keeping with Jable 6.4 , the solid lines represent the inpact of the short-tem interest rate, the broken lines refer to the long-ferm interest ate and the lines made up of dots and dashes reflect the relative importance of imowations in the mortgage rate. 
an innovation in the long-term interest rate, and subsequently by a shock in the mortgage rate. In this setting, $84 \%$ of the variance of the 36 periods-ahead forecast of the short-term interest rate is caused by Auctuations in the short-term interest rate itself. Fluctuations in the long-term interest rate explain $15 \%$ of the variance, with the remaining part being due to fluctuating mortgage rates. As the middle diagram shows, only $29 \%$ of the variance of the long-term interest rate forecast is explained by fluctuations in the short-term interest rate. Even when the long-term interest rate is orthogonalized second, it still accounts lor more than $70 \%$ of its own variance. Looking at the variance decomposition of the mortgage rate we see that $34 \%$ of the variance can be explained by fuctuations in the short-term interest rate. The majority of the variance in the mortgage rate is caused by varying long-term interest rates. If the long-tierm interest rate is orthogonalized first, $96 \%$ of the variance of the mortgage rate forecast of 36 periods-ahead is due to fluctuating long-term interest rates. This is illustrated in the bottom right-hand diagram of Figure 6.6.

The six diagrams of Figure 6.6 display that a one-factor model based on the stiont-term interest rate falls short in describing the mortgage rate dynamics. The long-term interest rate turns out to contain information about the dynamics of the mortgage rate which is not embodied in the short-term interest rate.

Figure 6.6 is based on the stationary specification of the VAR model. The wariance decompositions of the unit root specification, with $\Delta r$ replacing the level of the short-term interest rate $r$, are plotted in Figure 6.7. In this unit root specification, the influence of shocks in the long-term interest rate is larger than before. This time $35 \%$ of the variance of the 36 months-ahead forecast of the short-term interest rate can be explained by innovations in the long-term interest rate. For the variance in the long-term interest rate and mortgage rate this is 77 and $73 \%$, respectively. As the lower two panels on the left-hand side in Figure 6.7 show, the explanatory power of the short-term interest rate is much less than this.

This result becomes more obvious by changing the order in which the shocks occur. This is demonstrated by the plots on the right-hand side of Figure 6.7, where the longterm interest rate is orthogonalized first. After 36 monthe 65 percent of the variance in the short-term interest rate can be explained by a shock in the long-term rate. And this percentage continues to increase even after that time. With regard to the long-term interest rate and mortgage rate, we can conclude that in the long run, almost $100 \%$ of the variance of these wwo variables can be explained by the long-term interest rate.

Figures 6.6 and 6.7 clearly indicate that one factor interest rate models have serious shortcomings when the short-term interest rate is the leading indicator. When modelling the volatility of the mortgage rate, a single factor model based on the long-term interest: rate seems to be capable of explaining most of the long run variance. However, such a one-factor model fails to describe the short run volatility of the short-term interest rate correctly. 

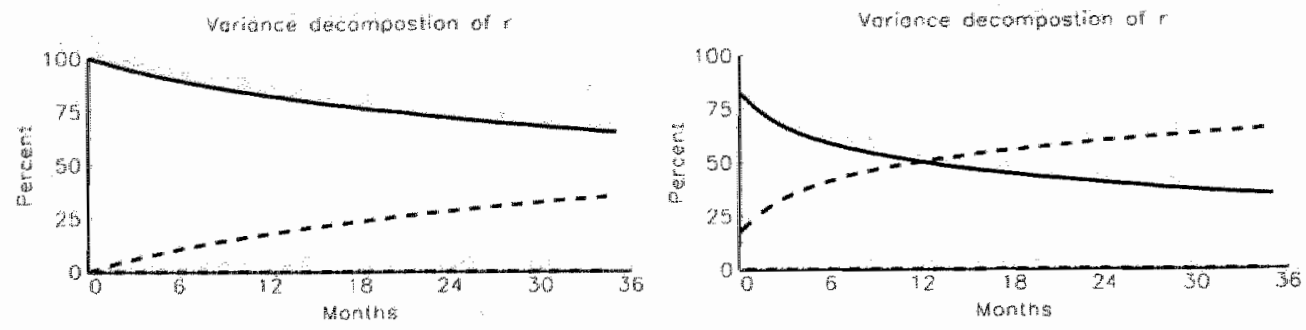

Yornome sidemposition of
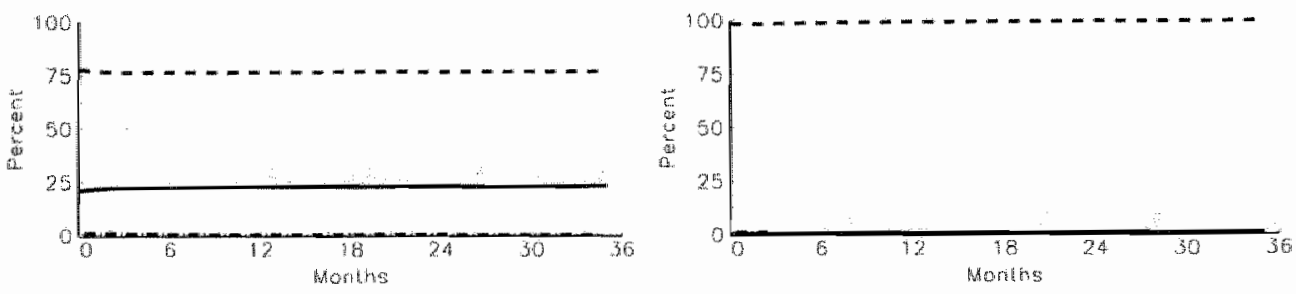

Voriones decompostion of $y$
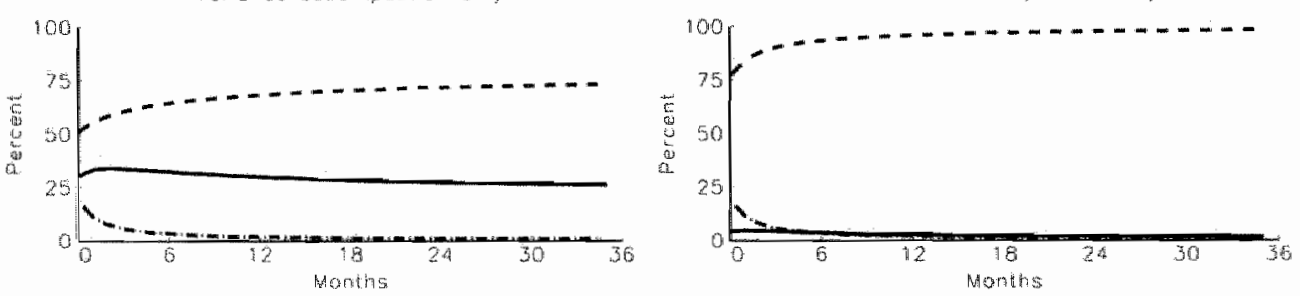

FIGURE 6.7: VARIANCE DECOMPOSTTION, UNIT ROOT PROCESS

The gaths on the left-liand side of this figure illustrate the variance decompositions when a shock in the finst difference of the shortitern interest rate is followed by an innowtion in the long-term interest rate, and subsequently by ahock in the mortgage inte. The right diagens show the variane decompositions when a shock in the longlem interest rate is followed by an innowation in the first differences of the short-term interst late, and subsequently by a shock in the mortgage rate. In keeping with Table 0.4, the solid lines represent the impact of the shortidn interest rate, the broken lines refer to the long-tern interest rate and the lines made up of dots and dashes reffect the relative importance of innowations in the mortgage rate. 


\subsection{Conclusion}

Many mortgage pricing models are based on the assumption that mortgage rate dynamics can be described by a single factor interest rate model. This chapter questions whether or not this assumption holds. For this, we analyze the empirical relation between the shortterm interest rate, the long-term interest rate, and the mortgage rate in the Netherlands. Vector AutoRegressive techniques are utilized to study the dynamic interactions between these variables.

The results of Granger causality tests, impulse response functions and variance decompositions show that single factor interest rate models have serious shortconings in describing the dynamics of the mortgage rate. For example, the Granger causality tests reveal that both the short-term and the long-term interest rate contain finformation about the mortgage rate. The impulse response functions demonstrate that innovations in the long-term interest rate have an additional effect on the level of the mortgage rate. Also, variance decompositions show that fluctuations in the long-term interest rate explain most of the variance of the mortgage rate. A one-factor model based on the long-term interest rate is therefore better capable of modelling mortgage rates than a model solely based on short-term interest rates. However, the short-run mortgage rate dynamics are better described by this latter variable.

Consequently, a one-lactor interest rate model is not sufficient in accurately describing mortgage rate dynamics. Hawing highlighted the need for additional factors, the next chapter develops a multi-factor model in order to price mortgages. 
मn 


\section{Chapter 7}

\section{Multi-factor interest rate models and the valuation of Dutch mortgages}

\subsection{Introduction}

No closed-form solutions are available to calculate the exact values of complex fixed-income securities like mortgages. For this we have to turn to numerical solution methods such as binomial trees, finite difference methods, and Monte Carlo simulations. The first two procedures have serious computational drawbacks when several underlying variables are used or when the payof of the security depends on the history of the underlying variable. In this case the number of branches in the interest rate tree expands rapidly. For large numbers of time steps, the tree becomes too complex to be ar efficient numerical procedure to solve the valuation problem.

The results of Chapter 6 indicate that empirical mortgage rate dynamics can be modelled more accurately when more than one factor is utilized. In keeping with this, a multifactor mortgage pricing model is developed. The short-term interest rate, the long-term interest rate and the mortgage rate are included as the state variables in this multi-factor model. The dynamic interactions between these variables are described by the VAR models developed in the previous chapter. The resulting VAR-parameters are utilized to simulate short-term, long herm and mortgage interest rates which are the input of the valuation procedure. As in Chapter 6, two alternative VAR specifications are utilized: with and withont a unit root for interest rates.

The advantage of a simulation procedure for mortgage pricing is that it can cope with complicated stochastic interest rate environments while simultaneously allowing detidled prepayment restrictions. Its largest disadvantage is that its forward-looking characteristics prevent it from being completely compatible with the dynamic programming solution.

Several studies apply simulation techniques to value Mortgage-Backed Securities. For example, Zenios (1993), Cagan, Carriero and Zenios (1993) and Paskov and Trauls (1995) discuss the valuation of MBS by means of Monte Carlo methods. Zenios (1993) uses empirical prepayment data provided by Bear Stearns to generate cash flows for each interest rate 
scentrio. Cagan, Cartero and Zenios (1993) assume that the Mortgage-Backed Security is fairly priced by the market and focus on the calculation of the option-adjusted spread. However, rather than elaborating on the economic interpretation of their results, Cagan, Garriero and Zenios stress the importance of speeding up the simulation procedure. The same holds true for Paskow and Trab who also use an empirically determined prepayment rule.

Schwartz and Torous (1989) employ Monte Carlo simulation methods to generate psemdo time series of the instantaneous risk-free interest rate and the long-term Treaswry rate. Similar to Brennan and Schwartz (1985), Schwartz and Torous (1989) assume that all information regarding the term structure of interest rates can be summarized by a shortterm and long-tern interest rate. This twofactor interest rate model is extended with a proportional-hacards model, as in Green and Shoven (1986), to estimate the infuence of various explanatory variables on the prepayment activity. Hence, the prepayment function in the Schwartz and Torous (1989) model is completely empirically determined. This is in contrast 40 McConnell and Singh (1993), who start with an optimal value-minimizing. call condition. The outcome of this first step is a series of critical boundaries sirmilar to the ones derived in Chapter 5 . In the second step, McConnell and Singh use Monte Carlo simulation techniques to generate interest rate paths. Prepayment is triggered when the interest rate path hits the critical boundary. This second step is necessary because the Collateralized Mortgage Obligations (CMO) walued by McConnell and Singh have a hiewachical structure of payments to the various tranches which requires knowledge of prior mortgage prepayments.

The contracts studied in this chapter include typical Dutch features that are not captured by the models of Schwartz and Torous (1989) and McConnell and Singh (1993), i.e., the annual prepayment restriction and the minimum interest rate guarantee included in many quotation offers are considered. We include transaction costs and concentrate on interest rate diven prepayments.

Similar to the CMOs valued by McConnell and Singh, Dutch mortgages with annual prepament restrictions are path-dependent in the sense that past prepayments influence future cash flow patherns. Since a multifactor process is used to model the interest rate dynamics we cannot denve the critical bounday by backward recursion as in McConmell and Singh. Instead we assune that the mortgage is refinanced as soon as this reduces the future cost for the borrower. This prepayment rule is compared with the optimal rule in Chapter 5 .

The chapter is organized as follows. Section 7.2 describes the mortgage contracts. Section 7.3 discusses the overall design of the valuation procedure. The applied interest rate risk benchmarks are summarized in Section 7.4. The valuation results follow in Section 7.5. Section 7.6 studies the sensitivity of the valuation results for the considered period. In Section 7.7 the results are compared with the results of the one-factor valuation algorithm developed in Chapter 5. And Section 7.8 concludes. 


\subsection{The mortgage contract}

The mortgage contracts considered in this chapter are very similar to the ones analyzed in Chapter 5. The valuation results from Chapter 5 are therefore used as a benchmark. The mortgage is an annuity which pays a constant monthly cash flow consisting of both interest and redemption. The maturity of the contract is thirty years with the contract rate being fixed for a five year period. After these five years, the contract rate is freely reset so that the interest rate risk does not extend to periods after the adjustment date.

In Chapter 5 fully callable contracts were studied. However, most Dutch mortgage contracts are limited in this. Within a calendar year usually only 10 to $20 \%$ of the initial loan can be called without heavy penalties. These restrictions are included in the contracts studied in this chapter and compared with noncallable and freely callable characteristics, whereby we assume that all contracts start on January $1^{\text {st. }}$.

Preceding a mortgage contract, a Dutch bank normally offers a quotation which is walid for a few months. During these months, the client can consider the offer, while at the same time he is guaranteed the lowest contract rate realized on the mortgage market in that period. This offer is a free option for the client; there are no costs involved if he decides not to accept this offer. On the other hand, the writer of this option faces additional interest rate risk for which he would like to be reinbursed. The quotation offer is nomally effective for three months. Occasionally, this period is as large as six months.

\subsection{Valuation procedure}

The primary components of the valuation model are illustrated in Figure 7.1. The valluation procedure takes as input observed interest rates. The relations between those interest rates are described by Vector AutoRegressive (VAR) models for the short-term interest rate, a long-term interest rate and a mortgage rate. The resulling VAR parameters are used to generate interest rate paths. Along these paths the cash flow patterns are determined by taking interest rate driven prepayments in consideration. These cash fows are discounted with the simulated short-term interest rates adjusted for the market price of interest rate risk. The mortgage value is found by repeating this procedure many bimes and averaging the discounted cash flows.

\subsubsection{Interest rates simulation}

In Chapter 6 , two speciffcations of a VAR model are utilized to estimate the dynamic interactions between the short-term interest rate, the long-term interest rate and the mortgage rate in the Netherlands. In the first specification a stationary process is analyzed, and the second one includes a unit root. The weights of shocks in a stationary process decline geometrically with time such that they have no permanent effects, and the interest rates eventually return to their unconditional means. In the second specification of the VAR model, shocks have permanent effects on the interest rates levels. Both specifications are 


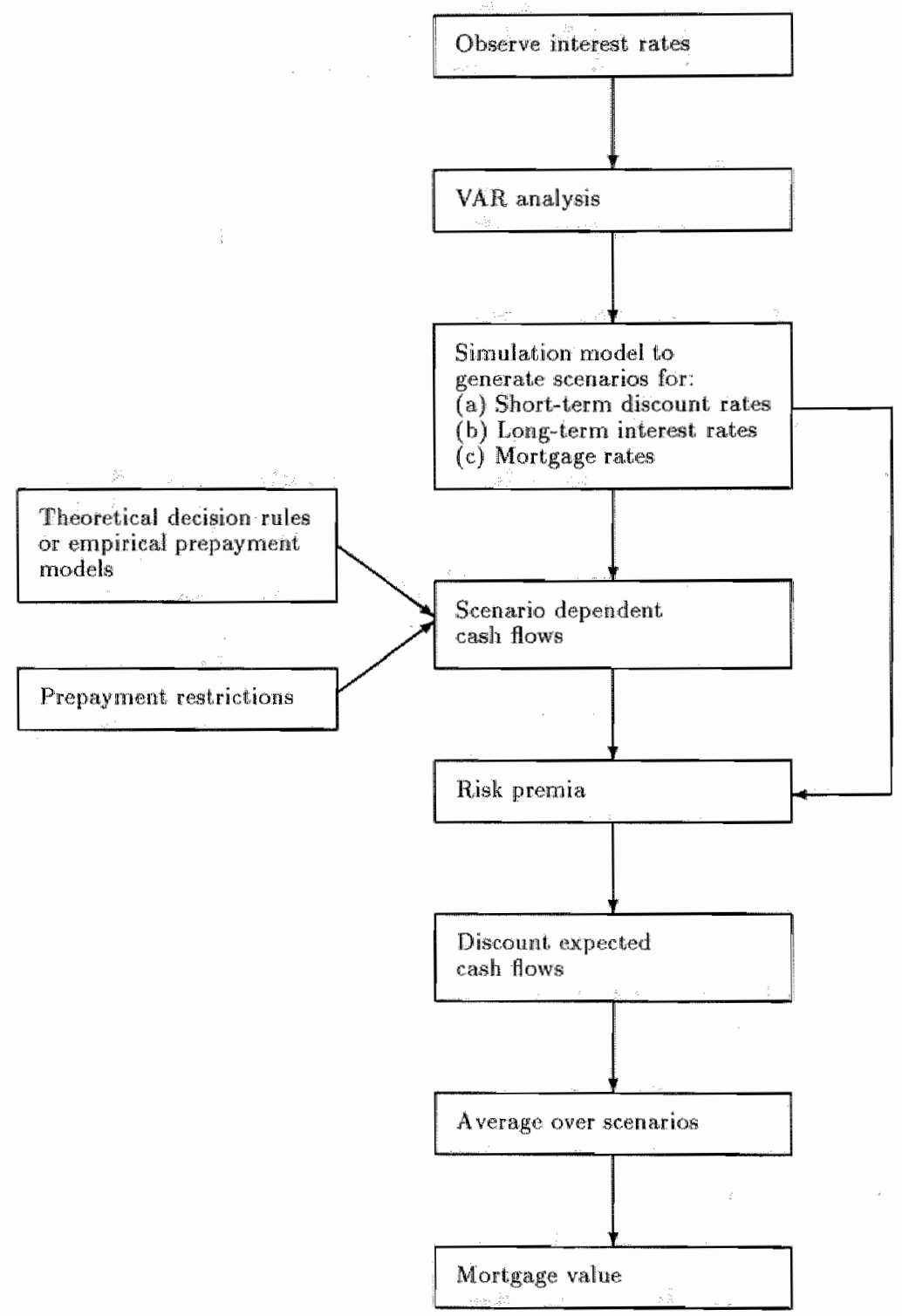

FIGURE 7.1: Simulation PROOEdURE 
discussed in detal in the previous chapter where the parameters are estimated for both versions of the VAR model.

A Monte Carlo simulation is carried out to generate various interest rate paths. The variability of the results is reduced by using the antithetic variable technique." The stochastic terms in these simulations are generated by the following bootstrapping procedure. Let $\varepsilon_{\mathbb{R}}$ be a $(3 \times 1)$ vector which contains the residuals from the VAR model at time $t$. By randomizing with replacement over the dimension of lime, a vector $\vec{t}$ is created with a length $n$ which equals the length of the simulated interest rate paths. Each element in $\tilde{l}$ corresponds with a month between January 1972 and December 1995 . We then create a pseudo-history by selecting the cross section stochastic error terms that correspond to the bootstrapped dates. This way an $(3 \times n)$ matrix $E_{\ddot{t}}$ is created which contains the stochastic error terms for the n-periods that the interest rates are simulated. By bootstrapping the errors from the VAR model in this way, we preserve the distributional chatacteristics of the correlated interest rate innovations.

Once the parameters are known and the residuals are drawn, only the initial interest, rates have to be chosen before the simulations can be run. For the short-term interest rate 4, 8 and 12\% were taken. The corresponding long-term interest rate and mortigage rate are found by increasing these short-term interest rates with the average spread observed in the sample period whenever the short-term interest rate was equal to 4,8 or $12 \%$, respectively. Consequently, these spreads differ for the different levels of the initial spot tates. Finally, we assume that the starting lagged values of the interest rate variables are the same as those at time $t=0$.

Table 7.1 shows the average nates and standard deviations of the short-term, long-term and mortgage interest rates at the end of the 60 months' fixed-rate period. These results are based on 30,000 simulation runs.

The differences between a stationary and a unit root process are obvious. Even though the rates are not yet completely converged, Table 7.1 clearly points out the mean reversion in the stationary process. If we lengthen the period, the short-term interest rate converges to $6.81 \%$, the long-term interest rate becomes $7.89 \%$, and the unconditional mean of the nortgage ratte is $8.84 \%$. These results are independent of the inilial rate, which is in sharp contrast with the results of the unit root process. Here the sixty months ahead interest. rates depend on the starting value of the interest rate. Table 7.1 also shows that for the unit root process, the average generated spreads between the mortgage rates, the long-term interest rates and the short-term interest rates are independent of the initial spot rate.

To preclude negative interest rates, the paths were truncated when necessary. This causes the standard deviations to be relatively low at an initial spot rate of $4 \%$. Especially when there is no upward drift at such a low interest rate this has a substantial impaction the standard deviations and explains why the volatility at $4 \%$ is lower than at higher rates.

\footnotetext{
In essence the antithetic variable technique cones down to simulating two paths ai the same time by using both the postive and negative value of the drawing. That is, if $E$ is included in the firsti path, $-c$ is used in the second. See Hull (1997) for a more detailed discussion.
} 
TABIE 7.1: DESCFHTIVE STMISTMS OF THE INTEREST RATES

\begin{tabular}{|c|c|c|c|c|c|c|}
\hline \multirow{2}{*}{$\begin{array}{l}\text { VAR spechication } \\
\text { Initial spot rate }\end{array}$} & \multicolumn{3}{|c|}{ stinonary } & \multicolumn{3}{|c|}{ unit root } \\
\hline & $4 \%$ & $8 \%$ & $12 \%$ & $4 \%$ & $8 \%$ & $12 \%$ \\
\hline & \multicolumn{6}{|c|}{ After 60 months } \\
\hline Shorthem interest rate & 6.39 & 7.09 & 7.64 & 4.76 & 7.81 & 10.65 \\
\hline Standrat dovation & 2.25 & 2.36 & 2.43 & 2.41 & 3.28 & 3.60 \\
\hline Tong-term interest rate & 7.98 & 8.22 & 8.88 & 5.94 & 8.98 & 11.82 \\
\hline Standard deviation & 1.44 & 1.50 & 1.51 & 2.29 & 2.76 & 2.86 \\
\hline Mortgage ratue & 8.32 & 9.18 & 9.85 & 6.90 & 9.95 & 12.78 \\
\hline Standard deviation & 1.46 & 1.52 & 1.53 & 2.27 & 2.75 & 2.86 \\
\hline
\end{tabular}

In addition to Table 7.1, Figure 7.2 displays the average interest rate paths generated by the stationary specifiction of the VAR model. These paths are based on the same 30,000 simulation runs. The upper diagrams clearly illustrate the mean-reversion in this process. Independent of the initial rates, the interest rates converge to the same levels. These diagrams also show the differences between the initial spreads at different starting ratues. For example, at an initial short-term interest rate of 8 percent the spread between the long-term interest rate and the mortgage rate is only 20 basis points, while at 12 percent tha intial spread between the short-term and long-term interest rate is very small.. The lowe diagrams yield a close up look of the mortgage rates. These rates determine the oppoturity costs for the borrower who considers refinancing. Therefore, they influence the prepayment bohavior which on its um affects the valuation of the mortgage. In Section 7.5. where we digcuss throsults, wo will frequently refer to this figure.

\subsubsection{Cash flows and prepayment behavior}

Anumity -mortgage contracts pay a constant monthly cash flow which consists of both inherest and relomption paymants. The periodical cash flows, $M_{0}$, are a function of the contract rate, the sive of the principal and the time to maturity:

$$
M_{0}=U_{0} \frac{(1-v)}{v\left(1-v^{2}\right)^{2}}
$$

where to is the principal, $T$ is the time lo maturity and $v=\frac{1}{(1+y(0))}$, with $y(0)$ being the contract rate derermined at the $=00^{2}$

Besides these factors the prepaynent bahavion of the borrower influences the cast

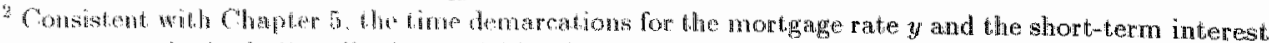

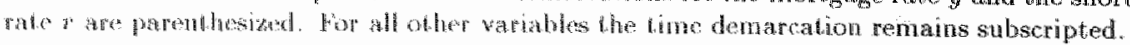



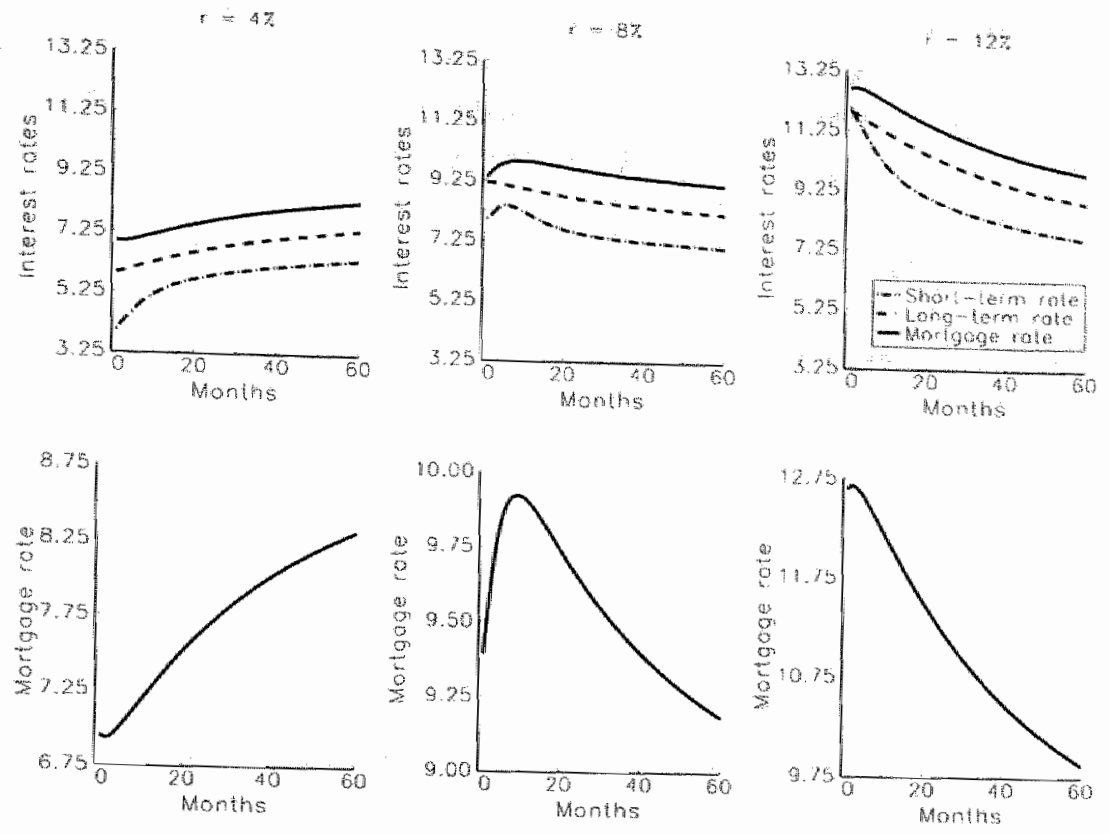

Figure 7.2: AVerage interest rate paths

The upper diagrams of this figure show the average interest rate paths generated by the stationary VAR model. The lower diagrams yield a close up look at the mortgage rates. The $r$ value on top of each column represents the short-term interest rate at which the simulations started. The results are derived by 30,000 simulation muns based on a VAR analysis of Dutch interest rates between 1972 and 1995 .

How pattern. With prepayments playing such an important role, it is necessary to model them accurately. Depending on the scope of the study two approaches aro possible. First. prepayment behavior can be described by a formal econometrical model estimated by using historical data. This approach is preferable if the goal of the research is in modolling the observed economic behavior. This is done in Chapter 9 which studies ihe Dutch prepayment experience of mortgages in the early nineties. That study suggests ways in which the prepayment behavior should be modelled more formaliy, but is not yet suited for the applications in this chapter. For that, more accurate and comprehensive data must be collected, not only reganding prepayment rates themselves but also about the many variables that infuence them. Since both the quantity and quality of the avalable data on the Dutch mortgage market are not yet sufficient, the first approach is ruled out.

If the purpose of the study is to analyze the interest ratie risks faced by tha mortgagee, a theoretical prepayment decision rule is preferable. In this chapter the same rult will be used as in Chapter 5 , recognizing that in strict sense this prepayment rule is not optimal. 
In this chapter we assume that the mortgage will be prepaid as soon as this reduces the future costs for the borrower. Therefore we calculate each month the monthly payment $M_{i}^{*}$ as if a new contract sharts with a maturity equal to the remaining time to maturity of the existing contract. The new contract rate is equal to that month's simulated mortgage rate. The principal of this new loan is equal to the outstanding debt multiplied by $(1+c)$, where a are the up-front costs a borrower has to pay to replace the old contract by a new one. If the resulting monthly payment $M_{t}^{*}$ is less than the original $M_{0}$, the borrower considers prepaying the contract. If he replaces the existing contract with a new one he will save each month, until the reset date, an amount equal to $\left(M_{0}-M_{i}^{*}\right)$. These monthy savings can be deposited on a bank account on which he earns interest. The exact payment of interest, however, depends on future interest rates which are unknown at time $t$ when the prepayment decision must be made. However, the term structure of interest rates can be approximated by interpolating between the short-term interest rate and the long-term interest rate, which are both generated by the simulation procedure. This approximation is used to calculate the expected value of $S_{\tau}$, which is the amount the mortgagor will have at his disposal on the bank account on the reset date $\tau$ if he decides to refinance the contract at time $t$. This money can be used to reduce the outstianding debt on that day. The borrower is indifferent between refinancing the contract and holding on to it if $S_{\mathrm{r}}$ is large enough to offset the potential higher debt of the new loan on the reset date. ${ }^{3}$ We assume that the mortgagor prepays the contract as soon as:

$$
\tilde{U}_{r}-S_{r}<U_{r}
$$

where $U_{T}$ is the outstanding debt on the reset date $\tau$ if the contract is not prepaid at time $t$, while $\tilde{U}_{r}$ reflects what the debt will be at time $\tau$ if the contract is prepaid at time $t$.

Throughout this chapter we assume that the mortgage is prepaid as soon as Inequality (7.2) holds. We exclude exogenous prepayments which are unrelated to interest rates. Nor are prepayments consiclered which exceed the annual penalty-free restrictions. Consequently, when the borrower decides to (partially) prepay the mortgage he only faces the up-lront fees $c$ of starting a new contract. Even though the borrower has to pay these upfront costs, the lender will not receive them since they refer to setting up a new contract and are therefore received by the new issuing party. Initially, these costs are assumed to be equal to one percent of the principal. Later alternative costs are also considered.

\subsubsection{Pricing}

The pricing model accepts as input the simulated short-term interest rates and the cash flows as determined by the contract and the prepayment behavior model. The present value of these cash flows are calculated by using risk-adiusted discount rates. For this we adjust the unconditional mean of the short-term interest rate such that it includes the

\footnotetext{
3 Sie Section 5.2 .4 for a devaled disctussion on this prepayment rulle.
} 
market price of risk. The alternatiwe VAR specifications denand for different approaches in this. If the short-term interest rate follows a stationary process, the infunte horizon yield converges to $R_{\infty}$, independently of the initial spot rate. Setting $R_{\infty}$ at a particular walue, say $R_{\infty}=8 \%$, we can solwe for the market price of risk. The same approach was used in Chapter 5.

For the unit root process this approach does not work, since now the short-term interest rates do not converge to one level. To derive an appropriate market price of risk measure, we assume that the price of an $n$-period zero-coupon bond is equal to its value at time $n$ discounted by the short-term interest rates plus a risk premium over the intermediate periods. In terms of yields this reads: ${ }^{4}$

$$
\frac{1}{\left(1+R_{n, t}\right)^{n}}=\prod_{s=0}^{n-1} \frac{1}{\left(1+r_{t+s}+\lambda\right)^{n}}
$$

where $R_{n, t}$ is the yleld to maturity on an $n$-period zero-coupon bond at time $t_{t}$ is the short-term interest rate which holds for one period, and $\lambda$ is the risk premium. Mowing to natural logarithms, Equation (7.3) can be approximated by:

$$
n \ln \left(1+R_{n, t}\right) \approx \sum_{s=0}^{n-1}\left(v_{t+s}+\lambda\right)
$$

such that

$$
R_{n, t, t} \approx \frac{1}{n} \sum_{s=0}^{n-1}\left(r_{t+s}+\lambda\right)
$$

From which follows:

$$
\begin{aligned}
R_{n, t}-r_{t} & \approx \frac{1}{n} \sum_{s=0}^{n-1}\left(r_{t+s}-r_{i}+\lambda\right), \\
E\left[R_{n, t}-r_{t}\right] & \approx \frac{1}{n} \sum_{s=0}^{n-1}\left(E\left[r_{t+, s}-r_{i}\right]+\lambda_{s}\right. \\
E\left[R_{n, t}-r_{t}\right] & \approx \lambda .
\end{aligned}
$$

From Equation (7.8) follows that the average spread between the n-period yield and the short term interest rate is an appropriate measure for the risk premium. For the unit root process we therefore use the average spread between the short-term and long-tem interest rate observed during the sample period to adjust the discount rate such that it includes the market price of risk.

\footnotetext{
See Camplell, Lo and Mackinlay (1997) for a detailed discussion on this.
} 


\subsection{Interest rate risk}

The price/nterest rate curve of a mortgage shows how sensitive the mortgage value is to interest rate changes. A linear approximation, such as duration, for this interest rate sensitivity results in a substantial error when callable contracts are considered. Therefore. a more direct measure of interest rate risk has been introduced: the effective duration $\Delta$; which is defined as the semi-elasticity of the mortgage with respect to the short-term interest rates

$$
\Delta(r(0), y(0))=-\frac{\partial \ln V(r(0), y(0))}{\partial r(0)}
$$

where $V$ represents the value of a mortgage contract whose contract rate equals $y(0)$ and $r(0)$ is the initial short-term interest rate. In this chapter a numerical approximation for $\Delta$ is used:

$$
\Delta(r(0), y(0))=-\frac{V(r(0)+h, y(0))-V(r(0)-h, y(0))}{[(r(0)+h)-(r(0)-h)] V(r(0), y(0))} \times 100 .
$$

The small deviation of the initial short-term interest rate, $h$, is assumed to be one basis point. As discussed in the previous chapter, such a shock in the short-term interest rate has an instantaneous effect on both the long-term interest rate and mortigage rate. The size of these effects follow from the Choleski decomposition of the covariance matrix resulting from the VAR analysis. As a consequence of these shocks, the starting values of the short. term, longterm and mortgage interest rate change so that new simulated interest rate paths have to be generated. To determine the stochastic error terms in this, the same matrix $E_{i t}$ as in Section 7.3.1 is utilized. From the resulting alternative interest rate paths, only the short-term interest rate paths are used. For the mortgage rate, which determines the prepayment behavior and thus the cash flow pattern, the original rates, starting at $y(0)$, are used. This way, we compute the partial derivative ancl are assured that only the effocts of changing discount rates are considered in the interest rate sensitivity analysis. In other words, there will be no discrete changes due to different prepayment behavior.

Acknowledging tha drawbacks of duration as a measure of interest rate risk, the results in Section 7.5 present this benchmark as it shows the weighted time to maturity, which is important for the funding of the mortgage.

\subsection{Valuation results}

This section presents the valuation results based on alternative VAR specifications, initial short term interest rates and penalty-free prepayment restrictions. Unless stated otherwise,

\footnotetext{
see DeRosa, Goodman and Zazzarino (1993) and Haensly, Springer and Waller (1993) for a discussion on this topic.

See Fabozi and Modigliani, Chapter $13(1992)$.
} 
the simulated interest rate paths are based on VA malyses whoh bok interest rates between January 1972 and December 1995 as input.

\section{The impact of annual prepayment restrictions}

Table 7.2 presents the computed values at origination of a noncallable contract and contracts which are limited or fully callable. A quotation offer gutantes is not issued with these contracts, and the up-front costs are set to $1 \%$ of the kan. The appled spread bo

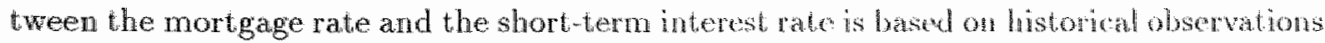
in the Netherlands. The mortgage yield is hereby equal to the arevge yield on ammity. mortgages with a maturity of 30 years and a fixed contrat rate period of 5 yerts thertsy, no distinction is made between alternative prepayment restrictions. Historically only $10 \%$ of the initial loan could be called within a calendar yea without penalty. Due to the increased competition this limitation is gradually widemed and nowadas ther are nany contracts which allow the annal prepayments to be as large as $20 \%$ of the initial loan. Despite the broadening of prepayment possibilitios, he average spread barely increased, as illustrated in Figure 5.3. This reflects the general impression that, due to the anmat limitations, prepayment risk is less important in the Nethertands than in the United States where prepayment restrictions are virtually unknown. However, Table 7.2 shows that wh is a misunderstanding as the value of a $10 \%$ penalty-free prepayment option equals one quarter of the value of a prepayment option without any limitations. The value of the $20 \%$ penalty-free prepayment option is even equal to hall the value of the $100 \%$ penalty-frea prepayment option!

The effective duration measures $\Delta$ in Table 7.2 show that the interest rate risk faced by the mortgagee decreases with increasing prepaynent freedom fos the borrower. This sidemeffect of loosening prepayment restrictions is cansed by the increased prepayment probability during early stages of the contract. This phenomenon shoutens the average life of a mortgage, as reflected by the duration-pattern in Table 7.2 , and hocrefore reduecs the probability of a large change in the contract value.

\section{The effect of mean-reversion on prepayment behavior}

The mean-reversion of the stationary process pulls the interest rates towards then uncornditional means. In the unit root process, the interest rates have a bigher volatility which explains why the option values at a 4 and $8 \%$ short-term interest rale level are higher when the unit root process is utilized. At higher interest rates, the downward frift induded in the stationary process overpowers the volatility characteristics and result in relatin. high option values.

What holds true for the option value is also valid for the duration: higher wolatility reduces the duration at low rates, while the downard drif shorters the duration at ligh rates. One duration figure in particular stands out. When the stationary VAR wodel its utilized and all prepayment restrictions are released, an initial short-kerm interest rato of 8 
THBLE 7.2: NORTGAGE VALUES: SAMPLE PERIOD JAN. 1972 - DEC. 1995

\begin{tabular}{|c|c|c|c|c|c|c|}
\hline \multirow{2}{*}{$\begin{array}{l}\text { VAR specification } \\
\text { Spot rate }\end{array}$} & \multicolumn{3}{|c|}{ stationary } & \multicolumn{3}{|c|}{ unit root } \\
\hline & $4 \%$ & $8 \%$ & $12 \%$ & $4 \%$ & $8 \%$ & $12 \%$ \\
\hline & \multicolumn{6}{|c|}{$0 \%$ penalty-free prepayment } \\
\hline Annuity walue & 100.27 & 102.41 & 108.98 & 104.65 & 101.78 & 102.61 \\
\hline Duration annuity & 50.34 & 48.53 & 46.47 & 50.66 & 48.41 & 45.79 \\
\hline \multirow[t]{2}{*}{$\Delta$ anmuity } & 0.63 & 0.61 & 0.58 & 0.63 & 0.60 & 0.57 \\
\hline & \multicolumn{6}{|c|}{$10 \%$ penalty-free prepayment } \\
\hline Mortigage value & 100.15 & $101.88^{\circ}$ & 106.39 & 103.65 & 101.07 & 101.65 \\
\hline Duration mortgage & 46.19 & 44.34 & 37.16 & 44.41 & 44.23 & 40.48 \\
\hline$\Delta$ mortgage & 0.61 & 0.59 & 0.54 & 0.59 & 0.58 & 0.54 \\
\hline \multirow[t]{2}{*}{ Option value } & 0.12 & 0.56 & 2.59 & 1.00 & 0.69 & 0.96 \\
\hline & \multicolumn{6}{|c|}{$20 \%$ penalty-free prepayment } \\
\hline Mortgage value & 100.04 & $101.33^{\circ}$ & 103.81 & 102.63 & 100.37 & 100.69 \\
\hline Duration mortgage & 42.11 & 40.18 & 27.37 & 37.89 & 40.06 & 34.94 \\
\hline$\Delta$ morlgage & 0.58 & 0.57 & 0.50 & 0.56 & 0.56 & 0.51 \\
\hline \multirow[t]{2}{*}{ Option value } & 0.23 & 1.10 & 5.17 & 2.03 & 1.41 & 1.93 \\
\hline & \multicolumn{6}{|c|}{$100 \%$ penalty-free prepayment } \\
\hline Mortgage value & 99.69 & 99.94 & 100.13 & 100.55 & 99.00 & 99.04 \\
\hline Duration mortgage & 24.58 & 27.01 & 9.52 & 19.31 & 27.34 & 20.35 \\
\hline$\Delta$ mortgage & 0.44 & 0.49 & 0.33 & 0.39 & 0.46 & 0.39 \\
\hline Option vallue & 0.58 & 2.50 & 8.86 & 4.10 & 2.77 & 3.60 \\
\hline $\begin{array}{l}\text { The table shows val } \\
\text { short-1erwi interest } \\
\text { pressed in months. } \\
\text { mortigage with respe } \\
\text { is not included in }\end{array}$ & tion resu & Tto based & 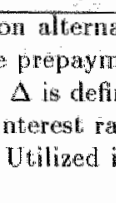 & VAR spec & fieations; & $\begin{array}{l}\text { initial } \\
\text { is ex- } \\
\text { of the } \\
\text { rantee }\end{array}$ \\
\hline
\end{tabular}


percent leads to a relative high duration of 27.01 months. The explanation for this can be found in the lower-middle diagram of Figure 7.2. This plot displays that, in this starting. situation, the mortgage rate initially tends to rise. This reduces the prepayment likelihood and results in a relative high duration measure.

TABLE 7.3: SPREADS

\begin{tabular}{lrrrrrr}
\hline VAR specification & \multicolumn{3}{c}{ stationary } & \multicolumn{3}{c}{ unit root } \\
Initial spot rate & $4 \%$ & $8 \%$ & $12 \%$ & $4 \%$ & $8 \%$ & $12 \%$ \\
\hline Initial spread & 295 & 140 & 65 & 295 & 140 & 65 \\
Spread after 60 months & 193 & 209 & 221 & 214 & 214 & 213 \\
Difference & -102 & +69 & +156 & -81 & +74 & +148 \\
\hline
\end{tabular}

The table shows the speads (in basis poincs) between the mortgage rate and the short-term interest rate at times $t=0$ and $t=60$, as well as the difference between the spreads at both periods. The initual spreads are based on the awerage spreads observed in the research period when the shortiterin interest ratte was equal to 4,8 and 12 percent. The spreads at time $t=60$ are deriwed by 30, 000 simulation runs based on VAR analyses of Dutch interast rates betweon 1972 and 1995.

In the unit root process, the annuity and mortgage contracts have a higher value when the initial short-term interest rate is 4 percent rather than 12 percent. This counterintuitive result can be explained with the help of Table 7.3 which shows that the initial spreads between the nortgage rate and the short term interest rate differ substantially. For example, the spread at a short-term interest rate of $4 \%$ is twice as large as at an initial spot rate of $8 \%$. Compared with the spread at $12 \%$, it is even 4.5 times larger. Due to the callable features, the mortgages are less sensitive to the spread differences than the noncallable annuity contract.

When the stationary process is utilized, the high initial spread at a short-term interest rate of 4 percent does not lead to relative high contract vahes because the short-term interest rate is pulled upwards to its unconditional mean.

\section{The impact of prepayment costs}

In Table 7.2 the up front costs of setting up a new mortgage loan to replace the existing contract are assumed to equal one percent of the unpiaid balance. In Figures 7.3 and 7.4 the mortgage and option values are plotted for alternative up-front costs. In Figure 7.3 the interest rate dyuamics are described by a stationary process. Due to the mean-reverting characteristics of this process the value of the prepayment option is low at low interest rates. At higher interest rates the value of the option increases, which makes it more sensitive to the up-front costs. When the unit root process is used, this sensitivity does not depend on the interest rate level. This is illustrated in Figure 7.4 , which clearly shows that the impact up-front costs have on the option value hardly depends on the initial level of the interest rate. This can be explained by the fact that due to the albsence of a mean-reverting drift, the option value depends only on the interest rate wollatility. As a 


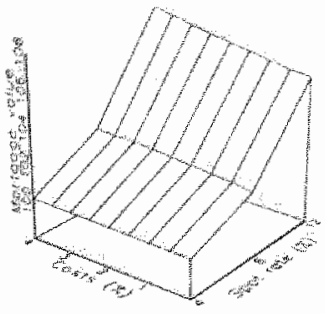

penolly ros: $10 \%$

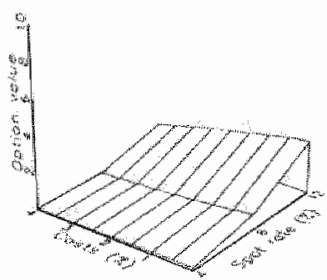

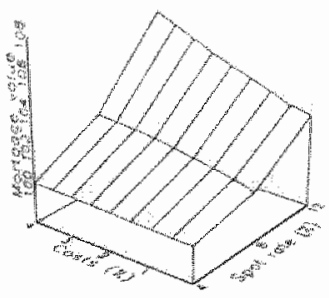

pantly are: $20 \%$

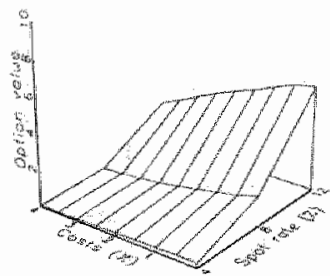

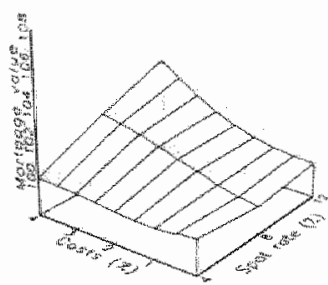

penonly free: 100\%

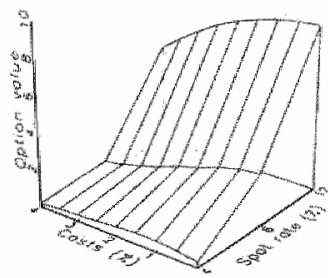

Figure 7.3: The INFLUENGe of UP-FRONT COST

These figures show the effect different up-front costs have on the mortgage and option value. The impact is illustrated for morlgages with different prepayment restrictions and different initial short-term interest raties. The interest rate dynamics are based on the stationary process.

consequence, the prepayment likelihood at low interest rates is much higher than when the stationary process is used. Since at high interest rates the opposite holds, the value of the prepayment option is less sensitive to the initial interest rate, and also the impact of the up-front costs depends less on this initial rate.

\section{The impact of minimum interest rate guarantees}

Preceding a mortgage contract, the borrower will gather information and compare alternative quotation offers. During this time for reflection the mortgage rate might alter, either to the advantage or disadvantage of the borrower. Many Dutch quotation offers contain a guaratitee in which the financial institute assures that at the end of the offer period, the borrower may set the contract at the lowest mortgage rate observed during that period. For antution offer period of 3 months and for initial spot rates of 4,8 and $12 \%$, the results are stmmarized in Table 7.4 .

The valuation results of mortgage contracts preceded by a quotation offer can not be directly compared with the mortgages studied in Table 7.2. These latter contracts take effect immediately, while the contracts considered in Table 7.4 are not issued untill the end of the offer period. The difference is illustrated in Figure 7.5.

In Figure 7.5 , a mortgage contract, which immediately takes effect at time $t^{\prime}$ is issued 

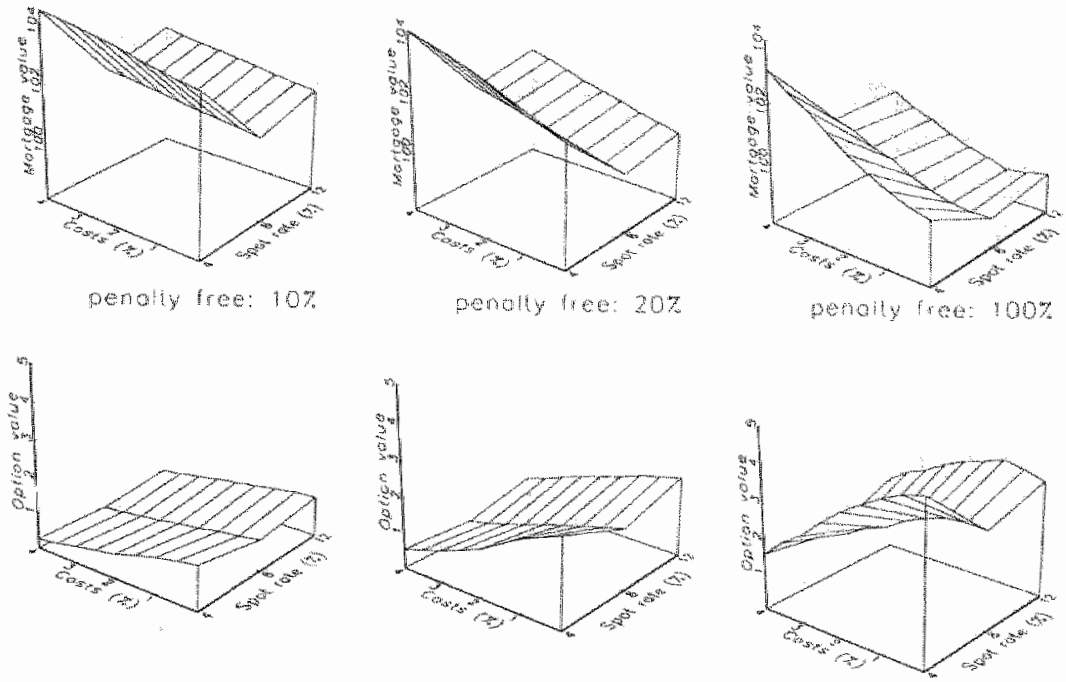

FIGURE 7.4: THE INFLUENCE OF UP-FRONT COST

These figures show the effect different up-front costs have on the mortgage and option value. The impach is illustrated for mortgages with different, prepayment restrictions and different initiall shori-tern interest rates. The interest rate dynamics are based on the unit root process.

with a contract rate matching state 2. (Note that state 1 correlates with the highest interest rates.) On the other hand, if a quotation offer precedes the contract, the mortgage will be issued at time ${ }^{*}$. If a minimum interest rate guarantee is embodied in the quotation offer, the contract is set at the lowest mortgage rate observed during the offer period, in which case the contract rate will correspond with state 4 . II such a guarartee is not included, the contract rate will be consistent witl state 3 : the one that occurs at the end of the offer period. Table 7.4 considers these latter two situations, $i . e$, it reports the difterences between the valuation results at time $t^{*}$ of wo contracts which are both preceded by a quotation offer, however, one contains a minimum interest rate guarantee while the other one does not. Only the differences between those two types of contracts are reported, whereby the results of a contract with a minimum interest rate guarantee are subtracted from the results of a contract without this assurance.

Contracts settled at the contract rate of time t* are expected to yid higher periodical payments than the ones settied at the lowest mortgage rate that occurred during the offer period. Hence, it is not surprising that Table 7.4 shows that the present values of the contracts preceded by an offer without a minimum interest rate guaranted are slightly higher than the values of the contracts which include this guarantee, Since the former contracts are issued at a higher contract trate there is a larger probability that they will 


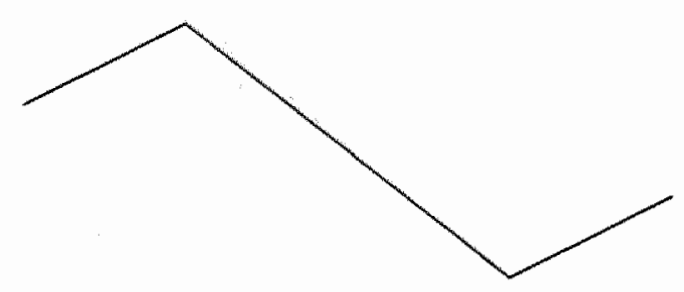

state: 1

state 2

state 3

state 4

$t^{*} t^{*}$

FIGURE 7.5: RANDOM MORTGaGe RATE PATH DURING QUOTATION OFFER PERIOD

TABLE 7.4: VALUES WITH AND WITHOUT A MINIMUM INTEREST RATE GUARANTEE

\begin{tabular}{|c|c|c|c|c|c|c|}
\hline \multirow{2}{*}{$\begin{array}{l}\text { Spot rate } \\
\text { VAR spec. }\end{array}$} & \multicolumn{2}{|c|}{$4 \%$} & \multicolumn{2}{|c|}{$8 \%$} & \multicolumn{2}{|c|}{$12 \%$} \\
\hline & stationary & unit root & stationary & unit root & stationary & unit root \\
\hline & \multicolumn{6}{|c|}{$0 \%$ penalty-free prepayment } \\
\hline Annuity value & 0.83 & 0.74 & 1.58 & 1.36 & 0.65 & 0.85 \\
\hline Dur. annuity & -0.13 & -0.11 & -0.25 & -0.22 & -0.09 & -0.13 \\
\hline \multirow[t]{2}{*}{$\Delta$ annuity } & 0 & 0 & 0 & 0 & 0 & 0 \\
\hline & \multicolumn{6}{|c|}{$10 \%$ penalty-free prepayment } \\
\hline Mortgage value & 0.76 & 0.60 & 1.21 & 1.16 & 0.40 & 0.67 \\
\hline Dur. mortgage & -0.98 & $\sim 0.88$ & 2.03 & -1.38 & -0.68 & $\sim 0.96$ \\
\hline$\Delta$ mortgage & -0.02 & 0 & 0 & 0 & 0 & 0 \\
\hline \multirow[t]{2}{*}{ Option vallue } & 0.06 & 0.15 & 0.36 & 0.20 & 0.27 & 0.18 \\
\hline & \multicolumn{6}{|c|}{$20 \%$ penalty-free prepayment } \\
\hline Mortgage value & 0.70 & 0.45 & 0.85 & 0.93 & 0.10 & 0.56 \\
\hline Dur. morligage & -1.82 & -1.64 & -3.92 & -2.71 & -1.44 & -1.75 \\
\hline$\Delta$ mortgage & 0 & -0.06 & $-0,02$ & -10.01 & 0 & -0.01 \\
\hline \multirow[t]{2}{*}{ Option vallue } & 0.10 & 0.28 & 0.71 & 0.43 & 0.55 & 0.30 \\
\hline & \multicolumn{6}{|c|}{$100 \%$ penalty-free prepayment } \\
\hline Mortgage value & 0.47 & 0.16 & 0.27 & 0.66 & 0.05 & 0.38 \\
\hline Dur. mortgage & -4.38 & -3.42 & -7.88 & -5.92 & -1.79 & -3.95 \\
\hline$\Delta$ mortgage & -0.03 & -0.02 & -0.05 & -0.04 & -0.02 & -0.0 .3 \\
\hline Option value & 0.36 & 0.58 & 1.31 & 0.69 & 0.71 & 0.49 \\
\hline
\end{tabular}

The table shows the differences between two contracts which are both preceded by a quotation offer. The results of a contrate with a minimum interest rate guarantee are subtracted from the results of a contract without this assurance. Utilized interest rates: Jam. 1972 - Dec. 1995, up-front fee: $1 \%$ of the loan, quotation offer guarantes: 3 months. Option value reflects the value of the prepayment option. 
be prepaid. This is reflected by the negative sign of the difference in duration, i.e., the duration of a contract without a minimum interest rate guarantee is smaller than the duration of a contract with this a guarantee.

Moderate and high starting rates yleld similar results. At an initial short-term interest rate of $8 \%$ the drift term is less emphatically present in the interest rate dynamics, while starting with a spot rate of $12 \%$ results in a negative drift which pulls both the discount and mortgage rate down. This negative drift increases the probability that the minimum mortgage rate is observed at the end of the offer period, such that the importance of a minimum interest rate guarantee decreases.

The results in Table 7.4 show that a minimum interest rate guarantee can always be offered at very low costs. Table 7.5 explains why. Because of the lower contract rate, prepayment is less likely if a minimum interest rate guarantee is included in the offer preceding the contract. Consequently, the prepayment option reduces in value.

\section{TABLE 7.5: SUBSTITUTION EFFECT}

\begin{tabular}{lccccc}
\hline VAR specification & \multicolumn{2}{c}{ stationary } & \multicolumn{2}{c}{ unit root } \\
Quotation guarantee & no & yes & no & yes \\
\hline & & Spot rate: & $\mathbf{4 \%}$ \\
Duration mortgage & 26.99 & 31.36 & 19.80 & 23.22 \\
Option value & 0.54 & 0.18 & 4.02 & 3.44 \\
\hline & & Spot rate: & $\mathbf{8} \%$ \\
Duration mortgage & 18.97 & 26.85 & 22.09 & 28.01 \\
Option valne & 3.80 & 2.49 & 3.49 & 2.80 \\
\hline & & Spot rate: & $\mathbf{1 2} \%$ & \\
Duration mortgage & 7.31 & 9.09 & 1.7 .77 & 21.72 \\
Option value & 9.57 & 8.85 & 3.87 & 3.38 \\
\hline
\end{tabular}

This table shows the substitution effech between the quotation offer guarantee and the prepayment option. The table reports the duration and option values of a fully callable mortgage contract preceeded by at three months' offer. Quatation gwarante indicntas whether or not a minimum interest rate guarantee is included un this ofter. Vtilized interest rates: Jan. 1972 - Dec 1995, up-front fee: $1 \%$ of the loan. Option value reflects the walue of the prepayment option.

In conformity with Table 7.2 , Table 7.5 shows that in the unit root setting the duration and option value hardly fuctuate between the different initial short-term interest rates. Due to the absence of a mean-reverting drift term, prepayment is equally likely at low and high starting rates. This partially explains why no pattern can be recognized in the results based on the unit root process shown in Table 7.5 . The other main cause is the fact that the historical spread between mortgage rates and short-term interest rates valies with interest rate levels. 
Table 7.5 reports the duration of the mortgage contract and the value of the prepayment option of a contract which is preceded by a three months" offer. If the maturity of this offer is lengthened, the interest rates described by the stationary process are further converged to their long-term rates when the period ends. For low initial spot rates this results in greater difference between the contracts with and without a minimum interest rate guarantee. At an initial spot rate of $8 \%$, this fluctuation is much smaller. Lengthening: the quotation offer period when the starting short-term interest ate is $12 \%$ reduces the prepayment likelihood and results in higher duration measures and lower option values. This holds true for both contract types. However, a contract which is preceded by an offer that embodies the guarantee shows a stronger reaction. The differences between both types of contracts therefore increase as the offer periods lengthens.

In case the unit root model is utilized, a longer quotation offer simply means a larger probability of a low contract rate. This reduces the prepaynent likelihood which causes the option value to decrease and the duration to increase.

\subsection{Sample period sensitivity}

The mortgage valuation model developed in Chapter 5 is based on various specifications of a one-factor interest rate model. The sample period in Chapter 5 was January 1981 through December 1994, while the VAR parameters which have been used in this chapter so-far are based on observations between January 1972 and December 1995. In onder to compare the malli-factor approach with the one-factor models, the VAlt's have been re estimated for the period January 1981 through December $1994 .^{7}$

The impact of the shortened period on the results of the multi-factor model can be seen by comparing Tables 7.1 and 7.2 with Tables 7.6 and 7.7 . The stationary process now shows lower interest rates and standard deviations, i.e., the unconditional means of the shortterm, long term and mortgage interest rates are $6.2 \%, 7.32 \%$ and $8.23 \%$, respectively. In other words, approximately 50 to 60 basis points less than before. Figure 7.6 plots the average mortgage rate path resulting from 30,000 simulation runs based on VAR analyses of Dutch interest tates between 1981 and 1994.

The most rematkable change in a contract value occurs at the spot rate of $4 \%$, where the annuty value is no longer above par when based on the stationary process. Despite the lower unconditional mean of the short-term interest rate, the infinite horizon discount

\footnotetext{
"Besides the WAP parameters, the risk adjustment fartors aro readapted for this change in reseam period. The need to adjust the initial sprods batwen the long-tem and shorterm interestiate, and between the mortigage rate and short-term inoterest rate was also chocked. These initial spreards are derwed from the observed interest rates and detemine the starting rates in the simulations. Hence, they influence Ho path that the interest rates follow afterwards. The spreads that hold for the whole 19721995 period at shorterm interest rates of 4 and $12 \%$ were also found to hold for the subperiod between 1981 and 1994. The spreads only needed in small adjustment at a short-term interest rate llevel of $8 \%$. The spread between the long-term and short-am interest rate decreased by 14.5 basis points from 119.5 to 105 , while the spread beween the morlgage bate and the shom-term interst rathe increased from 140 .5 basis points to 165 basis points.
} 
TABLE 7.6: DESCRIPTIVE STATISTICS OF THE INTEREST RATES

\begin{tabular}{lrccccc}
\hline VAR specification & \multicolumn{3}{c}{ stationary } & \multicolumn{4}{c}{ unit root } \\
Initial spot rate & $4 \%$ & $8 \%$ & $12 \%$ & $4 \%$ & $8 \%$ & $12 \%$ \\
\hline & \multicolumn{4}{c}{ After 60 months } \\
Short-term interest rate & 6.13 & 6.40 & 6.67 & 5.23 & 7.85 & 10.81 \\
Standard deviation & 1.77 & 1.76 & 1.77 & 2.65 & 3.16 & 3.26 \\
Long-term interest rate & 7.24 & 7.48 & 7.69 & 6.13 & 8.72 & 11.59 \\
Standard deviation & 1.22 & 1.22 & 1.22 & 2.57 & 2.89 & 2.92 \\
Mortgage rate & 8.14 & 8.38 & 8.61 & 7.07 & 9.66 & 12.55 \\
Standard deviation & 1.19 & 1.19 & 1.19 & 2.53 & 2.87 & 2.91 \\
\hline
\end{tabular}

The table shows the average rates and standard deviations of the shortwerm, long-term and mortgage interest rates at the end of the 60 months' fixed-rente period. The results are derived by 30,000 simulation rums based on VAR analy ses of Dutch interest rates between 1981 and 1994.

rate converges to the same $8 \%$ as imposed by the market price of risk adjustment. The risk premiun derived from interest rates observed between 1981 and 1994 is larger than the one based on the entire $1972-1995$ period. The average discount rate paths shown in Figure 7.7 include these risk premiums. Even though both paths eventually converge at an $8 \%$ level, the average discount factor during the first 60 months differs substantially. Dute to the on average higher discount factor, the annuity contract has a lower value in the 1981-1994 setting than in the 1972-1995 perspective.

For the stationary process, Table 7.2 reported a relative high duration at an initial spot rate of $8 \%$. Especially for a fully callable mortgage this measure stood out. In Table 7.7 this is no longer the case. Here the duration decreases with increasing interest rates, also when mortgages can completely be called without penatty. The explanation for this difference can be found by comparing the lower-middle diagrams of Figures 7.2 and 1.6 . When the parameters are based on the entire 1972-1995 period, the average mortgage rate path increases for the first 9 months, while only after 39 months the mortgage vate is back at its starting level. For the subperiod 1981-1994, these figures are 3 and 5 months, respectively. Hence, the prepayment likelihood is much larger in this tat ter case, as reffected by the lower duration measure and higher option value. Not only the duration, but also the $\Delta$ rist measure alters when the length and placenent of the sample period for the estimation of interest rate dynamics changes.

Similar to Table 7.2. Table 7.7 shows that the waluation results based on the unit root process are not in conformity with economic expectations. For example, the value of the annuity and mortgage contracts decrease with increasing initial interest rates. The sane holds true for the value of the prepayment option and also the duration measure does not reveal a consistent pattern. 
TABLE 7.7: MORTGAGE VAUUES: SAMPLE PERIOD JAN. 1981 - DEC. 1994

\begin{tabular}{|c|c|c|c|c|c|c|}
\hline \multirow{2}{*}{$\begin{array}{l}\text { VAR specification } \\
\text { Spot Rate. }\end{array}$} & \multicolumn{3}{|c|}{ stationary } & \multicolumn{3}{|c|}{ unit root } \\
\hline & $4 \%$ & $8 \%$ & $12 \%$ & $4 \%$ & $8 \%$ & $12 \%$ \\
\hline & \multicolumn{6}{|c|}{$0 \%$ penalty-free prepayment } \\
\hline Annuity value & 99.51 & 103.49 & 108.47 & 105.14 & 104.22 & 102.77 \\
\hline Duration annuity & 50.28 & 48.42 & 46.51 & 50.67 & 48.38 & 45.81 \\
\hline \multirow[t]{2}{*}{$\Delta$ annuity } & 1.55 & 1.48 & 1.42 & 0.83 & 0.79 & 0.75 \\
\hline & \multicolumn{6}{|c|}{$10 \%$ penalty-free prepayment } \\
\hline Mortgage value & 99.45 & 1.02 .50 & 105.4: & 104,03 & 103.09 & 101.77 \\
\hline Duration mortgage & 46.75 & 40.56 & 35.27 & 45.04 & 42.86 & 40.28 \\
\hline$\Delta$ mortgage & 1.47 & 1.34 & 1.22 & 0.79 & 0.75 & 0.71 \\
\hline \multirow[t]{2}{*}{ Option value } & 0.06 & 0.99 & 2.99 & 1.1.1. & 1..14 & 1.00 \\
\hline & \multicolumn{6}{|c|}{$20 \%$ penalty-free prepayment } \\
\hline Mortgage value & 99.39 & 1.01 .53 & 102.49 & 102.91 & 101.97 & 100.74 \\
\hline Duration mortgage & 43.17 & 32.42 & 23.36 & 39.14 & 37.10 & 34.54 \\
\hline$\Delta$ montigage & 1.39 & 1.20 & 1.01 & 0.74 & 0.71 & 0.67 \\
\hline \multirow[t]{2}{*}{ Option value } & 0.12 & 1.96 & 5.98 & 2.23 & 2.25 & 2.03 \\
\hline & \multicolumn{6}{|c|}{$100 \%$ penalty-free prepayment } \\
\hline Mortgage value & 99.30 & 99.87 & 99.69 & 100.68 & 100.02 & 99.25 \\
\hline Duration mortgage & 27.05 & 14.13 & 5.40 & 21.94 & 22.20 & 20.24 \\
\hline$\Delta$ mortgage & 0.96 & 0.70 & 0.36 & 0.52 & 0.53 & 0.50 \\
\hline Option value & 0.20 & 3.62 & 8.78 & 4.45 & 4.19 & 3.53 \\
\hline
\end{tabular}

The table slows valuation results based on alternative VAR specifications, initial short-term interest rates, and penalty-free prepayment conditions. Duration is expressed in montlss. The effectine duration $\Delta$ is defined as the semi-elasticity of the mortgage with respect to the short-term interest rate. A quotation offer guarantee is not included in the mortgage contracts. Vtilized interest rates: Jan. 1981 . Dec. 1994, up-front fee: $1 \%$ of the loan. 

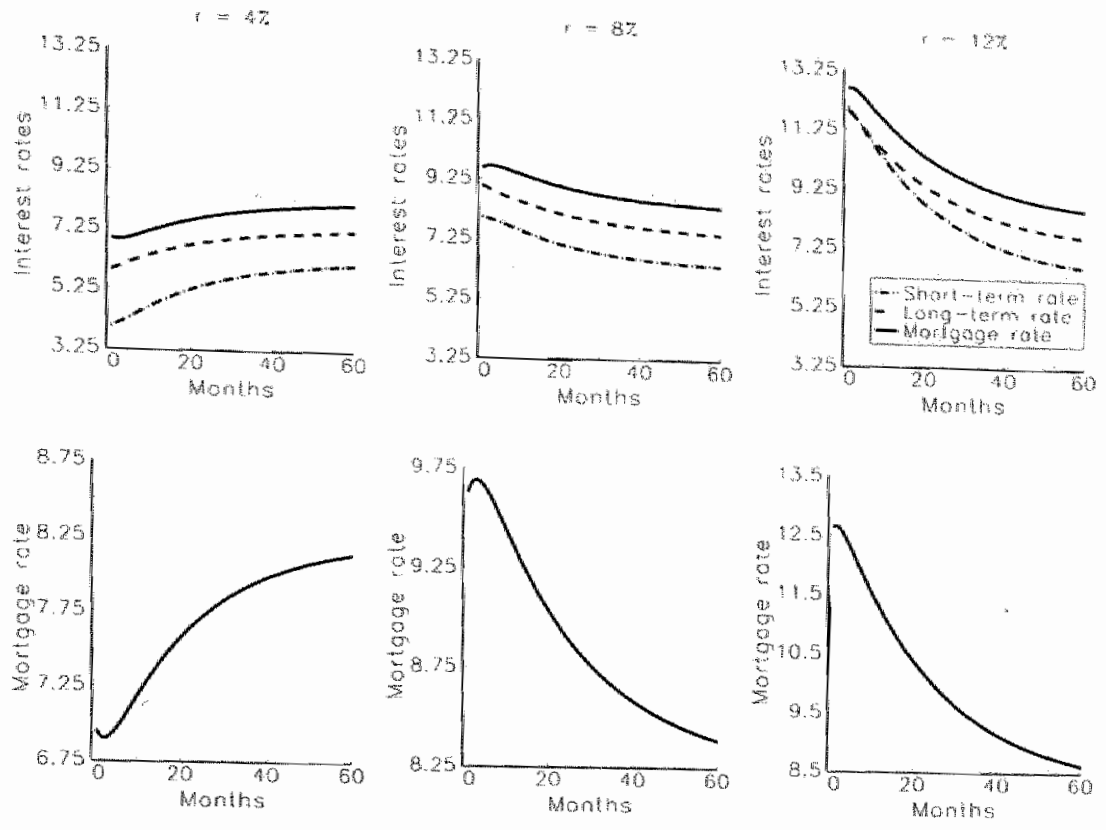

Figure 7.6: AVERAGE MORTGAGE RATE PATH

The upper diagrams of this figure show the average interest rate path generatrd by the stationary WAR model. The lower diagrams yield a close up look at the morigage rates. Tha * value on top of efch column represents the shot-tern intwest rate at which the simulatons started. The reenth are derived by 30,000 simulation runs besed on VAR andysts of Duth interest rates between 1981 and 1994.

\subsection{One-factor models versus multi-factor models}

This section compares the results of the valuation procedure based on the one-factor models developed in Chapter 5 with those of the multi-lactor approach. Sinco Chapter 5 concon trates on noncallable annuites and fully callable mont,gage contracts we focus solely on the same here.

The left-hand side of Table 5.6 in Chapter 5 shows the valuation results based on thres one-factor interest rate models where mortgage rates are exogenously related to short-berm interest rates. This exogenous specification is empirically detemined based on historical observations in the Netherlands. The results reported in Table 5.6 are based on the same prepayment rule as applied in this chapter.

Table 7.8 presents the changes in the results when angle factor model underlying the pricing algorithm is replaced with a mult-lactor interest rate process. The figures are found by subtracting the results of the malti-factor model from those of the vartous one factor models. Note that the spreads between the short-txerm interest rate and the mortgage ratro 


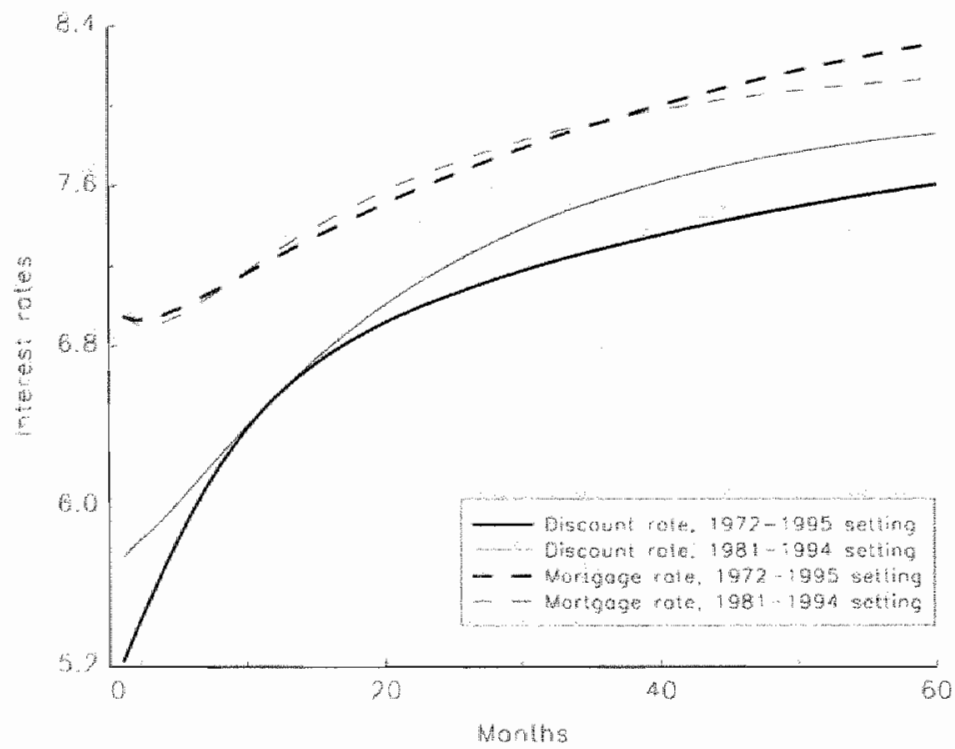

Figure 7.7 : AVERAGE MORTGage RATE PATH

The bold lines in this figure slow the average discount and mortgage rate paths resulting from 30,000 simulations based on the stationary specification of the VAR model which took interest rates obserwed between 1972 and 1995 as inpul. The thin lines are based on interest rates observed between 1981 and 1994. "The discount rate is equal to the short-term interest rate adjusted for the market price of risk. "The initial short-term interest iratie equals $4 \%$.

are not the same in both settings. At an initial spot rate of $4 \%$, the one-factor models utilize apread which is 70 basis points higher than its counterpart in the multiwactor sethings. A. a spot wate of $8 \%$, the spread in the one factor models is 53 basis points less 1han tho spread applied in the multi-factor model, while at an initial spot rate of $12 \%$ it is 48 basis points higher. ${ }^{8}$

In Chapter 5 as well as in this chapter, we use the effective duration measure to analyze the inpact of small adjustment in the short-term interest rate on the mortgage value. In Chater b, the distance between successive interest rate grid points detemined the size of this small adjustment. Consequently, adjustments of 10 basis points were studied. In the simulation approach we are free to choose a particular adjustment. The $\Delta$ measures reported in this chapter are based on dewations in the short-term interest rate of one basis point, $i . r_{\text {. }}$ the variable $h$ in Equation (7.1.0) is equal to one basis point. To bring the $\Delta$ measures of both chapters in line with one another we also calculated the effective duration

\footnotetext{
In Chepter 5 we fithed the function $y(t)=f((r(t))$, where $y(t)$ is the mortgage rate and $r(t)$ is the Whonthen intereat rate. In this maptrer we calculate the awerage spreads at spot rates of 4,8 and $12 \%$ pathe: than estimating the entite functional relation.
} 
$\Delta$ based on deviations of 10 basis points. This hardly changed the $\Delta$ meastre, so that the interest rate risk benchmark reported in Table 7.7 can be compared with its counterpart in Table 5.6 .

TABLE 7.8: ONE-FACTOR MODELS VERSUS MULTI-FAOTOR MODELS

\begin{tabular}{lrrrrrr}
\hline VAR specification & \multicolumn{3}{c}{ stationary } & \multicolumn{3}{c}{ unit rool } \\
Spot rate & $4 \%$ & $8 \%$ & $12 \%$ & $4 \%$ & $8 \%$ & $12 \%$ \\
\hline \multicolumn{3}{c}{ CIR model - multi-factor model } \\
Annuity value & 6.24 & 0.58 & 1.65 & 0.61 & -0.15 & 7.35 \\
Duration annuity & -0.56 & -0.20 & -0.89 & -0.95 & -0.16 & -0.19 \\
$\Delta$ annuity & 0.62 & 0.59 & 0.52 & 1.34 & 1.28 & 1.19 \\
Mortgage value & 5.08 & 0.42 & 0.57 & 3.70 & 0.27 & 1.00 \\
Duration mortgage & 14.11 & 2.25 & 0.45 & 19.22 & -5.82 & -14.39 \\
$\Delta$ mortgage & -1.97 & -0.56 & -0.45 & -1.53 & -0.39 & -0.59 \\
Option value & 1.18 & 0.16 & 1.08 & -3.07 & -0.41 & 6.39 \\
\hline
\end{tabular}

Nonlinear model - multi-factor model

\begin{tabular}{lrrrrrr} 
Annuity value & 7.27 & -0.41 & 0.93 & 1.64 & -1.14 & 6.63 \\
Duration annuity & -0.44 & -0.27 & -0.99 & -0.83 & -0.23 & -0.29 \\
$\Delta$ annuity & -1.29 & 2.49 & -0.69 & -0.57 & 3.18 & -0.02 \\
Mortgage value & 7.26 & -0.67 & 0.54 & 5.88 & -0.82 & 0.98 \\
Duration mortgage & 21.30 & 4.88 & -1.65 & 26.41 & -3.19 & -20.24 \\
$\Delta$ mortgage & -0.94 & 0.72 & -0.39 & -0.50 & 0.89 & -0.53 \\
Option value & 0.02 & 0.26 & 0.40 & -4.73 & -0.31 & 5.65 \\
\hline & Nonparametric model - multi-factor model \\
Annuity value & 0.74 & 0.68 & 6.30 & -4.89 & -0.05 & 12.00 \\
Duration annuity & -0.88 & -0.18 & -0.51 & -1.27 & -0.14 & 0.19 \\
$\Delta$ annuity & -1.31 & -0.06 & -0.57 & -0.59 & 0.63 & 0.10 \\
Mortgage value & 0.76 & -0.40 & 0.39 & -0.62 & -0.55 & 0.83 \\
Duration mortgage & 9.85 & -2.90 & -1.32 & 14.96 & -10.97 & -16.16 \\
$\Delta$ mortgage & -0.75 & -0.13 & -0.28 & -0.31 & 0.04 & -0.42 \\
Option value & -0.01 & 1.07 & 5.91 & -4.26 & 0.50 & 11.16 \\
\hline
\end{tabular}

The numbers in whe table are found by subtracting the results of the mullifactor model from those of the various one-factor modelis. The single factor models are based on the empirical relation between short-term interest rates and mortgang rates in the Netherlands.

Table 7.8 shows that the effects of the alternative interest rate processes on the mortgage values are minor. Except at an initial spot rate of $4 \%$, the diflerence betwem tho mortgage valuation results based on a single or multi-lactor interest rate model does mot exced $1 \%$. However, one may not conclude that the underlying interest rate process is therefore unimportant. The $\Delta$ measure, which we saw earlier was sensitive to the period unden consideration, turns out to be very responsive to the interest rate process as well. The 
inlerest rate sensilivity is largest when a multi-factor approach is used.

As previously mentioned, the stationary mult-factor process prescribes that the discount rate will converge at the sume $8 \%$ level as in the single factor specifications. Ditferences in the valuation results are therefore mainly caused by spread differences between the short-term interest rate and the nortgage rate, and by differing mean-reversion drits and deviating interest rate volatilities.

The unit root process requires an alternative approach to inclucle the market price of interest rate risk. As a consequence, the dynamics of the discount rate in the single factor approaches differ substantially from the dynamics described by the multi-factor unit root specification. This difference complicates the comparison of the results.

Chapter 5 also considers an optimal prepayment rule which states that the borrower prepays when the value of the mortgage, if left uncalled, exceeds the outstanding debt plus any transaction costs associated with refinancing. As discussed in Chapter 5 , this prepayment rule can only be used when the mortgage rate is endogenously determined as a function of the short-term interest rate. This enclogenous relation is derived by imposing that the mortgage walue at origination equals the face value of the loan. Even though this requirement is not imposed on the multi-factor pricing algorithm, we can compare both approaches because the multi-factor approach yields mostly mortgage values close to par. Table 7.9 presents the differences between the results of both approaches. Once again, Table 7.9 focuses on noncallable annuities and fully callable mortgage contracts and the figures represent the differences between the valuation results of both approaches.

Table 7.9 displays that the mortgage and annuity values found by the alternative pricing algorithms are very similar, but that the risk measures differ strongly. When noncallable annuities are studied the fluctuations in the duration are rather small, but when fully callable contracts are analyzed, this measure alters substantially, especially at low rates. In absolute numbers, the $\Delta$ measure is much smaller than the duration. Consequently, the deviations in the $\Delta$ measure stand out less, even though the proportional mutation is much larger. Both Tables 7.8 and 7.9 exhibit the impact which the underlying interest rate model has on risk measures and therefore on the required hedging strategy.

\subsection{Conclusion}

Vahuation in Chapter 5 proceeds through a discrete/finite state Markov chain, for which three empirical one-factor dynamic processes for the short-term interest rate are specified. The fundamental variable in these single factor models is the instantaneous interest rate which is assumed to be the sole factor influencing mortgage rate dynamics. The results of Chapter 6 , however, indicate that the mortgage rate dynamics can be modelled more accuraty when more factors are considered. We therefore include the long-term interest: rate and the morkgage rate as two additional factors in this chapter. The dynamic inleractions between these variables are described by the Vector AutoRegressive processes 
TABLE 7.9: ONE-FACTOR MODELS VERSUS MUETI-FACTOR MODELS

\begin{tabular}{|c|c|c|c|c|c|c|}
\hline \multirow{2}{*}{$\begin{array}{l}\text { VAR specification } \\
\text { Spot rate }\end{array}$} & \multicolumn{3}{|c|}{ stationary } & \multicolumn{2}{|c|}{ wint root } & \multirow[b]{2}{*}{$12 \%$} \\
\hline & $4 \%$ & $8 \%$ & $12 \%$ & $4 \%$ & $8 \%$ & \\
\hline & \multicolumn{6}{|c|}{ CIR model - multi-factor model } \\
\hline Annuity value & 4.05 & 1.47 & 0.06 & -1.58 & 0.74 & 5.76 \\
\hline Duration annuity & -0.24 & -0.33 & -0.68 & -0.63 & -0.29 & 0.02 \\
\hline$\Delta$ annuity & 0.63 & 0.58 & 0.52 & 1.35 & 1.27 & 1.19 \\
\hline Mortigage value & 0.70 & 0.13 & 0.31 & -0.68 & -0.02 & 0.75 \\
\hline Duration mortgage & 3.10 & -5.31 & -1.86 & 8.21 & -13.38 & -16.70 \\
\hline$\Delta$ mortgage & -0.91 & -0.52 & -0.16 & -0.47 & -0.35 & -0.30 \\
\hline \multirow[t]{2}{*}{ Option value } & 3.36 & 1.34 & -0.25 & 0.89 & 0.77 & 5.00 \\
\hline & \multicolumn{6}{|c|}{ Nonlinear model - multi-factor model } \\
\hline Annuity value & 3.29 & 2.22 & -1.48 & -2.34 & $\mathbb{1} .49$ & 4.22 \\
\hline Duration annuity & 0.13 & -0.66 & -0.65 & -0.26 & -0.62 & 0.05 \\
\hline$\Delta$ annuity & -1.29 & 2.46 & -0.69 & -0.57 & 3.15 & -0.02 \\
\hline Mortgage value & 0.70 & 0.13 & 0.31 & -0.68 & -0.02 & 0.75 \\
\hline Duration mortgage & -3.82 & -0.21 & -2.92 & 1.29 & -8.28 & -17.76 \\
\hline$\Delta$ mortgage & -0.87 & -0.20 & .0 .24 & 4.36 & -0.03 & -0.38 \\
\hline \multirow[t]{2}{*}{ Option value } & 2.60 & 2.09 & -1.79 & -1.65 & 1.52 & 3.46 \\
\hline & \multicolumn{6}{|c|}{ Nonparametric model - multi-factor model } \\
\hline Annuity value & 2.61 & 3.33 & 5.45 & -3.02 & 2.60 & 11.14 \\
\hline Duration annuity & -1.17 & -0.57 & -0.40 & -1.56 & -0.53 & 0.30 \\
\hline$\Delta$ annuity & -1.31 & -0.06 & -0.57 & -0.59 & 0.63 & 0.10 \\
\hline Mortgage value & 0.70 & 0.13 & 0.31 & -0.68 & -0.02 & 0.75 \\
\hline Duration mortgage & -7.14 & -5.23 & -1.70 & -2.03 & -13.30 & -16.54 \\
\hline$\Delta$ mortgage & -0.83 & -0.46 & -0.25 & -0.39 & -0.29 & -0.39 \\
\hline Option value & 1.92 & 3.20 & 5.13 & 2.33 & 2.63 & 10.38 \\
\hline
\end{tabular}

The figures in this table are found by subtraching the results of the mulli-ficior model from those of the various one-factor models. The single factor models are based on the endogenously derived relation between short-term interest rates and mortgage rates in the Netherlands, whereby it is assumed that the nortgagor prepays the contract when the value of the contract, if left uncalled, exceeds the ont standing debt plus any transaction costs. 
developed in the previous chapter. The resulting VARarameters are applied to simulate the short-term, long-term and mortgage interest rates which are used as the input of the waluation procedure.

Two specifications of the VAR model are utilized to describe the dynamic interactions between the interest rates. In the first specification a stationary process is analyzed, whille the second one includes a unit root. The walue of the prepayment option turns out to be especially sensitive to the chosen VAR specification underlying the mortgage pricing algorithm. The up-front costs of starting a new contract also have a substantial impact on the value of the prepayment option. Minimum interest guarantees frequently embodied in gututation offers preceding a Dutch contract seems to only have a small effect on the value and interest rate characteristics of a mortgage contract.

There is tendency to believe that the prepayment option embodied in Dutch contracts is of minor importance in comparison to the United States because of the annual prepayment restrictions. Although less important than in the US, the valuation results clearly show that the limited prepayment option is not insignificant, because the value of a jo\% penaltyfree prepayment option equals one quarter of the value of a prepayment option without any limitations. The value of the $20 \%$ penally-free prepayment option is even equal to half the value of the $100 \%$ penalty-free prepayment option!

The valuation results from the unit root specification of the VAR model are often not in lieeping with general economic theory. For example, instead of an increasing value of the annulity and mortgage contract with higher initial interest rates, exactly the opposite is observed. We would also expect to see a pattern in the duration and option value correlating with interest rate fuctuation. However, no such pattern can be detected.

In order to bring the muti-factor approach in line with the one-factor models of Chapter 5 , the $V A R$ analyses, which form the basis of the pricing algorithm, are repeated with interest rates observed between January 1981 and December 1994. This adjustment in the consinlered period turns ont to have a major impact on the value of the risk measures of Whe contract, i.e the effective duration $\Delta$ increases substantially when the sample period is shoptrened.

Mortgage valuation algorithms based on both multifactor interest rate processes yield mortgage values which are very similar to the results based on the one-factor models. However, the interest rate sensilivity of a mortgage contract is substantially influenced by the choice of a particular interest rate model. As a result, the required hedging strategy will depend on which model has been chosen. 


\section{Chapter 8}

\section{A repeat sales index for residential property in the Netherlands}

\subsection{Introduction}

For most individuals, the purchase of a house is the largest investment of a lifetime. "To analyze the risk and retum characteristics of this investment we develop an index for residential property in the Netherlands. This index will show the general price novements in the Dutch property market between May 1973 and December 1995. The index is of interest to institutional investors, tax authorities, academic researchers, and if will help homeowners with their personal finance decisions. Risk and return properties of the housing market determine the diversification possibilities and therefore the composition of homeowners." portfolios. Moreover, the index enables mortgagees to undergo quantitative research regarding default risk. ${ }^{1}$

A resiclential price index should give a representalive image of the tendency of the housing market and has to reflect the fluctuations in house prices rathet that the changing composition of houses sold in the different periods. The characteristirs of the houses sold change from period to period. Consequently, indices based on summary shatistios lith the mean and median price of all properties sold in given period have serous drawbacks.

Methodologies used to construct a constant quality house price index can be divided into three major categories: the hedonic method, the repeat sales method and thr hybrd method. In this paper we focus on the repeat sales method introduced by Bahloy, Muth and Nourse (1963) and refined by Case and Shiller (1987).

The remainder of this paper is onganized as follows. In Section 8.2 wo briefly aloscribo the alternative methodologies for construeting a constant quality real estate index. The weighted repeat sales method as presented by Case and Shiller (1987) will be explaned in more detall in Section 8.3. The house price data used in this paper will be summarized in

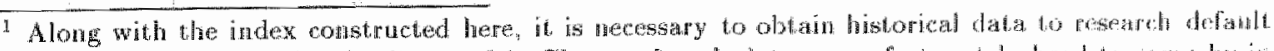
behavior in the Netherlands. As discussed in Chapter 2 such datare anfortubuly hand to come by in the Netherlands.
} 
Section 8.4 . The results follow in Section 8.5 . The conclusions and recommendations for future research wre summand in Section 8.6 .

\subsection{Index methodologies}

Factors that influence the price of residential property can be divided into two major categories. The first eategory encompasses property characteristics, the most important of which is probably the location of the house. Property size, age and condition are also included whin this category. The second category is made up of economic factors, such as the mortgage rate and inflation. The first category is the starting point for a real estate index constructed with a hedonic regression method, while an index based on a repeat sales regression focuses directly on market factors. Both methodologies are combined in the hytrid method.

Originally, the thedonic technique was developed by Court (1939) for the automobile market. After the theoretical elaboration by Rosen (1974), it was widely applied to the real estate market. The basic idea behind the hedonic method is that the price of a house congists of a combination of property attribute prices, like lot size, number of rooms, the existence of a garage, et cetera. In the hedonic aegression technique, the observed sale prices are regressed on these property characteristics. Hereby it is assumed that the prices of these attributes remain constant over time. This is especially a shortcoming when the real estatie index covers an extensive period of time. The coefficients resulting from the hedonic regression indicate the extent to which each of the atributes contribute to the tolal price of the house. A constant quality residential property index can be derived from the hedonic regression results if the coefficients are allowed to be time-heterogeneous.

A hedonic regression will only yield an unbiased index if the correct set of explanatory variables and the correct mathematical relation between these regressors are used. In the exceptional case that these requirements are met, it will still be difficult to execute the regression because the required data are often not avalable. Additionally, the hedonic method does not tise all information efficiently. A single property which is sold twice con tains information which can be used more efficiently than is done by a hedonic regression. Most attributes will not have changed in between the two transaction dates of such a repeat sales pair. The difference in price will only be aflected by the attributes that did change and the elapsed time between transactions. The repeat sales method utilizes the avalable information of these repeated transactions much more efficiently.

The data required to rum a repeat sales regression consists of prices from properties that are sold more than once in the observed period. Using this sample allows the calculation of price changes for each individual house. The difference between the ratural logarithm of the selling and the buying prices is regressed on a set of dummy variables, one for each lime period in the sample except for the base period. These dummy variables can take three walues: the dummy corresponding to the first sale of the house is -1 , and the second 
sale dummy equals +1 . In all other cases the dummy wariale is zero. The repeat sales index is found by computing the exponent of the estimated coefficients.

The repeat sales method controls for house quality by using the information from property specific price fluctuations. After all, it is the same house that is looked at. It is hereby assumed that the quality is constant during the intra-sale interval such that renovations between sales are ignored. Homes sold after long time intervals are less likely to meet this assumption. Despite this, these homes have relatively more weight in the original repreat sales method than homes sold over short time interwals. Case and Shiller (1987) attempt to control for this by applying a Generalized Least Squares technique instead of the Ordinary Least Squares method proposed by Bailey, Muth and Nourse (1963).

If the residential property prices follow a random walk, the three stage least squares technique suggested by Case and Shiller (1987) will correct for any heteroskedasticity in the data. After running the Ordinary Least Squares (OLS)regression as proposed by Bailey, Muth and Nonrse (1963), the second stage consists of an OLS regression of the squared residuals on a constant and the time between sales. Subsequently, a weighted least squares regression is run such that the weights are the estimated standard deviations of the second stage. The exponent of the estimated coefficients from the third stage yields the weighted repea: sales index.

Alongside heteroskedasticity in the data, a second source of inefficiency in the repeat sales method shows up in the large number of sales that are required before a reasonable repeat sales sample is obtained. Instead of using all available transaction data, only a small portion is used. If this subsample is not representative for the entire propertiy population, the index will be biased. Relatively new houses, and those with undesirable features, are not likely to be included in the repeat sales sample, while so-called starter homes might be over-represented. Clapp, Giaccotto and Tirtroglu (1.991) argue that this does not influence the index. They state that all properties in a given area should appreciate at approximately the same rate. If starter homes appreciate at a faster rate than other properties, these lat ter properties will become more in demand. As a result, the prices of these properties will be driven up and the discrepancy will disappear.

The repeat sales method assumes that no house attribute changes between transactions. Strictly speaking, no transaction pair can ever meet his assumption because the age of the property will be higher at the second sale. The negative effect of aging implies that a repeat sales index based on homes whose only changing attribute is the increased age will be biased downwards, and thus systematically lower than a pure price index. On the other hand, correcting the index for all depreciation is not advisable either. Depreciation of a property is caused by both physical deterioration and changing market preferencess. Homeownerss can control most of the physical deterioration and therefore, the property index needs no adjustment. If we assume that houses are well maintained, only general factors that infuence the whole market will cause depreciation. A real estate index constructed to show the general tendency of the housing market should thus include those market factors such that a correction for this aspect is undesirable. 
In addition to renovation, subsample and depreciation bias; a fourth source of potential bias in the repeat sales index may arise when a geometric mean is used instead of an aribmetic mear. 'The coefficients estimated by the repeat sales regression are arihmetic means of logged growth rates. The repeat sales index is found by taking the exponent of these coefficients. This logarithmic transformation results in an index which is based on geometric means, making it more diffeult to interpret. The value of a real estate portitolio is equal to the sum of the values of the individual properties rather than the product of the separate houses. In other words, portolio values are arithmetic transformations of prices and not geometric transformations. A real estate index based on arithmetic means is therelore mone preferable than an index based on geometric means. Unfortunately, the index based on the repeat sales methodology is a geometric index. Since a geometric mean will alway be less than or equal to an arithmetic mean, the repeat sales index is downward biased.

Finally, fnancial indices are often used as a benchmark for performance measurement. The repent sales index is not suited for this. Nor can the index be used to settle derivative contracts, the reason for which can be found in the so-called "revision volatilty". As time advances, new information becomes available: houses that were not embodied in the original subsanple might now be sold for an second time and therefore be included in the repeat sales clata set. This extra information about the first and second sale of those houses will influence both the current and the past index numbers. Consequently, settling contracts and awarding bonuses to investors on the basis of repeat sales index numbers may result in retraction. when new information comes available.

In 1991, Case and Quigley presented a hybrid method which uses all available information and utilizes the controls inherent in repeat transactions. To achieve this, they divide the total data set into three subsets. The first subset contains information on property sold only once, the second embodies data regarding repeat transactions of properties where attributes did not change between both sales dates, and the third includes repeat transactions of properties whose attributes did change. For each of these subsets a separate regression equation is set up: the first being a pure hedonic equation, the second being a pure repeat sales equation and the third being a modified repeat sales equation. In fact this is a system of three semingly unrelated regression equations as described by Zellner $(1902)$.

By combining the hedonic and repeat sales technique, the hybrid method includes both the desirable and undesirable teatures of the two approaches. It increases the efficiency of the repeat sales estimator at the cost of potential specification bias in the hedonic part of the system. 'liwo other shortcomings of the hedonic model come into play here as well. The first being the assumption that the prices of the property attributes remain constant over time, and the second being the lack of data required to estimate the parameters.

In contrast to Case and Quigley (1991), Case, Pollakowski and Wachter (1991) found that using the hybrid method instead of the hedonic or repeat sales methods does not increase efficiency. By comparing the hedonic and repeat sales index they found that 
Whe later index displays smaller increases in house prices than the former. A similar result was found by Mark and Goldberg (1984) and by Cannaday and Yang (1995). The empirical results of Cannaday and Yang (1995) support the hypothesis that a repeat sales index is downward biased if no conrection for depreciation bakes place. In disagreenent with this, Gatalaff and Ling (1994) found that indices based on median, repeat sales and hedonic methods all produce good estmates of the property index. Clapp, Giaccotio and Tintiroglu (1991) perceived that over long periods of time (they suggest three years or more) a repeat sales index does not systematically differ from an index based on all avalable transaction data. Abraham and Schauman observe in addition to these mixed results, that the weighted repeat sales index based on the data set from the Federal Home Loan Mortgage Corporation (Freddie Mac) behaves like other indices up until 1985. Alter that the index shows a stronger growth than the others. The probable consensus of all these studies is found by Gatzlaft and Haurin (1996), who conclude that a pure repeat. sales index is biased upward during a period of ecomomic growh and downward during a period of economic weakness.

This literature review slows that empirical sudies disagree about which methotology is preferable above all others. Although theoretically superior, the hedonic and hybrid methods did not necessarily turn out to be better than the repeat sales technique. Fur thermore, both the hedomic and hybrid method are hard to implement. In order to oblain unbiased estimates of a property index it is essential that the hedonic regression equation is correctly specified with respect to both functional form and regressors. This factor, along with the limited availability of data, prompted us to choose the weighted repeat sales methoclology in constructing a residential property index for the Netherlands.

\subsection{Weighted repeat sales methodology}

In this section we will describe the computations involved with the weighted repeat sales method. Basically, a Generalized Least Squares (GLS) estimation is employed with weights that are related to the time between two consecutive transactions of one property unit.

Suppose that we have data on repeat sales for a sample period of lenght $T$. Let. $P_{\text {r }}$ be the property walue at time $T \in\{1, \ldots, T\}$. The superscript on the time inclex fers to the $k^{\text {th }}$ repeat sale $(k=1, \ldots, K)$. A complete repeat salle comprises a pair $\left\{P_{\gamma_{1}}, P_{r_{2}}\right\}$. The first number corresponds with the purchase value and the second number coincides with whe value of the property at the selling date. In the first step we perform the following regression:

$$
\begin{aligned}
& \ln P_{\sigma_{z}^{k}}-\ln P_{\pi_{1}^{k}}=\beta_{t}\left(\delta_{t+t_{2}^{k}}-\delta_{k r_{1}^{k}}\right)+\varepsilon_{k}, \quad \varepsilon_{k} \sim I I D\left(0, \sigma_{\varepsilon}^{2}\right), \\
& \tau_{1}^{k}, \pi_{2}^{k} \in\{1, \ldots, T\}, \quad k=1, \ldots, K, \quad t=\mathbb{1}, \ldots, T,
\end{aligned}
$$


with

$$
\delta_{t \tau_{i}^{k}}= \begin{cases}1, & t=\tau_{i}^{k} \quad i=1,2, \quad t=1, \ldots, T \\ 0, & \tau_{i}^{k}=1, \quad i=1,2, \\ 0, & \text { otherwise. }\end{cases}
$$

In words, the changes in logarithmic prices are regressed on a set of dummy variables that take vallues -1 and $]$ at the times of buying and selling, respectively. The coefficients $\beta_{t}$ are the estimates for the logarithmic repeat sales index. The dummy variables for the first period $t=1$ are set to zero for identification.

In eartier studies on repeat sales indices, notably Bailey et al. (1963), the error terms $\varepsilon_{k}$ are assumed to have a constant variance. This assumption has been disputed by Case and Shiller (1987). These authors argue that the length of the time interval between sales is related to the variance. In fact, they assume that the logaritlim of a particular price consists of three parts: a general level $c_{r}$, an uncorrelated random wall $x_{\tau^{*}}$ and a property-specific random error $\eta_{\pi}$ :

$$
\ln P_{\tau^{k}}=c_{\tau}+x_{\tau^{k}}+\eta_{\tau^{k}}, \quad \eta_{\tau^{k}} \sim I D D\left(0, \sigma_{n}^{2}\right)
$$

with

$$
x^{k}=x_{\tau}^{*}-1+k_{T^{k}}, \quad k_{\tau^{k}} \sim N\left(0, \sigma_{x}^{2}\right) .
$$

Consequently, Case and Shiller (1.987) suggest to run an additional regression, in which estimates for the mnknown variances of the idiosyncratic error term and $\nu_{r}$ must be found. "This regression reads:"

$$
\hat{\varepsilon}_{k}^{2}=2 \sigma_{n}^{2}+\sigma_{x}^{2}\left(\tau_{2}^{k}-\tau_{1}^{k}\right)+\xi_{t},
$$

with $\sigma_{n}^{2}$ and $\sigma_{i p}^{2}$ the coefficients to be estimated. The GLS estimation procedure is finished by repeating the first-stage regression with the left-hand side variables $\left(\ln P_{r_{2}^{k}}-\ln P_{\tau_{1}^{k}}\right.$ ) replaced by

$$
\frac{\ln P_{\tau_{2}^{k}}-\ln P_{r_{i}^{k}}}{\sqrt{2 \hat{\sigma}_{n}^{2}+\hat{\sigma}_{x}^{2}\left(\tau_{2}^{k}-\tau_{1}^{k}\right)}}
$$

The dummy variables are adjusted accordingly. The new coefficients $\beta_{t}^{\text {GLS }}$ are the estimates of the logarithmic weighted repeat sales index.

From gquation $(8.3)$ we know that

$$
\ln P_{r_{k}}-1 \| P_{r_{i}^{k}}=c_{T_{2}}-c_{r_{1}}+\sum_{j=r_{1}}^{T_{1}} \Delta x_{j^{k}}+\eta_{r_{2}^{k}}-n_{r_{j}^{k}}
$$

with

$$
\begin{aligned}
\Delta x_{\pi^{k}} & =\varepsilon_{r^{k}} \quad \varepsilon_{r^{k}} \sim N\left(0, \sigma_{x}^{2}\right), \\
\eta_{T^{k}} & \sim \operatorname{l}\left(0, \sigma_{\eta}^{2}\right)
\end{aligned}
$$

such that

$$
\sigma_{\ln P_{\mathrm{r}_{2}^{k}}^{2}-\ln p_{\left.r_{1}^{k}\right)}^{2}}^{2}=\left(\tau_{2}^{k}-\tau_{1}^{k}\right) \sigma_{x}^{2}+2 \sigma_{\eta_{i}}^{2}
$$

From which equation (8.5) follows directly. 
The heteroskedasticity correction of Case and Shiller encompasses the conrections proposed by Bailey et al. (1963) for correlated errors. When a particular house has been sold more than twice within the sample period the errors on the price differential are correlated, because of common appearances of sale price errors $\eta_{\mathrm{T}}{ }^{3}{ }^{3}$

The heteroskedasticity correction of Case and Shiller (1987) has been subject to considerable debate." Many of the corrections that have been suggested try to incorporate property-specific characteristics, yielding so-called bybrid property indices. Other approaches focus on the GLS procedure itself. For the US market the Federal Home Loan Mortgage Corporation (Freddie Mac) and the Federal National Mortgage Association (Fannie Mae) have made a weighted repeat sales index in which the second-stage regression is replaced by

$$
\hat{\epsilon}_{k}^{2}=c_{0}+c_{1}\left(\tau_{2}^{k}-\tau_{1}^{k}\right)+c_{2}\left(\tau_{2}^{k}-\tau_{1}^{k}\right)^{2}+\xi_{k}
$$

In fact, many functional forms are possible here. It is very difficult to determine a priori an economically sensible form. Another way to look at the heteroskedasticity issue, is to model it in a conditional way, as was first proposed by Engle (1982). These AutoRegressive Conditional Heteroskedasticity (ARCH) models have been successfully applied in a wide variety of financial problems. ${ }^{5}$ We will leave this subject for further research.

\subsection{Data description}

The data used to construct the weighted repeat sales index for residential property in the Netherlands was collected by members of the Dutch Association of Real Estate Agents (NVM) from May 1973 to February 1996. Currently, the association arranges around 57 percent of all transactions on the Dutch residential property market. In 1995 the association reported 87,642 sales of the total 154,750 residential transactions recorded by the land registry.

Before the data was used to estimate the repeat sales property index, a correction was made for the differences in the sale conditions. Subsequently, bouses which had been sold more than six times during the observed period, and those whose recorded price was less than 10,000 guilders were eliminated. ${ }^{6}$ Transaction pairs which yielded average monthly returns above 5 percent were also taken out of the data because in those cases a change in

${ }^{3}$ In order to obtain the Beiley et. al. (1963) comection, Equation (8.5) has to be truncated ho

$$
\varepsilon_{k}^{2}=2 \sigma_{n}^{2}+\varepsilon_{i}
$$

See, for example. Wang and Zorn (1995) and the references theren. Goemman and Spieged (1995) add an intercept tern to the weighted repeat salles procedure to capture home ing rovenents and other foced coste. We estimated the repeat sales index both with and without this constant term. Both appoaches yidel very similar resulte. In the remainder of this chapter we therefore only pregent the index based on the origginal approach proposed by Case and Shiller.

5 See Bollerslev et. al. (1992) for a survey an ARCH nodels and vis applications in finance.

Dsing the exchange rate of August. ${ }^{\text {th }}$, 1996 this amont is equal to $6,040 \mathrm{US}$ dollars. 
housing guality most certainly took place. Another reason to exclude these obserwations is that houses could lave beer split into smaller dwelling units.

After these adjustrients, 228, 144 repeat sales pairs were extracted from a total of $1,089,176$ transactions which were registered between May 1973 and Febtuary 1996, indusively. The observations of January and February 1996 are induded in the repeat sales subsample since they eontain additional information used to estimate a repeat sales index covering the period to December 1995. It goes without saying that those observations are excluded in the mean and median indices which run until the end of 1995.

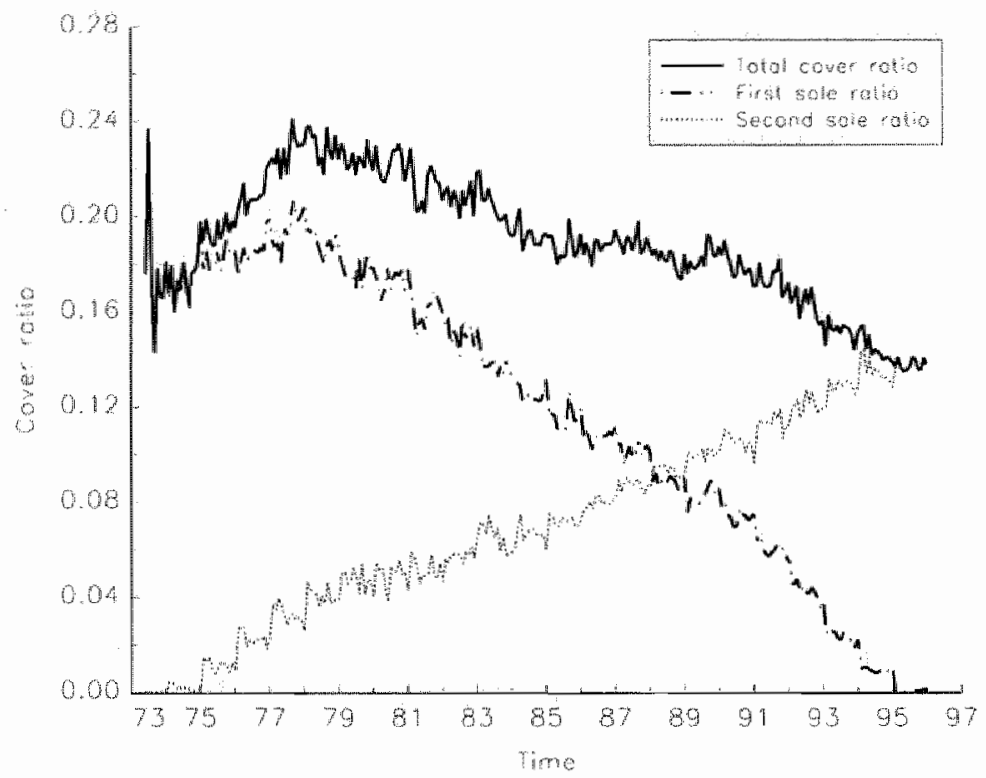

Figure 8.1: Cover pato

In Figure 8.1 the cover ratio of the repeat sales subsample is plotted over time. The cover ratio shows the proportion of all transactions conered by the repeat sales subsample. For month t the cover ratio is calculated as:

$$
\text { cover ratio }=\frac{K_{t}^{-}+K_{t}^{+}}{2 N_{t}}
$$

where $h_{-}^{-}$is the number of fits sales included in the repeat sales subsample for month $t_{\text {, }}$ $k_{i}{ }^{*}$ is the number of second sales embodied in the same subsample, and $N_{t}$ represents the number of transactions included in the complete NVM data set for that month. The cover ratio would be equal to one, if each transaction was both the second sale of an old repeat sales pair and the first sale of a new pair. However, as long as new houses are buitt and old houses are taken down, a cover ratio of one is unfeasible. For our data set an average cover ratio of 0.21 is found. 

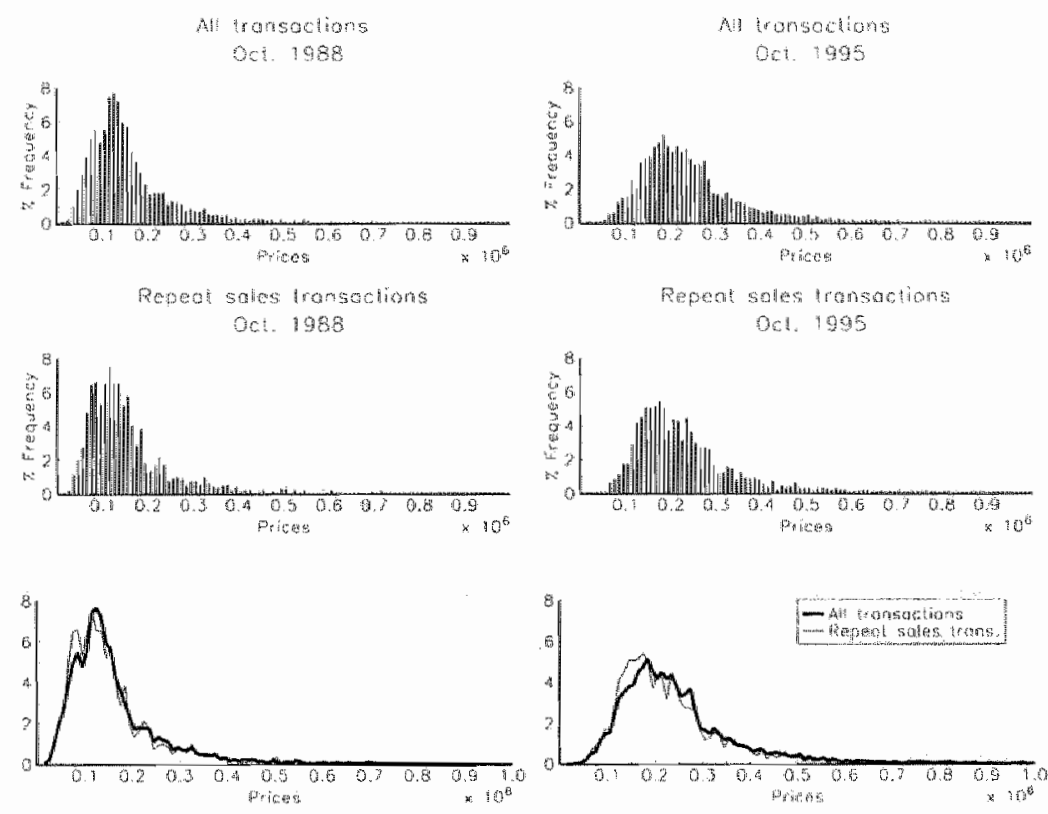

FIGURE 8.2: DISTRIBUTION OF RESIDENTIAL PROPERTY PRICES IN THE NETHERLANDS

The histograms in this figure show the relative rrequency distributions of house prices in different months. The upper diagrams are based on all transactions, while the midille only use house prices included in the repeat sales subsample. The lower diagram shows the difference between both distributions. Note thall prices are expressed in nominal guildets. 
For both the total population and the repeat sales stubample, the relative frequency distributions of house prices are ploted in Figure 8.2 for October 1988 and October 1995 , respectively. The upper diagram of this figure is based on all observed sale prices, while the middle diagram only uses house prices included in the repeat sales subsample. Both diagrang show that house prices are highly skewed to the right. For such heavily skewed distributions, the median is generally considered to be a better measure of central tendency than the mean. A property index based on the median of house prices is therefore recommended above an index based on the mean. A constant quality property index is naturally preferable to both summary statistic methods.

To compare the relative trequency distributions at one glance the relative frequency polygons of both the total population and the repeat subsample are plotted in the lower diagram of Figure 8.2. The lower diagram shows that for all three periods the house prices in the repeat sales subsample are only slightly more skewed to the right than the house prices in the total sample.

\subsection{Results}

There are different techniques for constructing a repeat sales index. As mentioned prewionsly, the introduction of the original technique proposed by Bailey, Muth and Nourse (1963) was followed by the adjustments made by Case and Shiller (1987). In Figure 8.3 the Dutch residential property indices are plotted for the two alternative repeat salles estimation methodologies. Alongside these repeat sales indices, Figure 8.3 also shows two summary statistic indices, based on the mean and median of the realized sale prices.

As previously mentioned, Freddie Mac and Fannie Mae further modified the weighted repeat sales methodology in their Consumer Mortgage Home Price Index (CMHPI) for the US market. However, applying this methodology to the Dutich data results in an index which is very similar to the weighted repeat salles index as illustrated in Figure 8.3 and is therefore not plotted here.

In contrast to the repeat sales indices, the two summary statistic indices originally revealed a statistically significant seasonal pattern. Both the mean and median index shown in Figure 8.3 are corrected for seasonality by regressing the index on a set of eleven dummy vinables, one lor exch month. This restlted in the loss of 11 months of observations. For purpose of comparison, the base period for the repeat sales indices is also moved from May 1973 to April 1974 . The difference between the mean and median index is small, as is the difference between the alternative repeat sales indices. However, the dissimilarity between the mean and median indices on the one hand and the repeat sales indices on the other is remarkable. This discrepancy seems to correspond with the conclusion drawn by Gatzlaff and Haurin (1996): during periods of economic growth the repeat sales index for resictential property increases laster than both summary statistic indices, while during periods of economic wealiness it decreases more rapidly. 


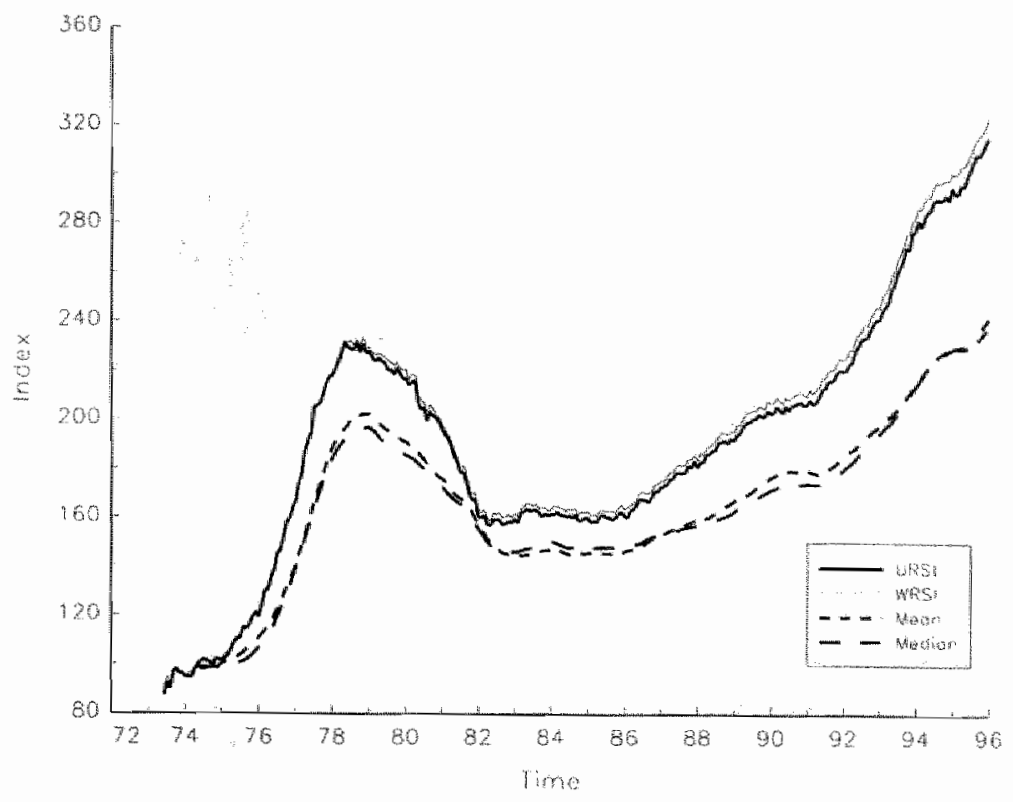

Figure 8.3: Indices for DUTCH RESIDENTIAL PROpERTY

This figure shows alternative price indices for residential property in the Netherlands. URSI and WRSI represent the urweighted and weighted repeat sales index, respectively. Marn and Median reflect the indices based on the corresponding summary statiatics.

All indices are based on observed transactions. The aversion of homeowners to sell their property during a downturn in the housing market might result in a selection bias for all four indices. Furthemore, in contradiction to the summary statistic indices which are based on the full data set of more than one million transactions, the repeat sales methodology utilized only a subsample of the observed transactions to estimate the indices. This sample selectivity might cause another bias in these indices. Following Goetzmann (1993) we studied the distributions of the separate series retums to examine this.

In Figure 8.4 the distribution of the monthly increments of both the unweighted and weighted repeat sales index are plotted. Additionally, the distributions of the crosssectional mean and median indices are included in the figure. The summary statistics of these distributions are presented in Table 8.1. The statistics correspond with the characteristics of many financial time series; moderate autocorrelation and loptokurtosis.

A positive skewness parameter indicates that the upper tail of the distribution is thicker than the lower tail such that the distribution is skewed to the right. If it is true that people avoid selling their homes during a downturn of the market we would expect to find a rightskewed distribution of returms and therefore a positive value of the skewness measurement. As Table 8.1 illustrates the results are not nombiguous. T"be distribution of the increments 

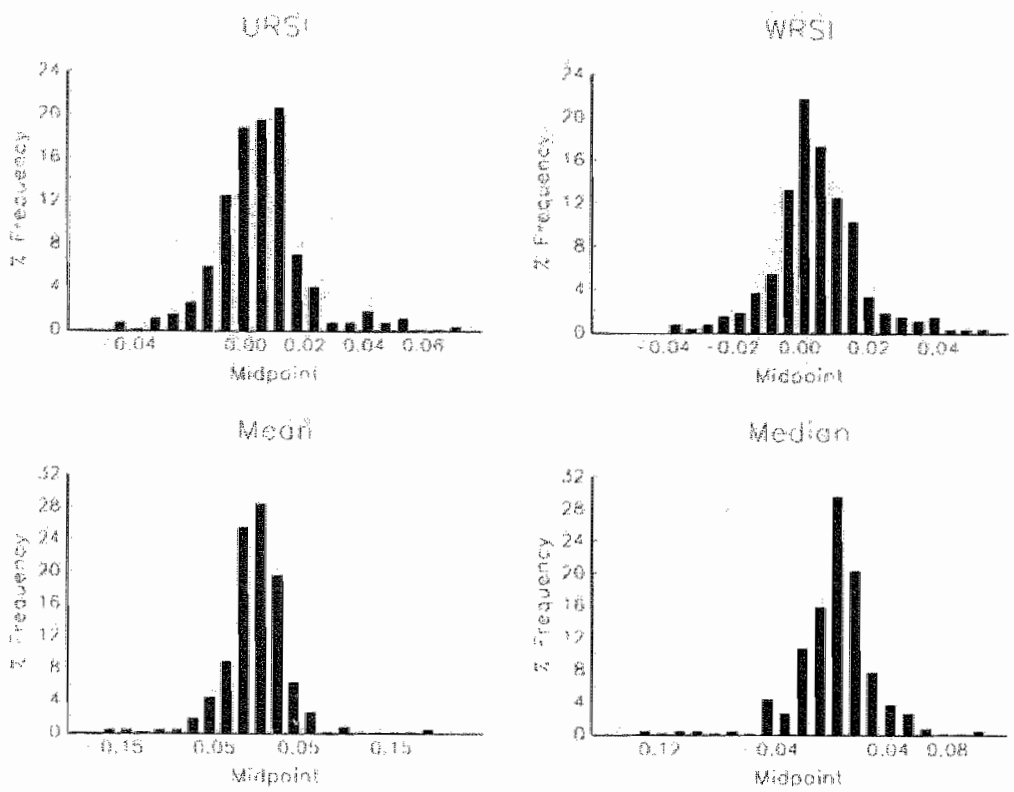

Filgure 8.4: Distribution of MONTHLY Nominal Returns

This figure shows the distrihutions of the nominal returns based on alternative housing price indices. URSY and WRST correspond with the anweighted and weighted repeat sales index. respectivedy. Mean and Medinn are hased on the summary statistic indices.

in the repeat sales indices exhibit positive skewness. This suggests that homeowners are unwlling to sell their property during a recession period in the housing maket. The legulive skewess measurements found lor the distribution of the returns on the summary statistic indices suggest the opposite. To study to what extent this contradiction causes the dissimilurily in the indices as ploted in Figure 8.3, a mean and median index based soldy on the repeat sales subsumple is constructed. The divergence between both groups of indices renains the same. This rules ont the argument that a selection bias has crept into the repat sales subsample, implying that the purale of the discrepancy between the repeat sales indices and stmmary statistic indices remains unsolved.

In order to analye how the wealth of homeowners changed over the years, these nom inal indices need to be adjusted for inflation. The IMF consumer price index for the Netherlands, adjusted for seasonality, is used for this. The resulting real weighted repeat

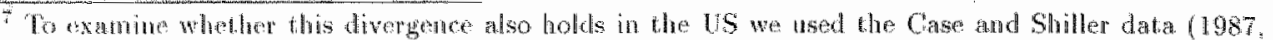
1090) to construth both a wighted repeat sales and a median index. The results are similar to what wh found for the Duth marke; When estimated for submarkets (the 4 cities in the US data and the 12 provines in the Mutch dateif the repeat sales and the median index follow each other closely. Howewer. when all data are used to construct one "umbrelle" index, the discrepancy between a weighted repeat sales and a medisu index siands out. 
TABLE 8.1: SUMMARY STATSTIOS

\begin{tabular}{lrrrr}
\hline Method & URSI & WRSI & Mean & Median \\
\hline Average increment & 0.48 & 0.47 & 0.35 & 0.33 \\
Standard Deviation & 1.49 & 1.29 & 3.24 & 2.48 \\
Skewness & 0.69 & 0.31 & -0.07 & -0.67 \\
Kurtosis & 5.99 & 5.10 & 10.63 & 7.84 \\
\hline
\end{tabular}

Note: The period of abservation is from Meay 1973 to December 1995. The average increment and standard deviation are presented als monthly percentages. The skewness of a series $x$ is calculatod as $S K=\frac{1}{\sigma_{x}^{3}} E\left[\left(x_{i}-x\right)^{3}\right]$. The thekness of the tails is mensumet by the kutosis: $h h^{2}=\frac{1}{\sigma_{x}^{*}} E\left[\left(x_{1}-x\right)^{4}\right]$.

selles index for Dutch residential property is shown in Figure 8.5 together with the $95 \%$ confidence interval. Since no seasonality correction is needed, the bese montl was mowed back to the first month of relevant observations, that is May 1973.

Figure 8.5 clearly shows the real estate bubble of the late seventies and caly eightios. This bubble was manly caused by high infltion levels while the mortigage rate did not increase proportionally. Between January 1975 and June 1976, the inllation rate was mostly higher than the mortgage rate. This is Hhastrated in the lower diagram of Figne 8.6. The upper diagram of this figure shows that the inflation peaked in Jamuary 1975. The arnualized intlation rate in that montl was 11.09 percent white the mortgage rate was only 10.71 percent. Additionally the interest paid on anortgage was and still is tax deductible. This means that a homeowner who fnanced her house with a mortgage in January 1975 while facing an income tax of 50 percent made a profit of 5.74 percent. These "Free lanches" drove up housing demand and therefore prices. Another explanation for the real estate bubble is that homeowners aticipated an increase in future incomes by

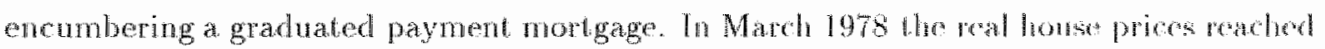
a peatk which has not been achieved since then. Becanse there was no conomic fondulion for real house pricing to be this ligh, the bubble exploded.

The bubble exploded when the infation decreased such that the differme butherth the mortgage and inflation rates changed to normal proportions. Additionally, duc to the econonic recession in the early eightics, many mortgagors faco fuancial dificulles. Especially, those mortgagors whose property was encumbered by a gradunted nomgage encountered financial difficulties.

Since 1986 real house prices are increasing steadily, with the excoption of 1990 , As Figure 8.5 shows, the real wighted repeat sales index stayed almost constant dung that year. The explanation for this can be found in the tax rewision which took offext on the first of a January 1990 , whereby the sum of income taxes and preming lewied by the govermment decreased for most people. However, due to diminisher dax fedtuctibility on mortgage interest payments this revision resulted in higher net monthly mor gage costs and therefore decreased housing demand. As Figute 8.5 illustratus, this affert dominated the 


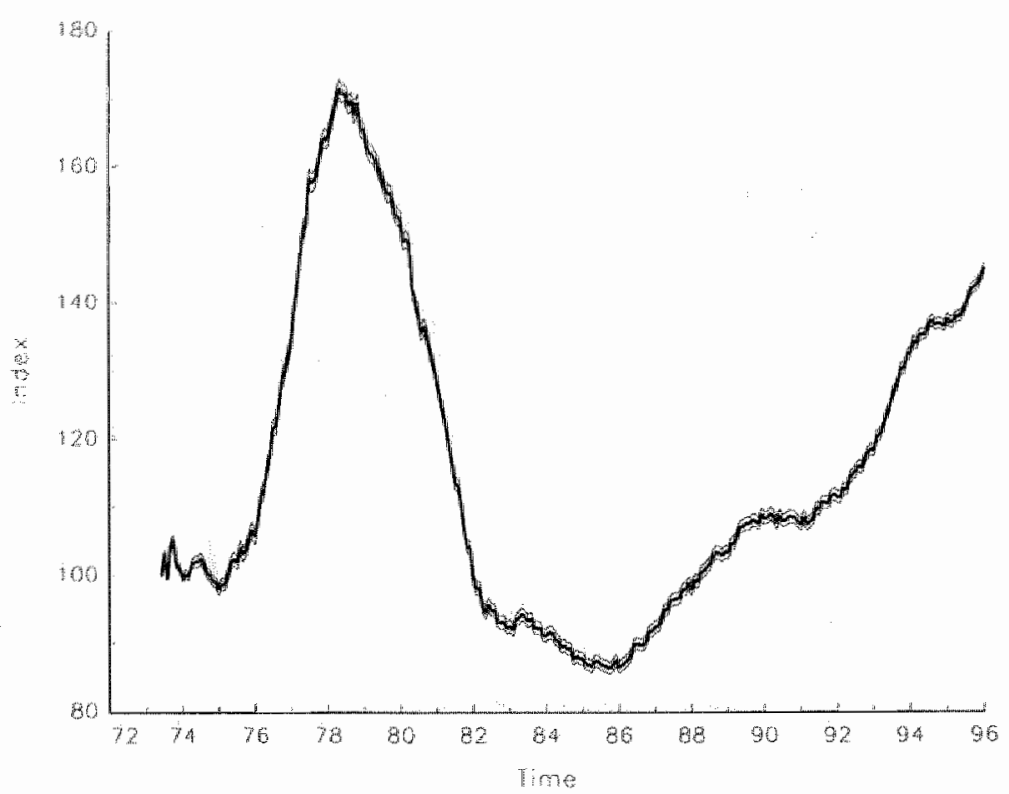

FIGURE 8.5: RIGAL WEIGHED REPEAT SALES INDEX FOR "THE NETHERLANDS

This figure shows the real weighted repeati sales index for Dutch residential property together with the $95 \%$ confidence interval.

income effect which stipulates that housing demand will rise if disposable income increases. At the end of 1995 , the value of the real weighted repeat sales index is 144.88 , which is equal to its walue on March 1977 and April 1980.

\subsection{Conclusion}

In this paper we have constructed a repeat sales index for residential property in the Netherlands. The data used to estimate repeat sales indices were supplied by the Dutch Association of Real Estate Agents, which covers $5 \%$ of the Dutch housing market. In total, 228,144 repeat sales pairs were used to calculate alternative repeat sales indices. Alongside the unweighted repeat sales index, a weighted repeat sales index (WRSI) was constructed by applying a Generalized Least Squares estimation technique to correci for heteroskedasticity in the index. Wo find no notable differences in the estimated repeat sales indices. When compared with indices based on cross-sectional means or medians our WRSls shows a stronger growth. This difference remains even when the same repeat sales sample of houses is used to compute both summary statistic indices. Apart from the difference in levels, the repeat sales index also has much lower volatility when compared 

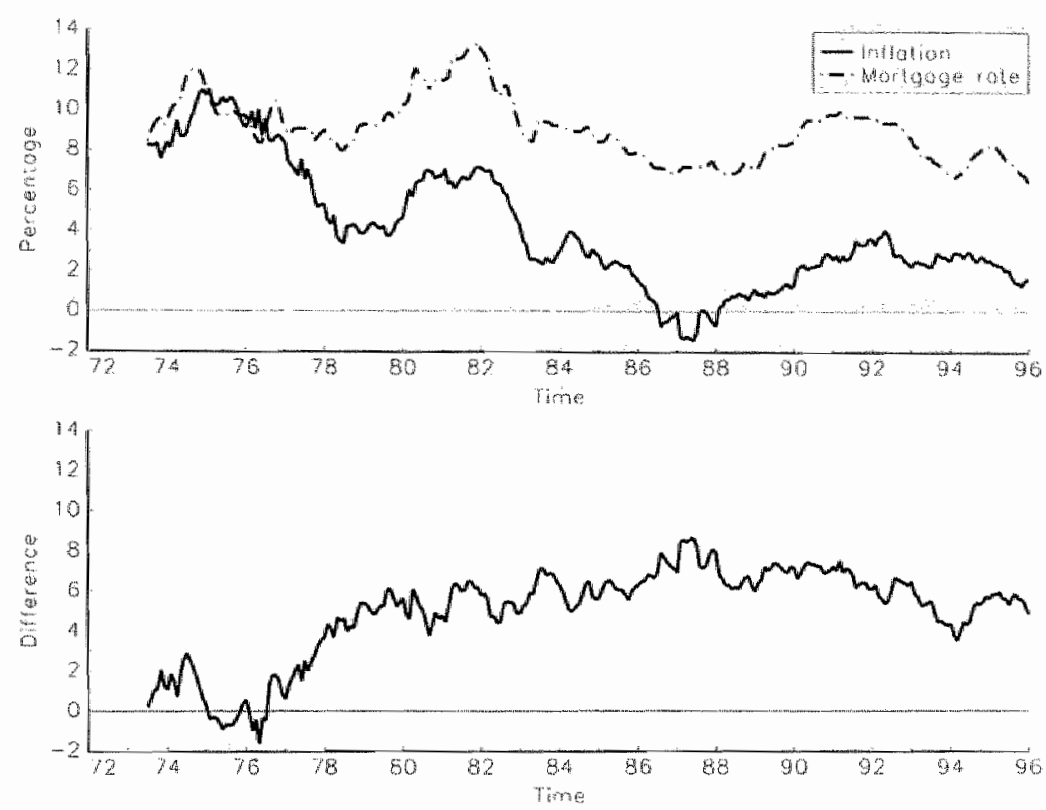

FIGURE 8.6: DUTOH INFlation AND MORTGAGE RATES

The upper diagram of this figure shows the times series of the inflation rate and the mortgage rate. The lower diagram plots the difference. 
whin the mean and median indices. This is a consegnence of the methodology itself. Neverthess we are conficent of the validity of the repeat sales index as a representative indicator of the wallue of residential properties in the Netherlands.

The estimated jndex clearly shows the real estate bubble of the late seventies and early eighties. The basis of the nominal index is May 1973. Five years later a level of 255.37 was reached, sich that the average annual return during that period exceeded $20 \%$. After this period of shapply rising prices the real estate bubble exploded. Over the following 7 years and 3 months the nominal index decreased by an average of $4.74 \%$ per annum. th Scptomber 1985 the hotsing prices started to rise again. Between September 1985 and Decmber 1995 the indeximered by an average of $7 \%$ a year. For comparison, the average anmuat stock return for each of these three periods was equal to $2.31,18.61$ and $12.02 \%$, respectively. These higures include dividends but the return on residential properties is only based on price Anctuations, and the rent-savings are ignored. For first-ime buyers, such savings are undoubledy a major factor in choosing to purchase a house rather than renting one, especially when roughly the same monthly payment could result in full ownership of 1he house. Homeowners who hope to save towards their pension in this way do face the risk of retajuly low house prices at the the they want to convert their property into money. These individuals should be particularly interested in the risk and return characteristics of residential property. 


\section{Chapter 9}

\section{Empirical mortgage prepayment behavior in the Netherlands}

\subsection{Introduction}

The mortgage valuation models described in Chapters 5 and $T$ assume that prepayments are solely interest rate driven. American prepayment data, however, show that readontial mortgage bortowers regularly prepay their mortgage even though the refuancing rate exceds the contract rate on the existing mortgage, while others fail to axerise their pre payment option when it would financially be wise to do so. Optimal call valnation nodels can not explain this behavior. Valuation models in which prepayments are exogenously specified override this shortcoming. However, empirical nodels have other himitibions. For example, Lucas (1987) pointed ont that relations found in empirical studies are basto on historical observations and can therelore not be used to consider the future impact of today"s policy changes. In other words, it is difficult to predict prepayment behavion if contracts are in roduced will diflerent conditions.

lexogenous prepayment valuation models can be divded into two categories. Morigage prepayment models developed by Dunn and McConnell $(1981 \mathrm{a}, \mathrm{b})$. Brennan and Sathart (1985), Kau, Keenan, Muller and Epperson (1992), Giliberto ard Ling (1993), Ardwer and Ling (1993) and Stanton (1995) take an optimal call valuation model as a starling pont

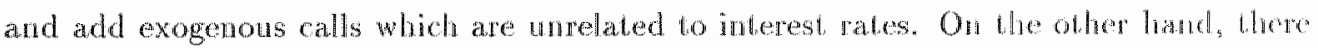
are strictly empirical prepayment models, which do not assume any oplimal futhavion, The prepayments are solely based on historical relatons with explanatory varialies. "Thes second category of exogenous prepayment models includes the proportional hatard models by Green and Shoven (1986) and Schwartzand Torous (1989), and the more doxeriphe models by Richard and Roll (1989). Kang and Zenios (1992) ind Golub and Pohlman $(1994)^{1}$

The purpose of this chapter is to contrbute to the understanding of mortgage prepay-

Chapter 3 discheses these modeds in more datal. 
ment belavior in the Netherlands. For this we analyze the prepayment data of a large mowtgage provider in the late eighties and eary nineties. The observed prepayment rates are related to various measurable lactors suggested by economic theory. Section 9.2 describes the data used in this chapter. Unfortunately, our data set has serious limitations: the number of included contracts is rather small (as is the number of observed prepayments) and the sample period is limited to the first five and a hall years of a contract.

The remainder of this chapter is organized as follows. Section 9.3 compares the observed prepayment activity with optimal prepayment behavior. In Section 9.4 the prepayment data are modelled on the basis of five factors affecting prepryment behavior: seasonality, refinance incentives, aging, loan-to-value and housing price effects. In Section 9.5, these five factors are considered simultaneously in a mulli-variate analysis. Section 9.6 concludes.

\subsection{Description of the data}

\subsubsection{Individual loan data}

The morligage data analyzed in this chapter are from clients of Assurantieconcern Stad Rotherdam anno $1790 \mathrm{~N} . \mathrm{V}$, a large independent Dutch insurance company quoted on the Amsterdam Stock Exchange. For a period of almost five years, 183 traditional mortgages with life insurance and 150 savings mortgages were followed. ${ }^{2}$

Since almost no repayments take place during the term of these mortgage contracts, the outstanding balances remain untouched. Consequently, the interest costs to the mortgagors do not decline ower the years. However, interest paid on a mortgage is tax deductible in the Netherlands, while the return on the life insurance of both the traditional and savings mortgage is not taxed as long as some fiscal conditions are met. These restrictions are described in Chapter 2. An individual wo uses a traditional mortgage with life insurance or a saving morigage to finance his home makes optimal use of the facilities offered by the tax athorities. These tax facilities make (partial) prepayment of mortgages with life insurance nhd savings mortgages often unatiractive. Therefore we expect to observe much less prepayment activity in our Dutch data set than in most American studies. Table 9.1 confums this expectation. This vable separates the andyzed contracts by their month of issue, April, May and June 1990, respedively. These months were chosen because Assurantieconcen Stad Rotherdam anvo $1720 \mathrm{~N} . \mathrm{V}$. issued their first savings mortgage in April 1990. The prepayment behavior of the considered contracts is followed until December 1995. In the underlying time span 91 partial prepayments and 46 complete prepayments on morlgages with life insurance occurred. For the savings mortgages these numbers are 47 and 14 , respectively.

Regularly, individuals buy a new home before the old one is sold. Otten the new home is financed by a mortgage with a bridging loan. Commonly, this bridging loan has a matitury

\footnotetext{
2 For a mope detailed discussion on both mortgage types see Chapter 2.
} 
TABLE 9.1: SUMMARY STATISTIOS REGARDIRG MORTOAQE OONTRACTS

\begin{tabular}{|c|c|c|c|c|c|c|}
\hline \multirow{2}{*}{$\begin{array}{l}\text { Mortgage } \\
\text { Month of issue }\end{array}$} & \multicolumn{3}{|c|}{ Tradifomal } & \multicolumn{3}{|c|}{ Sarings } \\
\hline & April & May & June & April & May & June \\
\hline Contracts & 67 & 74 & 42 & 50 & 60 & 31 \\
\hline Partial prepayments & 35 & 34 & 22 & 10 & 23 & 11 \\
\hline Complete prepayments & 14 & 15 & 17 & 0 & 10 & 4 \\
\hline $\begin{array}{l}\text { This bable reports the num } \\
\text { savings mortgages include } \\
\text { quarter of } 1990 \text {. The seco } \\
\text { reports the mumber of con } \\
\text { states the number of part } \\
\text { and December } 1905 \text {. Row } \\
\text { observed during that per }\end{array}$ & row & $\begin{array}{l}\text { splay } \\
\text { ed in } \\
\text { gents }\end{array}$ & $\begin{array}{l}\text { he cont } \\
\text { he cort } \\
\text { serven }\end{array}$ & $\begin{array}{l}\text { ith life } \\
\text { e issued } \\
\text { issue. } \\
\text { ing mon } \\
\text { en the n }\end{array}$ & $\begin{array}{l}\text { Wram } \\
\text { thes } \\
\text { e thir } \\
\text { Rov } \\
\text { nih of }\end{array}$ & $\begin{array}{l}\text { and } \\
\text { rand } \\
\text { row } \\
\text { four } \\
\text { ssue } \\
\text { ents }\end{array}$ \\
\hline
\end{tabular}

of 12 months or less, and will be repaid with the revenue of the old house once it is sold. The contracts studied in this chapter are corrected for these bridging loans. The analyzed contracts are also cleaned of loans to employees and related insurance brokers who receive a discount on the contract rate and thus exhibit different prepayment behavior.

TABLE 9.2: SUMMARY STATISTIOS REGARDING CONTRACT RATES

\begin{tabular}{lccccccc} 
Mortgage & \multicolumn{3}{c}{ Traditional } & \multicolumn{3}{c}{ Savings } \\
Month of issue & April & May & June & & April & May & June \\
\hline Average & 8.26 & 8.30 & 8.67 & & 8.88 & 9.01 & 9.00 \\
Stand. Dew. & 0.54 & 0.57 & 0.53 & 0.56 & 0.60 & 0.58 \\
Maximum & 9.20 & 9.60 & 9.25 & 9.95 & 9.85 & 9.75 \\
Minimum & 7.00 & 6.80 & 6.85 & 7.30 & 7.25 & 7.40 \\
Median & 8.25 & 8.32 & 8.95 & 8.95 & 9.25 & 8.95
\end{tabular}

This table reports the initial contract rates of the mortgages isstued by Assurantieconcerm 5 tad Ralterdam ano $1720 \mathrm{~N}$. in the second quater of 1990 .

Figure 9.1 illustrates the distribution of the initial contract rates for which the summary statistics are reported in Table 9.2. Both histograms in Figure 9.1 are based on anixture of contracts. Both first and second mortgages are included, as are contracts whose mortgage rate is fixed for a 1,5 or 10 year period, the time to maturity varies between 20 and 30 years and also the loan-to-value ratio differs substantially between the individual contracts. "The diversity of contract specifications is reflected in the high dispersion of the contract rates as illustrated by both Figure 9.1 and Table 9.2. The contracts have in common that only $10 \%$ of the initial loan can be prepaid in a calendar year whout a penalty.

\footnotetext{
3 The loan-tomathe ratio compares the anount of the loan whine watue of the underlying property.
} 

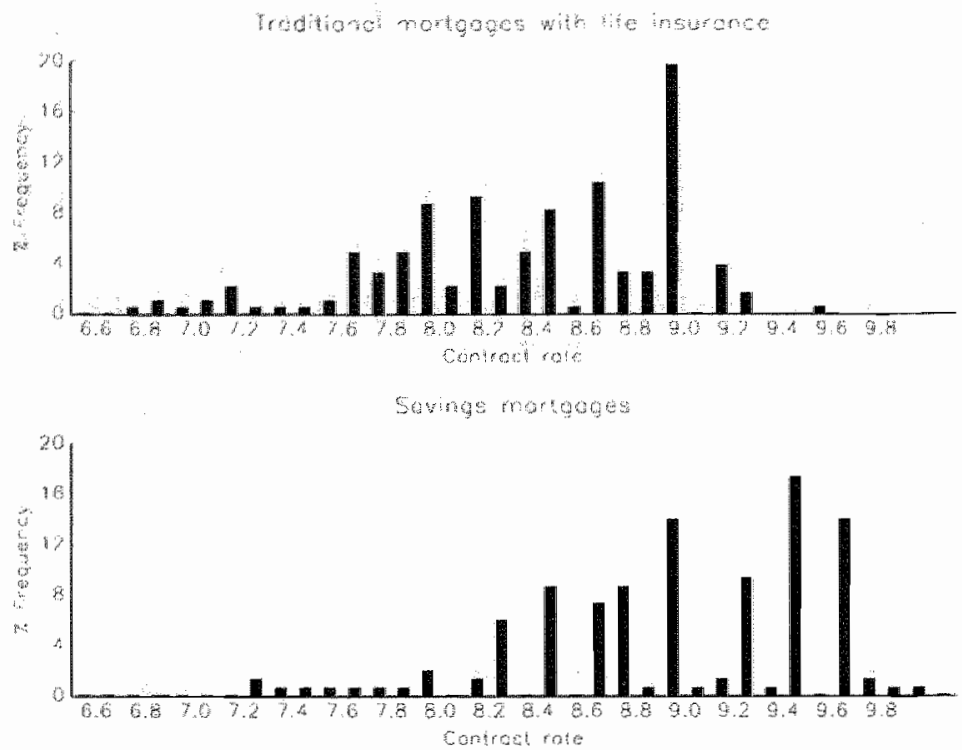

FIGURE 9.1: INITIAL CONTRACI RATE

The histograns in this figure show the freguency distributions of the initial contract rates of the mortgage contracts shudied in this chapter.

\subsubsection{Aggregate data}

We also have prepayment data at an aggregate level which refers to the total amoun of prepayments received by Assurantieconcen Stad Roterdam anno 1790 N.V. in each month between Jamury 1986 and June 1994. The book value of the outstanding mortgage portfolio at the beginning of each month is also known, so that the prepayment rates can be calculated and the monthly fucturtions be analyzed. A clistinction is made between tralitional mortgages with lile insurance and savings mortgages. The first savings mortgage was issued only in April 1990 , such that prepayment data for this loan type is only avalable rrom May 1990 on. The contract rates of the mortgages which prepay are known. Howaver, Whe remuing time to maturity, blue fixed-rate period, the initial loan and the underlying whe of the property are unknown.

\subsection{Observed and interest rate driven prepayment be- havior}

Chapters 5 and 7 consider optimal prepayment behavior where the borrower replaces the mortgage if this reduces his future monthly payments. In Figure 9.2 this optimal prepayment behavion is compared with the prepayments observed in the Stad Rotterdam data. 
set concerning the individual contracts.
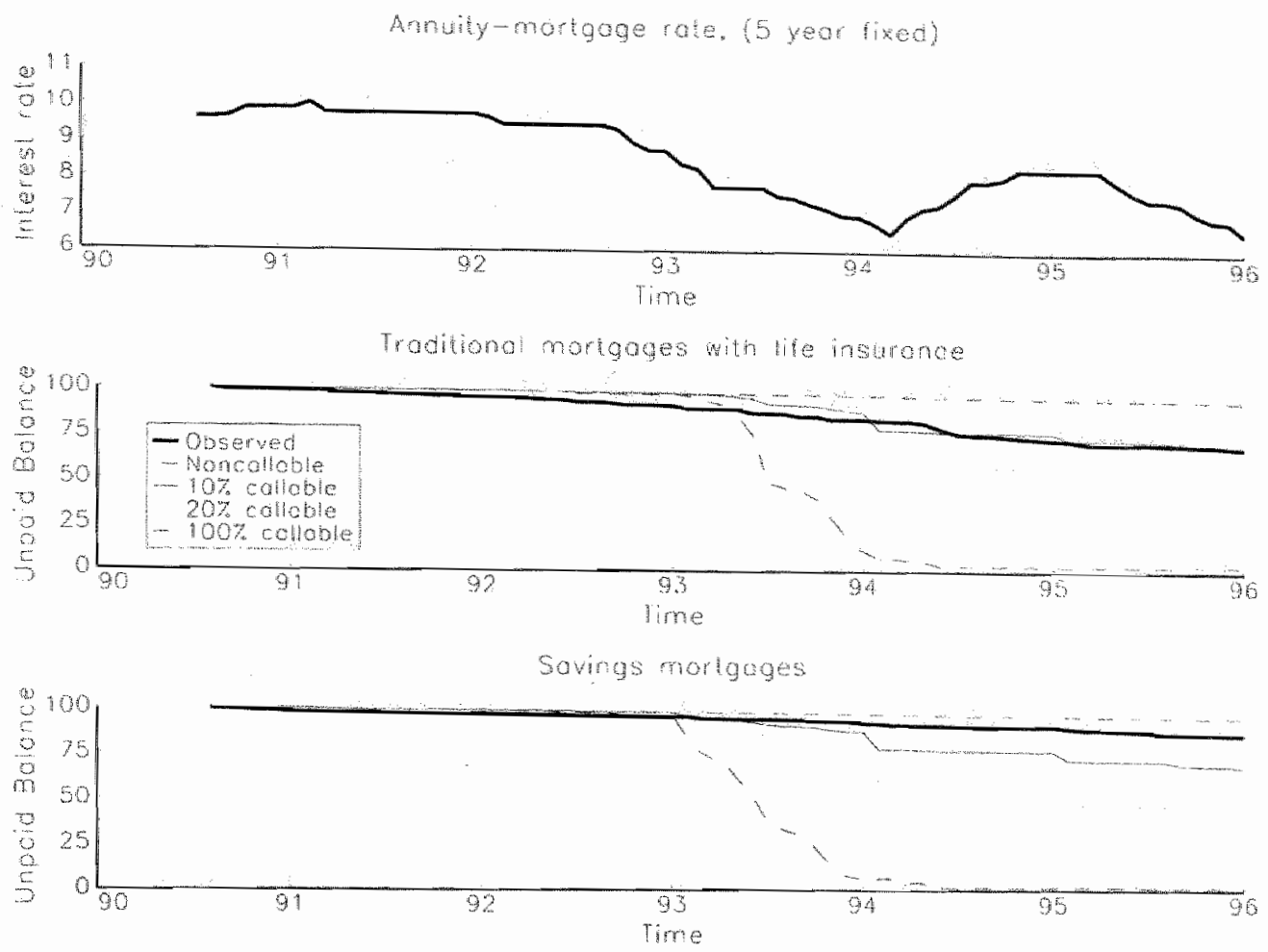

FIGURE 9.2: OBSERVED VERSUS OPTIMAL PREPAYMENT BEHAVIOR

The upper diagram of this figure shows the time series of the annully-montgage rate. The other wo diagroms eompare the observed prepayment behavior with the optimad prepayntent. Behavior.

The upper diagram illustrates the mortgage rate on an average Dutech annuity - mortgage contract whose maturity is 30 years with the contract rate being fixed for a five year pertod. The contract rate of comparable traditional mortgages with life insurance is aqual to this annuily rate, while a practitioners ruteof thumb states that the contract rate of savings mortgages is 30 basis points higher. Throughout, this chapter, this rule-withumb is assumed to hold. To adiust for altermative fixed-rate periods, we used spreads observed on the captut market. The spread between the Holland Interbank one year yield and the Datastrean constructed benchmark for redemption yields on Dutch government bonds with a matarity of five years, and the spread between this latter varible and the compandale 10 year benchmark, were added to the fve year fixed mortgage rates. This way time-varying spreats were used to approximate time series of mortgage rates for contracts whose rate is fixed for a one and ten year period, respectively. 
These time serves are utilized to model prepayment behavior as was done in Chavters 5 ard 7 . Fach month the monthly payment $M_{t}$ is calculated as if a similar new contract starts with a matury equal to the remaining line to maturity of the existing contract, and a contract rate which is equal to the mortgage rate corresponding to that month. The principal of this new contract is equall to the outstanding loan multiplied by $(1+c)$, where $c$ are the up-front costs a borrower has to pay to replace the old contract by a new one. If the realting monthly payment $M_{t}$ is less than the original $M_{0}$ and the anmal prepayment limit has not been reached, the borrower is assumed to prepay (part of) the mortgage. Hereby we assume that prepayments never exced the annual penalty-free restrictions, that the up-front costs equal one percent of the ontstanding balance and that existing contracts are only replaced by new contracts with the same fixed-rate period and by contracts of the same type, eithe traditional mortgages with life insurance or savings mortgages.

The middle diagram of Figure 9.2 illustrates the consolidated outstanding balance (COB) of the pool of traditionall mortgages with life insurance. ${ }^{4}$ The bottom diagram plots the same for savings mortgages. The unpajd balance was rescaled such that the consolidated outstanding balance on July 1 sit, 1990 corresponds with one hundred. The bold line displays the observed unpaid balance at diferent points in time. The thin lines illustrate what the unpaid balance would have been if the above described prepayment decision rule was followed, whereby alternative anmual prepayment restrictions are considered. Both the observed and the optimal prepayment behavior include periodical repayments.

Figure 9.2 shows that the redemption of traditional mortgages with life insurance is larger than the redemption of savings mortgages. This is caused by both higher periodical re- and prepayments. In the second half of the sample period, the graph of the unpaid balarce of the traditional mortgages with life jusurance shows nuch resemblance with the line representing the unpaid balance of optimal-called annuity-contracts with an annual 10 percent prepayment limit. Since the prepayment option on a traditional mortgage with life insurance is also limited to 10 percent per calendar year, this result suggest rational prepayment behavior of the nortgagor.

The lines representing the partially callable contracts show a decline in the unpaid balance at the beginning of 1995 , despite the fact that the interest rate does not decrease. This is purely a callendar effect: Given the contract rates occurring at the end of 1994 , borrowers want to prepay their loans. However, if their annual prepayment limits have already been reached, they are not allowed to do so. Together with the new year 1995 , a new prepayment option comes along which gives the mortgagor the right to prepay an additional 10 or 20 percent of the initial loan during that calendar year.

"The consolidated outstading balance (COB) at Gime $t$ is equal to the outstanding loan at that dime minus the money actued in the saving accont. Data regarding the savings accounts are not awalable. However, the contract tate is lnown so that the smount included in the sawings account cau be estimated. 


\subsection{Modelling Dutch prepayment data}

Chapter 3 discusses four explanatory variables which appean in different qualities in different empirical mortgage prepayment studies. The refnonchy incentive reffects that homeowners tend to refinance their mortgage when the current mortgage rate is far enough under the contract rate. Seasonality measures the correlation between prepayment rates and the month of the year. The phenomenon that prepayment rates are low in the beginning of the contract and increase towards a stable level as the mortgage ages is known as seasoning. And finally, burnout describes the decline in prepayment rates as mortgage contracts age through interest rate cycles. Both seasoning and bumout are aging factors. The first one describes the prepayment behavior at the beginning of the mortgage contract, while the latter one focuses on later stages of the contract life Other economic variables are also sometimes included, e.g. loan-to-value ratios and housing price developments.

The various prepayment determinants are discussed in this section. The discussion borrows from Richard and Roll (1989), Kang and Zenios (1992) and Golub and Polyman (1994). Where possible onr results will be compared with theirs.

\subsubsection{Seasonality effects}

Seasonality captures the cyclical wariations in prepayment rates. The seasonal pattern is expected to be related to the activity on the housing market. It is commonly believed that residential property transactions increase in the spring and gradually reach a pealk during summer months. This increased activity is expected to resuli in a similat seasonal pattern of the prepayment rates. This is empirically confirmed in studies by Richard and Roll (1989) and by Kang and Zenios (1992); Prepayment activity is at its lowest in March, after which it increases to more moderate levels in spring and summer, but the real peak is reached in autumn or early winter.

Figure 9.3 illustrates the seasonality effects in the Netherlands based on the aggregate data set. The prepayment rate is calculated by dividing the received prepayments by the consolidated outstanding balance at the begining of the month. The ratio is multiplied by 100 and represents the prepayment per 100 gailders principal outstanding. The upper diagram illustrates the prepayment rate over the years for both contract lypes. "The lower left diagram plots the average prepayment rate per month of traditional mortgages with life insurance. The seasonal fluctuations show mucla resemblance with the pattorns found by Richard and Roll (1989) and Kang and Zenios (1992). The prepayment rates are relatively low in the begiming of the year, begin to rise in the spring and reach a peak in July which. suggests that the delay in passing through prepayments is rather small in the Netherlands.

The annual prepayment restrictions embodied in Dutch mortgages and the fact that a calendar year coincides with a tax year might cause the other prepayment peak in Decembiner.

The bottom right diagram of Figure 9.3 displays the seasonal patterr of savings mort- 

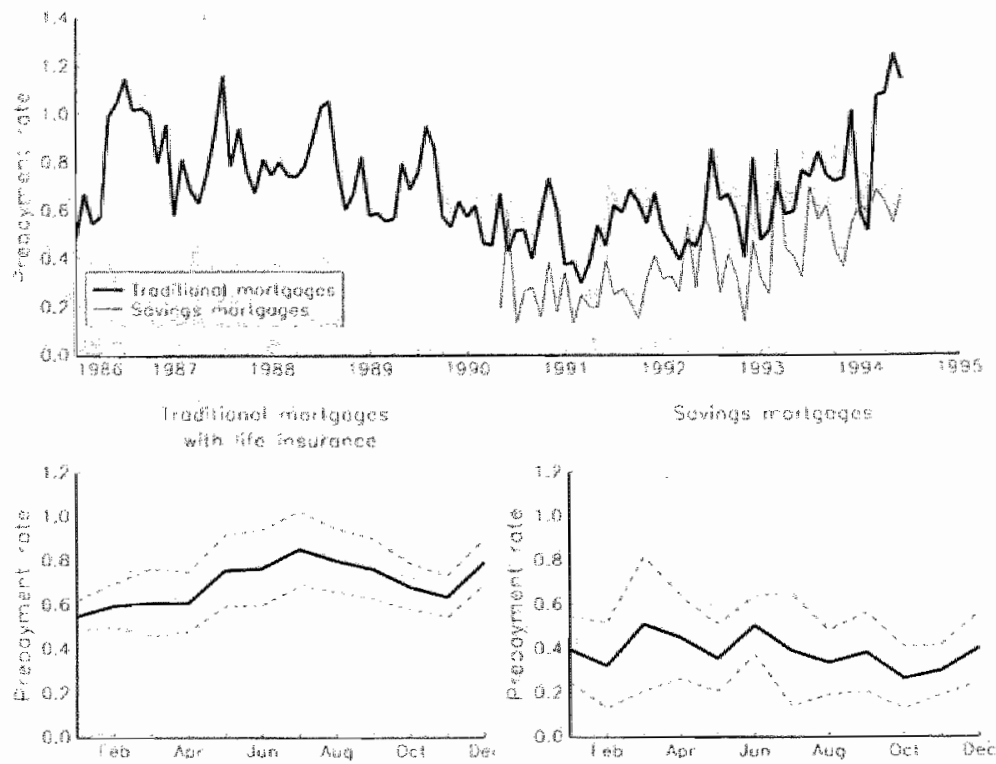

Figure 9.3: SEASONALITY EFFECT

The upper diagran of this figure shows the prepayment pate over the years. The lowe: diagrams plot ithe anerage prepayment, rate per montlly. The thin-doted lines clisplay the $95 \%$ confidence interwals.

gages' prepayment rates. This time the seasonal pattem is less clear.

\subsubsection{Refinance incentives}

Deching intersis wates provide an incentive for homeowners to refinance their mortgage. Following Richand and Roll 1989), Kang and Zenios (1992), and Gohlu and Pohman (1994), wo measure the refinance incentive by computing the anmity value per guilder of principal outstanding. The present value of a 30 year annuity in month ${ }_{1}, A_{t}$, per guilder of monthly payment equals"

$$
A_{t}=\frac{1-\left(1-y_{t}\right)^{t-3{ }^{-30}}}{y_{t}}
$$

where $y_{t}$ is the mortgage rate in month $t^{5}$ When yo represents the contract rate of the cxistug notgage, the outstanding balance, per unit of monthly payment, can be written as:

$$
O B_{i}=\frac{1-\left(1-y_{0}\right)^{t-360}}{y_{0}}
$$

Hence, the anmity whe per gilder of principal outstanding reads:

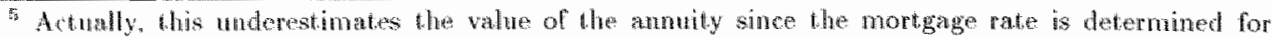
partiolly andally morligage loans.
} 


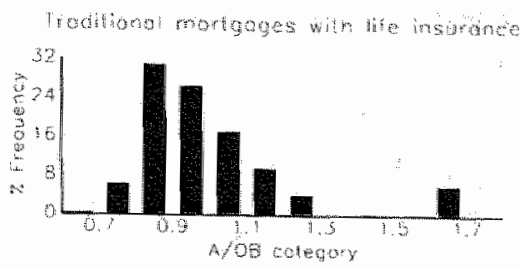

An composs

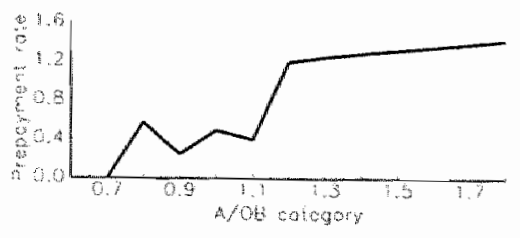

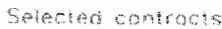

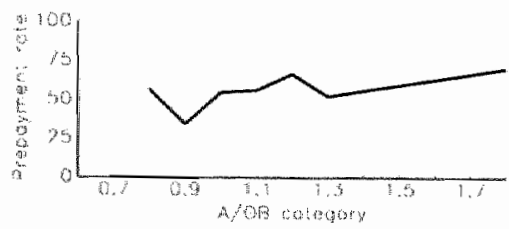

sumes mor mogs

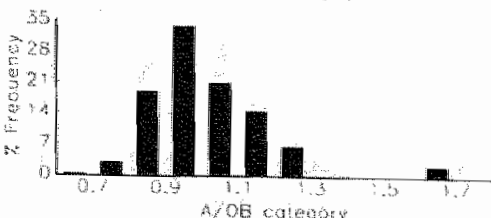

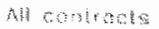

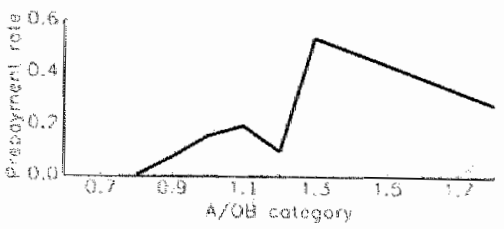

yanted rontents

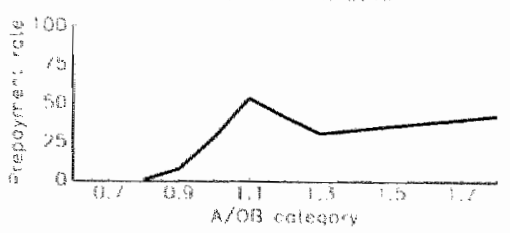

FIGURE 9.4: REFINANCE INCRNTIVE

The upper diagrams of Figure 9.4 show the requency distribution of the At ratio categories for boh mortgage types. The middle and lower diagrams plot the weighted average prepayment rate per category.

$$
\frac{A_{i}}{O B_{t}}=\frac{y_{0}}{y_{t}}\left(\frac{1-\left(1-y_{t}\right)^{t-360 t}}{1-\left(1-y_{0}\right)^{t-360}}\right) .
$$

Borrowers will prepay their mortgage when the $\frac{A_{r}}{\partial B}$ ratio exceds some critical valite. The exact level of the ratio that triggers prepayment depends on the rofinacing costs. which vary among individuals, and the stochastic process for intercest rates.

To incorporate a potential delay in respording 00 a change in interest rates, Richard and Roll (1989), Kang and Zenios (1992) and Golub and Pohlman (1994) use wotghted axerages of recent values of the ratio to measure the refinance incendive. Their results illustrate a non-linear relation between the prepayment rate and the refonace incertive ratio. For ratios below one, the refinance rate exceeds the contract rato and prepayment activity is relatively low. The prepayment rate increases mpidly for refinance incentive ratios larger than 1.

Figure 9.4 summarizes the results for the Dutch data set concerning the individual contracts. To determine the refinance incentive for cach contract in ach month. the awerage of its three most recent $\frac{A_{t}}{O B_{y}}$ ratios is used. The resulting matios are divicled oven 9 categories. The first category contains ratios less than 0.6 , the other ones have a bandwidth 
of 0.10, whila the las one embodies ratios exceding 1.30. The upper diagrams of Figare 9.4 show the frequency distributions of these watio categories for both mortgage types. For each category, the weighted average prepayment rate is calculated and plotted in both middle diagrams." In confomity with Figure 9.3, this prepayment rate represents the prepayment per 100 guilders princtpal outstanding. Fven though these middle diagrams suggest that the prepayment activity increases with $\frac{A_{1}}{O B_{1}}$ values, there is no clear $S$-shape, non- Linear relation wible. The relation is distorted by a few outhers which have a major efrect on the outcome, and by the fact that most of the time no prepayments are observed. If these zeroprepayments are left ont, we find a pattern as illustrated by the lower diagrams of Figure 9.4 .

TABLE 9.3: REFINANCE INCENTIVE

\begin{tabular}{|c|c|c|c|c|c|c|c|}
\hline & $a$ & $\beta_{1}$ & $\beta_{2}$ & $\beta_{3}$ & $\beta_{4}$ & $\beta_{5}$ & $R^{2}$ \\
\hline vallue & -1.16 & -4.59 & 0.42 & 7.86 & 0.60 & -2.69 & 0.32 \\
\hline standard error & 0.47 & 2.25 & 3.27 & 3.39 & 3.40 & 2.34 & \\
\hline
\end{tabular}

In Table 9.3 we regress the prepayment ratio on the prevaling refinance incentive ratio and four of $i$ ts lags in months. During these months the mortgagor can reconsider the new information, compare new offers and finally make a decision to refinance or not. The $R^{2}$ resulting from the regression shows that 32 percent of the variability in prepayment rates can be explained by current and past refinance incentives. Not all parameters are positive due to malticollinearity. However, the sum of the parameters is equal to 1.61 , which indigates that the prepayment activity is positive related to refinance incentives.

\subsubsection{Aging}

Both seasoning and burnout refer to the aging of the mortgage loan. Seasoning describes the general idea behind the PSA prepayment benchmark, discussed in Chapter 3 . It reflects that prepayment rates are low shortly after the mortgage is originated and increase to a stable level in course of time. Burnout on the other hand tries to measure the tendency of prepayment rates to slow down over time.

Recall that the American PSA benchmark prescribes prepayment rates to increase linearly for the first thirty months of the contract's existence. After these initial thity months the monthly prepayment rates are assumed to be $6 \%$ a year of the outstanding

6 Weighted averages are calculated based on the consolidated ontstanding balance (COB) of each mortgage contract. 
balance for the remainder of the mortgage term. To analyze the seasoning effect. Riothard and Roll (1989) and Kang and Zenos (1992) distinguish alternative morlgage pools based on the refinance incentive ratio. Richard and Roll find that discount mortguges $\left(\frac{1}{0} B_{\mathrm{F}}=0.8\right)$ fully level off in about nine years, although $75 \%$ seasoned after five years. Par mortgages $\left.\frac{A_{t}}{O B_{k}}=1\right)$ take about five years to fully season, and premium mortgages $\left(\frac{A_{t}}{O B_{t}}=1.2\right)$ need just over thirty months. Kang and Zenios find very similaresults.
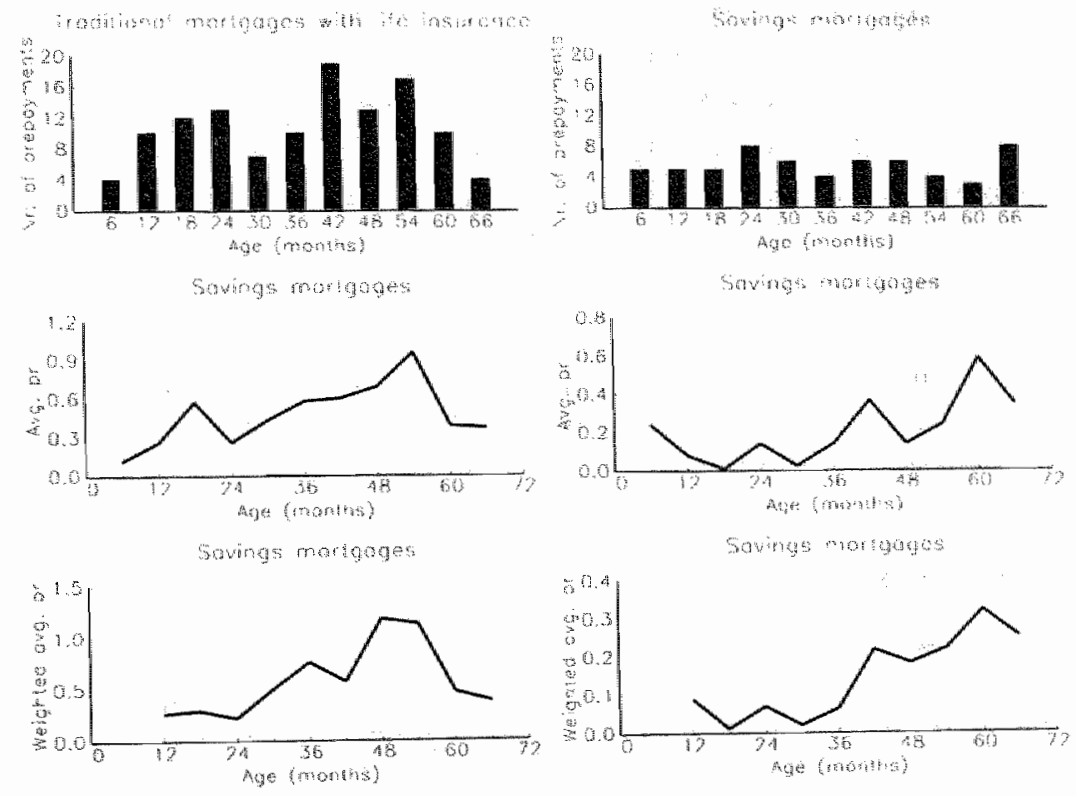

\section{FIGURE 9.5: AGING EFFEGT}

The upper diagrans of this figure show the mumber of prepaynents observed in the nonsidm

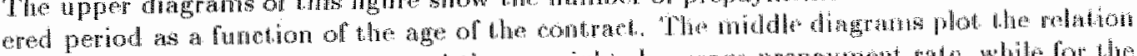

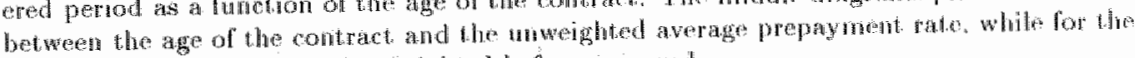

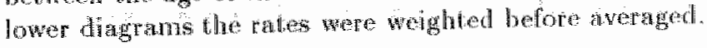

Due to our limited data set, no distinction can be made betwern disconn, par and premium mortgages in the Netherlands, nor can the age effect be studied on a monthly basis, instead a six months period is chosen. The limitations of our data set are cleaty laid open in the upper diagrams of Figure 9.5. These two histograms show the number of contracts which were (partially) prepald at a specific age. Both histograms illust nate liat. the prepayment frequency is rather low.

The middle diagrams display the relation beween the age of a contract and the wn weighted average prepayment rate, while for the bottom diagrams the prepayment rates were weighted before averaged. All suggest the same: prepayment rates gradually increasc with the collapse of time. However, nothing points to a stable, seasoned prepayment fovel reached in the first 5 to 6 years of a contract's existence. 


\subsubsection{Loan-to-value}

Loan-to-value is the ratio of the initial loan to the forced-sale falue of the underlying residential property. The higher this ratio, the smaller the lender's protection for losses which might occir when the borrower defaults and the property has to be sold. As such, the loan-lo-value ratio is more closely related to default risk than to prepayment risk. However, in our data set we can not make a distinction between the termination of a contiact due to prepayment or default.

Before tuming to the lon-to-value analysis, the upper diagram of Figure 9.6 summarizes the relative frequency distributions of the property values underlying the individual mortgage contacts analyzed in this chapter. In keeping with Chapter 8 , the distributions of house values are skewed to the right. Subsequently, Figure 9.6 illustrates that neither a relation exists between contract rates and forced-sale values of underlying homes, nor between contract rates and loan-to-value ratios. This insinuates that the reimbursement required by londers for facing additional prepayment/termination risk is rather low. The lower diagrams indicate that a large risk preminm can also not be justified. In these diagrams the number of prepayments divided by the number of contracts in a specific loan-to-value catggory is plotted against these loan-to-value classes.

\subsubsection{Housing prices}

With strong housing market conditions as observed in the considered period, borrowers who can not meet their financial burden will sell their property and prepay the mortgage. Fxercising their default option is most likely much more expensive, so that this option will only be exercised when the mortgagors' equity in their: homes become negative. Consequently, the number of defaults is rather low in this sample period of rising housing prices. This might also explain why no positive relation is found between prepayment activity and loan-10-value ratios.

Figure 9.7 plots the prepayment rate against the monthly mutation in housing prices. These mutations are based on the weighted repeat sales index for residential property in the Netherlands, as developed in Chapter 8 . The prepayment rates are derived from the data set which contains prepayment information on an aggregate level. The scatter diagram shows no relation between the economic variables. Including lags in the housing price fuctuations does not improve this picture, nor does averaging over a longer period than one month.

\subsection{Multi-variate analysis}

Following the analyses of the separate effects, Richard and Roll (1989), Kang and Zenios (1992) and Golub and Pohlman (199!) integrate the factors into al multiplicative model to determine the conditional prepayment rates (CPR): 

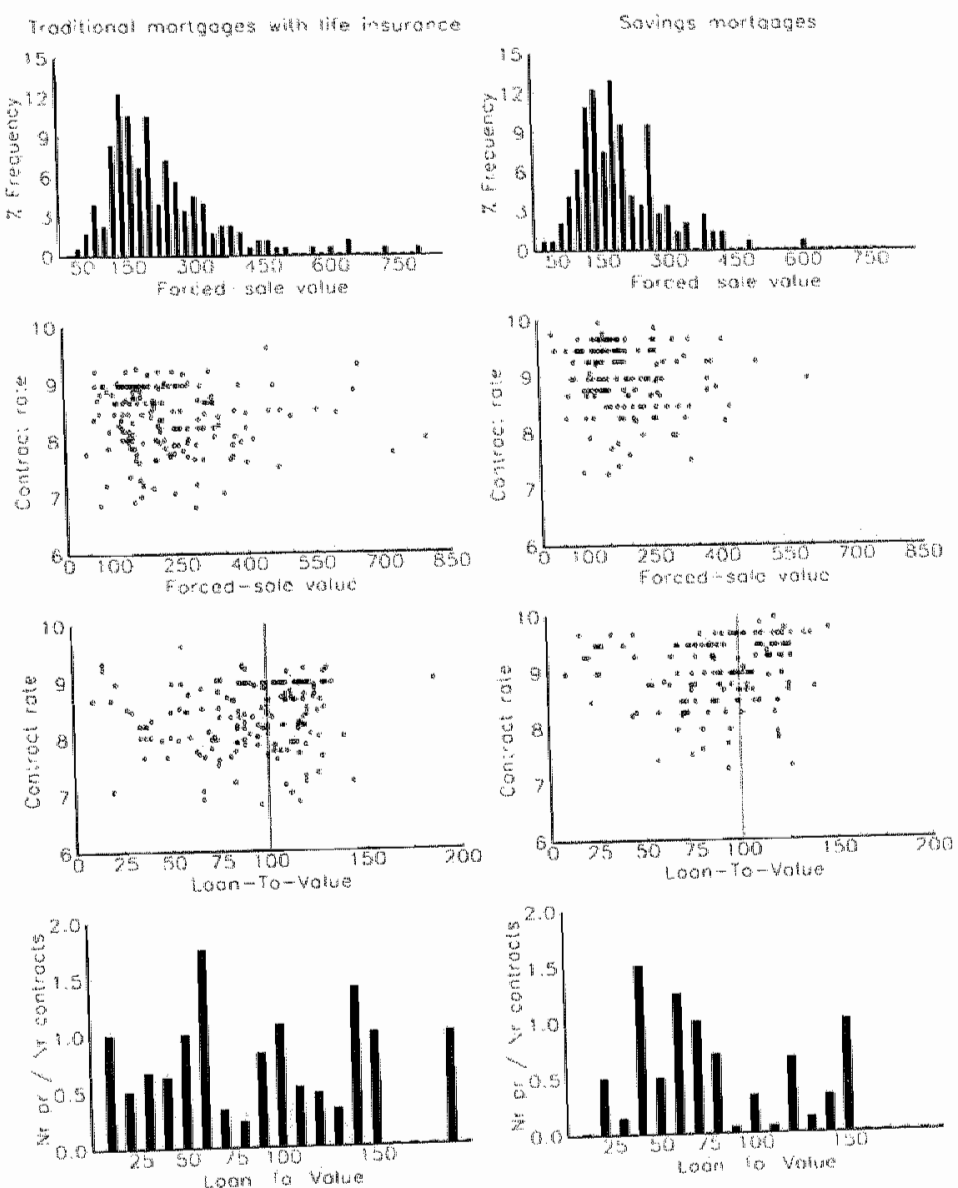

\section{FIGURE 9.6: LOAN-TO-VALUE}

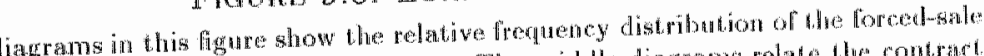

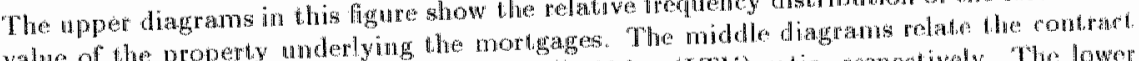

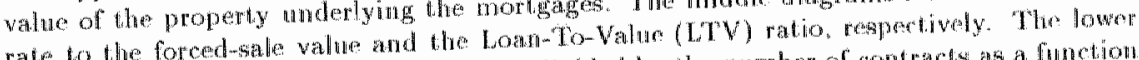

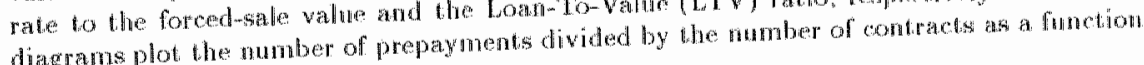
diagrams plot the number of 


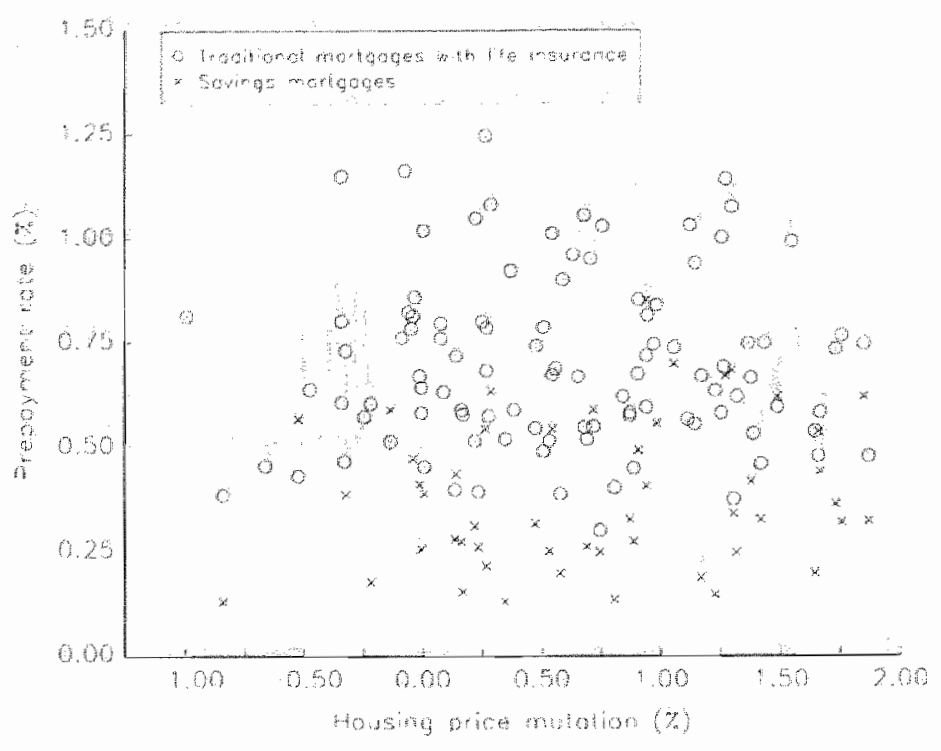

FIGURE 9.7: HOUSING PRICE EFFEGT

This figure studies the relation between housing prices and prepayment activity.

$\mathrm{CPR}=$ seasonality $\times$ refinancing incentive $\times$ seasoning $\times$ burnout.

Since not all factors were found to be significant, we have chosen for an alternative approach to combine the independent variables into one prepayment model. Rather than deternining the parameters for each component separately, we estimate them simulaneously with multiple regressions. For this we have combined all individual loans into one pool. The consolidated outstanding balances of the indlwidual contracts are used to cal. culate the weighted average contract rate, age, loan-to-value ratio and refinance incentives of this pool.

We statted with a general multiple regression in which the prepayment rates are related to all explanatory variables described in this chapter. For the refinance incentive we used the curent ratio, as well as four of its lags. The age of the loan, the loan-to-value ratio. the bousing price fluctuations and dummy wables for the seasonality effect are also included in this general regression. And to capture the impact of past prepayment behavior on current prepayment rates, we added the cumulative past prepayments to this list of independemt variables.

The success of the regression in predicting the prepayment rates within the sample is graphically shown in the top diagram of Figure 9.8. The goodness of fit is measured by $R^{8}$. Which for this regression is equal to $53.2 \%$. This means that more than hall of 
the variability in the prepayment rates can be explained by the aforementioned set of explanatory variables. Howexer, not all regression coefficients are statistically significant. Whether or not the corresponding variables should be included in the set of explanatory variables is therefore open to question. Including these watables wil increase $R^{2}$, regardles the importance of the variables. We can use the adjusted $R^{2}$ as an attemative goodness of fit measure. This $R_{\text {adj }}^{2}$ allows for the trade-oft between increased $R^{2}$ and decreased degrees of freedom, such that adding an extra independent variable does not automatically lead to an increase in the goodness of fit benchmark. "The adjusted $R^{2}$ of the general mulliple regression is equal to $30.3 \%$. Omitting the statistically not significant explanatory variables leads to a more tractable model with an $R_{\text {od }}^{2}$ of $36.3 \%$. This restricted regression model is summarized in Table 9.4 , and the fit ted values are plotted in the bot tom diagram of Figure 9.8 .
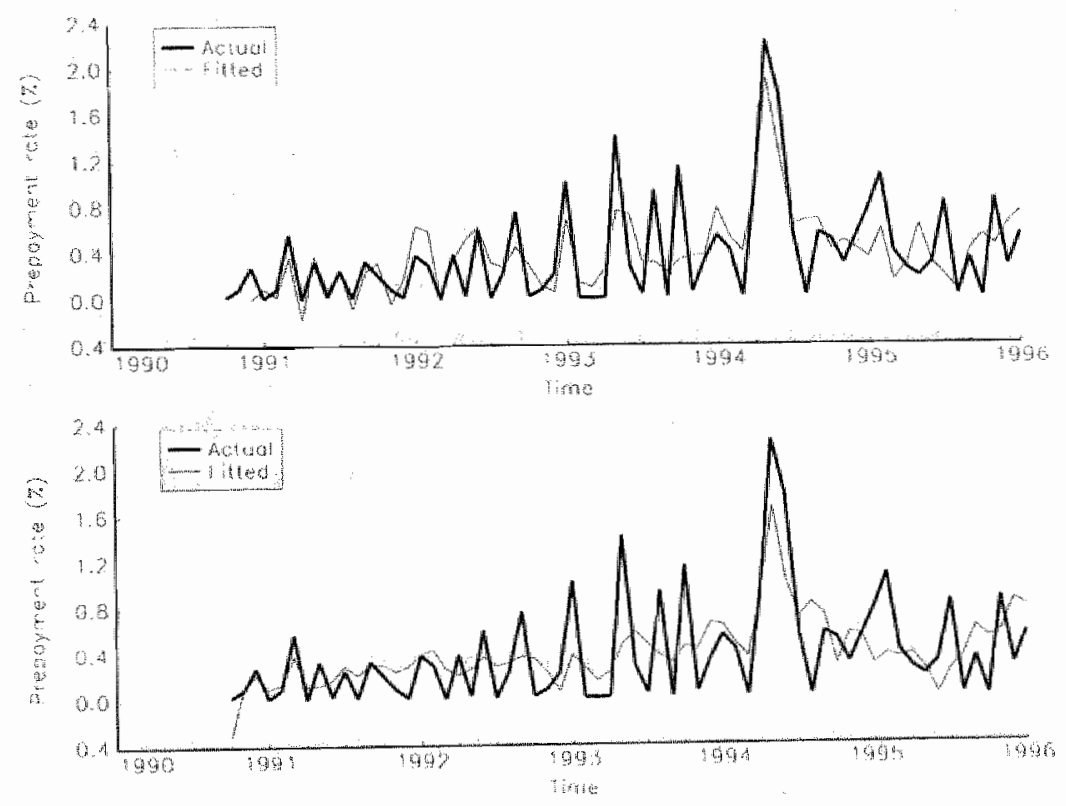

\section{FIGURE 9.8: ACTUAL AND ESTHMATED PREPAYMENT RATES}

The top diagram of this figne plots the actual prepayment ates of the anstructed mortgage pool together wh the fited tates esthated by the general maltiplon re gression. The botion diagram shows the estinates based on the restricted muliphe pegresion.

The seasonal dummies, the housing price fuctuations and the wefinance incentives with lags of one, three and four months are no longer included in the restricted regression model.

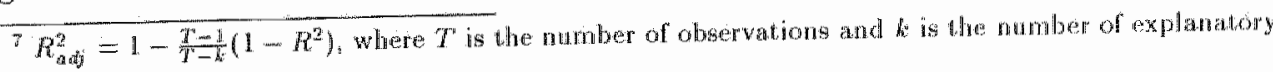
variables. 


$$
\begin{aligned}
& \left.\frac{A_{1}-2}{O B_{0-2}}\right)+\beta_{3} A g t+\beta_{4} L T V+\beta_{5} \operatorname{CUN}\left(w_{i-1}\right)+\epsilon_{2} \\
& \begin{array}{llllll}
\beta_{2} & \beta_{3} & \beta_{4} & \beta_{5} & R^{2} & R_{\text {wdj }}^{2}
\end{array} \\
& \begin{array}{lllllll} 
& 9.07 & 0.14 & 0.11 & -0.07 & 0.41 & 0.36
\end{array} \\
& \begin{array}{lllll}
1.83 & 0.05 & 0.04 & 0.03
\end{array}
\end{aligned}
$$

les to the explanatory power of the model was too small. revailing refinance ratio, the two month lagged refinance he loan-to-value tatio and the prepayment history. This by the factor CUM $\left(p r_{-1}\right)$ which represents the cumulative nonth. The greater past prepayments, the smaller current a. The opposite holds for the loan-to-valne ratio and the mortgage contracts only during the first five and half years 3 is therefore in line with the seasoning effect which states shortly atter the mortgage is originated and increase to a The sample period is too short to detect a seasoned level, ayment rates increase during the first five and half years of

re included in the regression models to capture the interest. he festricted regression model we suffice with the current of two months. The other lagged refinance incentive ratios reducing the explanatory power of the regression model. egression reported in Table 9.3 with its counterpart of the hows the explanatory power of the refinance incentives and arest rate driven prepayments. However, this result must ecause the strong relation between the prepayment activity arily based on the enomous prepayment peak observed in o months after the mortgage rate reached its lowest level in ser diagram of Figure 9.2 displays that at the end of 1995 at the same level as in the first quarten of 1994 . Despite nt activity does not approach the lewels of early 1994. This thenomenon: prepayments depend not only on the refinance n the path taken by the mortgage rate. Borrowers sensitive ill prepay as soon as the refinancing incentive is large enough, tgagors in the pool. Consequently, a smaller proportion of 
the remaining mortgagors will respond the second time the refinamoe incentive ratio has this ralue.

To capture individual incentives to prepay or default he mortgage contract crosssectional information should be included in the above analysis. Explanatory variables included in various cross-sectional studies are summarized by Cunningham and Capone (1990) who categorize them as mortgage related, borrower related, property related, or macroeconomic variables. ${ }^{3}$

Unfortunately, our Dutch data set does not allow an in-depth cross-sectional analysis which incorporates the above variables. The mortgagors characteristics in particular are lacking. Applying a cross-sectional analysis based on the explanatory variables described in Section 9.4 will yield very similar nesults as our multiple regressions, because all nortgages included in our data set are issued in the second quarter of 1990 . This means that they are all issued with similar conditions and contract rates, that they all have the same age and face the same trend in housing prices. This latter is also refected in similar developments of the individual loan-to-value ratios. In other words, there is not enough variety anongst the individual contracts to distinguish one facton from another more clearly by using crosssectional techniques rather than time series analyses.

\subsection{Conclusion}

This chapter provides some preliminary empirical results on mortgage prepayment behayior in the Netherlands. The prepayment data analyzed in this chapter is providod by Assurantieconcem Stad Rottendam anno 1700 N.V. The observed prepayment behavior of mortgagors whose annual prepayment option is limited to $10 \%$ of the initial lown shows much resemblance to the behavior described by the prepayment decision rule described in Chapters 5 and 7 .

In this chapter we try to reveal empirical relations between the observed prepayment rates and economic variables. The analyses incorporate the main determinants of prepayment models described in the economic literature: seasonality, interest rates, age, loan-10. value ratios and housing prices.

A seasonal pattern is observed in the Duth data set: In early spring the prepayment rates are relatively low. After this the prepayment aclivity increases and reaches a maximum in July. Due to the anmal limited prepayment option embodied in most. Dutch contracts and due to tax effects, another peak is uncovered in December. Following Richard and Roll (1989) and Kang and Zenios (1992) the refinance incentive is measured by computing the annuity value per guilder of principal outstanding. For ratios less than one, the corresponding prepayment activities are low. Only once the ratio exceds one, the prepayment rates start to increase rapidy. Regarding the age of the contract, the results

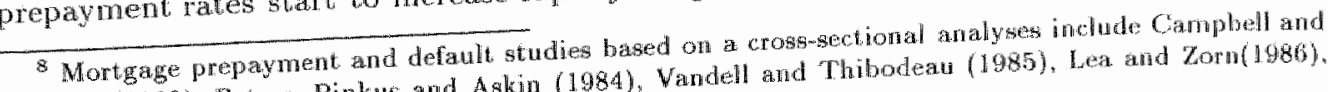
Dietrich (1983), Peters, Pinkus and Askin (1984), Vandell and Thibodeau (1985), Lea and 20 orn(1986),

Sa-Aadu (1988), and Cinnirgham and Capone (1990) 
indicte that prepayment rates gradually increase with the passing of the However, no seasoned level is observed. The impact of the Loan-To-Value ratios and housing price mutations is also considered bot their impact on the observed prepayment rates is less. char.

Interest rate driven refuance incentives have the most explanatory power, e.g. roughly one third of the variablity in prepayment activity can be explained by refinance incentive rutios. This explanatory power can be increased to more than 50 percent by including the aforementioned dememinats: seasonality, age, loan-to-value ratios and housing prices.

Even though most of the rellions ofserwed in this chapter confom to accepted acononic theory, not all of them are statistically significant. This is mainly a consequence of the small sample plus the lact that mortgage prepayment is often discouraged by the Dutch lax anthonties. More accurate prepayment data is required for an in-depth cross-sectional analysis of prepayment behavior in the Netherlands. 


\section{Chapter 10}

\section{Summary and concluding remarks}

The variety of mortgage fnance velicles has grown rapidly oven the last decade. It is now common for mortgages to have multiple embedded options. Without these options a mortgage would be an ordinary non-callable fixed-income security. The most impontant ambedded option is the option to prepay the morigage. This prepayment option is an American-style call option that gives the borrower (the mortgragon) the right to prepay the remaining principal before the contract matures. Similarly, the default possibility of a mortgage can be viewed as a put option. This option gives the borrower the right to sell the house to the lender (the mortgagee) at a price equal to the remaning book value of the mortgage.

Due to the resemblance of mortgages to a risk-free asset with various embedded options, recent mortgage valuation models are based on bond option pricing techniques. The starting point in those methodologies is a description of the term structure of interest rates which refers to the relationship between interest rates on lixed-income securities of different maturities. Just like each interest rate derivative, a nortgage contract is an asst. whose value depends on the level of interest rates. As with any bond, when interest rates increase, the value of a montgage decreases. But due to the borrowers' option to prepay. the rise in value is limited when interest rates decrease.

In the Netherlands, mortgage contracts are commonly only partially callable. Willin a callendar year, only 10 to 20 percent of the initial loan can be prepaid without cost. Additional prepayments are setted at costs equal to the present value of the difference between future payments of a new mongage and the existing contract. Sometimes a fixed penalty of 250 to 500 guilders is also charged. These typical Duth characteristics are described in Chapter 2, alongside various aspects of the Dulch mortgage market. This market has become bighly dynamic as reflected by the sharp increase in the variety of loan types, the increasing interest in the secondary martet and the substantial growth in the market.

For example, by the end of 1996,379 billion guilders were outstanding on Dutch residential mortgages, and the number of newly issued residental montgage contracts increased in 1996 by $42 \%$ to 550 thousand (CBS, 1997 ). More than one thind of the new contracts re. 
nes, causing the increase in the total amount of mortgage debt to trail the nding. The importance of rmortgage replacements and hence prepayments e mortgage pricing algorithms developed in this thesis.

ig to the newly developed waluation models, Chapter 3 reviews the literac and touches on severat relevant mortgage pricing issues. The first such rtance of the stochastic enviroment of the mortgage, most commonly deynamics of the short-tem interest rate. The other main elements are the finterest rates, a model to relate the mortgage rate to this term structure, rent behavior model:

sat of Chapter 3 summarizes the economic literature on empirical prepaywhereby the assumption that borrowers try to minimize the market value : is relaxed. Rather than imposing optimal call decisions, these studies ad prepayment behavior. Four main determinants are observed to affect rsty, mortgagors tend to replace the existing mortgage when the prevailing $s$ far enough under the contract rate. This refinance incentive is found to jortant factor determining prepayment. Secondly, seasonality measures the 1 the month of the year and prepayment activity, which appears to usually wh and peak in the antumn months. The remaining two factors, seasoning e both related to the age of the contract. Seasoning refers to the observed prepayment rates at the beginning of the contract, and burnout describes $r$ prepayment rates to decline as the mortgage ages.

re summarized in Chapter 3 reveals that numerical procedures are required Ex mortgage contracts. Chapter 4 introduces these numerical methords. ort description of finite difference and simulation methods, this chapter zus to the interest rate tree approach. The principles of nortgage pricing th the help of small-scale examples. The techniques studied in Chapter 4 Thapter 5 to value a more realistic mortigage contract.

ocuses on the impact alternative prepayment rules have on the value and k of morigages. For this we distinguish between an optimal prepayment rule sss boundary. Under optimality, prepayment is triggered when the present ortgage, if left uncalled, exceds the outstanding debt plus any refinancing I with refinancing the loan. The moneyness boundary prescribes prepayment $s$ the future costs for the borrower. This latter prepayment rule lakes the natives open to the homeowner in consideration, while the optimal rule on the discount rate, i.e., the prevaling mortgage rate does not play an in the prepayment decision! As a consequence, the optimal prepayment be used if the mortgage rate is endogenously derived as a function of the rest rate. The moneyness boundary, on the other hand, can also be applied gage rate is exogenously specified. For example, in Chapter 5 , we use both American historical relation between the short-term interest rate and the to value the mortgage contract. 
It is common in the Netherlands for mortgages to be only patially callable. The prepayment risk premum included in these contracts refects the strict prepayment conditions. Consequenty, wtizing the empirical relation between Dutch mortgage and sthort-tem in terest rates to value freely prepayable mortgages produces values which are under par. Mortgages have fewer prepayment restrictions in the US, such that the prepayment risk premium observed in the US data might be more appropriate here The mortgage values that are obtained when the American risk premim is used are not only higher than when the Dutch premium is applied, they are also all above par. However, the resulting interest rate sensitivity measures suggest that the value of the mortgage contract decreases with decreasing interest rates. This counter-intuitive result emphasizes the need for an endogenous model to relate the mortgage rate to the short-term interest rate.

In Chapter 5 , the endogenous mortgage rate is derived by fixing the mortgage value at origination to the principal value of the loan. This is cone for both the optimal prepayment rule and the suboptimal rule which states that the mortgage contract should be replaced if this reduces the future costs for the borrower. This distinction substantially influences the functional relation between the mortgage rate and the short-tem interest rate. And also the resulting interest rate risk measures are found to be sensitive to the chosen prepayment rule. Both prepayment rules emphasize, however, the substantial prepayment risk faced by mortgagees when the annual prepayment restrictions are onitted.

To derive the relation between the mortgage rate and the short-term interest rate, Chapter 5 assumes that all interest rates are driven solely by the short-term interest rate. The way the short-term interest rate dynamics are nodelled may therefore influence the valuation results. To study this, we specify thee empirical one-factor models. Chapter 5 compares the mortgage valuation results from the CIR model with those of a nonlinear model and a noparametric model, all based on Dutch short-term interest rate data. The different mean-reverting and volatility characteristics explain most of the differences anong the three interest rate processes. The interest rate risk measures are found to be especially sensitive to the underlying interest rate process.

Various authors have questioned the single factor assumption and argue llow a multi factor interest rate process is required to model the mortgage rate dynamics. In Chaptwer 6 we approach this question by studying the empirical relations between short-term interest. rates, long-term interest rates and mortgage rates in the Netherlands between 1972 and 1995. Vector AutoRegressive (VAR) techniques are used to analyte the dyntmic interactions between these variables. The results are presented for both a stationary specification of the VAR model consistent with mean-revering interest rate rodels, and anit root specification modelling a random walk.

Independent of the VAR specification, Chapter 6 reveals the shortcomings of a onefactor interest rate model. The results indicate that a multi-factor model containing the short-term and long-term interest rate as well as the mortgage rate describes the mortgage rate dynamics more accurately. The VAR parameters estimated in Chapter 6 are utilized to simulate short-term, long-term and mortgage interest rates in a multi-factor mortgage 
pricing model developed in Chapter $T$.

By using simulation tedniques, we can integrate complicated stochastic interest rate avironments and delailed prepayment restrictions in one mortgage pricing algorithm. Chapter 7 bulds on the freely callthle contracts studied in Chapter 5 by further considering contracts which are only partially callable within a calendar year, and studying the minimum interest rate guarantee included in many Dutch quotation offers. This latter gutantee reduces the prepayment likelihood and is found to increase the duration of the montgage contract and decrease the wallue of the prepayment option. Despite the annual limitations, Chapter 7 shows that these prepayment options are valuable, fog. the value of $10 \%$ penalty-free prepayment option equals one quarter of the value of a prepayment option without any limilations. The valte of the $20 \%$ penalty-free prepayment option is even equal to that the value of the $100 \%$ penalty-free prepayment option!

In order to compare the single factor with the nulti-factor approach it was first necessary to bring the VAR analysis period in line with the one-factor model period. Rather than using interest rates observed between January 1972 and December 1995 , we switched to rates observed over the $1981-1994$ period. This adjustment in the considered period in. the multi-factor approact turns ont to have a major impact on the interest rate sensitivity of a mont.gage contract.

The use of a multi-factor pricing algorithm versus a single factor approach is similarly important. Even though both approaches yield very similar mortgage values, the risk masures differ substantially. Consequently we conclude that, despite the limited effect the allermate interest rate processes have on the mortgage value, the choice for one or the other specific interest rate molel has a major impact on the required hedging stratiegy.

Chapter 8 switches away from mortgages and focus on to the housing market. A repeat sales index is constructed to study the fuctuations in housing prices in the Neberlands between May 1973 and December 1995. This price index for residential property shows a palder similar to the time series for newly tegistered mortgages and the growt of total mortgage debt in the Netherlands. Until 1978, both the price of residential property and the total amount of outstanding nortgage debt increased rapidly. After 1978 the real estate bubble exploded. Housing prices dropped in real terms by more than 40 percent over a period of lour years. The number and guilder value of newly issued mortgages decreased by a comparable percentage. In the mid-eighties, the number of newly issued mortgage contracts started to increase again, as did property prices. However, the weighted repeat sales index constructed in Chapter 8 shows that, in real terms, the value of the index on Decenber. 1995 is still below its all-time maximum ol May 1978.

Chapters 5 and 7 assume that the borrower tries to minimize the market value of the loan. The resulting prepayment behavion depends on the mortgage rate at which mortgagors may refinance their loan. American prepayment data reveals that residential mortigage borrowers regularly prepay their nortgage even though the refinancing rate exceeds the contract rate on the existing mortgege. Others fail to exercise their prepayment option when it would be financially wise to do so. The models developed in Chapters 5 and 
7 are unable to explain this behavior. Chapter 9 takes an empirical appronch and describes the prepayment behavior observed in the Netherlands. The observed prepayment behavior resembles the theoretical results found in Chapters 5 and $T$.

The second part of Chapter 9 relates the observed prepayment behavior to various variables suggested by the economic literature outhed in Chapter 3. The seasonal pattern observed in the Dutch data shows that prepayment activity is at it lowest during early spring, after which it increases up to a maximum in July. Due to tax considerations and the approaching expiration of unused annual prepayment options. we observe another peak in December. The refinance incentive is also found to be an important factor in determining prepayment behavior. The age of the contrack, the loan-to-value ratio and housing price fluctuations have a less pronounced impact on prepayment rates.

Even though most of the empirical relations presented in Chapter 9 conform to economic theory, not all of them are statistically significant. A more in-depth analysis of Dutch prepayment behavior requires more accurate data, not only regarding the prepayment rates themseves but also for the many wariables that infuence them. 


\section{Nederlandse samenvatting / Dutch summary}

Fen bypotheek is een lening met onnoerend goed als onderpand. Dit onderpand dient als zekerheid woor de geldgever. Mocht de bypotheekgever namelijk in gebreke blijen en nieb aan zijn financiele verplichtingen voldoen, dan is de hypothecknener gerechtigd het onderpand te verkopen en met de opbrengsten de vorderingen te verrekenen. Merk hierbij op dat de hypotheekgever degene is die het onroerend goed in onderpand geeft, terwijl de hypotheeknemer de lening verstrekt.

Onder invloed van de lage rente is de Nederlandse hypotheekmarkt de laatste jaren sterk gegroeid. Zo nam het aantal vitstaande hypotheekcontracten in 1996 met $11,16 \%$ toe tot 4,34 miljoen. Te zamen vertegenwoordigden deze contracten en hypothecaire schuld van 379 miljard gulden. Met 15,6 miljoen inwoners betekent dit dat per hoofd vant de Nederlandse bevolking 24 duizend gulden aan hypotheekschuld uitstond.

Een derde van de 550 duizend contracten die in 1996 werden afgesloten, werden gebrail t. om reeds bestaande hypothecaire leningen te vervangen (CBS, 1997). Dit grote aunt,al oversluitingen benadrukt dat hypotheekgevers veelvuldig gebruil maken van de mogelijkheid om de bestaande bypotheek vroegtijdig af te lossen en te vervangen door een nieuwe lening. Deze opzegmogelijkheid herbergt een risico voor de geldgever. Deze weet namelijk niet of de hypotheekgever de hoofdsom volgens wooraf opgesteld schena zal terugbetalen of dat. vervroegd zal worden afgelost.

Zoals voor de meste vastrentende leningen, geldt ook woor een hypothecaire lening dat de marktwaarde afneent als de rente stijgt. Bij een rentedaling word de wardestigging echter beperkt door de optie on wervroegd af te lossen. In dit geval zullen hypotheekgevers namelijk besluiten om de hypotheek over te sluiten nat een lagere rente. Hypotheeknemers proberen dit negatieve effect op te vangen door aflossingen slechts beperkt boetewije toe te staan. Zo mag in Nederland per kalencierjar gewoonlijk slechts 10 tot 20 procend. van de orginele hoofdsom boeterij worden afgelost. Extra aflossingen brengen kosten met zich mee die meestal gelijk zijn aan de contante warde van hot renteverschil. Dozo characteristieken die kenmerkend zijn voor Nederlandse hypotheekcontracten worden in hoofdstuk 2 toegelicht.

Naast de standard hypotheekvormen die in hoofdstuk 2 besproken worden, werschijnen er steeds vaker nieuwe produkten op de markt die de hypotheekgever meer vijheden 
bieden. Deze wrijheden bemoeilijken het warderen van een hypotheek en vragen om een goed warderingsmode. En ook het sterk toegenomen arntal oversluitingen, de groejende hypothelmarkt en de toegenomen interesse voor de openbare tweedehands markt bewadrukken het belang van een accuraat bypothekwarderingsmodel.

Een warderingshodel voo hyptheken bestat nit verschillende componenten, wart: wan het model dat de rente dyramiek beschrijf een van de meest belangrijke is. Twee andere componenten relateren deze dynamiek an de rente termijnstruetum en an de bypothoekrente. Daarnast is een model dat het aflossingsged lag beschrift noodzakelijk."

Voordat word overgegan tot het daadwerkeljk ontwikkelen van een warderingsmodel, vat hoofdstuk 3 de literature op dit gebied samen. In dit hoofdstuk wordt uitgebreid stilgestaan bij de werchillende mogelijkheden on het aflossingsgedrag van de hypotheekgever te modelleren. Hierbij word een onderscheidt gemaakt tussen exogene en endogene modellen.

Exogene modellen relateren het wastgenomen aflossingsgedrag arn factoren die kenmerlkend zijn voor het hypotheekcontract, het onderpand en de hypotheekgever. Natutrlijk worden ook seizoensinvloeden nacro-economische grootheden, zoals rentestan den. meegenomen in deze analyse. Exogene modellen worden op Wall Street veelvuldig loegepust om hypotheekportefeuilles te wateren. Voor Nederland is deze methode veel minder geschikt omdat het empirisch modelleren van het aflossingsgedrag een uitgebreide dataset vereist die in Nederland niet woorhanden is. In Amerika, wat de markt voor Mortgage-Backed Securities al decennia lang bestaat, zijn deze gegevens in voldoende mate aanwezig om een adequat affossingsmodel te construeren. De Amerkaanse bevindingen kunnen echter niet zonder meer worden toegepast in Nederland, datwoor zijn de verschillen tussen de hypotheekmarkten en contractvormen te groot.

Om Nederlandse hypotheekcontracten te warderen dienen we gebruik te maken van theoretische modellen warin het aflossingsgedrag endogeen bepaald wordt. Het allossingsgectrag is hierbij niet gebaseerd op warnemingen, maar op beslisregels die worden opgesteld door do analyst. Deze methode is bij uitstek geschikt on het renterisico voor de geldgever in kaart te brengen en wordt in de hoofdstukken 5 en 7 dan ook gebruikt om de warde en rentegevoeligheid wan een hypotheek te bepalen. De beschouwde hypotheek kan ieclere mand volledig worden algelost. Ondat de warde van een contract met deze optic niet. analy tiscth bepaald kan worden moeten we gebruik maken wan numerieke methoden zoals: die in hoofdstuk 4 besproken worden. In dit hoofdstuk statit de zogenaande renteboombenadering centraal. Aan de hand van eenvoudige voorbeelden worden de sterke en zwakke punten van deze methode toegelicht. De voorbeelden veronderstellen dat een hypotheek word algelost. zodra de netto contante warde van de toekomstige kasstromen hoger is dan do uitstaande schuld. Het aflossingsgedrag wordt in deze optiek dus beparald door de dynamiek van de rente die gebruilt wordt on de kasstromen te verdisconteren. De nieuwe contractronte wartegen het individu kan herfinancieren speelt hierbij geen enkele rol. In

\footnotetext{
Th prinaipe dient ook een component te worden opgenonen die de mogelijheid dat de hypothemgerer

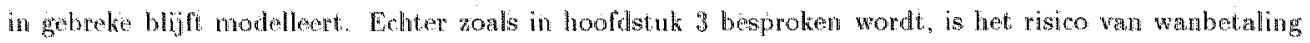

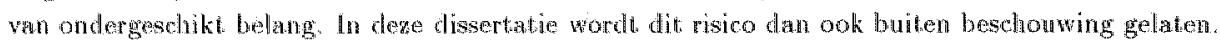


hoofdstuk 5 vergelijken we deze allosregel met ren regel die volledig gebaseerd is op de rente wartegen de hypotheekgever een nieuwe lening kan aangan.

De aflosregel die gebaseerd is op de disconteringstente kan alleen gebruikt worden indien de relatie tussen de bypotheekrente en de korte rente endogeen bepaald is. Dat wil reggen dat de hypotheekrente dusdanig an de korte rente gerelateerd is dat de netto contante warde van de lening gelijk is aan de hoofdsom. Als een exogene relatie gebruikt wordt kan het gebeuren dat deze aflosregel de hypotheckgever voorschniff om hin contract over te sluiten op een moment dat de hypotheekrente hoger is dan de rente op zijn huidige lening. Dit is niet mogelijk indien de beshissing om al dan niet af te lossen gebaseerd is op de rente wartegen he individu kan herfnancieren. In deze situatie kumen dan ook exogene specificaties gebruikt worden on de hypotheekrente an de korte rente te relateren. ${ }^{2}$ In hoofdstuk 5 gebruilien we bijwoorbeeld de empirische relaties tussen de korte rente en de hypotheekrente in Nederland en in de Verenigde Stiaten.

De Nederlandse relatie heeft als voordeel dat de onderliggende rentedynamiek de Nederlandse situatie beschrijft. Een nadeel is echter dat de hypotheekrente gebaseend is op contracten die in een kalenderjar slechts gedeeltelijk boetcvrij aflosbaar zijn, terwijl het contract dat in hoofdstuk 5 onderzocht wordt iedere maand in z'n geheel mag worden afgelost. Het gebruik van deze historische relatie leidt in sommige gevallen dan ook tot prijzen beneden par. Ondanks het leit dat Amerikaanse contracten minder afosrestricties kennen blijkt ook de Amerikaanse relatie niet geschikt om het nieuwe hypothoekcontract te analyseren. De waarde van het contract is ditmaal weliswar in iedere siluatie boven par, maar de rente-risico maatsitaven worden megatiel.

Bovenstaande leert ons dat exogene specificaties weliswaar gebruikt kunnen worden om snel een cerste indruk te krijgen van de warde en het rente-risico van een hypotheekcontract, maar dat voor een meer nauwheurige analyse een endogene relatie tussen de korte rente en de hypotheekrente de voorkeur verdient. In hoofdstuk 5 wordt deze endogene relatie afgeleid voor beide aflostegels. De resullerende relaties blijken in sterke mate af te hangen van de onderliggende aflosregel. Zo leidt de aflosmegel die gebaseerd is op do dis. conteringsente altijd tot een hogere hypotheekrente dan wanner de aflossingsbeslissing gebaseerd wordt op de rente wartegen de hypotheekgever zijn lening kan herfinancioren. Als deze laatste aflosregel gebruikt wordt zien we dat de endogene relatie tussen beide rentes een lakker verloop kent.

Om endogeen de hypotheekrente af te leiden hebben we in hooldsitu 5 verondersteld dat de bypotheekrente slechts afhangt van de korte rente. De manier warop do dynamiek in de korte rente gemodelleerd is zon daarom de resultaten kunnen beinvloeden. On dit te onderzoeken vergelijken we de resultaten van drie verschillende éen-factor modellen. Natat: het Cox, Ingersoll en Ross model gebruiken we en niet-juear en een niet-parametrisch model. Met name de rente-risico matastaven blijken gevoelig te zijn woor de manier waarop de dynamiek in de korte rente beschreven wordu.

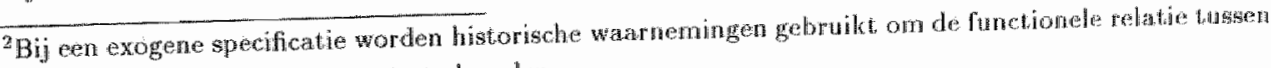
de hypotheetrente en de konte rente te bepallen.
} 
De aanname dat de dynamek in de hypotheekrente beschreven kan worden met cen éch-factor model is valk onderwerp van discussie. In hoofdstil 6 dragen we bij an deze discussie doon de empirische relatie tussen de korte terminin rente, de lange termin rente en de hypotheekrente in Nederland te onderzoelken. Om de dynanische interacties tussen deze variabelen te bestuderen maken we gebruik wan Vector AutoRegressieve (VAR) technieken en presenteren we de resultatien voor zowel een stationaire als een unit root specificatie van het VAR model. De eerste specificatie bevat drift termen die er voor zorgen dat de verschillende rentes steeds weer teng keren nar hun lange termijn gemiddelde. Dit in tegenstelling tot een unit root proces wat een random walk modelleert.

Beide VAR-specificaties onthuliten de tekortkomingen van een én-factor model. Fen multi-factor model dat naast de korte termijn rente, ook de lange temijn rente en de hypotheskrente bevat blijk beter in staat te ajn on de dymamiek in de hypotheekrente te beschrijven. In overeenstemming hiermee wordt in hoofdstuk 7 een muli-factor hypotheek waarderingsmodel ontwikkeld, warbij de VAR-parameters geschat in hoofdstuk 6 gebruikt worden om de korte rente, de lange rente en de hypotheekrente te simuleren.

Door simulatie-technieken te gebruiken kunnen we geavanceerde rente dynamieken en gedetailleerde flosrestricties in een model samenbrengen. Zo bestuderen we in hoofdstuk 7 niet alleen contracten die iedere maand volledig aflosbat zijn, maar houden we ook rekening met de in Nederland veel wook komende restrictie dat slechts 10 tot 20 procent van de initiële hoofdsom per kalenderjar boetevrij mag worden afgelost. Ook bestudeert hoofdstuk 7 de invloed van de rentedalgarantie die garandeert dat het contract wordt afgesloten tegen de laagste rente die voorkomt gedurende de periode dat de hypotheekofferte geldig is. Deze garantie verkleint de kans op verwroegde aflossingen en we vinden dan ook dat de gemiddelde duratie van een hypotheekcontract toeneemt als deze garantie verstrekt wordt.

De VAR-parameters die in het eerste gedeelte van hoofdstuk 7 worden gebruikt om ventes te simuleren, zijn gebaseerd op waarnemingen tussen januari 1972 en december 1995. In hoofdstuk 5 daarentegen, worden observaties tussen januari 1981 en december 1994 gebrukit on de één factot modellen te schatten. Om beide arapakken te kunnen vergelijken moten we dari ook eerst de VAR-parameters anpassen voor deze kortere subperiode. Deze anpassing blijkt een groot effect te hebben op de gemeten rentegevoeligheid van een Hypotheekcontract. Deze gevoligheid van de rente-risico maatstaven vinden we ook terug als we de verschillende éen factor modellen vergelijken met de multi-factor aanpak. Dit betekent dat de keuze voor een bepaald rentemodel verstrekkende gevolgen heeft voor de te wolgen hedging-strategie.

In hoofdstuk 8 word een zijstap gemalkt en richten we de aandacht op de Nederlandse huizemmarkt. Zoals reeds in hoofdstuk 2 naar voren is gebracht, wordt de overgrote meerderheid van alle hypothecaire leningen angewend om de aanschaf van een eigen woning te funducieren. Om te onderzoeken of de ontwikkelingen op de hypotheekmarkt en de woningmarkt elkaar volgen wordt in hoofdstuk 8 een index geconstrueerd die de prijsHuctuaties van Nederlandse koopwoningen tussen mei 1973 en december 1995 weergeeft. Deze index is gebaseerd op prijsontwikkelingen van afzonderlijke huzen. In tegenstelling 
tot indices die gebaseerd zijn op gemiddelde verkoopprijzen of op de median van doze prijzen, is de in hoofdstuk 8 beschreven index nawwelijks gevoelig voor de samenstelling van huizen die in een bepalde periode verkocht worden.

De huisprijzenindex toont een beeld dat overenstemt met de fluctualies op de hy. potheekmarkt. Tot 1978 stegen bijwoorbeeld zowel de huisprijzen als de total witstande bypothecaire schuld. En ook de in enstorting van de huizenmarkt eind jaren zeventig, begin jaren tachtig is weerspiegeld in de fuctuaties op de hypotheekmarkt. In centijdsbestek van minder dan vier jaar (1978-1982) daalde de huisprijzen in reele temen met meer dan 40\%. Eind 1995 is de huizenmarkt deze klap nog steeds niet te boven en ligt bet reels prijsniveaw van woningen nog onder dat van 1978.

De prijsfluctuaties van koopwoningen worden in hoofdstuk 9 gebruikt om empirisch het aftossingsgedrag van Nederlandse hypotheekgevers te onderzoeken. In tegenstelling tot de hoofdstukken 5 en 7 veronderstelt dit hootdstuk niet dat een hypotheekgever de marktwaarde van zijn of haar hypotheekcontract probeert te minimaliseren. In plaats daarvan richt hoofdstuk 9 zich op het waargenomen aflossingsgedrag van een kleine groep Nederlandse hypotheekgevers. Dit gedrag, dat grote overenkomsten blijkt te vertonen met de resultaten uit de theoretische hoofdstukken 5 en 7 , wordt gerelateerd aan verschillende factoren die in hoofdstuk 3 beschreven zijn.

In de Nederlandse affossingsdata valt een seizoenspatroon te herkennen dat in grote lijnen overeenstemt met de Amerikaanse resultaten. Ook in ons land word in het voorjaar minder afgelost dan in de rest van het jaar. Het maximum wordt in juli bereikt en niet, zoals in de Verenigde Staten, in de herfsmaanden. Het grootste verschil tussen het Nederlandse en Amerikaanse seizoenspatroon vinden we echter in december. Daar wat in de Verenigde Staten de aflossingen afnemen, zien we dat in Nederland in december meer dan gemiddeld wordt afgelost. De reden hiervoor is gelegen in het feit dat de aflosrestricties in Nederland normaliter gebonden zijn aan een kalenderjaar. De meeste hypothekencontracten laten bijwoorbeeld niet toe dat er meer dan 10 procent van de initiële hoofdsom per kalenderjatr boetevrij wordt afgelost. Mocht deze 10 procent"s nom in decenber nog nitu berikt sijn, dan zallen veel mensen beshitien on alsnog van deze optie gebruik te maken.

Naast het seizoenspatroon vinden we in hoofdstuk 3 dat de rente een belangrijke factor is om het wargenomen aftossingsged ragg te verklaren. En blijkt dudelijk een prikkel te zijn om te herfinancieren als de rente lagg is. De leeftijd van het contract, de relatio tussen de omvang van de lening en de waarde van het onderliggende pand on ook fuctuaties in husprijzen hebben een veel minder duidelijke invloed op hat allossingsgedrag. Het aantal warnemingen is echter te beperkt om hierut te concluderen dat dese variabelen het aflossingsgedrag niet beinvloeden. Voor een grondige empirische studie zijn meer gegevens vereist, niet alleen met betrekking tot het aflossingsgedrag, mar ook ontrent do varabelen die dit gedrag beïnvloeden. 


\section{Bibliography}

ABRAHAM, J.M. AND W.S. SCHAUMAN (1991), New Evidence on House Prices from Freddie Mac Repeat Sales, Journal of the American Real Estate and Urban Economics Association, 19(3), 333-352.

AbrahaMs, S.W. (1997). The New View in Mortgage Prepayments: Insight from Analysis all the Loan-by-Loan Level, The Journal of Fixed Incone, 7(1), 821.

AitT-Sahalia, Y. (1996a), Testing Continuous-Time Models of the Spot Interest Rate, The Review of Financial Studies, $9(2), 385-426$.

Aïr-Sahalia, Y. (1996b), Nonparametric Pricing of Interest Rate Derivative Securities, Econometrica, 64(3), 527-560.

ARChER, W.R. AND D.C. LING (1993), Pricing Mortgage-Backed Securities: Integrating Optimal Call and Empirical Models of Prepayment, Journal of the American Real Estate and Urban Economics Association, 21(4), 373-404.

ARCHER, W.R. AND D.C. LING (1995), The Effect of Alternative Interest Rate Processes on the Value of Mortigage-Backed Securities, Journal of Housing Research, 6(2), 285314.

Balley, M.J., R.F. Muth, AND H.O. Nourse (1963), A Regression Method for Real Estate Price Index Construction, Journal of the American Statistical Association, 58 , $933-942$.

BASSANT" E. (1994), Hypotheekgarantie over twee weken al operationeel, Het Financhele Dagblad, 4 .

BEckETT, S. AND C.S. Monms (1990), The Prepayment Experience of FNMA MortgageBacked Securities, unpublished manuscript, Federal Reserve Bank of Kansas cily.

BEnNINGa, S. AND A. Protopapadakis (1994), Forward and Futures Prices with Markovian Interest-Rate Processes, Journal of Business, 67(3), 401-421.

Black, F., E. DERMAN, AND W. TOY (1990), A One-Factor Model ol Interest Rales and its Application to Treasury Bond Options, Financial Analysts Journal, 46(1), $33-39$.

BOllerslev, T., R.Y. CHOU, AND K.F. KRONER (1992), ARCH Modeling in Fimance: a Review of the Theory and Empirical Evidence, Jourmal of Econometrics, 52, 5-59.

Boudoukh, J., M. RIChafdon, R. STanton, and R.F. Whitelaw (1995), A New Strategy for Dynamically Hedging Mortgage-Backed Securities, The Jourral of Derivatives, $2,60-77$. 
BoudoukH, J., M. RICHADSON, R. STANTON, AND R.F. WhITELAw (1997), Pricing Mortgage-Backed Securities in a Multifactor Interest Rate Environmen: A Multwanate Density Estimation Approach, The Review of Financial Studies, 10(2), $405-416$.

BRENMAN, M.J. AND E.S. Schwartz (1978), A Lattice Framework for Option Pricing with Two State Variables, Joumal of Financial and Quantilative Analysis, $13,461$. 474.

BRENNAN, M.J. AND E.S. SChwartz (1979), A Continuous-Time Approach to the Pricing of Boncs, Journal of Banking and Finance, 3, 133-155.

BREnNan, M.J. AND E.S. Schwartz (1985), Determinants of GNMA Mortgage Prices, Journal of the American Real Estate and Urban Economics Association, $13(3), 209$ 228.

Buser, S.A. And P.H. Hendershotr (1983), Pricing Default-Free Fixed-Rate Mortgages, Housing Finance Revieu, 3, 405-429.

Busen, S.A. P.H. HendenshotT, AND A.B. Sanders (1985), Pricing Life of Loan Rate Caps on Default-Free Adjustable-Rate Mortgages, Journal of the American Real Estate and Urban Economics Association, 13(3), 248-260.

Buser, S.A., P.H. Hendershotr, AND A.B. SANDERs (1990), Determinants of the Value of Call Options on Default-Free Bonds, Journal of Business, 63(1), s33-s50.

Bussel., A.P.J.M. VAN (1997), A VAR Analysis of Interest Rates in the Netherlands, Journal of Property Pinance, 8(3), 246-263.

Cacan, L.D., N.J. Carriero, and Zenios (1993), A Computer Network Approach to Pricing Mortgage-Backed Securities, Financial Analysts Journal, 55-62.

Campbell, J.Y., A.W. Lo, And A.C. MACKInlay (1997), The Econometrics of Financial Markets, Princeton University Press, New Jersey.

CAMPBELL, J.Y. AND P. PERRON (1991), Pitfalls and Opportnnities: What Macroeconomists should know about. Unit Roots, NBER Macroeconomics Annwal, 6, 141-201.

CAMPBill, J.Y. AND R.J. SHLLER (1987), Cointegration and Tests of Present Value Models, Journal of Political Ficonomy, 95(5), 1062-1088.

Camprell, T.S. AND J.K. Diethich (1983), The Determinants of Default on Insured Conventional Residential Mortgage Loans, The Journal of Finance, 38, 1569-1581.

Canabarro, E. (1995). Where do One-Factor Interest Rate Models Fail?, The Journal of Fixed lincome, $5(2), 31-52$.

Cannaday, R.E. AND T.L.T. YANG (1995), Housing Depreciation and Repeat Sales Housing Price Index, unpublished manuscript.

Case, B. AND H.O. Pollakowski (1991), On Choosing Among Honse Price Index Methodologies, Journal of the American Real Estate and Urban Economics Associatron, $19(3), 286-307$.

CAsE, B. AND J.M. Quigley (1991), The Dynamics of Real Rstate Prices, Review of Fconomics and Statistics, $73(3), 50-58$.

CASE, Kr.E. AND R.J. Shller (1987), Prices of Single-Family Homes since 1970: New Indexes for Four Cities, New England Economic Review, 45-56. 
CENTKAAL BUREAU VoOR DE STATISTEK (1965-1975), Hwpotheken en Hyotheekanden, Voorburg/theerlen.

CEnTRAal BUREAU voor de STATISTIEK (1976-1992), Statistek der Hypothekn, Voorburg/Heerlen.

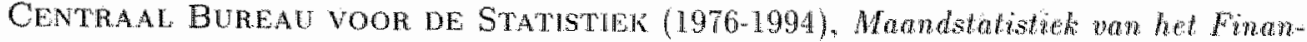
creweren, Voorburg/Heerlen.

CentraAl Bureau voor de STATISTEK (1993-1996), Financiele Maandstatistiek, Voorburg/Heerlen.

Centraal Bufeau voor de Statistiek (1995a), Sparen en Lenen im Nederland 1996, Holstad B.V., Voorburg/Heerlen.

CEnTRAal Bureau voor de Statristek (1995b), Vijemegentig Jaar Statistiek in Tijdreeksen 1899-1994, Voorburg/Heerlen.

CentraAl Bureau voor de STATISTIE (19950), Jarboek Wonen 1996: Feiten en Cajers over de Woningmarkt in Nederland, Kluwer Bedrijfswetenschappen, Voorburg/Heerlen.

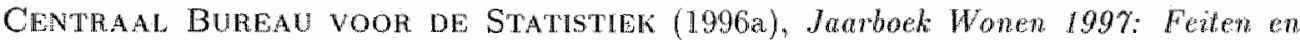
Chfers over de Woningmarkt in Nederland, Kluwer Bedrijtswetenschappen, Voorburg/Heerlen.

CentraAl BUREAU voor DE STATISTEK (1996b). Assurantie Jadrbock, Whwer Bedrijfiswetenschappen, Voorburg/Heerlen.

Centraal Bureau voor de StatisteK (1997), Persbericht: mear dan halj miljorn. nieuwe woninghypotheken in 1996, Vooburg/Heerlen.

Chan, K.C., G.A. Karoly, F.A. Longstaff, and A.B. Sanders (1992), An Empirical Comparison of Alternative Models of the Short-Term Interest Rate, The Jownal of Finance, 47(3), 1209-1227.

Chen, A. AND D. Lung (1989), Optimal Mortgage Refinancing with Stochastic Interest Rates, Journal of the American Real Estate ated Urbon Economics Assaciation, 17(3), 278-299.

CHEN, R.R. AND T.L.T. YANG (1995), The Relevance of Interest, Rate Processes in Pricing Mortgage-Backed Securities, Jownal of Houstmg Research, 6(2), 315-332.

CHeUK, T.H.F. AND A.C.F. Vonst (1997), Shout Floors, The Electronic dounal of Financial Risk, (2).

CHOI, S. (1996), Effective Durations for Mortgagew Backed Securities: Recipes for Improvement, The Jownal of Fited lncome, 5(4), 23-30.

Clapp, J.M., C. GiaccotTo, AND D. Thrtroglu (1991), Housing Price Indicies: Based on All Transactions Compared to Repeat Subsamples, Joumal of the American Real Estate and Unban Economics Association, $19(3), 270-285$.

Clauretie, T.M. and T.N. Herzog (1989), How State Laws Affect Foreclosure Cosis, in Secondary Mortgage Markets.

Cochrane, J.H. (1991), A critique of the application of unitoot tests, Journal of Economic Dynamics and Control, $15,275-284$. 
Condey, T.G. L.P. HANSEN, E.G.J. LUTTMER, AND J.A. SChETKMAN (1997), Short Tem Interest Rates as Subordinated Diffusions, The Review of Francial Sud(2) $10(3), 525-577$.

Counr, A. (1939), Hedoric Price Indexes with Automotive Examples, The Dynamics of Automobile Demand, General Motors.

Countadow, G. (1982), The Pricing of Options on Default-Free Bonds, Journal of Financial and Quantitatioe Analysis, 17(1), 75-100.

Cox, J.C., J.E. INGErsoll, AND S.A. Ross (1985a), An Intertemporal General Equilibrium Model of Asset Prices, Econometrica, 53(2), 363-384.

Cox, J.C., J.E. INGERSOLL, AND S.A. Ross (1985b), A Theory of the Term Structure of Interest Rates, Econometrica, 53(2), 385-407.

Cunnivgham, D.F. AND C.A. Capone (1990), The Relative Termination Experience of Adjustable to Fixed-Rate Mortgages, The Journal of Finance, 45(5), $1687-1703$.

Cunningham, D.F. And P.H. Hendershot (1984), Pricing FHA Mortgage Default Thsurance, frousting Finance Review, 3, 373-392.

DE KnUUK, A. AND W.T. VIssers (1996), De hypotheekrente regionaal bericht, in Sparen en lenen in Nederland 1997, Central Bureau voor de Statistiek.

DE NEDERlandone BANK (1965-1995), Anmal Reports and Quarterly Reviews, Amsterdam.

Derosa, P., L. Goodman, And M. Zazzarino (1993), Duration Estimates on MortgageBacked Securities, The Journal of Portfolio Management, 32-38.

Duffe, D. (1996), Dynamic Asset Pricing Theory, 2nd edition, Princeton University Press, Princeton, New Jersey.

DUNN, K.B. AND J.J. MCCONNELL (1981a), A Comparison of Alternative Models for: Pricing GNMA Mortgage-Backed Securities, The Journal of Finance, 36(2), 471-487.

DUNN, K.B. AND J.J. MOCONNELL (1981b), Valuation of GNMA Mortgage Backed Securities, The Jownal of Finance, 36(3), $599-616$.

Enonnotiz, P.M.A. (1994), Real Estate Diversification, Phild thesis, University of Lim. burg, Maastricht.

Eichrolrz, P.M.A. (1995), Regional Economic Stability and Mortgage Delault Risk in the Netherlands, Real Estale Economics, 23(4), 421-439.

ENGLE, R.F. (1982), Autoregressive Conditional Heteroskedasticity with Estimates of the Variance of United Kingdon Inflation, Ecomometrica, 50, $987-1007$.

ENGLE, R.F. AND C.W.J. GRANGER (1987), Cointegration and Error Correction: Representation, Estimation and Testing, Econometrica, 55, 251-276.

Epperson, J.F., J. B. Kau, D.C. Keenan, and W.J. Muller (1985), Pricing Default Risk in Morigages, Joumal of the American Real Estate and Urban Economics Association, 13(3), 261-272.

Fabozzi, F.J. AND F. Modglani (1992), Mortgage and Mortgage-Backed Securities Markets, Harvard Business School Press. 
Fortis INvestments (1996), Offering Concular: F.I. Mortgoge Securties B. W. Burrups Lid., Londort.

Foster, C. And R. VAn Order (1985), FHA Teminations: A Prelide to Rational Mortgage Pricing; Journal of the American Real Estate and Urban Econowics Asso. ciation, $13(3), 273-291$.

GatzlafF, D.H. AND D.R. HAurin (1996), Sample Selection Bins and Repeat Sales Index Estimates, unpublished manuscript.

GatzlaFF, D.H. AND D. Ling (1994), Measuring Changes in Local House Prices: An Emprical Investigation of Altermative Methodologies, Jownal of Unban Economics, $35,221-244$.

Guliberto, S. M. AND D.C.Ling (1992), An Empirical Investigation of the Contingent. Claims Approach to Pricing Residential Mortgage Debt, Journol of the American Real Estate and Urban Ecomomics Association, 20(3), 393 426.

Goltzmann, W.E. AND M. SpIEgEL (1995), Non-Temporal Components of Residential Real Estate Appreciation, Review of Economics and Statistics, 77, $199-206$.

GoedzMann, W.N. (1993), The Single Family Home in the Investment Portiolio, The Journal of Real Estate Finance and Economics, 6, 201-222.

Golub, B.W. And L. Pohlman (1994), Mortgage Prepayments and an Analysis of the Wharton Prepayment Model, Interfaces, 24(3), 80-90.

GRANGER, C.W.I. (1969), Investigating cansal relations by econometric models and crossspectral methods, Econometrica, 36, 424-438.

Green, J. And J.B. Shoven (1986), The Effects of Interest Rates on Mortgage Prepayments, Joumal of Money, Credit and Banking, 18(1), 41-59.

Hamitron, J.D. (1994), Time Series Analysis, Princeton University Press, Princeton, New Jersey.

HANESly, P.J., T.M. Springer, AND N.G. WAller (1993), Duration and the Price Behavior of Fixed-Rate Level Payment. Mortgages: An Analytical Investigation, The Journal of Real Estate Finance and Economics, 6, 157-166.

HÄRDLE, W. (1990), Applied Nan-Parametric Regression, Econometric Society Monagraplas, Cambridge University Press.

HEath, D., R. Jarrow, AND A. Morton (1990), Bond Pricing and the Tem Structure of Interest Rates: A Discrete Time Approximation, Jonmal of Financial and Quantitaliwe Analysis, 24(4), 419-440.

HEATH, D., R. JARFOW, AND A. MORTON (1992), Bond Pricing and the Term Structure of Interest Rates: A New Methodology for Contingent Claims Valuation, Econometrica, $60(1), 77-105$.

Hendershot, P.H. AND R. VAN ORder (1987), Pricing Mortgages: An Interpretation of the Models and Results, Journal of Financial Services Research, $1,19-55$.

HendershotT, P.H. AND J.D. ShILlNa (1985), Valuing ARM Rate Caps: Timplications of 1970-84 Interest Rate Behavior, Joumal of the American Real Estute and Urban Economics Association, 13(3), 317-332. 
Ho, T.S.Y. AND S.B. LeE (1986), Term Structure Movements and Pricing Interest Rate Contingert Glaims, The Journal of Finance, 41(5), 1011-1029.

HuANG, C. AND W. XIA (1996), Modelling APM Prepayments, The Journal of Frad Income, $5(4), 31-44$.

HuLc, J. (1997), Optons, Futwres, and Other Derivative Securties, 3nd edition, Prentice Hall International Editions, Englewood Clifs, New Jersey.

HuL, J. AND A. WhrTe (1990a), Valung Derivative Securities using the Explicit Finite Difference Method, Jonrnol of Financial and Quantitatiwe Analysis, 25(1), 87-100.

HULd, J. AND A. WhIT (1990b), Pricing Interest-Rate Derivative Securities, The Review of Financial Studies, $3(4), 573-592$.

Hull, J. AND A. Whrtie (1993), One-Factor Interest Rate Models and the Valuation of Interest-Rate Derivative Securities, Jonthal of Fancinl and Quantitative Analysis, 28(2), $235-254$.

HULL, J. AND A. WHITE (1994), Numerical Procedures for Implementing Term Stucture Models I: Single-Factor Models, The Journal of Derivalimes, 7-16.

JoHANSEN, S. (1988), Statistical Analysis of Cointegration Vectors, Journal of Economic Dynamics and Control, 12, 231-254.

KAM, C.A. DE (1997), De logica van de hypotheekrente-aftrek, ESB, (4091), 94-95.

KANG, P. AND S.A. ZEnIos (1992), Complete Prepayment Models for Mortgage-Backed Securities, Maragement Science, 38(11), $1665-1685$.

Kau, J.B. AND D.C. KEenan (1995), An Overview of the Option-Theoretic Pricing of Morigages, Jownal of Housing Research, 6(2), 217-..241.

KAU, J.B., D.C. KEENAN, AND T. KIM (1994), Default Probabilities for Mortgages, Joumal of Utban Economics, 35, 278-296.

Kau, J.B., D.C. KeEnan, W. J. Muller, AND.J.F. Epperson (1990), The Valuation and Analysis of Adjustable-Rate Mortgages, Mandgement Secence, 36(12), $1417-1431$.

KAU, J.B., D.C. KEENan, W.J. Muller, And J.F. Epperson (1992), A Generalized Valuation Model for Fixed-Rate Residential Mortgages, Jomrnal of Money, Credit. and Banking, 24(3), 279-299.

Gau, J.B., D.C. KEenan, W.J. Muller, and J.F.Epperson (1993), Option Theory and Floating-Rate Securities with a Comparison of Adjustable and Fixed-Rate Mortgages, Jowrnal of Business, 66(4), 595-618.

KAU, J.B. AND T. KM (1994), Waiting to Default: The Value of Delay, Jomnal of the American Real Estate and Urban Economices Association, 22(3), 539-551.

hoeduk, C.G., F.G.J.A. Nissen, P.C. Schotman, And C.C.P WolfF (1997), The Dynamics of Short-term Interest Rate Volatility Reconsidered, European Finance Review, $1,105-130$.

Kool, C.J.M. AND K.G. Rouwenhorst (1985), Risk Premia in Financial Markets: Comparing the Dutch and German Experience 1970-1983, unpublished manuscript, Erasmus Universily Rotterdam. 
LEA, M.J. AND P.M. Zorn (1986), Adjustable Rate Mortgages, Fluctuations in the Economic Environment and Lender Portfolio Change, Journal of the American Real Estate and Urban Economics Association, 14, 432447 .

Leung, W.K. And C.F. Sirmans (1990). A Lattice Approach to Pricing Fixed-Rate Mortgages with Default and Prepayment Options, Journal of the American Real Estale. and Urban Economics Association, 18(1), 91-104.

Lrterterman, R. And J. Scheinkman (1991), Common Factors affecting Bond Returns, The Journal of Fixed Income, 1, 54-61.

LongstafF, F.A. AND E.S. Schwartz (1992), Interest Rate Volatility and the Term Structure: a Two-Factor General Equilibrium Model, The Journal of Finonce, 47, 1259-1282.

LongstafF, F.A. AND E.S. SCH wartz (1993), Implementation of the Longstaff-schwartz Interest Rate Model, The Journal of Fixed Income, 3(2), 7-14.

Lowell, L. (1995), Mortgage Pass-Through Securities, in F.J. Fabozzi, (ed.), The Handbook of Mortgage-Backed Securities, Probus, Chicago, Illinois.

Lucas, R.E. (1987), Models of Bustiness Cycles, Yrjö Jahnsson Lectures, Basil Blackwell, Oxford.

Macaulay, F. (1938), Some Theorelical Problems suggested by the Movements of Interest Rates, Bond Yield and Stock Prices in the Uniled States since 1856, National Bureau of Economic Research.

MAfK, J.H. AND M.A. GoldBeng (1984), Alternative Housing Price Indices: An Evaluation, Journal of the American Real Estate and Urban Economics Association, 12(1), $30-49$.

MCCONNELl, J.J. AND M. SInGH (1993), Valuation and Analysis of Collaterized Mortgage Obligations, Management Science, 39, 692-709.

MCConnelt, J.J. ANd M. Singh (1994), Rational Prepayment and the Valuation of Collaterized Mortgage Obligations, The Journal of Finance, 49(3), 891-921.

Merton, R.C. (1994), Continuous-Time Finance, 2nd edition, Blackwell Publishers, Oxford.

Munnik, J.F.J. De and P.C. Schotman (1994), Cross-Sectional versus Time Series Estimation of Term Structure Models: Empirical Results for the Dutch Bond Market, Journal of Banking and Finance, 18, 997-1025.

Nelson, D.B. And K. Ramaswamy (1990), Simple Binomial Processess as Diffusion Approximations in Financial Models, The Revieve of Financiai Studies, 3(3), 393-430.

NeuveL, R.M. (1996), Nieuwe hypotheekproducten: meer lenen, maar lagere lasten, Bank- en Effectenbedriff, 45, 25-28.

Paskov, S.H. Ano J.F. Traub (1995), Faster Valuation of Financial Derivalives, The Journal of Portfolio Management, 22(1), 113-120.

Parruno, G.N. (1994), Mortgage Prepayments: A New Model for a New Era, The Journal of Fixed lncome, $4(23), 42-56$.

Pelsser, A. AND A.C.F. Vorst (1997), Pricing of Flexible and Limit Caps, unpublished manuscript, Ẹrasmus University Rotterdam. 
Pennon, P. (1989), The Great Crast, the Oil Price Shock and the Unit Root Hypothesis, Econometrica, 57(6), 1361-1401.

Penron, P. (1993), The Great Crash, the On Price Shock and Unit root Hypothesis: Fratum, Econometrica, 61 (1), 248249.

Peters, H.F., S.M. Pinkus, AND D.J. Askin (1984), Figuring the Odds: A Model of Prepayments, Secondary Mortgage Markets, $1,18-23$.

PEANN, G., P.C. SthotMAN, AND R. TsCHERNIG (1996), Nonlinear Interest Rate Dynamics and Implications for the Term Structure, Joumal of Econometrics, 74 , 149-176.

REMPT, M.H.G. (1993), Mortgage Banks and the Mortgage Bond in the Netherlands, in NOMOS, (ed.). Mortgage Banks and the Mortgage Band in Europe, Baden-Baden, chapter 9 .

Rendeman, R.J. And B.J. Bafterer (1980), The Pricing of Options on Debt Securities, Journal of Financial and Quantitative Analysits, 15(1), 11-24.

RICHARD, S.F. AND R. Roll (1989), Prepayments on Fixed-rate Mortgage-Backed Securities, The Journal of Portfolio Management, 15, 21-35.

Rosen, S. (1974), Hedonic Prices and Implicit Markets: Product Differentation in Pure Competition, Journal of Political Economy, 82, 34-55.

Ross, S.M. (1993), Introduction to Probability Models, כ̆th edition, Academic Press, San Diego.

SA-AADU, J. (1988), Legal Restrictions, Credit Allocation and Default Risk under Fixed and Adjustable Rate Mortgages, Housing Finance Review, 7, $225-247$.

Schalefer, S.M. AND E.S. Schwartz (1984), A Two-Factor Model of the Term Structure: An Approximate Analytical Solution, Journal of Financial and Quantitative Analysis, 19, 413-424.

Schotman, P.C. (1989), Empirical Studies on the Behaviour of Interest Rates and Exchange Rates, PhD thesis, Erasmus University, Rotterdam.

SOHWART, E.S. AND W.N. Torous (1989), Prepayment and the Valuation of MortgageBacked Securities, The Joumal of Finance, 44(2), 375-392.

Schwart $\%$, E.S. AND W.N. Torous (1992), Prepayment, Defaul, and the Valuation of Mortgage Pass-through Securities, Journal of Business, 65(2), 221-239.

Schwartz, E.S. AND W.N. Torous (1993), Mortgage Prepayment and Default Decisions: A Poisson Regression Approach, Joumal of the American Real Estate and Urban Economics Assoctation, 21(4), $431-449$.

SootT, D.W. (1992), Multivariate Density Estimation: Theory, Practice and Visualization, Willey, New York.

Shimko, D.C. (1992), Findne in Continuous-Time, Kolb, Miami.

SuVERMAN, B.W. (1986), Density Estmation for Statistics and Data A walysts, volume 26 of Monognaphs on Statistics and Applied Probability, Chapman and Hall, London.

Sims, C.A. (1980), Macroeconomics and Reality, Econometrica, 48, 1-48. 
STANTON, R. (1995), Rational Prepayment and the Valuation of Mortgage-Backed Securities, The Reviev of Fimancial Studes, $8(3), 677-708$.

Tauchen, G. (1995), New Methods for Estimation of Financial Models, invited lecture, WCEST, Tokyo.

Trtman, S. AND W. Tonous (1989), Valuing Commercial Mortgages: An Empirical Investigation of the Contingent Claim Approach to Pricing Risky Debt, The Journal of Finance, 44(2), 345-373.

UBS Gllobal Research (1996), F.I. Mortgage Securities B. V., UBS Services Itd., London.

U.S. Census Bureau (1980-1997). National Monthy Population Rsuthates.

VAN DE BEEK, P.A. AND W.T. VISSERS (1995), Hausse in overshilingen en tweade hypotheken, in Sparen en lenen in Nedendand 1996, Centraal Bureau voor de Stalistiek.

VANDELL, K.D. AND T. ThrbodeAu (1985), Estimation of Mortgage Defalts using Disaggregate Loan History Data, Joumal of the American Real Estate and Urban Economics Association, 13(3), 292-316.

Vander Hofk, J. (1996), Adjustable and Fixed-Rate Mortgage Termination, Option Values and Local Market Conditions: An Empirical Analysis, Journd of the Americam Rea! Estate and Urban Economics Association, 24(3), 379-406.

VAsıcek, O. (1977), An Equilibrium Characterization of the Term Structure, Jownat of Financial Economics, 5, $177-188$.

VERENIGING EIGEN HUIS (1994), Hypothekengids 1994-1995, Amersloort.

VERENIGNG EIGEN HUIS (1997), Hypothekengids 1997-1998, Amersfoort.

WANG, F.T. AND P.M. ZORN (1995), Repeat Sales: An Tntroductory Primer, unpublished manuscript, Federal Home Loan Mortgage Corporation.

ZELLNER, A. (1962), An Efficient Method of Estimating Seemingly Untelated Regressions and Tests for Aggregation Bias, Joumal of the American Statistical Association, 57, $348-368$.

Zenios, S.A. (1993), Parallel Monte Carlo Simulation of Mortgage-Backed Securitita, in S.A. Zenios, (ed.), Financial Optmization, Cambrige Universiby Press, Cambridge. 


\section{Curriculum Vitae}

Arjan van Bussel was born on September $21^{\text {st }}, 1970$ in Asten, the Netherlands. He graduated with distinction from Mastricht University in 1993. His Masters ihesis, "The duration of index-linked bonds", was researched and writen during an internship at the public pension fund ABP in Heerlen, the Netherlands. This thesis won both the Maastrich University student-research award in Economics and the AXA-Equity \& Law prize for the best Masters thesis in Finance. After completing a one-year Japan Studies Program at the International Christian University in Tokyo, Arjan wan Bussel returned to Mastrich University to work for the Finance Department where he wrote this Ph.D. dissertation on mortgage pricing. Since January $1^{\text {st }}$, 1998 , he bas been working at the B.V. NIB Mortgage-Backed Assets, a. 100\% subsidiary of De Nationale Investerings Bank (DNIB).

Arjan van Bussel is op 21 september 1970 in Asten geboren. In 1993 studeerde hij cum laude af alan de Faculteit der Economische Wetenschappen en Bedrijtskunde van de Universiteit Maastricht, toen nog Rijksuniversiteit Limburg genaamd. Zijn alstudeerseriptie, "De duratie wan een indexlening", is gebaseend op een stage bij het Algemeen Burgerlijk Pensioenfonds (ABP). Met deze scriptie won hij zowel de studentenprijs van de economische faculteit van de Universiteit Matutricht als de AXA Equity \& Law schiptieprijs. Van september 1992 tot en met angustus 1993 siudeerde Arjan van Bussel aan de International Christian University in Tokyo, alwar hij het Japan Studies Program met goed rosullata. afrondde. In september 1993 trad hij als assistent in opleiding in dienst bij de sectie fnanciering van de Universiteit Mastricht. Hij werkte das aan verschillende onderacksprojecten, waarwan dit proefschrift het resultaat is. Varaf 1 januari 1998 is hij werkzambij B.V. NBB Mortgage-Backed Assets, en $100 \%$ dochter wan De Nationate Imostcrings Bank (DNDB). 